\title{
Constraints on the timescale of animal evolutionary history
}

\author{
Michael J. Benton, Philip C.J. Donoghue, Robert J. Asher, Matt Friedman, \\ Thomas J. Near, and Jakob Vinther
}

\begin{abstract}
Dating the tree of life is a core endeavor in evolutionary biology. Rates of evolution are fundamental to nearly every evolutionary model and process. Rates need dates. There is much debate on the most appropriate and reasonable ways in which to date the tree of life, and recent work has highlighted some confusions and complexities that can be avoided. Whether phylogenetic trees are dated after they have been established, or as part of the process of tree finding, practitioners need to know which calibrations to use. We emphasize the importance of identifying crown (not stem) fossils, levels of confidence in their attribution to the crown, current chronostratigraphic precision, the primacy of the host geological formation and asymmetric confidence intervals. Here we present calibrations for 88 key nodes across the phylogeny of animals, ranging from the root of Metazoa to the last common ancestor of Homo sapiens. Close attention to detail is constantly required: for example, the classic bird-mammal date (base of crown Amniota) has often been given as 310-315 Ma; the 2014 international time scale indicates a minimum age of $318 \mathrm{Ma}$.
\end{abstract}

Michael J. Benton. School of Earth Sciences, University of Bristol, Bristol, BS8 1RJ, U.K.

mike.benton@bristol.ac.uk

Philip C.J. Donoghue. School of Earth Sciences, University of Bristol, Bristol, BS8 1RJ, U.K.

phil.donoghue@bristol.ac.uk

Robert J. Asher, Department of Zoology, University of Cambridge, Downing Street, Cambridge, CB2 3EJ,

U.K.r.asher@zoo.cam.ac.uk

Matt Friedman, Department of Earth Sciences, University of Oxford, South Parks Road, Oxford, OX1 3AN, U.K.mattf@earth.ox.ac.uk

Thomas J. Near, Department of Ecology and Evolutionary Biology, Yale University, P. O. Box 208106, 165

Prospect Street, New Haven, CT 06520-8106, U.S.A. thomas.near@yale.edu

Jakob Vinther. School of Earth Sciences, University of Bristol, Bristol, BS8 1RJ, U.K.

jakob.vinther@bristol.ac.uk

PE Article Number: 18.1.1FC

Copyright: Society for Vertebrate Paleontology February 2015

Submission: 1 August 2013. Acceptance: 7 December 2014

Benton, Michael J., Donoghue, Philip C.J., Asher, Robert J., Friedman, Matt, Near, Thomas J., and Vinther, Jakob. 2015. Constraints on the timescale of animal evolutionary history. Palaeontologia Electronica 18.1.1FC; 1-106;

palaeo-electronica.org/content/fc-1

Calibrations published in the Fossil Calibration Series are accessioned into the Fossil Calibration Database (www.fossilcalibrations.org). The Database is a dynamic tool for finding up-to-date calibrations, and calibration data will be updated and annotated as interpretations change. In contrast, the Fossil Calibration papers are a permanent published record of the information on which the calibrations were originally based. Please refer to the Database for the latest data. 
KEYWORDS: phylogeny; calibration; animals; Metazoa; birds; mammals

\section{INTRODUCTION}

This contribution represents one of a series, with calibration dates assessed and presented according to the principles enunciated by Parham et al. (2012). The paper has evolved from earlier efforts (Benton and Donoghue, 2007; Donoghue and Benton, 2007; Benton et al., 2009) and has been augmented by the addition of relevant nodes and authors.

Here we present calibrations for 88 key nodes, with a strong focus on vertebrates, reflecting current phylogenomic interest. There are 11 node calibrations for basal animal clades, 8 for deuterostomes and basal chordates, 21 for gnathostomes and fishes, 6 for basal tetrapods, 6 for reptiles/amniotes, 4 for birds, and 32 for mammals. Some of the calibrations given here have been included in previous compendia (e.g., Benton and Donoghue, 2007; Benton et al., 2009; Dos Reis et al., 2012; Near et al., 2012), but they are all revised in terms of key fossils, regional dating of formations, and the new international time scale (Gradstein et al., 2012; as updated in the 'International Chronostratigraphic Chart', last version consulted, v2014/10). We reverse the order of entries compared to our previous reports, reflecting now a phylogenetic sequence from the bottom up, rather than a hominid-focused approach from Homo sapiens towards ever more distant clades. Nodes are numbered in sequence, and keyed to the tree diagrams throughout the paper.

All calibrations are dependent on phylogeny. Differing clade boundaries can affect the position of a fossil, and so its role in fixing dates. We have paid attention to all current phylogenetic hypotheses for all clades considered, and we present what we regard as the best current consensus on the phylogeny of each group, incorporating both molecular and morphological data. Thus key sources for each phylogeny are specified.

We begin with an overview of the phylogenetic justifications that underpin the major clades, and follow with the calibration of key nodes in the history of animal life.

\section{PHYLOGENETIC OVERVIEW}

\section{Animals}

Animals (Metazoa) are generally motile heterotrophs, distinguished from Fungi and plants.
The fundamental division of Metazoa (Figure 1) is comprised of sponges, chordates, their last common ancestor and all of its descendants. The monophyly of Metazoa is widely accepted, substantiated on the basis of both molecular and phenotypic data (Eernisse and Peterson, 2004; Halanych, 2004; Philippe et al., 2009; Edgecombe et al., 2011). Metazoa is comprised of Bilateria/ Nephrozoa (chordates, arthropods, their last common ancestor and all of its descendants) plus Cnidaria, Placozoa, Ctenophora, and sponges (the monophyly or paraphyly of which remains contentious). Bilateria is divided into the two major clades Protostomia (arthropods, annelids, their last common ancestor and its descendants) and Deuterostomia (Echinodermata, Hemichordata, Acoelomorpha, Chordata). Protostomia comprises Ecdysozoa (Arthropoda, Kinorhyncha, Loricifera, Nematoda, Nematomorpha, Onychophora, Priapulida, Tardigrada) and Lophotrochozoa (Annelida, Brachiopoda, Ectoprocta, Entoprocta, Gastrotricha, Gnathostomulida, Mollusca, Nemertini, Phoronida, Platyhelminthes, Rotifera, Sipuncula).

\section{Deuterostomes and Basal Chordates}

Deuterostomia comprises chordates, echinoderms, hemichordates (Figure 2) and probably Acoelomorpha. Traditionally, hemichordates were paired with chordates to the exclusion of echinoderms, but the consensus of morphological and molecular studies (e.g., Eernisse and Peterson, 2004; Delsuc et al., 2006; Swalla and Smith, 2008; Cannon et al., 2009; Edgecombe et al., 2011; Röttinger and Lowe, 2012) now pairs hemichordates with echinoderms as the clade Ambulacraria.

Chordates have long been understood to include vertebrates, cephalochordates (amphioxus) and tunicates (sea squirts). The relative ordering of these had been debated, with Cephalochordata traditionally grouped with Vertebrata to the exclusion of Tunicata. Molecular work (e.g., Eernisse and Peterson, 2004; Delsuc et al., 2006; Swalla and Smith, 2008; Cannon et al., 2009; Edgecombe et al., 2011; Röttinger and Lowe, 2012) places cephalochordates as the sister clade to Tunicata plus Vertebrata, as clade Olfactores.

The relationships of the basal vertebrates to each other have been controversial. For a long time, zoologists grouped the living lampreys and hagfishes together as Cyclostomata. The first cla- 


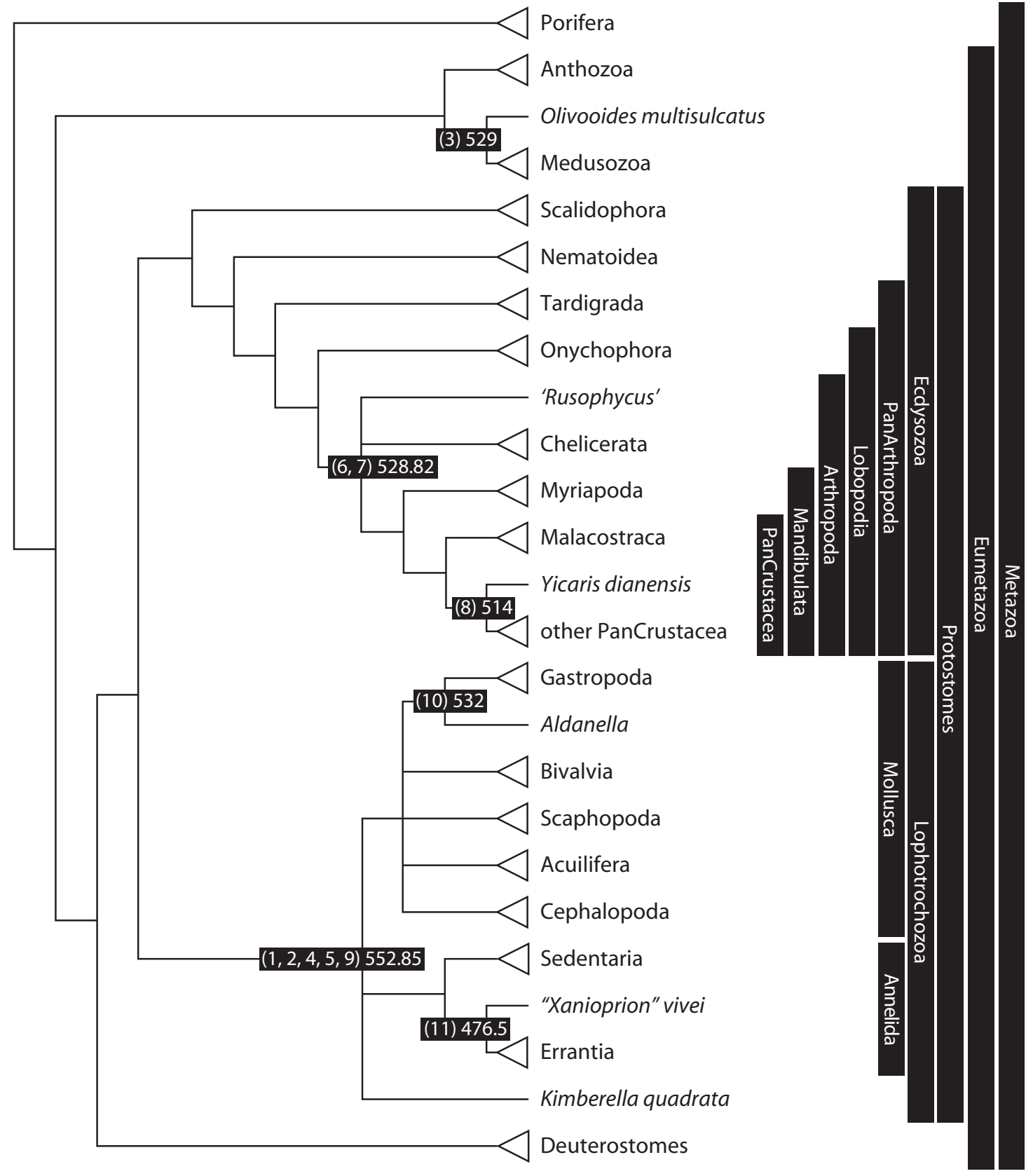

FIGURE 1. Calibration diagram for metazoans.

distic studies considered Cyclostomata paraphyletic, generally recognizing a closer relationship between lampreys and Gnathostomata, than hagfishes. Molecular phylogenetic studies generally recover a monophyletic Cyclostomata (reviewed by Kuraku et al., 2009), which is corroborated by a study of microRNAs and morphology (Heimberg et al., 2010) that identified four unique microRNA families shared by hagfishes and lampreys, and so resuscitated Cyclostomata (specifically, morphological data are indecisive on the question of cyclostome monophyly versus paraphyly). The statistical significance of these apomorphies has been contested by Thompson et al. (2014). These phylogenetic issues are important as they affect the placement of fossils relative to crown clades in the stem lineage to Gnathostomata.

\section{Jawed Vertebrates}

The phylogeny of Gnathostomata (Figure 3), the jawed vertebrates, has been revised substantially, especially with regard to extinct groups. Liv- 

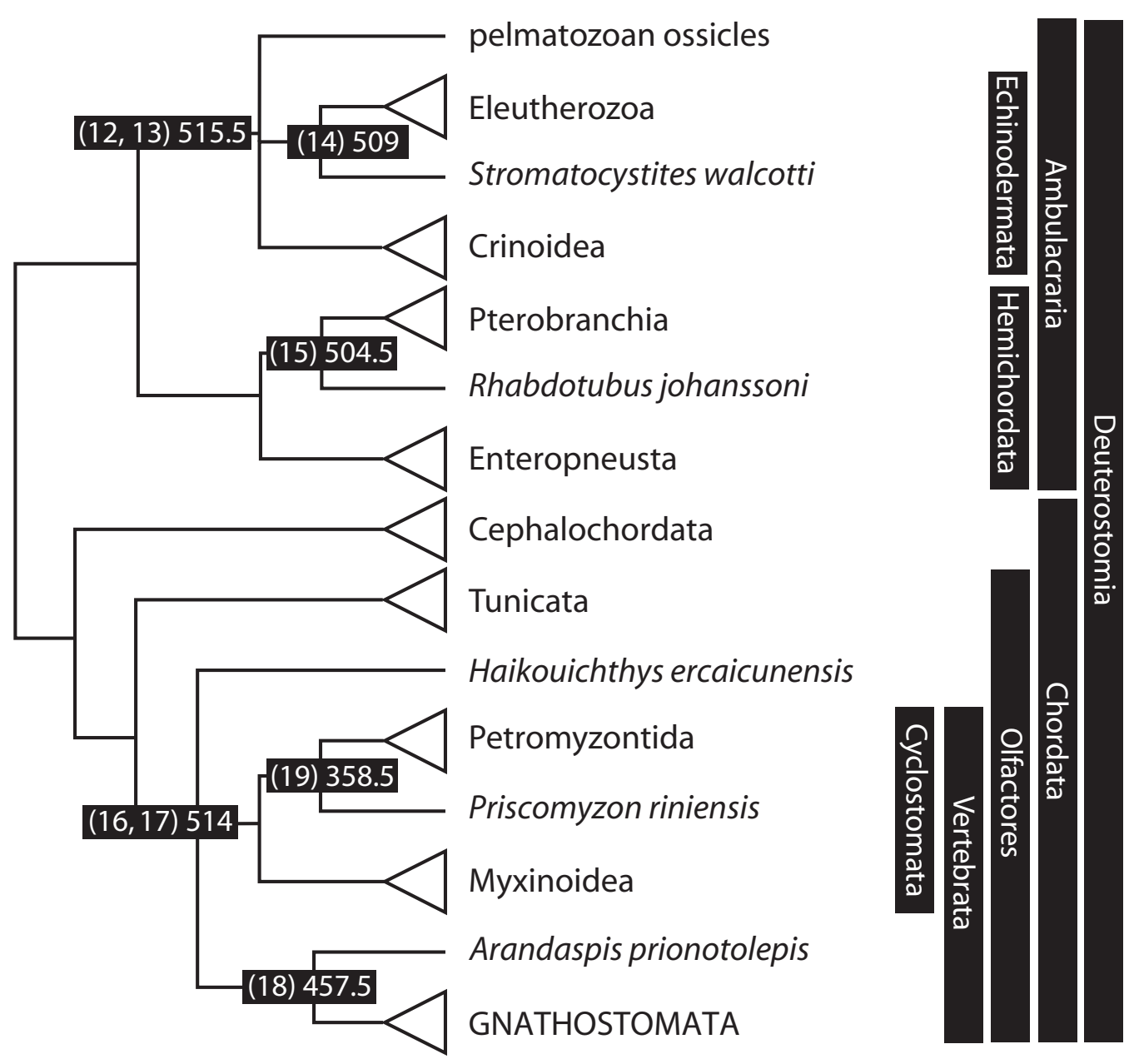

FIGURE 2. Calibration diagram for deuterostomes, including basal chordates.

ing gnathostomes are grouped into Chondrichthyes (cartilaginous fishes, including the sharks, rays, and ratfishes) and Osteichthyes (bony fishes and tetrapods), and are joined by two extinct groups: Acanthodii (Ordovician-Permian) and Placodermi (Silurian-Devonian). The status of placoderms as a clade is unclear, with many phylogenetic analyses suggesting that they are a grade of stem gnathostomes (Brazeau, 2009; Davis et al., 2012; Zhu et al., 2013; Dupret et al., 2014; Brazeau and Friedman, 2014). The acanthodians, long difficult to position phylogenetically, appear to include either an assortment of stem gnathostomes, stem chondrichthyans, and stem osteichthyans (Brazeau, 2009; Davis et al., 2012; Brazeau and Friedman, 2014) or stem chondrichthyans alone (Zhu et al., 2013; Dupret et al., 2014; Brazeau and Friedman, 2014). Within Osteichthyes, the division into Actinopterygii (ray-finned fishes) and Sarcopterygii (lobe-finned fishes and tetrapods) has long been clear (reviewed in Friedman and Brazeau, 2010).

To provide basic orientation, we provide dates for the bases of crown Gnathostomata, Chondrichthyes, Osteichthyes, Sarcopterygii, and Rhipidistia below, extending then to Tetrapoda (terrestrial osteichthyans).

\section{Ray-Finned Fishes}

The dates presented here reflect divergences between important ray-finned fish model systems (Danio, Oryzias, Gasterosteus, Takifugu, Tetraodon), as well as splits that define major divisions of ray-finned fish classification, species-rich clades, or both (Figures 4-6). Because of the coarse resolution of this survey, the precise formulation of calibrations given here differs from those provided in divergence-time analyses of actinopterygians that rest on a dense sample of extant lineages (e.g., Near et al., 2012, 2013; Betancur-R. et al., 2013). Where relevant, we explicitly identify 

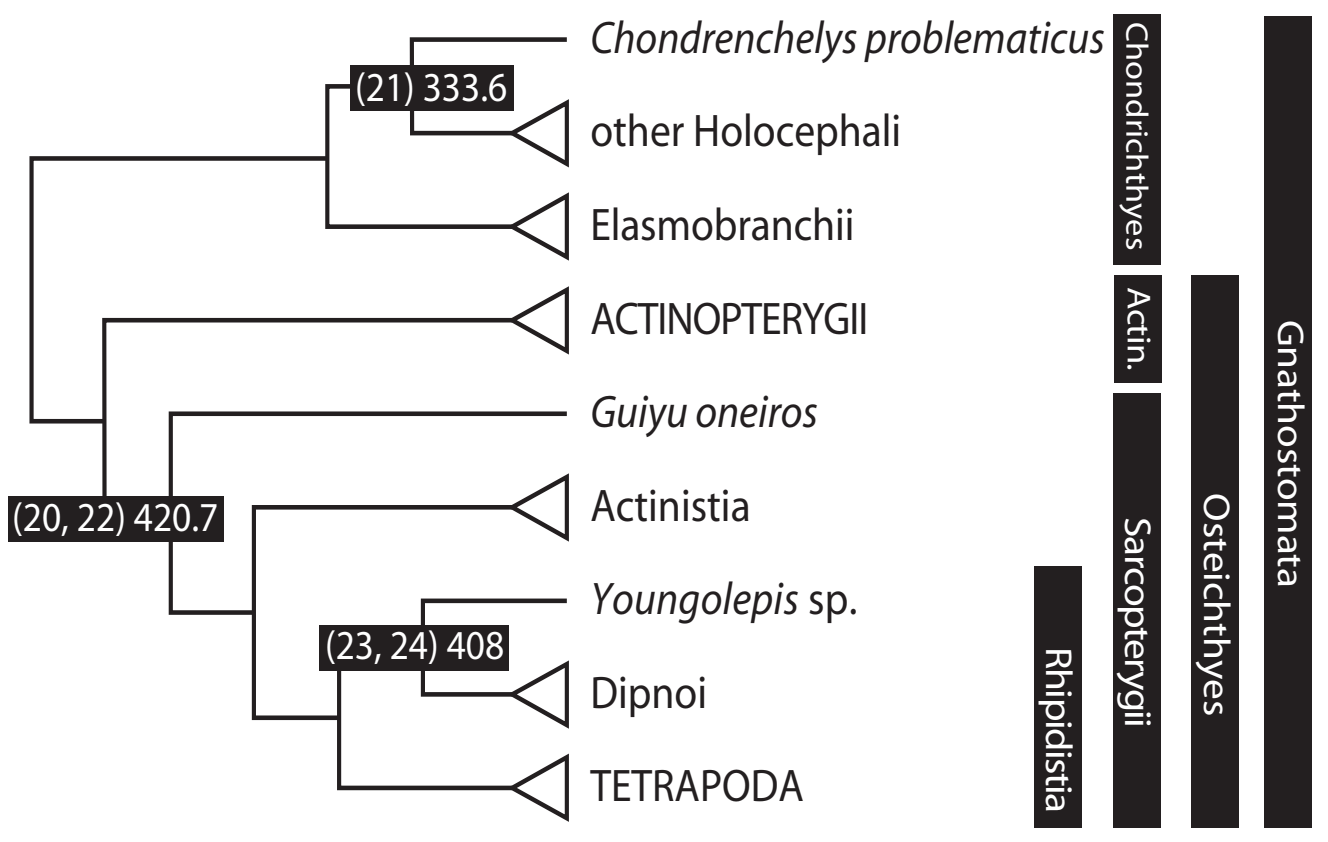

FIGURE 3. Calibration diagram for gnathostomes.

updates relating to the age assessments or phylogenetic interpretations of specific fossils.

At the broadest scale, there is a now a stable hypothesis of relationships among living ray-finned fishes based on both morphological and molecular datasets. Cladistia (bichirs and ropefish) include two extant genera, and form the sister group to all remaining Actinopterygii, collectively known as Actinopteri. The divergence that defines crown Actinopteri is that between Chondrostei, which includes sturgeons and paddlefishes, and Neopterygii, the clade containing Halecomorphi (bowfin), Ginglymodi (gars), and Teleostei (teleosts). Most possible patterns of relationships have been proposed between these three neopterygian clades, but two in particular have enjoyed considerable exposure: the holostean and halecostome hypotheses. The classical scheme uniting bowfin and gars within Holostei to the exclusion of teleosts was rejected by early cladistic studies, which instead placed teleosts and bowfin as each others' closest relatives in Halecostomi (Patterson, 1973). The halecostome hypothesis was dominant throughout the last quarter of the $20^{\text {th }}$ century, but molecular analyses and renewed anatomical investigation targeting neopterygian relationships now strongly support a monophyletic Holostei (e.g., Grande, 2010; Near et al., 2012; Broughton et al., 2013; Betancur-R et al., 2013).
Although the relationships among extant representatives of the major actinopterygian divisions is stable, there is less certainty concerning the placement of Paleozoic fossils, with respect to the deepest splits between living ray-finned fish groups. In general, the Permo-Carboniferous record of actinopterygians represents perhaps the most poorly studied aspect of the vertebrate fossil record (Hurley et al., 2007; Friedman and Sallan, 2012; Sallan, 2014). There are several published hypotheses depicting the relationships of Paleozoic actinopterygians relative to extant ray-finned clades (Patterson, 1982; Gardiner, 1984; Gardiner and Schaeffer, 1989; Lund et al., 1995; Coates, 1998, 1999; Arratia and Cloutier, 2004; Gardiner et al., 2005; Hurley et al., 2007). These studies vary considerably in terms of taxonomic and morphological scope, and there are instances of major disagreement between them (e.g., the exclusion of any Paleozoic taxa from the actinopterygian crown in some trees presented by Cloutier and Arratia, 2004). This has led to a corresponding diversity of calibration schemes for deep divergences within actinopterygians (e.g., Hurley et al., 2007; Santini et al., 2009; Near et al., 2012; Broughton et al., 2013; Betancur-R. et al., 2013). We therefore restrict our list of calibrations for the deepest splits within the ray-finned fish tree to those examples broadly agreed upon across competing phylogenetic solutions. 

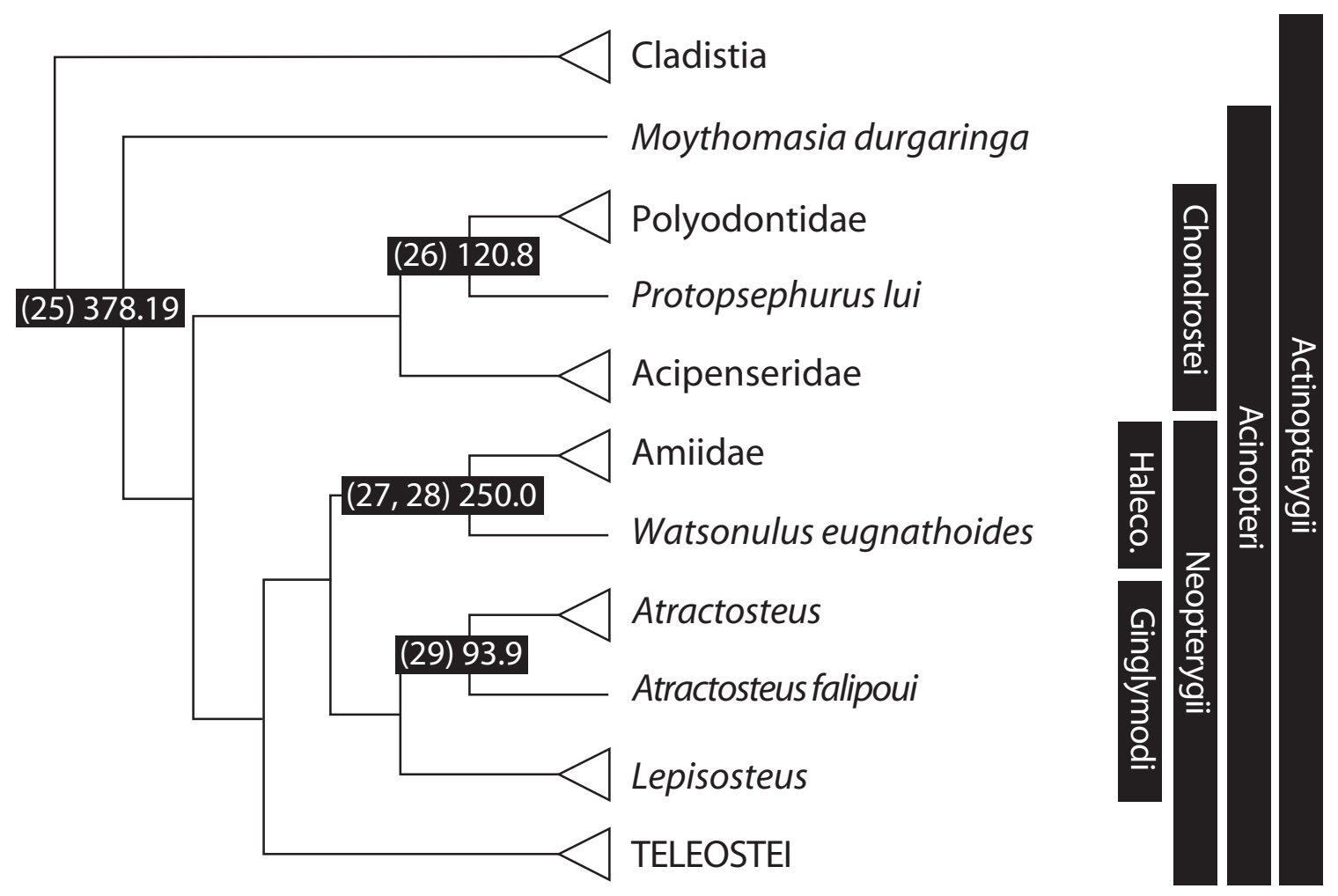

FIGURE 4. Calibration diagram for actinopterygians (Chondrostei, Holostei).

\section{Tetrapods}

The phylogeny of Lissamphibia (modern amphibians and their ancestors) and the basal Tetrapoda (Figure 7) is based on various sources. Most authors regard Lissamphibia as monophyletic, based on the morphological characters of pedicellate teeth and cutaneous respiration (Parsons and Williams, 1963; Benton, 1990; Ruta et al., 2003; Ruta and Coates, 2007), although Carroll (2001) and Anderson (2008) have preferred to seek multiple origins of lissamphibians from among Paleozoic tetrapods. Most molecular phylogenetic studies (e.g., Frost et al., 2006; Roelants et al., 2007; Pyron, 2011; Pyron and Wiens, 2011) confirm the monophyly of Lissamphibia. An exception is the recent work by Fong et al. (2012) who found a salamander-caecilian sister relationship, but cannot distinguish whether Lissamphibia is monophyletic or paraphyletic. This pairing of Caudata and Gymnophiona is unexpected, as morphological evidence supports a pairing of Caudata and Anura (Parsons and Williams, 1963; Benton, 1990; Carroll, 2001; Anderson, 2008). The general view is then that Anura (frogs and toads), Caudata (salamanders and newts), and Gymnophiona (caecilians) are each monophyletic, and that the last is outgroup to a clade Batrachia formed from Anura + Caudata.

The clade Tetrapoda was defined by Anderson (2001, p. 171) as 'a stem taxon comprising all taxa crownward of Elpistostegalia' whereas Laurin (2002) preferred the crown-clade definition, as 'the last common ancestor of amniotes and lissamphibians, and all its descendants'. These meanings are debated (Laurin and Anderson, 2004), without conclusion.

\section{Amniotes}

The dates for key amniote nodes presented below are based on a single phylogeny of the key amniote groups, based on nearly unanimous current understanding of the roots of the phylogeny of modern birds and mammals (Figure 8). The encompassing clade is Amniota, which includes all tetrapods that lay an amniotic egg, characterized by its tough (sometimes mineralized.) enclosing shell and the extraembryonic membranes (chorion, allantois, amnion), namely 'reptiles', birds, and mammals. The traditional, paraphyletic group 'reptiles' includes turtles, lizards, snakes, the tuatara, and crocodilians, and it is paraphyletic because it excludes birds and mammals. The broad relationships within Amniota have been established thanks 


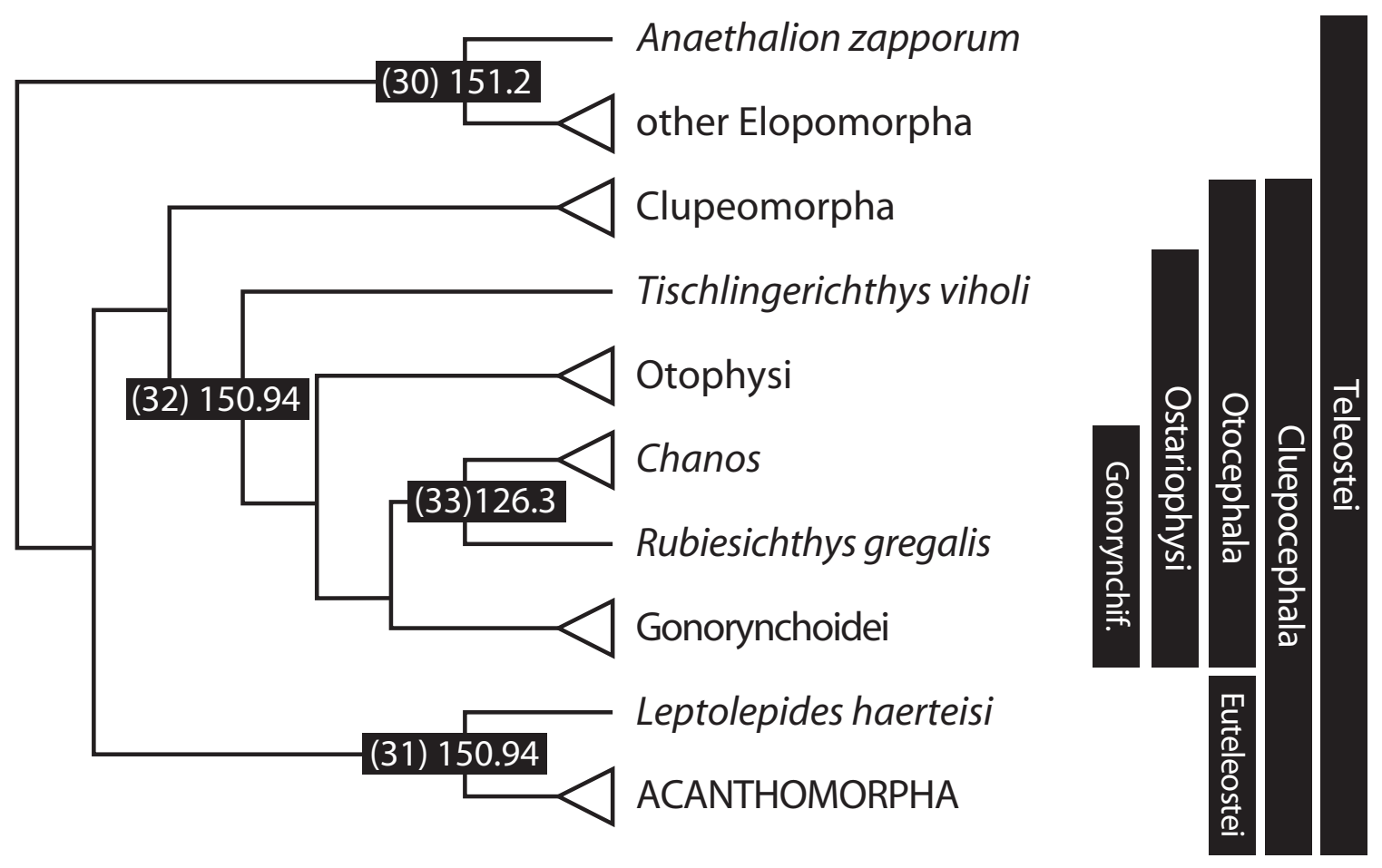

FIGURE 5. Calibration diagram for actinopterygians (basal teleosts and Clupeocephala).

to numerous cladistic analyses (e.g., Benton, 1985; Gauthier, 1986; Evans, 1988; Laurin and Reisz, 1995; deBraga and Rieppel, 1997), and confirmed by molecular analyses (Hedges and Poling, 1999; Meyer and Zardoya, 2003). The major bone of contention remains the placement of Testudines, turtles, whether in their traditional spot, as a part of Anapsida/ Parareptilia (Laurin and Reisz, 1995; Lee, 2001; Werneburg and Sánchez-Villagra, 2009; Lyson et al., 2010) or as a diapsid subclade, allied either with archosauromorphs (Kumazawa and Nishida, 1999; Cao et al., 2000; Zardoya and Meyer, 2001; Meyer and Zardoya, 2003; Iwabe et al., 2005; Field et al., 2014) or lepidosauromorphs (Rieppel and Reisz, 1999; Hill, 2005; Lyson et al., 2012).

The meanings of Amniota, Reptilia, Anapsida, Diapsida, Archosauria, and many other major clade terms have been much discussed, and debates have focused on whether each term should be given either a node-based or stembased definition, and whether each should refer to its more or less traditional extent or to the crown group. We follow the most recent discussions of the topic (e.g., Modesto and Anderson, 2004; Tsuji and Müller, 2009), and adopt this sequence of terms for the major clades of interest (Figure 6).

Amniota was defined as a stem-based clade, namely 'any Recent tetrapod more closely related to Mammalia than to Anura and all extinct descendants of their most recent common ancestor' (Sereno, 1999, p. 330). However, Modesto and Anderson (2004, p. 820) prefer a node-based definition, so it is consistent with their stem-based definitions for the two subtended clades, Synapsida and Reptilia. Therefore, the definition of Amniota as a node-based clade would be 'the most inclusive clade containing Lacerta agilis Linnaeus, 1758 and Homo sapiens Linnaeus, 1758'.

Reptilia is the clade that includes parareptiles, turtles, and diapsids, but excludes synapsids, and the definition allows for a variety of phylogenetic positions for Testudines, whether they should turn out to be diapsids or not. Its definition is as a stembased clade, namely 'the most inclusive clade containing Lacerta agilis Linnaeus, 1758 and Crocodylus niloticus Laurenti, 1768, but not Homo sapiens Linnaeus, 1758' (Modesto and Anderson, 2004, p. 819). Synapsida would then have an equivalent stem-based definition as 'the most inclusive clade including Didelphis marsupialis Linnaeus, 1758 and Homo sapiens Linnaeus, 1758, but not Lacerta agilis Linnaeus, 1758'.

Eureptilia is also defined as a stem-based taxon, as 'the most inclusive clade containing Captorhinus aguti Cope, 1882 and Petrolacosaurus kansensis Lane, 1945 but not Procolophon trigoniceps Owen, 1876' (Tsuji and Müller, 2009, p. 76). 

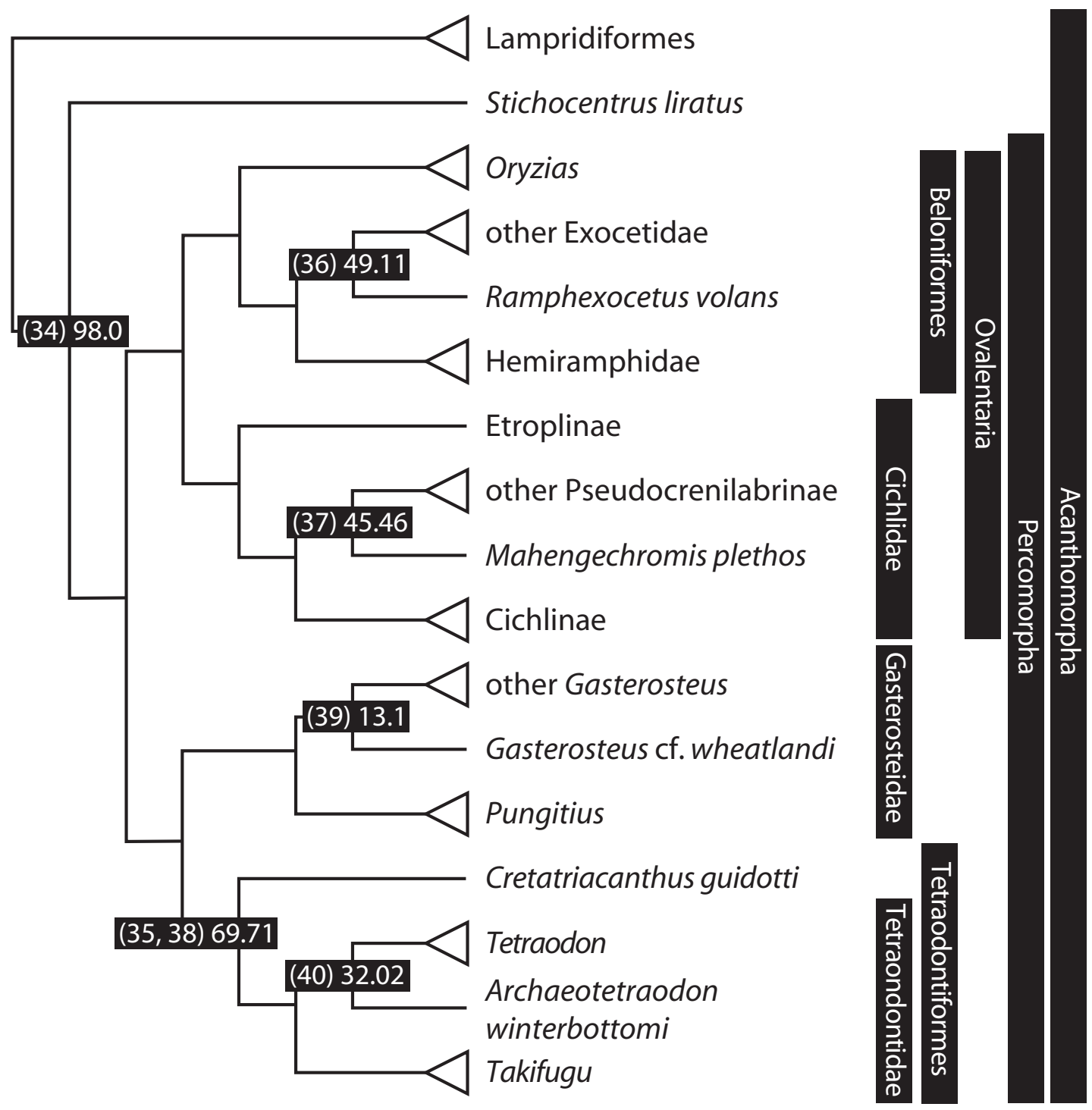

FIGURE 6. Calibration diagram for actinopterygians (Acanthomorpha).

Diapsida is defined as a node-based taxon, comprising the most recent common ancestor of araeoscelidians, lepidosaurs, and archosaurs, and all its descendants' (Laurin, 1991). This is a noncrown-clade definition, including as it does the common ancestor of extant lizards and birds (= crown Diapsida) plus some stem groups, down to Araeoscelidia, the traditional definition.

Lepidosauromorpha is defined as a nodebased taxon, as 'Sphenodon and squamates and all saurians sharing a more recent common ancestor with them than they do with crocodiles and birds' (Gauthier et al., 1988, p. 27). Lepidosauria is defined as a node-based taxon, as 'the most recent common ancestor of Sphenodon and squamates and all of its descendants' (Gauthier et al., 1988, p. 34).

Archosauromorpha is a stem-based taxon, defined as 'extant archosaurs and all extinct saurians that are closer to them than they are to extant lepidosaurs' (Gauthier, 1994). Archosauria is a node-based clade, defined by Sereno (2005) as The least inclusive clade containing Crocodylus niloticus Laurenti, 1768 and Passer domesticus Linnaeus, 1758.' This a crown clade, equivalent to Benton's (1999) Avesuchia, and different from the traditional Archosauria, which includes stem forms such as Proterosuchus, Erythrosuchus, Euparkeria, and Proterochampsa. Using the crown term Archosauria makes the date of origin of the clade 

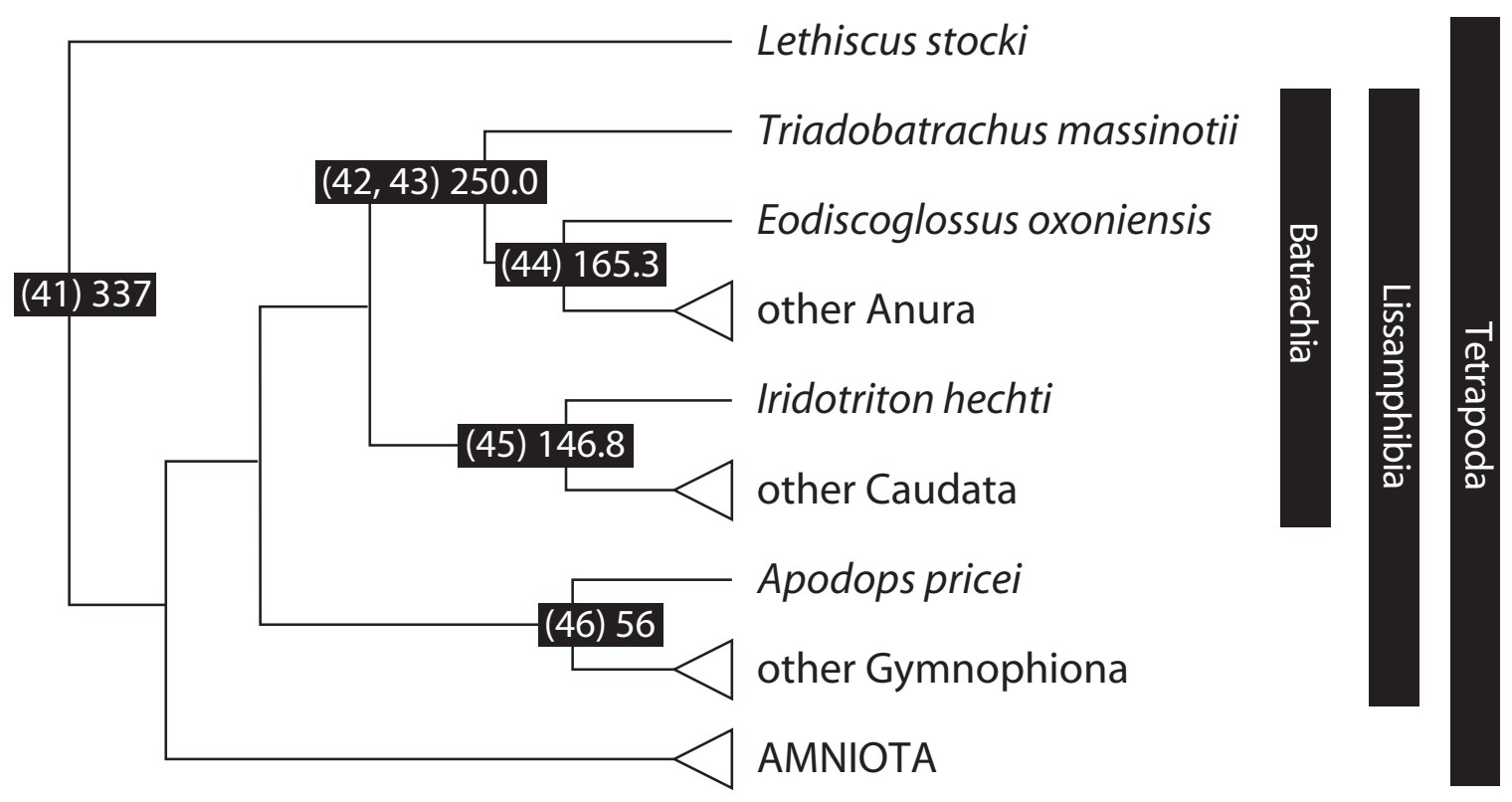

FIGURE 7. Calibration diagram for tetrapods.

equivalent to the common ancestor of modern crocodilians and birds.

We can provide dates for crown-group Amniota, Reptilia, Diapsida, Archosauria, Crocodylia, Aves, Lepidosauria, and Squamata, but not for major intermediate clades such as Eureptilia, Lepidosauromorpha, Archosauromorpha, Crurotarsi, Avemetatarsalia, or Dinosauria, because, although each contains extant members, the other major components of each of these clades are extinct.

\section{Birds}

The five key avian nodes dated below are based on a single phylogeny that reflects nearly unanimous current understanding of the roots of the phylogeny of modern birds (Figure 9). The encompassing clade is Ornithurae, a broad clade that includes all modern birds as well as many fossil forms such as Hesperornis and Ichthyornis, and this has been given a stem-based definition by Gauthier (1986): 'extant birds and all other taxa, such as Ichthyornis and Hesperornis, that are closer to extant birds than is Arhaeopteryx.' This definition was revised by Gauthier and de Queiroz (2001, p. 27) to an apomorphy-based one: 'Ornithurae refers to the clade stemming from the first panavian with a "bird tail", namely, a tail that is shorter than the femur (subequal to or shorter than the tibiotarsus) with a pygostyle of avian aspect...' The clade Ornithurae is thereby distinguished from entirely extinct bird clades such as Confuciusornithidae and Enantiornithes. However, the node in the cladogram equivalent to Ornithurae (Figure 7) cannot be investigated by phylogenetic study of extant forms because it contains many extinct taxa at its base and along the stem to Neornithes.

Within Ornithurae, all modern birds are included within the clade Neornithes (Figure 7), which consists of the subclades Neognathae and Palaeognathae, a long-held view (Huxley, 1867; Pycraft, 1901), based initially on morphological differences in the palate, and confirmed by cladistic and molecular phylogenetic studies (Cracraft et al., 2004; Dyke and Van Tuinen, 2004; Ericson et al., 2008; Hackett et al., 2008; Pacheco et al., 2011). Within Neognathae are two major subclades, Galloanserae (for waterfowl, landfowl, and their relatives) and Neoaves (all other modern flighted birds), based on several independent molecular and morphological phylogenetic analyses (e.g., Dyke and Van Tuinen, 2004; Livezey and Zusi, 2007; Ericson et al., 2008; Hackett et al., 2008; Pacheco et al., 2011; Mayr, 2014).

\section{Mammals}

There is now little ambiguity concerning the phylogenetic branching patterns among mammalian clades (reviewed in Springer et al., 2004 and Asher et al., 2009). The interrelationships implied by most mammalian orders, families, tribes, and genera have been accurately recognized since the 19th century. Distinction of the three extant major groups (monotremes, marsupials, placentals) has a similarly long history among zoologists (Gregory, 

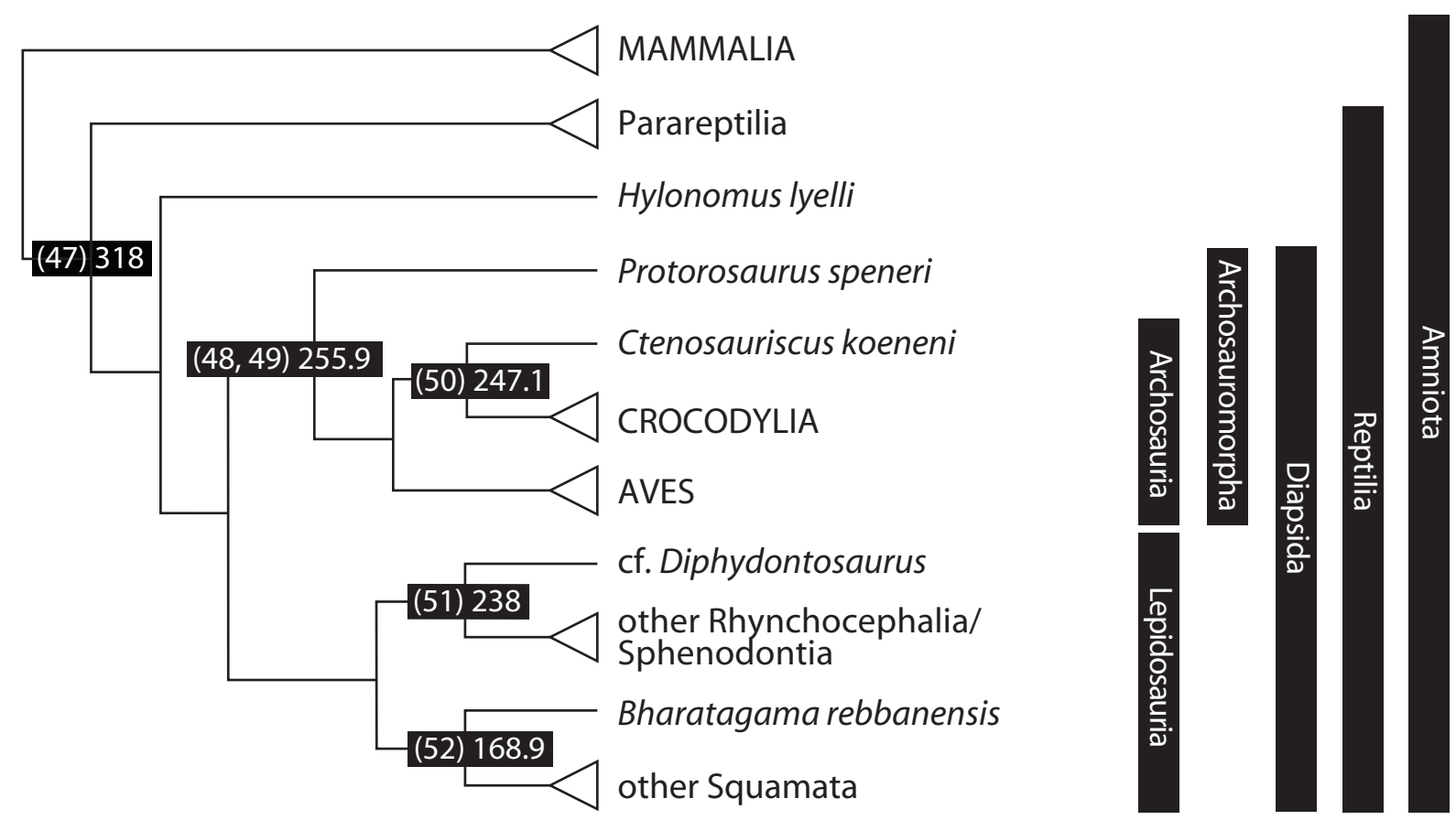

FIGURE 8. Calibration diagram for amniotes.

1910). What has changed substantially during the last decade is the level of confidence in the interordinal relationships among mammals. In the early 1990s, questions such as the relations of hyraxes were hotly debated (Fischer and Tassy, 1993); an affinity of bats with primates was generally suspected (Kaas and Preuss, 1993; but see Beard, 1993); the integrity of the "Insectivora" was skeptically regarded (MacPhee and Novacek, 1993); and the monophyly of terrestrial Artiodactyla was widely commended (Prothero, 1993). Serious questions also surrounded the possibility that marsupials and monotremes were related to the exclusion of placentals (Janke et al., 1997), and relations within marsupials were not well resolved (Springer et al., 1994).

Since 2000 , debate on each of these topics has been replaced with consensus, to the point where most participants in what used to be disagreements now consider a much more limited set of possible resolutions compared to the astronomically huge number of possible trees (Felsenstein, 1978) for the over 5000 extant species of mammals. Several authors (including one of us, RJA) who previously interpreted datasets in favor of phylogenetic affinity between (for example) tenrecs and lipotyphlan insectivorans (Asher, 1999), or of marsupials plus monotremes (Janke et al., 1997), now publish datasets consisting of molecular and in some cases morphological data (Asher, 2007;
Hallström and Janke, 2010) that are consistent with others first published in the late 1990s (Springer et al., 1997; Stanhope et al., 1998) and foreshadowed in earlier studies (e.g., Sonntag and Le Gros Clark, 1925; DeJong et al., 1981, 1993). This work reflects what is today a genome-backed consensus supporting, among other nodes, therians to the exclusion of monotremes and four major clades within placental mammals: Afrotheria, Xenarthra, Laurasiatheria, and Euarchontoglires (Murphy et al., 2001; Wildman et al., 2007; Prasad et al., 2008; Meredith et al., 2011).

The increase in consensus in mammalian phylogenetics is relative, and there are of course some persistent areas of ambiguity (reviewed in Asher et al., 2009). Nevertheless, stability in the mammalian Tree of Life enables progress on other fronts, including a framework by which common ancestors of mammalian groups may be hypothesized to have existed in the geological past. Here, we review the fossil record pertinent to those nodes, expanding upon the discussion in Benton et al. (2009) and reflecting the topology in Figures 10 and 11, based on the analyses of Asher (2007), Nishihara et al. (2009), and Meredith et al. (2011), and (where appropriate) using the taxonomy outlined by Asher and Helgen (2010). Following the methods and criteria summarized in Benton et al. (2009) and Dos Reis et al. (2012), and based on paleontological data, we provide minimum and 


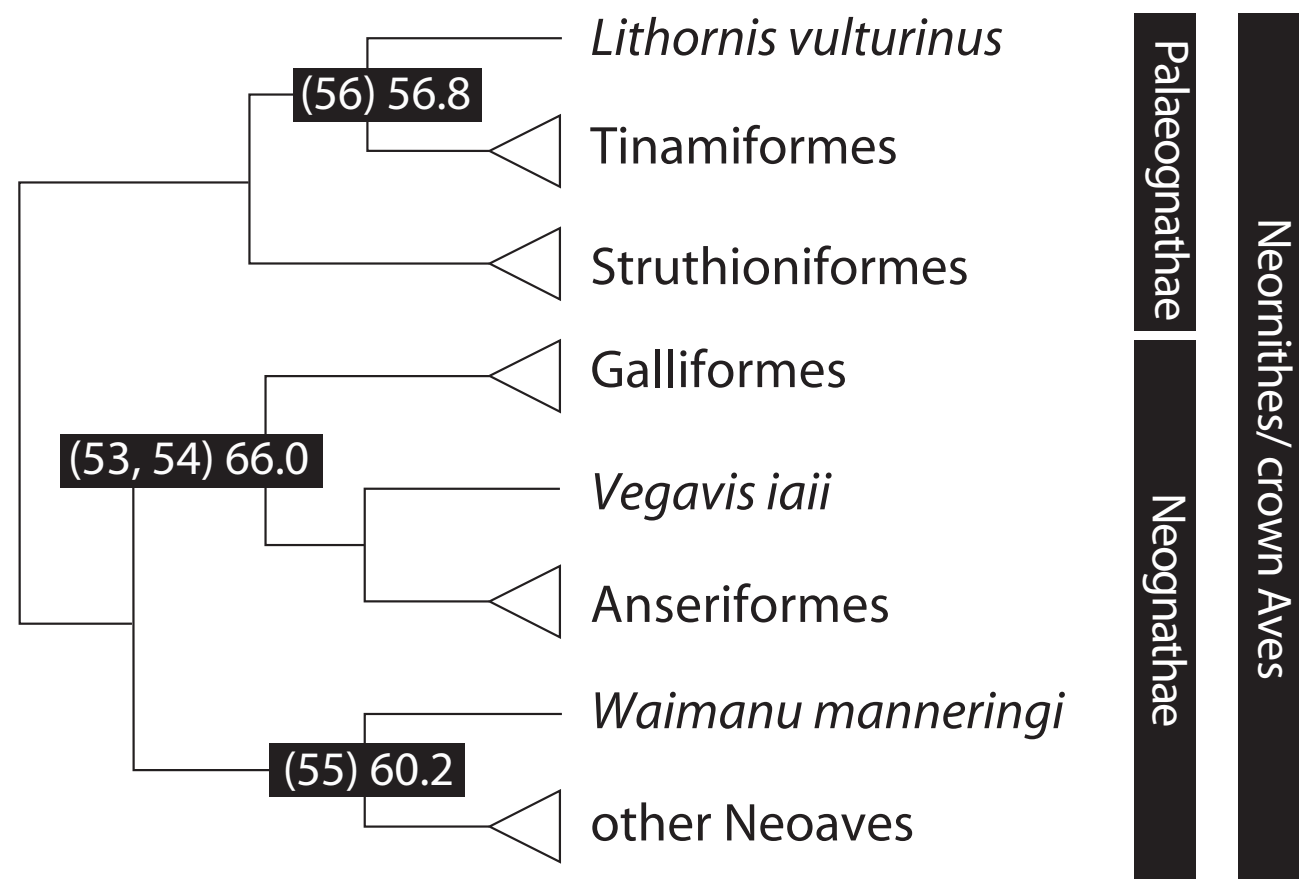

FIGURE 9. Calibration diagram for birds.

estimated maximum dates for divergences implied by each of the common ancestors detailed below.

An issue relevant to many of the mammalian nodes discussed here is the paleontological case that has occasionally been made for the presence of crown placentals deep in the Mesozoic. Historically, "placentals" have been argued to exist prior to the K-Pg boundary. McKenna and Bell reported the oldest lipotyphlan as Otlestes from the Cenomanian of Uzbekistan, but Archibald (2003) regarded it as a basal eutherian, lacking derived characters of Lipotyphla, or any other modern order. More recently, Averianov and Archibald (2005) synonymized it with Bobolestes (from the same local fauna) and regarded it as a possible zalambdalestoid. Somewhat younger is Paranyctoides from the Turonian of Asia and the Campanian of North America, and Batodon from the Maastrichtian of North America, both regarded as lipotyphlans by McKenna and Bell (1997) but not unequivocally reconstructed as such by other authors (e.g., Archibald, 2003).

Based on recent phylogenetic study (Asher et al., 2005; Wible et al., 2009; Goswami et al., 2011; O'Leary et al., 2013), no definitive record of any crown-group placental mammal exists prior to the $\mathrm{K}-\mathrm{Pg}$ boundary, despite a relatively good fossil record that documents numerous mammalian groups during the Mesozoic, including both metatherians and eutherians (Luo, 2007; Luo et al.,
2011). A tenuous link between ca. 95 Ma zalambdalestids and modern Glires has been suggested on several occasions (Van Valen, 1967; Archibald et al., 2001) but has been disproven (Kielan Jaworowska, 1978; Asher et al., 2005; Wible et al., 2007, 2009; Goswami et al., 2011). Some molecular clock studies suggest deep Cretaceous roots for crown placental orders (Springer et al., 2003; Bininda-Emonds et al., 2007, 2012). Other molecular clock studies, including the largest and most recent (Hallström and Janke, 2010; Dos Reis et al., 2012) also postulate some incursion of modern placental orders into the Cretaceous, but the "fuse" by which ancestors of crown groups originated during the Cretaceous has become much shorter, from over 120Ma (Kumar and Hedges, 1998) to a common ancestor for all Placentalia no older than $89 \mathrm{Ma} \pm 1 \mathrm{Myr}$ (Dos Reis et al., 2012). Notably, Dos Reis et al. (2012) and Hallström and Janke (2010) sampled genomic-scale datasets (ca. 20Mb in the former and $3 \mathrm{Mb}$ in the latter), compared to the ca. $0.04 \mathrm{Mb}$ dataset used to infer divergence dates of Meredith et al. (2011). This difference in data availability was likely behind the relatively small error margins from Dos Reis et al. (2012) of ca. $1 \mathrm{Ma}$, compared to those from other clock studies (e.g., Meredith et al., 2011), which frequently exceeded $15 \mathrm{Ma}$ for deep placental nodes.

Thus, we consider it likely that at least some placental mammal groups originated during the 


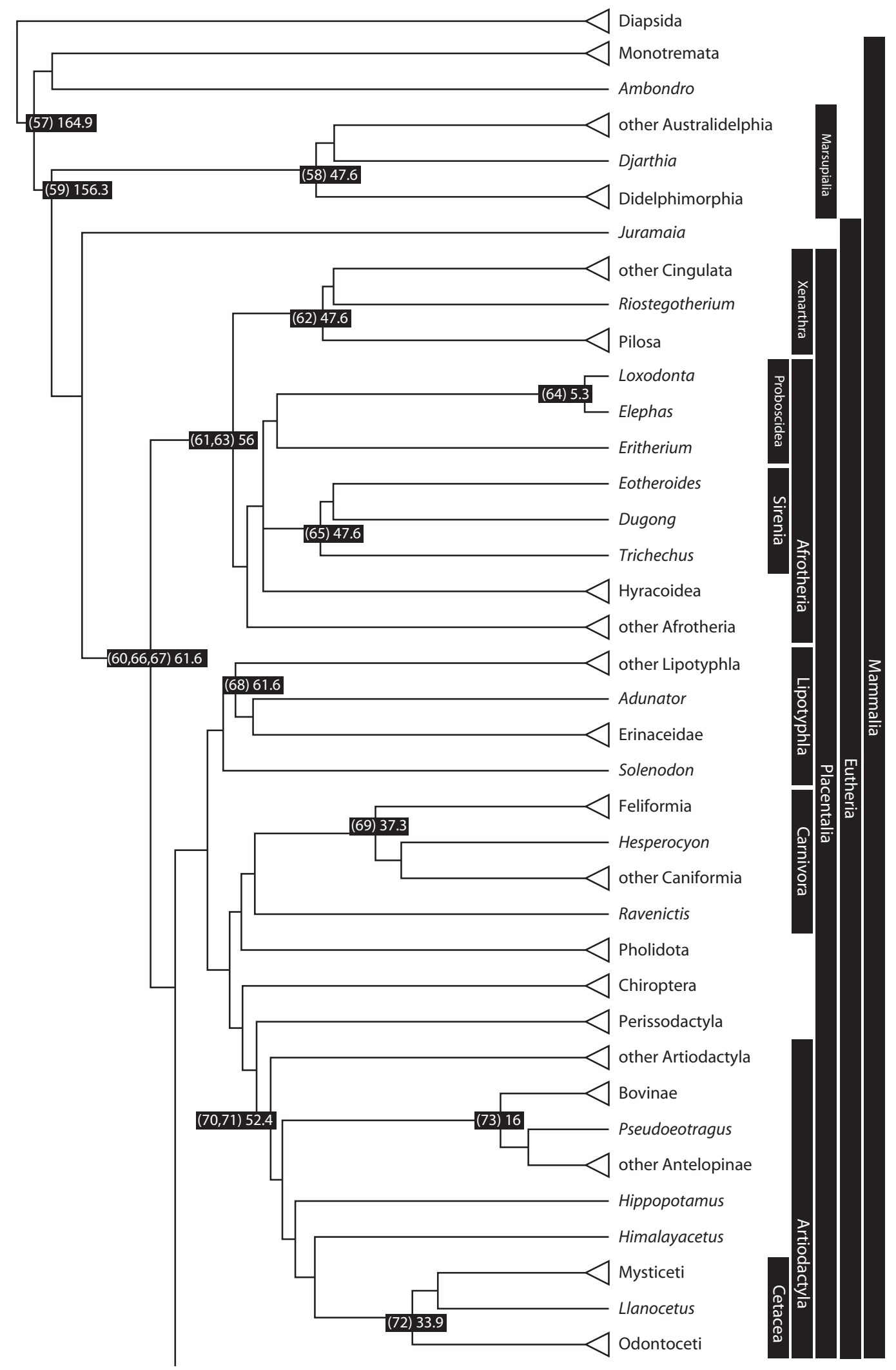

EUARCHONTOGLIRES (Fig. 11)

FIGURE 10. Calibration diagram for mammals, excluding Archonta. Euarchontoglires continued into Figure 11. 

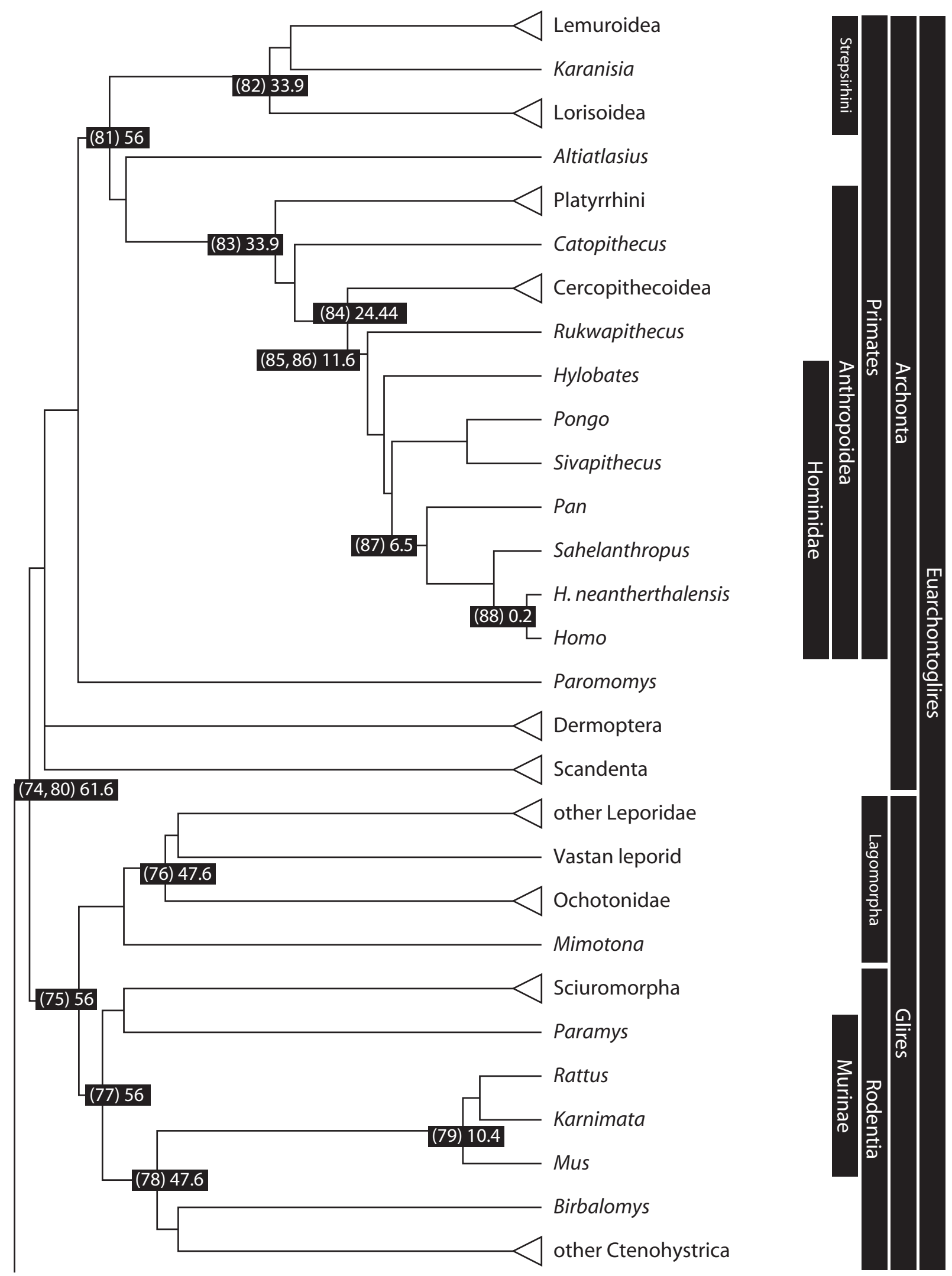

OTHER MAMMALS (Fig. 10)

FIGURE 11. Calibration diagam for Archonta, including Primates. Other mammals continued in Figure 10. 
Mesozoic, even though the paleontological case for identification of any crown placental order prior to the K-Pg boundary remains lacking. Given the presence of stem lineages of crown placental clades close to the K-Pg boundary (e.g., Carnivora, as detailed below), it is reasonable to conclude that small population size and/or as-yet unsampled tropical environments may explain the lack of diagnostically placental remains during the latest Cretaceous. Moreover, we regard the conclusion of O'Leary et al. (2013) - that crown Placentalia was completely absent prior to the K-Pg boundary-as a conflation of paleontological first appearances with actual speciation events (Dos Reis et al., 2014).

A therian node deeper than Euarchontoglires with some paleontological documentation is the divergence of Eutheria from other mammals in the late Jurassic, represented by Juramaia (Luo et al., 2011). This taxon is known from the Daxigou site of the Tiaojishan Formation, Liaoning Province, Northeastern China, and has been constrained by radiometric dates to derive from deposits of just over $160 \mathrm{Ma}$ in age (Luo et al., 2011). Biostratigraphic comparisons suggest the Tiaojishan Formation exhibits an older fauna and flora compared to the Jehol biota of the Yixian Formation (Hu et al., 2009; Lü et al., 2009). The equivalent marine stage in the GTS 2012 (Gradstein et al., 2012) timescale would be the Oxfordian, with a lower boundary of 163.5 Ma \pm 1.1 Myr. Thus, 164.6 Ma comprises a soft maximum, which we use repeatedly for the divergences of the high-level, crown placental groups discussed below.

It is worth commenting here on some core issues about the determination of soft maxima for mammalian nodes, points that also have a bearing on the debate just reviewed between apparently ancient molecular dates and much younger fossil dates. Unlike the Carboniferous deposits preceding the infamous bird-mammal calibration (Reisz and Müller, 2004), the Mesozoic and Paleogene deposits in which mammals are well known in most continents clearly do not suffer from an overall paucity of terrestrial vertebrate-bearing rocks. Inference of a soft maximum amounts to making the case that, in opposition to the cliche, absence of evidence really is evidence of absence. For example, there are many groups of Jurassic and Cretaceous mammaliaforms, thanks to an abundance of geological facies that preserve relevant habitat, but these deposits lack crown placentals (Wible et al., 2007; Goswami et al., 2011; O'Leary et al., 2013). Hence, when we use records of near-relatives of clade $X$ to argue that clade $X$ does not occur at time $Y$, this is of course contingent on the understanding that they could have been there but are not based on the existence of facies preserving their near relatives, among which are at least some ecological analogues. We therefore take this as the basis for assessing a probability (a "soft maximum") that clade $X$ had not yet evolved.

In this paper we have deleted several mammalian clades dated by Benton et al. (2009), namely Ferungulata, Scrotifera, and Zooamata, as none is supported by Meredith et al. (2011). Both Nishihara et al. (2009) and Hallstrom and Janke (2010) place bats within "Ferungulata," contrary to the text in Benton et al. (2009). In contrast, Meredith et al. (2011) place perissodactyls and artiodactyls (including Cetacea) together in Euungulata (Waddell et al., 1999) and chiropterans adjacent to Euungulata (excluding Carnivora).

\section{CROWN METAZOA (1)}

Node Calibrated. The clade comprised of sponges and eumetazoans (all animals bar sponges), their last common ancestor and all of its descendants. There has been debate concerning the monophyly versus paraphyly of sponges and whether ctenophores are a sister clade to sponges plus Eumetazoa, or whether ctenophores are themselves eumetazoans (Sperling et al., 2009; Nosenko et al., 2013). A basal position for ctenophores has been revealed to be an artifact of poor model selection and conflict between variable rate loci (Nosenko et al., 2013). Our calibration for crown Metazoa is independent of whether sponges are monophyletic or paraphyletic.

Fossil Taxon and Specimens. Kimberella quadrata (Paleontological Institute, Russian Academy of Sciences PIN 3993/4003). Several hundred specimens are kept at this institution.

Phylogenetic justification. Kimberella preserves several features that demonstrate it is a bilateral metazoan with an anterior-posterior axis (Fedonkin and Waggoner, 1997; Fedonkin et al., 2007; Ivantsov, 2009, 2010). Specimens are often found associated with a distinct bipartite feeding trace emerging from one end of the body indicative of a feeding apparatus with two major denticles and a grazing behavior. There appears to be a ventral creeping sole surrounded by concentric units of tissue and a dorsal soft-bodied carapace. The morphology and feeding behavior has been accredited to a molluscan affinity. No coherent argument has been presented that calls into question the lophotrochozoan affinity of Kimberella (see Discussion). 
Minimum Age. $550.25 \mathrm{Ma}$

Soft Maximum Age. $833 \mathrm{Ma}$

Age Justification. The White Sea Biota, in which Kimberella is most common, has been dated using $\mathrm{U}-\mathrm{Pb}$ zircon dates to either $558 \mathrm{Ma} \pm 1 \mathrm{Myr}$ (Martin et al., 2000) or $552.85 \pm 2.6 \mathrm{Ma}$ (Narbonne et al., 2012; Gradstein et al., 2012). Specimens are also known from the Ediacara of Australia (Glaessner and Wade, 1966; Wade, 1972), but the age of this unit is less well constrained. We select the date published in 2012 as our minimum hard constraint.

A soft maximum constraint can be established on the approximately coeval (Halverson et al., 2005; Halverson et al., 2007) middle Neoproterozoic Lagerstätten in the Bitter Springs Formation of central Australia (Schopf, 1968) and the Svanbergfjellet Formation of Spitsbergen (Butterfield et al., 1994), which preserve in three dimensions at a cellular level of fidelity prokaryotes, sphaeromorph acritarchs, multicellular algae, and multifarious problematica, but nothing that could be interpreted as a total group metazoan. The absolute age of the Bitter Springs Formation is the better constrained, through correlation to a volcanic sequence in the upper Loves Creek Formation, allied to the Gairdner Dyke Swarm (Hill et al., 2000; Hill and Walter, 2000), dated at $827 \mathrm{Ma} \pm 6 \mathrm{Myr}$, thus $833 \mathrm{Ma}$.

Discussion. The morphology and observed feeding behavior of Kimberella is demonstrative of an agile bilaterian metazoan moving by the means of a creeping sole. Some contention has been aired about the rigor of this assessment and a more general bilaterian affinity has been aired (Butterfield, 2006), but this assessment was based on the assumption that the feeding apparatus of annelids could be plesiomorphic for the crown group, which is a demonstrably derived character of aciculate annelids not present in stem-group annelids (Eibye-Jacobsen, 2004).

We have considered a number of claims for older records of Metazoa, but these are rejected. These claims include the intriguing hypothesis that Dickinsonia is a placozoan-grade organism (Sperling and Vinther, 2010), but which does not require Dickinsonia to be a placozoan clade organism. Rogov et al. (2012) describe convincing evidence of bioturbation but the minimum age interpretation of this evidence is the same as for Kimberella, which presents a much more convincing case for the existence of bilaterians. Liu et al. (2010) described c. $565 \mathrm{Ma}$ trace fossils which they interpret as evidence of a muscular metazoan-grade organism, drawing particular comparison to polypoid cnidarians, though they later retreat from argu- ing that these traces necessarily indicate the existence of animals (Liu et al., 2010). Pecoits et al. (2012) describe putative bilaterian burrows from sediments dated to older than $585 \mathrm{Ma}$. There has been some debate over their age, some claiming a younger, Carboniferous or Permian age (Gaucher et al., 2013), which Pecoits et al. (2013) have attempted to refute. Regardless, the preservation of the traces is not convincing and is probably associated with a textured surface indicative of a microbial mat capable of preserving such structures (Droser and Gehling, 2012). Thus, we exclude these traces as evidence for the minimum constraint on crown-Metazoa, though our soft maximum constraint must encompass it. Finally, Love et al. (2009) have recovered putative demosponge biomarkers from the Cryogenian, in sediments intercalating deposits from the Sturtian and Marinoan glaciations. Thus, a minimum constraint on the age of crown Metazoa could be established on the age of the younger, Marinoan glaciation, which is $635.51 \mathrm{Ma} \pm 0.54 \mathrm{Myr}$, thus $634.97 \mathrm{Ma}$. However, Siegl and colleagues have shown that genes encoding the 24-isopropyl steroid biomarker are present in the genome of a eubacterium, Poribacteria, which has an apparently symbiotic relationship with demosponges (Siegl et al., 2011). Siegl and colleagues have not demonstrated that Poribacteria synthesizes the critical 24-isopropyl steroid biomarker and, regardless, it could still be marshaled in evidence for demosponges if Poribacteria has a demonstrable obligate relationship with demosponges, and that it extends to the Cryogenian. But these remain variables and, therefore, the evidence from Poribacteria clearly calls into question its veracity as evidence of the existence of demosponges and, therefore, crown-Metazoans in the Cryogenian.

\section{CROWN EUMETAZOA (2)}

Node Calibrated. The clade comprised of Bilateria and Cnidaria, their last common ancestor and all of its descendants. In this we assume that ctenophores are crown Eumetazoa, but our calibration is not contingent upon this since there are no older uncontentious records of ctenophores.

Fossil Taxon and Specimens. Kimberella quadrata (Palaeontological Institute, Russian Academy of Sciences PIN 3993/4003). Several hundred specimens are kept at this institution.

Phylogenetic Justification. Kimberella preserves several features that demonstrate it is a bilateral metazoan with an anterior-posterior axis (Fedonkin and Waggoner, 1997; Fedonkin et al., 2007; 
Ivantsov, 2009, 2010). Specimens are often found associated with a distinct bipartite feeding trace emerging from one end of the body, indicative of a feeding apparatus with two major denticles and a grazing behavior. There appears to be a ventral creeping sole surrounded by concentric units of tissue and a dorsal soft-bodied carapace. The morphology and feeding behavior has been accredited to a molluscan affinity. No coherent argument has been presented that calls into question the lophotrochozoan affinity of Kimberella.

Minimum Age. $550.25 \mathrm{Ma}$

Soft Maximum Age. $636.1 \mathrm{Ma}$

Age Justification. The White Sea Biota, in which Kimberella is most common, has been dated using $\mathrm{U}-\mathrm{Pb}$ zircon dates to either $558 \mathrm{Ma} \pm 1 \mathrm{Myr}$ (Martin et al., 2000) or $552.85 \pm 2.6 \mathrm{Ma}$ (Narbonne et al., 2012; Gradstein et al., 2012). Specimens are also known from the Ediacara of Australia (Glaessner and Wade, 1966; Wade, 1972), but the age of this unit is less well constrained. We select the date published in 2012 as our minimum hard constraint.

A soft maximum constraint is based on the maximum age interpretation of the Lantian Biota (Yuan et al., 2011). This together with the Doushantuo Biota (Yuan et al., 2002) provides a series of Lagerstätten preserving the biota in Orsten- and Burgess Shale-like modes of fossilization. None of these Lagerstätten, least of all the Lantian, preserves anything that could possibly be interpreted as even a total group eumetazoan and on this basis we define our soft maximum constraint at $635.5 \mathrm{Ma} \pm 0.6 \mathrm{Myr}$ (Condon et al., 2005) and, thus, $636.1 \mathrm{Ma}$.

Discussion. The morphology and observed feeding behavior of Kimberella is demonstrative of an agile bilaterian metazoan moving by the means of a creeping sole. Some contention has been aired about the rigor of this assessment and a more general bilaterian affinity has been aired (Butterfield, 2006), but this assessment was based on the assumption that the feeding apparatus of annelids could be plesiomorphic for the crown group, which is a demonstrably derived character of aciculate annelids not present in stem-group annelids (Eibye-Jacobsen, 2004).

There are a number of claims for older records of Eumetazoa that we have considered but rejected as credible evidence on which to establish a minimum constraint on the diversification of crown Metazoa. Rogov et al. (2012) describe convincing evidence of bioturbation but the minimum age interpretation of this evidence is the same as for Kimberella, which presents a much more con- vincing case for the existence of eumetazoans. Liu et al. (2010) described c. 565 Ma trace fossils, which they interpret as evidence of a muscular metazoan-grade organism, drawing particular comparison to polypoid cnidarians, though they later retreat from arguing that these traces necessarily indicate the existence of animals (Liu et al., 2010). Pecoits et al. (2012) describe putative bilaterian burrows from sediments dated to older than 585 Ma. There has been some debate over their age, some claiming a younger Carboniferous or Permian age (Gaucher et al., 2013), which Pecoits et al. (2013) have attempted to refute. Regardless, the preservation of the traces does not meet expectations, that it should be associated with a textured surface indicative of a microbial mat capable of preserving such structures (Droser and Gehling, 2012). Thus, we exclude these traces in evidence for the minimum constraint on crown-Eumetazoa, though our soft maximum constraint must encompass it.

\section{CROWN CNIDARIA (3)}

Node Calibrated. The clade comprised of Anthozoa and Medusozoa, their last common ancestor and its descendants. The monophyly of crown Cnidaria is well established on the basis of anatomical and molecular evidence (Daly et al., 2007).

Fossil Taxon and Specimens. Olivooides multisulcatus (Geological Museum of Peking University: GMPKU3083-GMPKU3090), Dengying Formation, Fortunian Stage, constituting a range of embryonic and post-embryonic developmental stages.

Phylogenetic Justification. Olivooides is known from embryonic and post-embryonic stages of development, including a polyp theca, characteristic of scyphozoans, and a medusa stage (Dong et al., 2013).

Minimum Age. 529.0 Ma

Soft Maximum Age. 636.1 Ma

Age Justification. Olivooides multisulcatus cooccurs with Anabarites trisulcatus, which is indicative of the middle of the Fortunian Stage of the Terreneuvian Series, the first of the Cambrian. The top of the Fortunian Stage is dated at 529.0 Ma (Peng et al., 2012).

A soft maximum constraint is based on the maximum age interpretation of the Lantian Biota (Yuan et al., 2011). This, together with the Doushantuo Biota (Yuan et al., 2002), provides a series of Lagerstätten preserving the biota in Orsten- and Burgess Shale-like modes of fossilization. None of these Lagerstätten, least of all the Lantian, preserves anything that could possibly be 
interpreted as even a total group eumetazoan and on this basis we define our soft maximum constraint at $635.5 \mathrm{Ma} \pm 0.6 \mathrm{Myr}$ (Condon et al., 2005) and, thus, $636.1 \mathrm{Ma}$.

Discussion. The oldest possible record of a cnidarian is Sinocyclocyclicus guizhouensis from the Ediacaran Doushantuo Formation (Xiao et al., 2000; Liu et al., 2008) but the evidence of its affinity to Cnidaria amounts to little more than its tabular structure, which is reminiscent of tabulate corals. Putative Ediacaran medusoid cnidarians (Wade, 1968; Glaessner, 1971) have been reinterpreted as microbial communities (Grazhdankin and Gerdes, 2007) or trace fossils (Jensen et al., 2002). Frondlike Ediacarans have been interpreted as pennatulacean cnidarians, but this comparison is unconvincing (Antcliffe and Brasier, 2007, 2008). The terminal Ediacaran skeletonizing organisms Cloudina, Namacalathus, Nemapoika, and Sinotubulites have been considered total-group cnidarians (Wood, 2011), but this comparison has no material basis. Liu and colleagues (2010) described c. 565 Ma trace fossils, which they interpret as evidence of a muscular metazoan-grade organism, drawing particular comparison to polypoid cnidarians, though they later retreat from arguing that these traces necessarily indicate the existence of animals (Liu et al., 2010). Thus, Olivooides multisulcatus, known from embryonic and post-embryonic stages of development including a polyp theca and medusa stage, is the oldest phylogenetically secure crown-cnidarian. Its pentaradiate symmetry has led to speculative hypotheses of an affinity to echinoderms, however, O. multisulcatus co-occurs with the tetraradial Quadrapyrgites, to which it is comparable in all aspects bar symmetry.

\section{CROWN BILATERIA/NEPHROZOA (4)}

Node Calibrated. The clade comprised of protostomes and deuterostomes, their last common ancestor and all of its descendants.

Fossil Taxon and Specimens. Kimberella quadrata (Paleontological Institute, Russian Academy of Sciences PIN 3993/4003). Several hundred specimens are kept at this institution.

Phylogenetic Justification. Kimberella preserves several features that demonstrate it is a bilateral metazoan with an anterior-posterior axis (Fedonkin and Waggoner, 1997; Fedonkin et al., 2007; Ivantsov, 2009, 2010). Specimens are often found associated with a distinct bipartite feeding trace emerging from one end of the body, indicative of a feeding apparatus with two major denticles and a grazing behavior. There appears to be a ventral creeping sole surrounded by concentric units of tissue and a dorsal soft-bodied carapace. The morphology and feeding behavior has been accredited to a molluscan affinity. No coherent argument has been presented that calls into question the lophotrochozoan affinity of Kimberella (see Discussion).

Minimum Age. 550.25 Ma

Soft Maximum Age. $636.1 \mathrm{Ma}$

Age Justification. The White Sea Biota, in which Kimberella is most common, has been dated using $\mathrm{U}-\mathrm{Pb}$ zircon dates to either $558 \mathrm{Ma} \pm 1 \mathrm{Myr}$ (Martin et al., 2000) or $552.85 \pm 2.6 \mathrm{Ma}$ (Narbonne et al., 2012; Gradstein et al., 2012). Specimens are also known from the Ediacara of Australia (Glaessner and Wade, 1966; Wade, 1972), but the age of this unit is less well constrained. We select the date published in 2012 as our minimum hard constraint.

A soft maximum constraint is based on the maximum age interpretation of the Lantian Biota (Yuan et al., 2011). This, together with the Doushantuo Biota (Yuan et al., 2002), provides a series of Lagerstätten preserving the biota in Orsten- and Burgess Shale-like modes of fossilization. None of these Lagerstätten, least of all the Lantian, preserves anything that could possibly be interpreted as even a total group eumetazoan and on this basis we define our soft maximum constraint at 635.5 Ma $\pm 0.6 \mathrm{Myr}$ (Condon et al., 2005) and, thus, $636.1 \mathrm{Ma}$.

Discussion. The morphology and observed feeding behavior of Kimberella is demonstrative of an agile bilaterian metazoan moving by the means of a creeping sole. Some contention has been aired about the rigor of this assessment and a more general bilaterian affinity has been aired (Butterfield, 2006), but this assessment was based on the assumption that the feeding apparatus of annelids could be plesiomorphic for the crown group, which is a demonstrably derived character of aciculate annelids not present in stem-group annelids (Eibye-Jacobsen, 2004).

There are a number of claims for older records of Bilateria that we have considered but rejected as credible evidence on which to establish a minimum constraint on the diversification of crown Metazoa. These include putative bilaterian burrows from sediments dated to older than 585 Ma. There has been some debate over their age, some claiming a younger Carboniferous or Permian age (Gaucher et al., 2013), which Pecoits and colleagues have attempted to refute (Pecoits et al., 2013). Regardless, the preservation of the traces does not meet expectations that it should be associated with a textured surface indicative of a micro- 
bial mat capable of preserving such structures (Droser and Gehling, 2012). Thus, we exclude these traces in evidence for the minimum constraint on crown-Metazoa, though our soft maximum constraint must encompass it.

\section{CROWN PROTOSTOMIA (5)}

Node Calibrated. The clade comprised of Lophotrochozoa and Ecdysoa, their last common ancestor and all of its descendants.

Fossil Taxon and Specimens. Kimberella quadrata (Paleontological Institute, Russian Academy of Sciences PIN 3993/4003). Several hundred specimens are kept at this institution.

Phylogenetic Justification. Kimberella preserves several features that demonstrate it is a bilateral metazoan with an anterior-posterior axis (Fedonkin and Waggoner, 1997; Fedonkin et al., 2007; Ivantsov, 2009, 2010). Specimens are often found associated with a distinct bipartite feeding trace emerging from one end of the body, indicative of a feeding apparatus with two major denticles and a grazing behavior. There appears to be a ventral creeping sole surrounded by concentric units of tissue and a dorsal soft-bodied carapace. The morphology and feeding behavior has been accredited to a molluscan affinity. No coherent argument has been presented that calls into question the lophotrochozoan affinity of Kimberella (see Discussion).

Minimum Age. $550.25 \mathrm{Ma}$

\section{Soft Maximum Age. $636.1 \mathrm{Ma}$}

Age Justification. The White Sea Biota, in which Kimberella is most common, has been dated using $\mathrm{U}-\mathrm{Pb}$ zircon dates to either $558 \mathrm{Ma} \pm 1 \mathrm{Myr}$ (Martin et al., 2000) or $552.85 \pm 2.6 \mathrm{Ma}$ (Narbonne et al., 2012; Gradstein et al., 2012). Specimens are also known from the Ediacara of Australia (Glaessner and Wade, 1966; Wade, 1972), but the age of this unit is less well constrained. We select the date published in 2012 as our minimum hard constraint.

A soft maximum constraint is based on the maximum age interpretation of the Lantian Biota (Yuan et al., 2011). This, together with the Doushantuo Biota (Yuan et al., 2002), provides a series of Lagerstätten preserving the biota in Orsten- and Burgess Shale-like modes of fossilization. None of these Lagerstätten, least of all the Lantian, preserves anything that could possibly be interpreted as even a total group eumetazoan and on this basis we define our soft maximum constraint at $635.5 \mathrm{Ma} \pm 0.6 \mathrm{Myr}$ (Condon et al., 2005) and, thus, $636.1 \mathrm{Ma}$.

Discussion. The morphology and observed feeding behavior of Kimberella is demonstrative of an agile bilaterian metazoan moving by the means of a creeping sole. Some contention has been aired about the rigor of this assessment and a more general bilaterian affinity has been aired (Butterfield, 2006), but this assessment was based on the assumption that the feeding apparatus of annelids could be plesiomorphic for the crown group, which is a demonstrably derived character of aciculate annelids not present in stem-group annelids (Eibye-Jacobsen, 2004).

\section{CROWN ECDYSOZOA (6)}

Node Calibrated. The clade comprised of Arthropoda, Onychophora, Tardigrada, Nematoda, Nematomorpha, Kinorhyncha, Loricifera, and Priapulida, their last common ancestor and all of its descendants; monophyly has been demonstrated on the basis of coding and non-coding molecular data (Campbell et al., 2011).

Fossil Taxon and Specimens. Rusophycus trace fossils in Member 2 of the Chapel Island Formation of the southwestern Burin Peninsula of southeastern Newfoundland, defining the base of the Rusophycus avalonensis Biozone. Arbitrarily, we fix this calibration on a specimen from this unit figured by Narbonne et al. (1987: figure 6I; Geological Survey of Canada, GSC 85983).

Phylogenetic Justification. Rusophycus trace fossils are widely accepted to have been produced by arthropod-grade organisms, showing bilateral symmetry and evidence of segmented limbs used in their construction, an apomorphy of Arthropoda (Budd and Jensen, 2000).

Minimum Age. 528.82 Ma

Soft Maximum Age. $636.1 \mathrm{Ma}$

Age Justification. Rusophycus occurs well below the first animal body fossils in Cambrian sections around the world (Crimes and Jiang, 1986; Crimes, 1987; Goldring and Jensen, 1996; Macnaughton and Narbonne, 1999; Weber and Zhu, 2003). In many of these regions, records of Rusophycus begin with proximity to the base of the Cambrian. However, their ages are only well constrained in sections in Newfoundland, Canada, and Yunnan, China. Of these, records of Rusophycus begin low in Member 2 of the Chapel Island Formation of the southwestern Burin Peninsula of southeastern Newfoundland, defining the base of the Rusophycus avalonensis Biozone (Narbonne et al., 1987). The Biozone is itself dated through correlations to a section in New Brunswick where the younger ash bed has been dated by U-Pb series to $530.02 \mathrm{Ma} \pm$ 1.2 Myr (Isachsen et al., 1994; Peng et al., 2012), 
thus providing for a minimum constraint of $\mathbf{5 2 8 . 8 2}$ Ma.

A soft maximum constraint is based on the maximum age interpretation of the Lantian Biota (Yuan et al., 2011). This, together with the Doushantuo Biota (Yuan et al., 2002), provides a series of Lagerstätten preserving the biota in Orsten- and Burgess Shale-like modes of fossilization. None of these Lagerstätten, least of all the Lantian, preserves anything that could possibly be interpreted as even a total group eumetazoan and on this basis we define our soft maximum constraint at $635.5 \mathrm{Ma} \pm 0.6 \mathrm{Myr}$ (Condon et al., 2005) and, thus, $636.1 \mathrm{Ma}$.

\section{CROWN LOBOPODIA (7)}

Node Calibrated. This is the crown clade comprised of Arthropoda and Onychophora, their last common ancestor and all of its descendants. The monophyly of this clade has been established through phylogenetic analysis of both non-coding and protein-coding gene datasets (Campbell et al., 2011).

Fossil Taxon and Specimens. Trace fossils in Member 2 of the Chapel Island Formation of the southwestern Burin Peninsula of southeastern Newfoundland, defining the base of the Rusophycus avalonensis Biozone. Arbitrarily, we fix this calibration on a specimen from this unit figured by Narbonne et al. (1987: figure 6I; Geological Survey of Canada, GSC 85983).

Phylogenetic Justification. Rusophycus trace fossils are widely accepted to have been produced by arthropod-grade organisms, showing bilateral symmetry and evidence of segmented limbs used in their construction, an apomorphy of Arthropoda (Budd and Jensen, 2000).

Minimum Age. $528.82 \mathrm{Ma}$

Soft Maximum Age. 636.1 Ma

Age Justification. Rusophycus occurs well below the first animal body fossils in Cambrian sections around the world (Crimes and Jiang, 1986; Crimes, 1987; Goldring and Jensen, 1996; MacNaughton and Narbonne, 1999; Weber and Zhu, 2003). In many of these regions, records of Rusophycus begin with proximity to the base of the Cambrian. However, their ages are only well constrained in sections in Newfoundland, Canada, and Yunnan, China. Of these, records of Rusophycus begin low in Member 2 of the Chapel Island Formation of the southwestern Burin Peninsula of southeastern Newfoundland, defining the base of the Rusophycus avalonensis Biozone (Narbonne et al., 1987). The Biozone is itself dated through correlations to a section in New Brunswick where a younger ash bed has been dated by U-Pb series to $530.02 \mathrm{Ma} \pm$ 1.2 Myr (Isachsen et al., 1994; Peng et al., 2012), thus providing for a minimum constraint of 528.82 Ma.

A soft maximum constraint is based on the maximum age interpretation of the Lantian Biota (Yuan et al., 2011). This, together with the Doushantuo Biota (Yuan et al., 2002), provides a series of Lagerstätten preserving the biota in Orsten- and Burgess Shale-like modes of fossilization. None of these Lagerstätten, least of all the Lantian, preserves anything that could possibly be interpreted as even a total group eumetazoan and on this basis we define our soft maximum constraint at $635.5 \mathrm{Ma} \pm 0.6 \mathrm{Myr}$ (Condon et al., 2005) and, thus, $636.1 \mathrm{Ma}$.

\section{CROWN ARTHROPODA (8)}

Node Calibrated. This is the clade comprised of chelicerates, myriapods and crustaceans, their last common ancestor and all of its descendants. The monophyly of Euarthropoda, comprised of the sister clades Chelicerata and Mandibulata (itself comprised on Myriapoda and Pancrustacea) has been established on the basis of protein-coding and noncoding molecular data, as well as morphological data (Rota-Stabelli et al., 2010).

Fossil Taxon and Specimens. Yicaris dianensis (Key Laboratory for Paleobiology, Yunnan University: YKLP 10840), holotype, consisting of an almost complete articulated specimen (Zhang et al., 2007).

Phylogenetic Justification. Yicaris dianensis is an unequivocal member of crown-Crustacea based on the possession of a number of limb-based characters demonstrating not merely eucrustacean, but entomostracan and malacostracan affinity (Zhang et al., 2007).

Minimum Age. $514 \mathrm{Ma}$

Soft Maximum Age. $636.1 \mathrm{Ma}$

Age Justification. Yicaris dianensis was recovered from the Yu'anshan Formation at Xiaotan section, Yongshan, Yunnan Province, attributed to the Eoredlichia-Wutingaspis Biozone (Zhang et al., 2007). Chinese Cambrian stratigraphy has been revised substantially and the Eoredlichia - Wutingaspis Biozone is no longer recognized (Peng, 2003; Peng, 2009). However, Eoredlichia is known to co-occur with Hupeidiscus, which is diagnostic of the Hupeidiscus-Sinodiscus Biozone, which is formally recognised as the second biozone of the Nangaoan Stage of the Qiandongian Series of the Cambrian of China (Peng and Babcock, 2008). 
The Nangaoan is the proposed third stage of the Cambrian System for the International Geologic Timescale (Peng et al., 2012). Thus, a minimum constraint can be established on the age of the top of the Nangaoan, which has been dated to $514 \mathrm{Ma}$ (Peng and Babcock, 2008; Peng et al., 2012).

A soft maximum constraint is based on the maximum age interpretation of the Lantian Biota (Yuan et al., 2011). This, together with the Doushantuo Biota (Yuan et al., 2002), provides a series of Lagerstätten preserving the biota in Orsten- and Burgess Shale-like modes of fossilization. None of these Lagerstätten, least of all the Lantian, preserves anything that could possibly be interpreted as even a total group eumetazoan and on this basis we define our soft maximum constraint at $635.5 \mathrm{Ma} \pm 0.6 \mathrm{Myr}$ (Condon et al., 2005) and, thus, $636.1 \mathrm{Ma}$.

Discussion. There are older records of arthropods than Yicaris dianensis, notably trilobites, but their membership among Arthropoda is contested (it is not clear whether trilobites are stem-Euarthropoda, stem-Chelicerata or stem-Mandibulata). Wujicaris muelleri (Zhang et al., 2010) has an equal claim to being the earliest record of Arthropoda, but it is of equal age to the holotype of Yicaris dianensis.

\section{CROWN LOPHOTROCHOZOA (9)}

Node Calibrated. The clade comprising mollusks, annelids, brachiopods, phoronids, nemerteans, bryozoans, entoprocts, platyhelminth flatworms, rotifers, acanthocephalans, gnathostomulids, and gastrotrichs. The phylogeny among lophotrochozoans is still highly debated. The clade has been recognized by both non-coding (Halanych et al., 1995; Wheeler et al., 2009) and protein coding datasets (Dunn et al., 2008).

Fossil Taxon and Specimens. Kimberella quadrata (Paleontological Institute, Russian Academy of Sciences PIN 3993/4003). Several hundred specimens are kept at this institution.

Phylogenetic Justification. Kimberella preserves several features that demonstrate it is a bilateral metazoan with an anterior-posterior axis (Fedonkin and Waggoner, 1997; Fedonkin et al., 2007; Ivantsov, 2009, 2010). Specimens are often found associated with a distinct bipartite feeding trace emerging from one end of the body, indicative of a feeding apparatus with two major denticles and a grazing behavior. There appears to be a ventral creeping sole surrounded by concentric units of tissue and a dorsal soft-bodied carapace. The morphology and feeding behavior has been accredited to a molluscan affinity. No coherent argument has been presented that calls into question the lophotrochozoan affinity of Kimberella.

Minimum Age. $550.25 \mathrm{Ma}$

Soft Maximum Age. 636.1 Ma

Age Justification. The White Sea Biota, in which Kimberella is most common, has been dated using $\mathrm{U}-\mathrm{Pb}$ zircon dates to either $558 \mathrm{Ma} \pm 1 \mathrm{Myr}$ (Martin et al., 2000) or $552.85 \pm 2.6 \mathrm{Ma}$ (Narbonne et al., 2012; Gradstein et al., 2012). Specimens are also known from the Ediacara of Australia (Glaessner and Wade, 1966; Wade, 1972), but the age of this unit is less well constrained. We select the date published in 2012 as our minimum hard constraint.

A soft maximum constraint is based on the maximum age interpretation of the Lantian Biota (Yuan et al., 2011). This, together with the Doushantuo Biota (Yuan et al., 2002), provides a series of Lagerstätten preserving the biota in Orsten- and Burgess Shale-like modes of fossilization. None of these Lagerstätten, least of all the Lantian, preserves anything that could possibly be interpreted as even a total group eumetazoan and on this basis we define our soft maximum constraint at 635.5 Ma $\pm 0.6 \mathrm{Myr}$ (Condon et al., 2005) and, thus, $636.1 \mathrm{Ma}$.

Discussion. The morphology and observed feeding behavior of Kimberella is demonstrative of an agile bilaterian metazoan moving by the means of a creeping sole. Some contention has been aired about the rigor of this assessment and a more general bilaterian affinity has been aired (Butterfield, 2006), but this assessment was based on the assumption that the feeding apparatus of annelids could be plesiomorphic for the crown group, which is a demonstrably derived character of aciculate annelids not present in stem-group annelids (Eibye-Jacobsen, 2004).

\section{CROWN MOLLUSCA (10)}

Node Calibrated. The clade comprising the latest common ancestor of chitons and gastropods and all of its descendants.

Fossil Taxon and Specimens. Aldanella yanjiahensis, often synonymized with Aldanella attleborensis Shaler and Foerste 1888, from the Dahai member of the Zhujiaqing Formation in the middle Meishucunian of China, TU Berlin collection NO. YXII02-02 (Steiner et al., 2007).

Phylogenetic Justification. Aldanella is a dextrally coiled mollusc assigned to the Pelagiellida. The distinct assymetries and the preservation of muscle scars (Runnegar, 1981) suggest that it is a partially coiled stem-group gastropod.

Minimum Age. $532 \mathrm{Ma}$ 
Soft Maximum Age. $549 \mathrm{Ma}$

Age Justification. Aldanella yanjiahensis has been found to be associated with Watsonella crosbyi and Oelandiella korobkovi in the Dahai member in the middle Meishucunian of China (Steiner et al., 2007). It has been suggested that this assemblage serves as a biozone. Chemostratigraphic correlations place this unit in the Nemakit Daldynian within the interval 534-532 Ma (Maloof et al., 2010).

We established a soft maximum constraint on the approximate maximum age of the Nama Group (549 Ma; Narbonne et al., 2012; Grotzinger et al., 1995), which preserves an open marine community including the earliest animal skeletal remains, viz. Cloudina, Namacalathus, and Namapoika (Wood, 2011), but does not preserve the skeletal remains of molluscs, nor does any of the very widespread strata that preserve Cloudina. Since a biomineralized skeleton with distinctly molluscan microstructure (e.g., crossed lamellar tissue is a synapomorphy of crown molluscs), the absence of such remains in a suite of deposits ecologically compatible with molluscs and capable of preserving their remains, suggests their absence in the prior interval of Earth history.

Discussion. There are slightly older records of molluscs belonging to the sachitids in the NemakitDaldynian. However, the internal relationships among the molluscan classes are still in great flux (Kocot et al., 2011; Smith et al., 2011; Vinther et al., 2012), and the polarity of morphology of the ancestral mollusc is still up for debate. This means there is a strong possibility that these older forms are stem, not crown, Mollusca, and they are excluded as potential calibration fossils for the present. The fact that Aldanella possesses a dextrally coiled shell is very suggestive of a gastropod affinity whose derived morphology is not considered plesiomorphic for the Mollusca.

\section{CROWN ANNELIDA (11)}

Node Calibrated. A clade comprised of the common ancestor of Aciculata and the Clitellata and all of its descendants.

Fossil Taxon and Specimens. 'Xanioprion' viivei Hints and Nõlvak, 2006, from the Leetse Formation (Institute of Geology at Tallinn University of Technology GIT424-19).

Phylogenetic Justification. 'Xanioprion' viivei is a scolecodont, interpreted as the jaw apparatus of polychaete annelids and both from the same geological source.

Minimum Age. $476.5 \mathrm{Ma}$

Soft Maximum Age. 636.1 Ma
Age Justification. "Xanioprion' viivei is from a larger collection of scolecodonts from the Leetse Formaton (Hunneberg Stage) of Kadriorg in Tallinn, North Estonia. The unit has been correlated, based on chitinozoans, to the Paroistodus proteus Conodont Zone (Hints and Nõlvak, 2006), the top of which is dated to $476.5 \mathrm{Ma}$ (Cooper and Sadler, 2012).

A soft maximum constraint is based on the maximum age interpretation of the Lantian Biota (Yuan et al., 2011). This, together with the Doushantuo Biota (Yuan et al., 2002), provides a series of Lagerstätten preserving the biota in Orsten- and Burgess Shale-like modes of fossilization. None of these Lagerstätten, least of all the Lantian, preserves anything that could possibly be interpreted as even a total group eumetazoan and on this basis we define our soft maximum constraint at $635.5 \mathrm{Ma} \pm 0.6 \mathrm{Myr}$ (Condon et al., 2005) and, thus, $636.1 \mathrm{Ma}$.

Discussion. The oldest annelids are from the Early Cambrian of Sirius Passet (Conway Morris and Peel, 2008; Vinther et al., 2011) and the diverse assemblage of polychaetes from the Burgess Shale (Morris, 1979; Eibye-Jacobsen, 2004). These forms fall on the annelid stem (Eibye-Jacobsen, 2004). Recent developments in molecular phylogenetics have demonstrated that the annelids consist of two major clades: Aciculata and the Canalipalpata + Clitellata (Struck et al., 2011). Some forms are equivocal in terms of their placement at the base of the annelid tree such as the chaetopterids and the myzostomids (Struck et al., 2011), but other molecular approaches suggest that this topology is an artifact and that they fall within the annelids with respect to the sipunculans (Sperling et al., 2009; Helm et al., 2012). Nonetheless, aciculates with jaws are considered monophyletic and thus the oldest scolecodonts provide a minimum for the apperance of the annelid crown group.

\section{CROWN DEUTEROSTOMIA (12)}

Node Calibrated. The clade comprising chordates, echinoderms, hemichordates, their last common ancestor, and all of its descendants. Monophyly of this clade is established on the basis of phylogenetic analysis of protein coding (Bromham and Degnan, 1999; Furlong and Holland, 2002; Philippe et al., 2011) and non-coding molecular data (Wheeler et al., 2009).

Fossil Taxon and Specimens. Isolated pelmatozoan columnals, Micmacca Breccia of Morocco 
(Natural History Museum London, BMNH EE6828EE6846).

Phylogenetic Justification. The columnals exhibit a characteristic morphology and, more critically, a stereom structure is a characteristic of the echinoderm total group, acquired early in the stem-lineage (Swalla and Smith, 2008).

Minimum Age. $515.5 \mathrm{Ma}$

Soft Maximum Age. 636.1 Ma

Age Justification. The columnals were recovered from the Micmacca Breccia, which encompasses the upper part of the Cephalopyge notabilis Biozone, the Ornamentaspis frequens Biozone and, perhaps, the lower part of the Kymataspis arenosa Biozone (Geyer and Landing, 1995; Clausen and Smith, 2008). These records are effectively contemporaneous fragments of stereom that occur globally within the middle Atdabanian (=Age 3, Series 3 of GTS2012) Nevadella anabara Biozone (Kouchinsky et al., 2012; Zamora et al., 2013). This can be constrained by the latest Atdabanian date of $517.0 \mathrm{Ma} \pm 1.5 \mathrm{Myr}$ from a section in Morocco (Maloof et al., 2010).

A soft maximum constraint is based on the maximum age interpretation of the Lantian Biota (Yuan et al., 2011). This, together with the Doushantuo Biota (Yuan et al., 2002), provides a series of Lagerstätten preserving the biota in Orsten- and Burgess Shale-like modes of fossilization. None of these Lagerstätten, least of all the Lantian, preserves anything that could possibly be interpreted as even a total group eumetazoan and on this basis we define our soft maximum constraint at $635.5 \mathrm{Ma} \pm 0.6 \mathrm{Myr}$ (Condon et al., 2005) and, thus, $636.1 \mathrm{Ma}$.

Discussion. There are a number of claims of Cambrian vertebrates (Chen et al., 1999; Shu et al., 1999; Donoghue et al., 2000; Donoghue and Keating, 2014; Holland and Chen, 2001; Smith et al., 2001; Mallatt and Chen, 2003; Shu et al., 2003), tunicates (Shu et al., 2001; Lacalli, 2002; Chen et al., 2003), cephalochordates (Chen et al., 1995; Shu et al., 1996; Morris and Caron, 2012), stem-chordates (Dzik, 1995), hemichordates (Shu et al., 1996; Shu et al., 2004; Sato et al., 2008; Caron et al., 2010), echinoderms (Swalla and Smith, 2008) and stem-ambulacraria (Shu, 2003), and stem-deuterostomes (Vinther et al., 2011; Ou et al., 2012). None of these fossils is sufficiently secure in phylogenetic terms to justify their use in constraining the age of Ambulacraria in divergence time analyses (Donoghue and Purnell, 2009). Furthermore, their minimum age interpretation postdates that of the oldest record of an echinoderm stereom, which we use as the basis of our minimum constraint.

\section{CROWN AMBULACRARIA (13)}

Node Calibrated. The clade comprised of hemichordates and echinoderms, their last common ancestor and all of its descendants. The monophyly of Ambulacraria has been demonstrated robustly using molecular sequence data (Bromham and Degnan, 1999; Cameron et al., 2000; Furlong and Holland, 2002), non-coding molecular data (Wheeler et al., 2009; Philippe et al., 2011), though there are few anatomical synapomorphies beyond the dipleurula larva (Nielsen, 1997).

Fossil Taxon and Specimens. Isolated pelmatozoan columnals (Natural History Museum London, BMNH EE6828-EE6846).

Phylogenetic Justification. The columnals exhibit a characteristic morphology and, more critically, a stereom structure is a characteristic of the echinoderm total group, acquired early in the stem-lineage (Swalla and Smith, 2008).

Minimum Age. 515.5 Ma

Soft Maximum Age. $636.1 \mathrm{Ma}$

Age Justification. The columnals were recovered from the Micmacca Breccia, which encompasses the upper part of the Cephalopyge notabilis Biozone, the Ornamentaspis frequens Biozone and, perhaps, the lower part of the Kymataspis arenosa Biozone (Geyer and Landing, 1995; Clausen and Smith, 2008). These records are effectively contemporaneous fragments of stereom that occur globally within the middle Atdabanian (= Age 3, Series 3 of GTS2012) Nevadella anabara Biozone (Kouchinsky et al., 2012; Zamora et al., 2013). This can be constrained by the latest Atdabanian date of $517.0 \mathrm{Ma} \pm 1.5 \mathrm{Myr}$ from a section in Morocco (Adam C. Maloof et al. 2, 2010).

A soft maximum constraint is based on the maximum age interpretation of the Lantian Biota (Yuan et al., 2011). This, together with the Doushantuo Biota (Yuan et al., 2002), provides a series of Lagerstätten preserving the biota in Orsten- and Burgess Shale-like modes of fossilization. None of these Lagerstätten, least of all the Lantian, preserves anything that could possibly be interpreted as even a total group eumetazoan and on this basis we define our soft maximum constraint at 635.5 Ma \pm 0.6 Myr (Condon et al., 2005) and, thus, 636.1 Ma.

Discussion. Caron et al. (2010) have proposed a hemichordate affinity for Eldonia and allied forms, but they considered a broad diversity of competing 
interpretations, including lophotrochozoan affinity. Similarly, yunnanozoons have been considered crown-hemichordates (Shu et al., 1996; Shu et al., 2004) and stem-ambulacrarians (Shu, 2003), though they have also been considered chordates and even craniates, as well as stem-deuterostomes, stem-bilaterians and even ecdysozoans (Donoghue and Purnell, 2009). Vetulicystids have been interpreted as stem-echinoderms (Shu et al., 2004) but Swalla and Smith (2008) considered them to lack evidence of even a single echinoderm synapomorphy, questioning their assignment to Ambulacraria, but suggesting affinity to vetulicolians whose affinity is equally equivocal (Aldridge et al., 2007; Donoghue and Purnell, 2009), and usually consigned to the deuterostome stem-group (Vinther et al., 2011; Ou et al., 2012). None of these fossils is sufficiently secure in phylogenetic terms to justify their use in constraining the age of Ambulacraria in divergence time analyses.

\section{CROWN ECHINODERMATA (14)}

Node Calibrated. The clade encompasses the last common ancestor of all the extant echinoderm classes, and all of its living and extinct descendants.

Fossil Taxon and Specimens. Stromatocystites walcotti, Olenellus Beds (USNM 66483), holotype consisting of a largely complete articulated individual.

Phylogenetic Justification. Stromatocystites walcotti is identified as a crown echinoderm based on morphological phylogenetic analysis (Smith, 1985). S. walcotti exhibits crown-echinoderm synapomorphies, including a pentaradial body plan, water vascular system (inferred to be derived from the left hydrocoel), and stereom skeleton clearly place them in the crown group (Smith, 1984), as well as flat dorsal surface, which distinguishes $S$. walcotti as a stem-eleutherozoan.

Minimum Age. $509 \mathrm{Ma}$

Soft Maximum Age. $549 \mathrm{Ma}$

Age Justification. The earliest record of Stromatocystites is of Stromatocystites walcotti from the Olenellus Beds, Taconian, upper Lower Cambrian, eastern arm of Bonne Bay, western coast of Newfoundland (Smith, 1985), which equates to Series 2, Stage 4 of the Cambrian, the top of which is dated as $509.0 \mathrm{Ma}$, the attendant errors on which are unclear (Peng et al., 2012). The oldest echinoderms records, both articulated and discrete ossicles of stereom, have been recovered from the preceding Series 2, Stage 3 of the Cambrian (Kouchinsky et al., 2012), and it is likely that the stratigraphic coincidence of these occurrences is a consequence of facies bias within the rock record (A.B. Smith et al., 2013). Thus, we base our soft maximum constraint on the approximate age of the Nama Group (Narbonne et al., 2012), an open marine community that preserves the earliest biomineralized animals, including Cloudina, Namacalathus and Namapoika (Wood, 2011). Since the ancestral crown-echinoderm possessed a stereom skeleton, its absence from the Nama Group, and from other Cloudina-bearing strata worldwide, establishes a basis for their absence at this interval of Earth History.

Discussion. The identity of the oldest crown-echinoderm is not uncontroversial since there is considerable debate over the assignment of early echinoderms to the stem versus total-group. Among the earliest echinoderms are the gogiid eocrinoids (first appearance: Series 2, Stage 3) which some identify as members of crown-Echinodermata, while others assign them to the stem (Mooi, 2001). The affinity of Stromatocystites, probable sister group to all other edrioasteroids, is also contentious, with some identifying it as a stem-echinoderm (David et al., 2000). However, their pentaradial body plan, water vascular system (inferred to be derived from the left hydrocoel), stereom skeleton, and flat dorsal surface, clearly places it in the crown group and eleutherozoan total group (Smith, 1984).

\section{CROWN HEMICHORDATA (15)}

Node Calibrated. The clade encompasses the last common ancestor of all extant pterobranch and enteropneust hemichordates, and all of its living and extinct descendants. It has long been argued that pterobranchs belong within a larger clade of enteropneusts (Cannon et al., 2009; Röttinger and Lowe, 2012). However, recent analyses of microRNAs demonstrate convincingly that pterobranchs and enteropneusts form mutually exclusive clades (Peterson et al., 2013).

Fossil Taxon and Specimens. Rhabdotubus johanssoni, from the Eccaparadoxides pinus Zone, Norrtorp, Narke, Sweden (Swedish Museum of Natural History, Stockholm: SMNH Cn 67217), holotype, consisting of an almost complete articulated specimen.

Phylogenetic Justification. Rhabdotubus johanssoni exhibits clear evidence of cortical banding which demonstrates membership of total group, if not crown-Pterobranchia and, therefore, membership of crown-Hemichordata.

Minimum Age. 504.5 Ma 
Soft Maximum Age. 636.1 Ma

Age Justification. Rhabdotubus johanssoni was recovered from shales within the Eccaparadoxides pinus Zone (=Ptychagnostus praecurrens Zone) (Bengtson and Urbanek, 1986), which occurs within Cambrian Series 3, Age 5 (i.e. pre-Drumian) of GTS2012 (Peng et al., 2012).

A soft maximum constraint is based on the maximum age interpretation of the Lantian Biota (Yuan et al., 2011). This, together with the Doushantuo Biota (Yuan et al., 2002), provides a series of Lagerstätten preserving the biota in Orsten- and Burgess Shale-like modes of fossilization. None of these Lagerstätten, least of all the Lantian, preserves anything that could possibly be interpreted as even a total group eumetazoan and on this basis we define our soft maximum constraint at $635.5 \mathrm{Ma} \pm 0.6 \mathrm{Myr}$ (Condon et al., 2005) and, thus, $636.1 \mathrm{Ma}$.

Discussion. A number of putative hemichordates have been described from the Chengjiang and Burgess Shale biotas (Shu et al., 1996, 2004; Sato et al., 2008; Caron et al., 2010) but evidence of their affinity is insufficient to justify constraining the age of crown Hemichordata in divergence time analyses.

\section{CROWN CHORDATA (16)}

Node Calibrated. This is the clade comprising vertebrates, tunicates, cephalochordates, their last common ancestor and all of its descendants. Monophyly of Chordata is established on the grounds of phylogenetic analysis of protein-coding (Delsuc et al., 2008; Philippe et al., 2011) and noncoding molecular data (Heimberg et al., 2010).

Fossil Taxon and Specimens. Haikouichthys ercaicunensis (Yunnan Institute of Geological Sciences, Kunming: HZ-f-12-127), holotype, consisting of an almost complete articulated specimen. Phylogenetic Justification. While the crown-vertebrate affinity of Haikouichthys ercaicunensis is contested within the context of cyclostome monophyly, its crown-chordate affinity is not, on the basis of phylogenetic analysis by R.S. Sansom et al. (2010).

Minimum Age. $514 \mathrm{Ma}$

Soft Maximum Age. $636.1 \mathrm{Ma}$

Age Justification. The Chengjiang Biota occurs within the Yu'anshan Member of the Heilinpu Formation, which is assigned to the Eoredlichia-Wutingaspis Biozone (Hou et al., 2004) and occurs above the first appearance of trilobites. While the dating of the Eoredlichia-Wutingaspis Biozone is problematic because the fauna is endemic, the first stratigraphic appearance of trilobites is the proposed definition of the base of Cambrian Series 2 (Peng et al., 2012), the lower part of which (proposed Cambrian Age 3 (Peng et al., 2012)) is equivalent to the Nangaoan of South China (Peng, 2003) and encompasses fully the Chengjiang Biota (Peng et al., 2012). This allows us to establish the maximum age of the Chengjiang Biota on the base of the Nangoan, which is given as $521 \mathrm{Ma}$ in GTS 2012 (Peng et al., 2012). The minimum age is more problematic in that a more precise constraint relies on the assumption that the Eoredlichia-Wutingaspis Biozone of the Qiongzhusian Stage is equivalent to the Atdabanian (Hou et al., 2004), which has been substantiated well. Alternatively, we use the age of the Nangaoan-Duyunian Boundary, which is dated at $514 \mathrm{Ma}$ in GTS 2012 (Peng et al., 2012), which relies on a geochronological date from close to this boundary, within the Nangaoan, in Shropshire (Harvey et al., 2011).

A soft maximum constraint is based on the maximum age interpretation of the Lantian Biota (Yuan et al., 2011). This, together with the Doushantuo Biota (Yuan et al., 2002), provides a series of Lagerstätten preserving the biota in Orsten- and Burgess Shale-like modes of fossilization. None of these Lagerstätten, least of all the Lantian, preserves anything that could possibly be interpreted as even a total group eumetazoan and on this basis we define our soft maximum constraint at $635.5 \mathrm{Ma} \pm 0.6 \mathrm{Myr}$ (Condon et al., 2005) and, thus, $636.1 \mathrm{Ma}$.

Discussion. There are a number of claims of Cambrian vertebrates (Chen et al., 1999; Shu et al., 1999; Donoghue and Keating, 2014; Donoghue et al., 2000; Smith et al., 2001; Mallatt and Chen, 2003; Shu et al., 2003), tunicates (Shu et al., 2001; Lacalli, 2002; Chen et al., 2003), and cephalochordates (Shu et al., 1996; Morris and Caron, 2012), but we select Haikouichthys ercaicunensis as the basis for this minimum clade age since it is among the oldest and it has been subject to the most scrutiny, and phylogenetic analyses concur on its membership of the vertebrate total group (Shu et al., 1999; Donoghue et al., 2003; Shu et al., 2003; R.S. Sansom et al., 2010).

\section{CROWN OLFACTORES (17)}

Node Calibrated. Olfactores is the clade encompassing the Tunicata and Vertebrata-Craniata, their last common ancestor and all of its descendants. The monophyly of Olfactores has received broad support from phylogenetic analysis of protein-coding genes, beginning with Delsuc and colleagues 
(Frédéric Delsuc et al., 2006; Delsuc et al., 2008). Fossil Taxon and Specimens. Haikouichthys ercaicunensis (Yunnan Institute of Geological Sciences, Kunming: HZ-f-12-127), holotype, consisting of an almost complete articulated specimen. Phylogenetic Justification. While the crown-vertebrate affinity of Haikouichthys ercaicunensis is contested within the context of cyclostome monophyly, its crown-chordate affinity is not (R.S. Sansom et al., 2010).

Minimum Age. $514 \mathrm{Ma}$

Soft Maximum Age. 636.1 Ma

Age Justification. The Chengjiang Biota occurs within the Yu'anshan Member of the Heilinpu Formation, which is assigned to the Eoredlichia-Wutingaspis Biozone (Hou et al., 2004) and occurs above the first appearance of trilobites. While the dating of the Eoredlichia-Wutingaspis Biozone is problematic because the fauna is endemic, the first stratigraphic appearance of trilobites is the proposed definition of the base of Cambrian Series 2 (Peng et al., 2012), the lower part of which (proposed Cambrian Age 3 (Peng et al., 2012)) is equivalent to the Nangaoan of South China (Peng, 2003) and encompasses fully the Chengjiang Biota (Peng et al., 2012). This allows us to establish the maximum age of the Chengjiang Biota on the base of the Nangoan, which is given as $521 \mathrm{Ma}$ in GTS 2012 (Peng et al., 2012). The minimum age is more problematic in that a more precise constraint relies on the assumption that the Eoredlichia-Wutingaspis Biozone of the Qiongzhusian Stage is equivalent to the Atdabanian (Hou et al., 2004), which has been substantiated well. Alternatively, we use the age of the Nangaoan-Duyunian Boundary, which is dated at $514 \mathrm{Ma}$ in GTS 2012 (Peng et al., 2012) and relies on a geochronological date from close to this boundary, within the Nangaoan, in Shropshire (Harvey et al., 2011).

A soft maximum constraint is based on the maximum age interpretation of the Lantian Biota (Yuan et al., 2011). This, together with the Doushantuo Biota (Yuan et al., 2002), provides a series of Lagerstätten preserving the biota in Orsten- and Burgess Shale-like modes of fossilization. None of these Lagerstätten, least of all the Lantian, preserves anything that could possibly be interpreted as even a total group eumetazoan and on this basis we define our soft maximum constraint at $635.5 \mathrm{Ma} \pm 0.6 \mathrm{Myr}$ (Condon et al., 2005) and, thus, $636.1 \mathrm{Ma}$.

Discussion. There are a number of claims of Cambrian vertebrates (Junyuan Chen et al., 1999; Shu et al., 1999; Donoghue and Keating, 2014;
Donoghue et al., 2000; M. P. Smith et al., 2001; Mallatt and Chen, 2003; Shu et al., 2003) and tunicates (Shu et al., 2001; Lacalli, 2002; J.Y. Chen et al., 2003), but we select Haikouichthys ercaicunensis as the basis for this minimum clade age since it is among the oldest and it has been subject to the most scrutiny and phylogenetic analyses concur on its membership of the vertebrate total group (Shu et al., 1999; Donoghue et al., 2003; Shu et al., 2003; R.S. Sansom et al., 2010).

\section{CROWN VERTEBRATA-CRANIATA (18)}

Node Calibrated. This is the clade that circumscribes all living vertebrates, their common ancestor and all its descendants. Within this framework we accept the overwhelming protein-coding (Kuraku et al., 1999; Furlong and Holland, 2002) and non-coding (Heimberg et al., 2010) molecular evidence supporting the monophyly of cyclostomes (hagfishes and lampreys). As such, we reject the distinction of 'vertebrate' and 'craniate' clades made when cyclostomes were considered paraphyletic with respect to Gnathostomata (Janvier, 1981), instead reverting to Linneaus' original name of 'Vertebrata-Craniata' for the vertebrate grouping. The crown clade Vertebrata-Craniata is comprised of the total group clades Cyclostomata and Gnathostomata.

Fossil Taxon and Specimens. Arandaspis prionotolepis (Commonwealth Palaeontological Collection, Canberra, Australia, CPC13202), holotype, encompassing the articulated rostral portion of the organism.

Phylogenetic Justification. Arandaspis prionotolepis is unequivocally a member of the gnathostome total group, based on a number of phylogenetic analyses (Janvier, 1996a, 1996b; Donoghue et al., 2000; Donoghue and Smith, 2001). It exhibits a number of unequivocal characters exclusive to total-group gnathostomes, most obviously including a mineralized dermal skeleton.

Minimum Age. $457.5 \mathrm{Ma}$

Soft Maximum Age. $636.1 \mathrm{Ma}$

Age Justification. The holotype of Arandaspis prionotolepis was recovered from the Stairway Sandstone Formation of Mt Watt, Amadeus Basin, Northern Territory, Australia (Ritchie and GilbertTomlinson, 1977). The age of the formation is constrained by the occurrence of the conodont Lenodus sp. cf. L. variabilis in the middle part of the Stairway Sandstone, which Davies et al. (2011) interpret as evidence for an early Darriwilian age. This is based on the assumption that Lenodus $s p$. cf. $L$. variabilis falls within the taxonomic range of 
Lenodus variabilis and $L$. antivariabilis which have a stratigraphic range limited to the upper Baltoniodus norrlandicus Zone to the Eoplacognathus variabilis and Yangtzeplacognathus crassus zones (Löfgren and Zhang, 2003). The most secure geochronological date appropriate to constrain the minimum age of the holotype of Arandaspis prionotolepis is the Darriwillian-Sandbian boundary, which is dated at $458.4 \mathrm{Ma} \pm 0.9 \mathrm{Myr}$, thus 457.5 Ma.

The soft maximum constraint encompasses the possibility that putative Cambrian vertebrates, such as Haikouichthys, Myllokunmingia (Shu et al., 1999), and Zhongjianichthys (Shu, 2003), are stem-cyclostomes. Thus, our soft maximum is based on the maximum age interpretation of the Lantian Biota (Yuan et al., 2011). This, together with the Doushantuo Biota (Yuan et al., 2002), provides a series of Lagerstätten preserving the biota in Orsten- and Burgess Shale-like modes of fossilization. None of these Lagerstätten, least of all the Lantian, preserves anything that could credibly be interpreted as even a total group eumetazoan and on this basis we define our soft maximum constraint at $635.5 \mathrm{Ma} \pm 0.6 \mathrm{Myr}$ (Condon et al., 2005) and, thus, $636.1 \mathrm{Ma}$.

Discussion. Arandaspis prionotolepis is by no means the oldest claim for a crown vertebrate. The oldest possible encompass soft-bodied taxa from the early Cambrian Chengjiang fauna, including Yunnanozoon and Haikouella (Holland and Chen, 2001; Mallatt and Chen, 2003), Zhongjianichthys, Myllokunmingia, and Haikouichthys (Shu et al., 1999; Hou et al., 2002; Shu, 2003; Shu et al., 2003). However, given the implications of cyclostome monophyly for the nature of the vertebrate crown-ancestor (Heimberg et al., 2010), evidence of their membership of the vertebrate crown-group is not sufficiently robust to discriminate the possibility that these organisms are invertebrates (some may belong to even more universal groupings (Donoghue and Purnell, 2009; R.S. Sansom et al., 2010), and it is certainly not sufficiently convincing to justify their use in calibrating or constraining a molecular clock analysis. Similarly, conodonts have been considered widely as crown-vertebrates, even stem-gnathostomes (Donoghue et al., 2000), but there remains a vigorous campaign to reclassify them as invertebrates (Blieck et al., 2010; Turner et al., 2010). Hence, we have reverted to records of skeletonized vertebrates since the possession of a dermal skeleton is an unequivocal stem-gnathostome character. The oldest records of these 'ostracoderms' occur as microscopic frag- mentary skeletal remains, which are problematic in the sense that they preserve no characters to further corroborate vertebrate affinity (M.P. Smith et al., 1996; Young et al., 1996; Young, 1997; Erdtmann et al., 2000). Thus, we have used the oldest records of articulated remains that, in addition to evidence of a mineralized dermal skeleton, preserve anatomical characters that are unequivocally indicative of membership of the vertebrate crown clade. These records are of the arandaspids Saccabambaspis janvieri (Gagnier, 1989) and Arandaspis prionotolepis (Ritchie and GilbertTomlinson, 1977). The phylogenetic affinity of these taxa has been established largely through combining evidence from both taxa which are very similar (Janvier, 1996a; Donoghue et al., 2000; Donoghue and Smith, 2001). We have singled out Arandaspis prionotolepis because the dating of the articulated remains of Saccabambaspis janvieri is extremely poorly constrained.

\section{CROWN CYCLOSTOMATA (19)}

Node Calibrated. The clade comprised of all living hagfishes and lampreys, their last common ancestor and all of its descendants. The monophyly of cyclostomes has long been contentious, a classical example of phylogenetic conflict between morphological and molecular data (Goodman et al., 1987). However, Heimberg et al (2010) have demonstrated that morphological data are indecisive on the question, and that both protein-coding and noncoding molecular data unequivocally support cyclostome monophyly.

Fossil Taxon and Specimens. Priscomyzon riniensis (Albany Museum, Grahamstown, Eastern Cape, South Africa, catalogue number AM5750), holotype, consisting of an almost complete specimen.

Phylogenetic Justification. Priscomyzon riniensis is unequivocally a member of total-group Petromyzontida, based on morphological phylogenetic analysis (Gess et al., 2006), including the presence of an oral hood, annular cartilages and circumoral teeth.

Minimum Age. $358.5 \mathrm{Ma}$

Soft Maximum Age. $636.1 \mathrm{Ma}$

Age Justification. The holotype of Priscomyzon riniensis was recovered from the Famennian Witpoort Formation (Witteberg Group) at Waterloo Farm, Grahamstown, South Africa. Thus, we established the minimum constraint on the top of the Famennian, the Devonian-Carboniferous Boundary, which is dated at $358.9 \mathrm{Ma} \pm 0.4 \mathrm{Myr}$ (Becker et al., 2012). 
The soft maximum constraint encompasses the possibility that putative Cambrian vertebrates, such as Haikouichthys, Myllokunmingia (Shu et al., 1999), and Zhongjianichthys (Shu, 2003), are crown-cyclostomes. Thus, our soft maximum is based on the maximum age interpretation of the Lantian Biota (Yuan et al., 2011). This, together with the Doushantuo Biota (Yuan et al., 2002), provides a series of Lagerstätten preserving the biota in Orsten- and Burgess Shale-like modes of fossilization. None of these Lagerstätten, least of all the Lantian, preserves anything that could credibly be interpreted as even a total group eumetazoan and on this basis we define our soft maximum constraint at $635.5 \mathrm{Ma} \pm 0.6 \mathrm{Myr}$ (Condon et al., 2005) and, thus, $636.1 \mathrm{Ma}$.

\section{CROWN GNATHOSTOMATA (20)}

Node Calibrated. Divergence between Osteichthyes and Chondrichthyes.

Fossil Taxon and Specimen. Guiyu oneiros Zhu et al., 2009 from the Kuanti Formation, near Xiaoxiang Reservoir, Qujing, Yunnan, China (holotype IVPP V15541, Insitute of Vertebrate Paleontology and Paleoanthropology, Beijing).

Phylogenetic Justification. Several clear features, including the presence of rhombic scales with peg-and-socket articulations, indicate that Guiyu is an osteichthyan. More specifically, Guiyu presents several synapomorphies of lobe-finned fishes (e.g., a dermal intracranial joint), with resolved phylogenetic solutions placing this genus on the sarcopterygian stem within the osteichthyan crown (Zhu et al., 2009; Friedman and Brazeau, 2010; Davis et al., 2012).

Minimum Age. 420.7 Ma.

Soft Maximum Age. 468.4 Ma.

Age Justification. The holotype of Guiyu oneiros was recovered from the Kuanti Formation, just below the first stratigraphic occurrence of the conodont index fossil Ozarkodina crispa, at a locality near Xiaoxiang Reservoir, Qujing, Yunnan, China (Wang, 2001; Zhu et al., 2009). However, since it is not possible to discriminate whether the first occurrence of $O$. crispa here coincides, postdates, or antedates its first occurrence in the type Ludlow of the Welsh Borderlands (it is not demonstrated that the occurrence of $G$. oneiros occurs within the preceding Ozarkodina snajdri biozone), the most appropriate age interpretation should be based on the geochronological age of the top of the O. crispa biozone, which immediately precedes the LudlowPridoli boundary in both the type Ludlow in the Welsh Borderlands of England and at the GSSP section for the Ludlow-Pridoli in the Daleje Valley, Prague, Czech Republic, where it is dated as 423 Ma \pm 2.3 Myr (Melchin et al., 2012). This yields a minimum age estimate of $420.7 \mathrm{Ma}$.

A maximum bound for the divergence between chondrichthyans and osteichthyans can be derived from diverse faunas of jawless, armored stem gnathostomes ('ostracoderms') of Middle to Late Ordovician age (Young, 1997; Erdtmann et al., 2000; Sansom et al., 1996, 2001, 2013; see calibration for crown Vertebrata-Craniata, Node 18). Isolated microremains of this age have been compared with chondrichthyans (e.g., Sansom et al., 2012), but phylogenetic interpretations of such materials are not secure, especially in the absence of articulated specimens of similar age showing unambiguous features of jawed vertebrates. We therefore propose the oldest of these Ordovician ostracoderm assemblages, from the Stairway Sandstone Formation of Mt Watt, Amadeus Basin, Northern Territory, Australia, as an estimated maximum bound for the gnathostome crown. The age of the formation is constrained by the occurrence of the conodont Lenodus sp. cf. L. variabilis in the middle part of the Stairway Sandstone, which Davies et al. (2011) interpret as evidence for an early Darriwilian age. This is based on the assumption that Lenodus sp. cf. L. variabilis falls within the taxonomic range of Lenodus variabilis and $L$. antivariabilis, which have a stratigraphic range limited to the upper Baltoniodus norrlandicus Zone to the Eoplacognathus variabilis and Yangtzeplacognathus crassus zones (Löfgren and Zhang, 2003). Jakobsen et al. (2014) have argued for a mid-Darriwlian age for the Stairway Sandstone on the basis of trilobites. The base of the Darriwillian is dated as 467.3 Ma $\pm 1.1 \mathrm{Myr}$, from which we give an estimated maximum bound of 468.4 Ma for the gnathostome crown. This value allows for the possibility that isolated scales (e.g., KaratajutéTalimaa and Predtechenskyj, 1995) and spines (Sansom et al., 2005) of latest Ordovician-early Silurian age might represent members of the chondrichthyan total group.

Discussion. The fact that the earliest definitive representative of the gnathostome crown group is a crown osteichthyan rather than a stem member of either Chondrichthyes or Osteichthyes suggests that the minimum age provided above likely represents a substantial underestimate. Many fossils older than Guiyu have been associated with crown gnathostomes in general and total-group chondrichthyans in particular (e.g., 'shark-like' scales from the Middle Ordovician; Sansom et al., 2012). 
We hesitate from using such remains as markers for the minimum time of origin of the gnathostome crown for three reasons. First, these materials are highly fragmentary, comprising isolated scales or fragmentary spine-like structures with a correspondingly limited set of characters that might be useful in determining their placement. Second, these materials are generally tied to chondrichthyans on the basis of phenetic similarity rather than synapomorphies; where derived characters are apparent, they are limited to one or two features. Third, and perhaps most significant, the interrelationships of early gnathostomes are currently undergoing considerable systematic revision as a consequence of rigorous cladistic interrogation. Particularly relevant is the status of 'acanthodians', broadly shark-like jawed vertebrates that have historically been associated with either the chondrichthyan or osteichthyan stem (reviewed by Brazeau and Friedman, 2014). Some recent analyses have queried the status of this fossil assemblage, placing canonical members in various positions within the gnathostome crown and along the stem (Brazeau, 2009; Davis et al., 2012; Zhu et al., 2013; Brazeau and Friedman, 2014; Dupret et al., 2014). Until the relationships of early jawed vertebrates stabilize and putative Ordovician gnathostome fragments can be placed more confidently within a tree, we advocate the use of a comparatively conservative fossil-based minimum for marking the origin of crown Gnathostomata.

\section{CROWN CHONDRICHTHYES (21)}

Node Calibrated. Divergence between Holocephali and Elasmobranchii.

Fossil Taxon and Specimen. Chondrenchelys problematicus from Mumbie Quarry, Glencartholm Volcanic Group, Upper Border Group of the Calcifererous Sandstone, Glencartholm, Scotland (NMS 1998.35.1, National Museum of Scotland, Edinburgh, Scotland).

Phylogenetic Justification. Chondrenchelys is recognized as a member of Holocephali based on the presence of numerous synapomorphies of that clade, including: complete fusion of the palatoquadrate with the braincase, absence of a precerebral fontanelle, an elongate ethmoid region, insertion of jaw adductor muscles anterior to the orbit, absence of persistent cranial fissures, a fused mandibular symphysis, a terminal posterior articulation of the mandible, a reduced number of tooth families, and tooth crowns reinforced with hypermineralized tissue (reviewed in Finarelli and Coates, 2014). Placement of Chondrenchelys within Holocephali is also supported by the formal cladistic analysis presented by Lund and Grogan (1997) and the manual solution given by Stahl (1999).

Minimum Age. $333.56 \mathrm{Ma}$

Soft Maximum Age. $422.4 \mathrm{Ma}$

Age Justification. Mumbie Quarry and the Glencartholm Fish Bed are lateral equivalents within the Glencartholm Volcanic Beds of Scotland (Finarelli and Coates, 2012, 2014). Foraminifera indicate that the Glencartholm Volcanic Beds span the boundary between the Holkerian and Asbian regional stages (Cater et al., 1989; Purnell and Cossey, 2004). This is roughly equivalent to the boundary between the Livian and Warnantian in the Western European subdivision of the Carboniferous (Davydov et al., 2012, p. 606), and places the Glencartholm Volcanic Beds within the midVisean of the global timescale. The top of the Asbian lies within the Gnathodus bilineatus Conodont Zone (Poty et al., 2014). Younger ash beds provide a minimum age for the top of this zone of 333.95 Ma \pm 0.39 Myr (Davydov et al., 2012). From this, we derive a minimum age for crown Chondrichthyes of $333.56 \mathrm{Ma}$.

Tillywhandland Quarry in Scotland (Trewin and Davidson, 1995), Wayne Herbert Quarry in England (Miles, 1973), and the Man on the Hill ('MOTH') site in Canada (Gagnier and Wilson, 1996) yield a diverse range of cladistically justified members of the chondrichthyan stem group (Brazeau, 2009; Davis et al., 2012; Zhu et al., 2013; Dupret et al., 2014; Brazeau and Friedman, 2014), but no crown chondrichthyans. These Lochkovian deposits predate the oldest body-fossil remains attributed to Chondrichthyes in an apomorphy-based sense (the Emsian Doliodus and Pucapampella; Maisey and Anderson, 2001; Miller et al., 2003). The base of the Lochkovian is dated as $419.2 \mathrm{Ma} \pm 3.2 \mathrm{Myr}$, from which we derive our soft maximum age for crown Chondrichthyes of 422.4 Ma.

Discussion. Chondrenchelys is a contemporary of Onychoselache and Tristychius, which are the oldest hybodontiforms and generally considered the earliest unambiguous members of Elasmobranchii sensu stricto (Dick, 1978; Coates and Gess, 2007). However, it is possible that the age of the chondrichthyan crown substantially predates these Visean taxa. Several putative holocephalans of Devonian age have been identified, but they are all represented by isolated and often fragmentary teeth (reviewed by Stahl, 1999 and Darras et al., 2008). These include Melanodus from the Givetian 
of France (Darras et al., 2008), Synthetodus from the early Frasnian of lowa, USA (Eastman, 1908; Stahl, 1999) and Thoralodus from the middle Famennian of Cabrières, Montagne Noire, southern France (Lehman, 1952; Lelièvre et al., 1987). An apparent exception to this rule is the poorly preserved body fossil of Plesioselachus from the Famennian of South Africa. Initial reports identified this taxon as a holocephalan (Anderson et al., 1994; Gess and Hiller, 1995), but subsequent studies have interpreted it as an elasmobranch sensu lato (Anderson et al., 1999; Gess, 2011; Gess and Coates, 2014). These holocephalan-like dentitions have never been included in formal phylogenetic analyses, although hand-drawn trees imply a range of potential placements within the chondrichthyan total group (Finarelli et al., 2012: figure S1). Some of the features used to identify Devonian holocephalan teeth (e.g., low crowned morphology coupled with the presence of osteodentine) are known in many early gnathostome lineages, raising questions about the reliability of identifications made on the basis of such limited remains (Finarelli and Coates, 2014, p. 57). Subsequent investigation of these materials might provide robust placements within Holocephali, but until that time we follow Finarelli and Coates (2014) in nominating Chondrenchelys as a reliable minimum marker for crown Chondrichthyes that best satisfies suggested practices for defining fossil calibrations (Parham et al., 2012).

\section{CROWN OSTEICHTHYES (22)}

Node Calibrated. Divergence between Actinopterygii and Sarcopterygii.

Fossil Taxon and Specimen. Guiyu oneiros Zhu et al., 2009 from the Kuanti Formation, near Xiaoxiang Reservoir, Qujing, Yunnan, China (holotype IVPP V15541, Institute of Vertebrate Paleontology and Paleoanthropology, Beijing).

Phylogenetic Justification. Several clear features, including the presence of rhombic scales with peg-and-socket articulations, indicate that Guiyu is an osteichthyan. More specifically, Guiyu presents several synapomorphies of lobe-finned fishes, with resolved phylogenetic solutions placing this genus on the sarcopterygian stem within the osteichthyan crown (Zhu et al., 2009; Friedman and Brazeau, 2010; Davis et al., 2012).

Minimum Age. $420.7 \mathrm{Ma}$

Soft Maximum Age. 444.9 Ma

Age Justification. The holotype of Guiyu oneiros was recovered from the Kuanti Formation, just below the first stratigraphic occurrence of the cono- dont index fossil Ozarkodina crispa, at a locality near Xiaoxiang Reservoir, Qujing, Yunnan, China (Wang, 2001; Zhu et al., 2009). However, since it is not possible to discriminate whether the first occurrence of $O$. crispa here coincides, postdates, or antedates its first occurrence in the type Ludlow of the Welsh Borderlands (it is not demonstrated that the occurrence of $G$. oneiros occurs within the preceding Ozarkodina snajdri biozone), the most appropriate age interpretation should be based on the geochronological age of the top of the O. crispa biozone, which immediately precedes the LudlowPridoli boundary in both the type Ludlow in the Welsh Borderlands of England and at the GSSP section for the Ludlow-Pridoli in the Daleje Valley, Prague, Czech Republic where it is dated as 423 Ma \pm 2.3 Myr (Melchin et al., 2012). This yields a minimum age estimate of $421.7 \mathrm{Ma}$.

Estimation of a soft maximum for the osteichthyan crown is complicated by the highly fragmentary nature of most gnathostome remains older than Guiyu (reviewed by Qu et al., 2010), coupled with ongoing revision to interpretations of the relationships of extinct gnathostome assemblages to living groups (Brazeau, 2009; Davis et al., 2012; Zhu et al., 2013; Dupret et al., 2014; Brazeau and Friedman, 2014). Scales aligned with chondrichthyans, the living sister group of osteichthyans, have been reported from the Middle Ordovician (Dariwillian; Sansom et al., 2012), but these taxonomic interpretations are admittedly tentative and supported by few characters. Similarly meagre remains from the Late Ordovician of Siberia are identified as the oldest acanthodians (KaratajutéTalimaa and Predtechenskyj, 1995; figure 5), a problematic group of jawed vertebrates that have recently been interpreted as stem chondrichthyans, stem osteichthyans, stem gnathostomes, or some combination of the three (Brazeau, 2009; Davis et al., 2012; Zhu et al., 2013; Brazeau and Friedman, 2014; Dupret et al., 2014). It is widely agreed that placoderms are a grade of stem gnathostomes (Friedman, 2007a; Brazeau, 2009; Davis et al., 2012; Zhu et al., 2013; Dupret et al., 2014; Brazeau and Friedman, 2014), more distantly related to osteichthyans than either chondrichthyans or acanthodians. However, the first record of placoderms postdates the earliest remains interpreted as possible chondrichthyans or acanthodians (Karatajuté-Talimaa and Predtechenskyj, 1995; Sansom et al., 2012). The first placoderms are known from the early Silurian (late Llandovery) of China (Wang, 1991). Unlike the oldest examples of chondrichthyans or acanthodians, 
the earliest placoderms can be clearly aligned with taxa known on the basis of more complete remains from younger strata and are attributed to yunnanolepiform antiarchs. Rocks of early Silurian age also yield a diversity of jawless fishes (Janvier and Blieck, 1993; Karatajuté-Talimaa and Predtechenskyj, 1995), but no remains clearly attributable to crownward portions of the osteichthyan stem despite the presence of suitable depositional settings. We therefore propose the base of the Llandovery, dated at 443.4 Ma $\pm 1.5 \mathrm{Myr}$ (Melchin et al., 2012 , p. 550), as a soft maximum bound for the divergence of crown Osteichthyes.

Discussion. Apart from Guiyu, several osteichthyans are known from the Ludlow on the basis of fragmentary remains of the dermal skeleton: Naxilepis, Ligulalepis, Andreolepis, and Lophosteus (reviewed in Qu et al., 2010). These genera were classically aligned with ray-finned fishes (e.g., Janvier, 1996a), but renewed study has shown that the characters used to support hypothesized actinopterygian affinities represent general features of bony fishes. Most, if not all, of these contemporaries of Guiyu are therefore likely to represent stem osteichthyans (Friedman, 2007a; Botella et al., 2007; Zhu et al., 2009; Friedman and Brazeau, 2010; Zhu et al., 2013).

\section{CROWN SARCOPTERYGII (23)}

Node Calibrated. Divergence between Actinistia and Tetrapoda.

Fossil Taxon and Specimen. Youngolepis sp. from the lower Xishacun Formation, Quijing, Yunnan, China (IVPP V10519.1, Insitute of Vertebrate Paleontology and Paleoanthropology, Beijing).

Phylogenetic Justification. Youngolepis is universally regarded as a stem-group lungfish in maximum parsimony (Cloutier and Ahlberg, 1996; Zhu et al., 1999; Zhu et al., 2001; Zhu and Yu, 2002; Friedman, 2007a; Zhu et al., 2009) and Bayesian (Friedman, 2007b; Zhu et al., 2009) analyses of sarcopterygian interrelationships based on morphological data. This makes the genus the oldest representative of crown Rhipidistia, the clade uniting lungfishes and tetrapods to the exclusion of coelacanths.

Youngolepis is best known from Youngolepis praecursor, the type species from the middle to late Lochkovian Xitun Formation of Yunnan, China. The anatomy of $Y$. praecursor is known in great detail (e.g., Chang, 1982), and it is character information from this species that is used to infer the position of the genus within sarcopterygian phylogeny. Although the specimens of Youngolepis sp. from the Xishacun Formation are fragmentary and poorly preserved, Zhu and Fan (1995) provide clear evidence for this generic identification. Therefore, the Youngolepis sp. specimen from the Xishacun Formation preserves synapomorphies that place it both in the dipnoan total group and in genus Youngolepis.

Minimum Age. $408 \mathrm{Ma}$

Soft Maximum Age. 427.9 Ma

Age Justification. The Xishacun Formation yields members of the micronatus- newportensis spore assemblage (Cai et al., 1994; Zhao and Zhu, 2010). The top of this zone lies near the end of the Lochkovian (Becker et al., 2012). The Lochkovian is dated as $419 \mathrm{Ma} \pm 3.2 \mathrm{Myr}$ to $410.8 \mathrm{Ma} \pm 2.8$ Myr, from which we derive our minimum age for the divergence of crown Sarcopterygii of $408 \mathrm{Ma}$.

A soft maximum age for the coelacanth-tetrapod divergence is given by the diverse late Silurian gnathostome assemblage of the Kuanti Formation, Yunnan, China. This deposit yields articulated remains of stem sarcopterygians, placoderms, and galeaspids (Zhang et al., 2010; Zhu et al., 2009, $2012,2013)$, as well as undescribed acanthodians (Zhu et al., 2009). Crown sarcopterygians are, however, completely lacking. We therefore propose the oldest possible age of this deposit as a maximum constraint for divergence between coelacanths and tetrapods. The base of the Ludlow is dated as 427.4 Ma $\pm 0.5 \mathrm{Myr}$, from which we derive an estimate of $427.9 \mathrm{Ma}$.

Discussion. Two lines of evidence suggest that our proposed minimum age for the origin of the sarcopterygian crown might represent a substantial underestimate. First, Youngolepis represents a minimum date for the appearance of a more restrictive clade of crown sarcopterygians: crown Rhipidistia. Second, middle to late Lochkovian deposits yield a diversity of crown-group sarcopterygians in addition to Youngolepis (Powichthys, Diabolepis, and Styloichthys; Jessen, 1980; Chang, 1984; Zhu and Yu, 2002), which implies an extensive pre-Devonian history for the group.

\section{CROWN RHIPIDISTIA (24)}

Node Calibrated. Divergence between Dipnoi and Tetrapoda.

Fossil Taxon and Specimen. Youngolepis sp. from the lower Xishacun Formation, Quijing, Yunnan, China (IVPP V10519.1, Insitute of Vertebrate Paleontology and Paleoanthropology, Beijing).

Phylogenetic Justification. Youngolepis is universally regarded as a stem-group lungfish in maximum-parsimony (Cloutier and Ahlberg, 1996; Zhu 
et al., 1999; Zhu et al., 2001; Zhu and Yu, 2002; Friedman, 2007a; Zhu et al., 2009) and Bayesian (Friedman, 2007b; Zhu et al., 2009) analyses of sarcopterygian interrelationships based on morphological data. This makes the genus the oldest representative of crown Rhipidistia, the clade uniting lungfishes and tetrapods to the exclusion of coelacanths.

Youngolepis is best known from Youngolepis praecursor, the type species from the middle to late Lochkovian Xitun Formation of Yunnan, China. The anatomy of $Y$. praecursor is known in great detail (e.g., Chang, 1982), and it is character information from this species that is used to infer the position of the genus within sarcopterygian phylogeny. Although the specimens of Youngolepis sp. from the Xishacun Formation are fragmentary and poorly preserved, Zhu and Fan (1995) provide clear evidence for this generic identification.

Minimum Age. $408 \mathrm{Ma}$

Soft Maximum Age. 427.9 Ma

Age Justification. The Xishacun Formation yields members of the micronatus- newportensis spore assemblage (Cai et al., 1994; Zhao and Zhu, 2010). The top of this zone lies near the end of the Lochkovian (Becker et al., 2012). The Lochkovian is dated as $419 \mathrm{Ma} \pm 3.2 \mathrm{Myr}$ to $410.8 \mathrm{Ma} \pm 2.8$ Myr, from which we derive our minimum age for the divergence of crown Sarcopterygii of $408 \mathrm{Ma}$.

A soft maximum age for the lungfish-tetrapod divergence is given by the diverse late Silurian gnathostome assemblage of the Kuanti Formation, Yunnan, China. This deposit yields articulated remains of stem sarcopterygians, placoderms, and galeaspids (Zhang et al., 2010; Zhu et al., 2009, 2012, 2013), as well as undescribed acanthodians (Zhu et al., 2009). Crown sarcopterygians and crown rhipidistians are, however, completely lacking. We therefore propose the oldest possible age of this deposit as a maximum constraint for the divergence between lungfishes and tetrapods. The base of the Ludlow is dated as 427.4 Ma $\pm 0.5 \mathrm{Myr}$, from which we derive an estimate of 427.9 Ma.

Discussion. The morphological variety apperent in stem lungfishes from late Lochkovian deposits in addition to Youngolepis (Powichthys and Diabolepis; Jessen, 1980; Chang, 1984) might be taken as evidence that our minimum is a substantial underestimate or that there was rapid divergence among rhipidistians in the earliest Devonian.

\section{CROWN ACTINOPTERYGII (25)}

Node Calibrated. Divergence between Cladistia and Actinopteri (Figure 4).
Fossil Taxon and Specimen. Moythomasia durgaringa Gardiner, 1984, from the Gogo Formation, Gogo Station, Fitzroy Crossing, Western Australia, Australia (holotype WAM 70.4.244, Western Australian Museum, Perth, Australia).

Phylogenetic Justification. Gardiner (1984), Gardiner and Schaeffer (1989), Coates (1998, 1999), and Gardiner et al. (2005) resolve Moythomasia as a crown-group actinopterygian. It is united with extant Actinopteri to the exclusion of Cladistia by a series of characters related to the pectoral-fin endoskeleton, neurocranium and parasphenoid, and lower jaw (Gardiner, 1984: 397).

Minimum Age. $378.19 \mathrm{Ma}$

Soft Maximum Age. $422.4 \mathrm{Ma}$

Age Justification. Conodont biostratigraphy provides a well-constrainted age estimate for Moythomasia durgaringa. The base of the Gogo Formation spans the Schmidtognathus hermanni to Palmatolepis punctata conodont zones, indicating a late Givetian-early Frasnian age. Fish-bearing concretions in the Gogo Formation, which yield material of Moythomasia, derive predominantly from the transitans Zone (Long and Trinajstic, 2010). The top of the Palmatolepis transitans Zone is dated to $380.38 \mathrm{Ma} \pm 2.189 \mathrm{Myr}$ (Becker et al., 2012), from which we derive a minimum age of 378.19 Ma.

A soft maximum bound on the origin of crown Actinopterygii can be derived from the age of the diverse bony fish faunas of the Xitun, Guijiatun, and Lianhuashan formations of eastern Yunnan, China. These deposits yield a range of early lobefinned fishes that include both stem- and crowngroup representatives (Zhao and Zhu, 2009), but actinopterygians are unknown from these horizons. Correlations with other deposits that can be dated on the basis of spore biostratigraphy indicate a late Lochkovian age. The base of the Lochkovian is dated as 419.2 Ma $\pm 3.2 \mathrm{Myr}$, from which we derive a soft maximum bound of for the origin of crown Actinopterygii of $422.4 \mathrm{Ma}$.

Discussion. Moythomasia is known from several European localities (e.g., the Baltics; BergischGladbach and Brandenberg Group, Germany; Gardiner, 1984; Otto, 1999; Lukševičs et al., 2010) that represent older horizons than the Gogo Formation. However, remains from these sites are known in less satisfactory detail than those from Gogo, so we have adopted a conservative strategy in using the exceptional, thoroughly-described material from this Australian Lagerstätte as the basis for our minimum age for the actinopterygian crown. 
Some authors place the Givetian genus Howqualepis, which is represented by multiple articulated specimens, as a crown actinopterygian (e.g., Gardiner and Schaeffer, 1989; Coates, 1999). If correct, this would require downward revision of the minimum age constraint provided here. However, Howqualepis is known in less satisfactory detail than Moythomasia and derives from lacustrine deposits dated on the basis of macrovertebrates, resulting in less secure age constraints relative to biozonation schemes applicable in marine settings (Young, 1993).

\section{CROWN CHONDROSTEI (STURGEONS AND PADDLEFISHES) (26)}

Node Calibrated. Divergence between Acipenseridae and Polyodontidae.

Fossil Taxon and Specimen. Protopsephurus liui Lu, 1994, from the Jianshangou beds, lower Yixian Formation, Jehol Group of Xitaizi, Ningcheng, eastern Nei Mongol, China (specimen TN P03042, Tianjin Natural History Museum, Tianjin, China).

Phylogenetic Justification. Protosephurus is resolved as the sister group of all remaining polyodontids in cladistic analyses (Grande et al., 2002; Hilton et al., 2011). Derived features supporting this arrangement include the presence of: welldeveloped anterior and posterior divisions of the fenestra longitudinalis, parietals extending posterior to the posttemporals, stellate bones, a serrated posterior margin of the subopercle, and 'microctenoid' scales (Hilton et al., 2011).

Minimum Age. $120.8 \mathrm{Ma}$

Soft Maximum Age. 201.5 Ma

Age Justification. Swisher et al. (1999, 2002) reported ${ }^{40} \mathrm{Ar} /{ }^{39} \mathrm{Ar}$ dates for ash beds within the lower Yixian Formation of $124.6 \mathrm{Ma} \pm 0.2 \mathrm{Myr}$, 124.6 Ma $\pm 0.3 \mathrm{Myr}, 125.0 \mathrm{Ma} \pm 0.18 \mathrm{Myr}$, and $125.0 \mathrm{Ma} \pm 0.19 \mathrm{Myr}$. These internal dates for the Yixian Formation have been applied as a minimum estimate for the origin of the chondrostean crown in previous analyses (e.g., Near et al., 2012). A more conservative estimate can be obtained using the age for basalts and andesites that overlie the Jianshangou beds. ${ }^{40} \mathrm{Ar}-{ }^{39} \mathrm{Ar}$ dating yields a mean age estimate of $121 \mathrm{Ma} \pm 0.2 \mathrm{Myr}$ for these volcanic units (Smith et al., 1995). We therefore set a minimum age for Protosephurus of $120.8 \mathrm{Ma}$.

Chondrosteans are not represented in diverse Early Cretaceous freshwater deposits older than the Yixian Formation (e.g., Woodward, 1915-1917; Yabumoto, 1994; the interpretation of the stem acipenseriform Peipiaosteus as Late Jurassic by Near et al., 2012 and others reflects outdated age esti- mates). However, given the patchy record of chondrosteans generally (see Discussion), we adopt an especially generous soft maximum age for the divergence between Acipenseridae and Polyodontidae. Our proposed soft maximum age is based on the early chondrostean Chondrosteus, from the Hettangian-Sinemurian Blue Lias Formation of Dorset, England. This genus is universally recovered as a stem chondrostean in cladistic analyses (e.g., Grande et al., 2002; Hilton and Forey, 2009; Hilton et al., 2011), and represents the earliest known member of Acipenseriformes (sensu Grande and Bemis, 1996). The base of the Hettangian is dated as 201.3 Ma $\pm 0.2 \mathrm{Myr}$ (Ogg et al., 2012a), from which we derive a soft maximum of 201.5 Ma.

Discussion. Although some individual taxa are known in stunning detail, the fossil record of chondrosteans is comparatively sparse. Apart from exquisitely preserved material from the Jurassic of Europe (Hilton and Forey, 2009), Cretaceous of Asia (Grande and Bemis, 1996; Grande et al., 2002) and North America (Grande and Bemis, 1991; Grande and Hilton, 2006), and Eocene Green River Lagerstätte (Grande and Bemis, 1991), most fossil chondrosteans are known from highly fragmentary material, most typically the dermal scutes of acipenserids (Hilton and Grande, 2006).

\section{CROWN NEOPTERYGII (27)}

Node Calibrated. Divergence between Holostei and Teleostei.

Fossil Taxon and Specimen. Watsonulus eugnathoides (Piveteau, 1935) from the Middle Sakamena Formation, Sakamena Group, Ambilombe Bay, Madagascar (syntype MNHN MAE $33 a, b$, Muséum national d'Histoire naturelle, Paris).

Phylogenetic Justification. Numerous cladistic analyses resolve Watsonulus as the sister group of all other halecomorphs (Gardiner et al., 1996; Grande and Bemis, 1998; Grande, 2010; Friedman, 2012a; Arratia, 2013; Xu et al., 2014), and thus a member of the crown Neopterygii generally and crown Holostei specifically. This placement is supported by the derived presence of features shared by Watsonulus and other halecomorphs including a 'double' jaw joint involving the symplectic and a concave posterior margin of the maxilla (Grande and Bemis, 1998).

In contrast to this current consensus, Olsen (1984) placed Watsonulus as a stem neopterygian based on the retention of several primitive features 
generally not found in crown neopterygians. However, some of these features have not been detected in the specimens by later researchers (e.g., an autogenous quadratojugal; Grande and Bemis, 1998), while others have a wider distribution within neopterygians than previously thought (e.g., presence of a clavicle in some stem teleosts; Arratia, 2013).

Minimum Age. 250.0 Ma

Soft Maximum Age. 331.1 Ma

Age Justification. The Sakamena Group in Madagascar spans from late Permian to Middle Triassic, and the Middle Sakamena Group/Formation is generally dated as lower Lower Triassic, the Upper Sakamena Group/ Formation, Lower to lower Middle Triassic. The entire Sakamena Group is some $4 \mathrm{~km}$ thick, and it is subdivided based on dominant lithologies: the middle portion is a sequence of shales and minor sandstones deposited in a lagoonal or shallow lacustrine and braided river environment, whereas the units below and above are dominated by sandstones and conglomerates indicating higher energies of deposition. Dating of the Sakamena Group is notoriously difficult, as there are no radiometric dates, there has been no magnetostratigraphic study, and the associated fossils are not classic biostratigraphically useful index fossils. Nonetheless, the Middle Sakamena Group is dated as Induan on the basis of the associated fauna of benthosuchid temnospondyls (like those of the Lystrosaurus Assemblage Zone of South Africa and the Vokhmian units of Russia, as well as plants also suggesting Induan age. The top of the Induan stage is dated as 'slightly older than' 251.2 Ma \pm 0.2 Myr (Mundil et al., 2010), and given as $250.01 \mathrm{Ma}$ by Ogg (2012, p. 718), so we select this age as the minimum constraint, namely 250.0 Ma.

Wastonulus represents the oldest definitive halecomorph, holostean, and crown neopterygian. This, combined with a rudimentary understanding of relationships among taxa in crownward portions of the neopterygian stem (including the so-called 'subholosteans'), renders the formulation of a soft maximum age for crown Holostei difficult. The absence of many of the proximal outgroups of Holostei in pre-Triassic deposits might be taken as evidence for the rapid radiation of neopterygians and their immediate relatives following the PermoTriassic extinction. However, the Permian record of ray-finned fishes is characterized by scarcity of deposits yielding well-preserved, articulated material (Hurley et al., 2007; Friedman and Sallan, 2012; Lloyd and Friedman, 2013; Sallan, 2014), suggesting this absence could be more apparent than real. The Mississippian (Serpukhovian) Bear Gulch Lagerstätte in Montana, USA, includes a great diversity of articulated actinopterygians (Lund and Poplin, 1999), including taxa interpreted as crownward members of the neopterygian stem (e.g., Discoserra; Hurley et al., 2007; Xu et al., 2014). Crown neopterygians are completely absent from this deposit. The base of the Serpukhovian is dated to $330.9 \mathrm{Ma} \pm 0.2 \mathrm{Myr}$, from which we derive a maximum age for crown Neopterygii of 331.1 Ma. Discussion. At least two Permian taxa have been interpreted as possible representatives of Holostei and therefore crown-group Neopterygii. The first of these, the early Permian (Artinskian) Brachydegma (Dunkle, 1939), was placed as a stem halecomorph in the cladistic analysis presented by Hurley et al. (2007). However, subsequent re-examination of the specimen has called into question the degree to which the characters used to support this interpretation are apparent in the specimen (Near et al., 2012; Broughton et al., 2013). We agree, and regard this taxon as a stem neopterygian (cf. Xu et al., 2014). The second candidate is Acentrophorus, which is represented by several species from the late Permian of Germany and the UK. This genus has classically been aligned with semionotids (e.g., Gill, 1923; Rayner, 1941; Patterson, 1973), which are now interpreted as a paraphyletic assemblage on the ginglymodin stem (Cavin, 2010; López-Arbarello, 2012). However, Acentrophorus has never been included in a published cladistic analysis, and despite an obvious phenetic resemblance to semionotids, does not show definitive evidence of specific features that unambiguously support placement in Ginglymodi or Holostei. If subsequent study corroborates these older, informal taxonomic arguments, then Acentrophorus would displace Watsonulus as the appropriate calibration for the neopterygian crown (cf. Broughton et al., 2013).

\section{CROWN HOLOSTEI (28)}

Node Calibrated. Divergence between Halecomorphi and Ginglymodi.

Fossil Taxon and Specimen. Watsonulus eugnathoides (Piveteau, 1935) from the Middle Sakamena Formation, Sakamena Group, Ambilombe Bay, Madagascar (syntype MNHN MAE 33a, b, Muséum national d'Histoire naturelle, Paris).

Phylogenetic Justification. Numerous cladistic analyses resolve Watsonulus as the sister group of all other halecomorphs (Gardiner et al., 1996; 
Grande and Bemis, 1998; Hurley et al., 2007; Grande, 2010; Friedman, 2012a; Arratia, 2013; Xu et al., 2014), and thus a member of the crown Neopterygii generally and crown Holostei specifically. This placement is supported by the derived presence of features shared by Watsonulus and other halecomorphs including a 'double' jaw joint involving the symplectic and a concave posterior margin of the maxilla (Grande and Bemis, 1998).

In contrast to this current consensus, Olsen (1984) placed this genus as a stem neopterygian based on the retention of several primitive features not found in crown neopterygians. However, some of these features have not been detected in specimens by later researchers (e.g., an autogenous quadratojugal; Grande and Bemis, 1998), while others have a wider distribution within neopterygians than previously thought (e.g., presence of a clavicle in some stem teleosts; Arratia, 2013).

Minimum Age. 250.0 Ma

Soft Maximum Age. $331.1 \mathrm{Ma}$

Age Justification. The Sakamena Group in Madagascar spans from late Permian to Middle Triassic, and the Middle Sakamena Group/Formation is generally dated as lower Lower Triassic, the Upper Sakamena Group/Formation, Lower to lower Middle Triassic. The entire Sakamena Group is some $4 \mathrm{~km}$ thick, and it is subdivided based on dominant lithologies: the middle portion is a sequence of shales and minor sandstones deposited in a lagoonal or shallow lacustrine and braided river environment, whereas the units below and above are dominated by sandstones and conglomerates indicating higher energies of deposition. Dating of the Sakamena Group is notoriously difficult, as there are no radiometric dates, there has been no magnetostratigraphic study, and the associated fossils are not classic biostratigraphically useful index fossils. Nonetheless, the Middle Sakamena Group is dated as Induan on the basis of the associated fauna of benthosuchid temnospondyls (like those of the Lystrosaurus Assemblage Zone of South Africa and the Vokhmian units of Russia, as well as plants also suggesting Induan age. The top of the Induan stage is dated as 'slightly older than' 251.2 Ma \pm 0.2 Myr (Mundil et al., 2010), and given as $250.01 \mathrm{Ma}$ by Ogg (2012, p. 718$)$, so we select this age as the minimum constraint, namely 250.0 Ma.

Wastonulus represents the oldest definitive halecomorph, holostean, and crown neopterygian. This, combined with a rudimentary understanding of relationships among taxa in crownward portions of the neopterygian stem (including the so-called 'subholosteans'), renders the formulation of a soft maximum age for crown Holostei difficult. The absence of many of the proximal outgroups of Holostei in pre-Triassic deposits might be taken as evidence for the rapid radiation of neopterygians and their immediate relatives following the PermoTriassic extinction. However, the Permian record of ray-finned fishes is characterized by scarcity of deposits yielding well-preserved, articulated material (Hurley et al., 2007; Friedman and Sallan, 2012; Lloyd and Friedman, 2013; Sallan, 2014), suggesting this absence is more apparent than real. The Mississippian (Serpukhovian) Bear Gulch Lagerstätte in Montana, USA, includes a great diversity of articulated actinopterygians (Lund and Poplin, 1999), including taxa interpreted as crownward members of the neopterygian stem (e.g., Discoserra; Hurley et al., 2007; Xu et al., 2014). Holosteans or any other crown neopterygians are completely absent from this deposit. The base of the Serpukhovian is dated to $330.9 \mathrm{Ma} \pm 0.2 \mathrm{Myr}$, from which we derive a maximum age for crown Holostei of $331.1 \mathrm{Ma}$.

\section{CROWN GINGLYMODI (29)}

Node Calibrated. Divergence between Atractosteus and Lepisosteus.

Fossil Taxon and Specimen. Atractosteus falipoui (Cavin and Brito, 2001), from "Unit 1", Kem Kem beds, Aoufous Formation, Tafilalt Basin, Morocco (holotype MDE F13, Museé des Dinosaures d'Espéraza, Espéraza, France).

Phylogenetic Justification. Grande (2010) places Atractosteus falipoui in an unresolved polytomy along with other fossil representatives of Atractosteus, the extant $A$. tropicus and the sister-species pairing of $A$. tristoechus and $A$. spatula. Monophyly of Atractosteus relative to Lepisosteus is supported by three uniquely derived features: the shape of the vomerine heads, medial curvature and expansion of the anterior coronoid, and absence of tooth plates on the second and third hypobranchials (Grande, 2010, fig. 546). The final character, however, cannot be assessed for fossil gars.

Minimum Age. 93.9 Ma

Soft Maximum Age. 145.0 Ma

Age Justification. Well-constrained dating for the Aoufous Formation has proven elusive, and a broad Albian-Cenomanian age estimate is common in older accounts. Cavin et al. (2010) have recently argued that the Aoufous Formation lies entirely within the Cenomanian, based on correlation with the early Cenomanian Bahariya Formation of Egypt (Catuneanu et al., 2006) made with 
reference to vertebrate faunas. A minimum age for the Kem Kem beds can be derived from the overlying marine Akrabou Formation, which is confidently dated as late Cenomanian on the basis of foraminifera and ostracodes (Ettachfini and Andreu, 2004). The Cenomanian is dated to 100.5 to $93.9 \mathrm{Ma}$ (Ogg et al., 2012b), from which we derive our minimum age of 93.9 Ma for crown Ginglymodi.

Atractosteus is only slightly younger than the oldest fossil lepisosteoids (sensu Lopez-Arbarello, 2012), Obaichthys and Dentilepisosteus from the Aptian-Albian Santana Formation of Brazil (Grande, 2010). The closest 'semionotiform'-grade relatives of gars-Pliodetes and Araripelepidotesderive from this same deposit (Lopez-Arbarello, 2012). However, gars are absent from older freshwater deposits that yield abundant 'semionotiforms' (e.g., the English and Belgian 'Wealden', and the lacustrine limestones of Las Hoyas and El Montsec, Spain; Traquair, 1911; Woodward, 19151917; Sanz et al., 1988; Wenz and Poyato-Ariza, 1994). Ranging in age from Aptian to Berriasian (Brenner et al., 1974; Peybernès, 1976; Schroeder et al., 1982; Martín-Closas and López-Morón, 1995; Gomez et al., 2002; Radley, 2006; Yans et al., 2012), these faunas provide an estimate for the maximum age of the divergence between Atractosteus and Lepisosteus. We take this to be equivalent to the base of the Berriasian, which is dated approximately as $145.0 \mathrm{Ma}$.

Discussion. After $A$. falipoui, the oldest fossil remains that can be confidently assigned to crown Ginglymodi are articulated skulls of Lepisosteus from the Campanian Judith River (Oldman) Formation of Alberta, Canada and Maastrichtian (infratrappean) Lameta Formation of Central Province, India (Grande, 2010). Other Late Cretaceous material is restricted to fragments that clearly belong to lepisosteids, but cannot be linked to either of the extant genera within this family on the basis of derived features (Grande, 2010: 718-740). Rather than indicating unreliability of our selected fossil minimum, this Cenomanian-Campanian gap in the record of definitive crown ginglymodins more probably reflects the relatively understudied Late Cretaceous record of freshwater fishes (Grande and Grande, 1999).

\section{CROWN TELEOSTEI (30)}

Node Calibrated. Divergence between Elopomorpha and Osteoglossocephala (Figure 5).

Fossil Taxon and Specimen. Anaethalion zapporum Arratia, 2000 from the Rögling Formation, village of Schamhaupten, near Eichstätt, Bavaria,
Germany (holotype JM SCH 85, Jura Museum, Eichstätt, Germany).

Phylogenetic Justification. The association between Anaethalion and elopomorphs has a long history, and has been tested by cladistic investigation. This genus is placed as a fossil sister group to the extant elopomorph Elops by Arratia (1997) in a maximum parsimony analysis of 135 morphological characters. A more focused analysis including multiple species of Anaethalion corroborates the close relationship between $A$. zapporum and extant elopomorphs, but suggests that the genus is paraphyletic (Arratia, 2000). Because these analyses include only a single extant elopomorph, it is impossible to constrain the placement of Anaethalion more precisely than total-group Elopomorpha (but see Arratia, 2013).

Minimum Age. 151.2 Ma

Soft Maximum Age. 252.7 Ma

Age Justification. The Rögling Formation underlies the more famous Solnhofen Formation, and is assigned to the Malm Epsilon division of the Franconian Jura (Viohl and Zapp, 2007). The beds at Schamhaupten can be constrained to the Neochetoceras rebouletianum Horizon within the Lithacoceras ulmense Subzone of the Hybonoticeras beckeri Ammonite Zone, indicating a latest Kimmeridgian age (Schweigert, 2007; Ogg et al., 2012a). The top of the Kimmeridgian is dated to 152.1 Ma $\pm 0.9 \mathrm{Myr}$ (Ogg et al., 2012a), from which we derive a minimum age of $151.2 \mathrm{Ma}$.

The earliest crown teleosts are approximately coeval with the first representatives of a series of more derived subclades, most notably total-group Euteleostei and crown-group Otocephala (see nodes 31 and 32 below for discussion). The rapid appearance of these groups in the Late Jurassic is likely driven, at least in part, by Lagerstätten effects reflecting the abundance of lithographic limestones of this age characterized by exceptional preservation. As a consequence, it is probable that the fossil-based minimum for the origin of crown teleosts substantially underestimates the true time of origin for this group. Crown teleosts are completely absent from older marine Lagerstätten of TriassicMiddle Jurassic age, including Besano-Monte San Giorgio (Ladinian; Tintori; 1998), the Zorzino Limestone (Norian; Tintori, 1998), the Posidonia Shale (Toarcian; Hauff and Hauff, 1981; Röhl et al., 2001), the Blue Lias (Sinemurian-Hettangian; Page, 2010; Forey et al., 2010), and the Oxford Clay (Callovian-Oxfordian; Hudson and Martill, 1991; Martill, 1991). Crown and stem teleosts are absent from a series of Induan sites in Greenland, 
Svalbard, Canada, and Madagacar that yield diverse fish faunas that contain abundant stem and crown neopterygians. We take these assemblages as defining the soft maximum bound for the origin of crown teleosts. The base of the Induan is dated as 252.2 Ma $\pm 0.5 \mathrm{Myr}$, from which we derive a maximum bound of $252.7 \mathrm{Ma}$.

Discussion. Fossils from the Late Jurassic lithographic limestones of southern Germany are widely applied as fossil calibrations for the age of the teleost crown (Hurley et al., 2007; Santini et al., 2009; Near et al., 2012; Broughton et al., 2013; Betancur-R. et al., 2013). Four genera from these deposits have been interpreted as elopomorphs: Anaethalion, Elopsomolos, Eichstaettia, and Daitingichthys. The placement of two of these genera-Anaethalion and Elopsomolos-in Elopomorpha has been corroborated by cladistic analysis (Arratia, 1997, 2000).

Elopsomolos is known from the Tithonian of Solnhofen and Kimmeridgian of Schamhaupten (Arratia, 1997, 2000), and Anaethalion is found at both of these horizons as well as the Kimmeridgian of Nusplingen (Arratia, 1987, 1997, 2000; PoyatoAriza, 1999). The beds at Nusplingen are slightly older than those at Schamhaupten, but both lie within the final ammonite zone and subzone of the Kimmeridgian (Schweigert, 2007), and we assign the same minimum age to both due to the coarseness of available timescales. We have selected a specimen of Anaethalion zapporum from Schamhaupten as our calibration for maximum transparency; this material is clearly described by Arratia (2000), whereas published accounts of Anaethalion that include fossils from Nusplingen do not explicitly indicate which individuals derive from this locality (Arratia, 1987). Elopsomolos, which is regarded as a closer relative of Elops than any species of Anaethalion (Arratia, 1997, 2000), is also known from Schamhaupten and therefore coeval with our calibration. However, we have not selected Elopsomolos as our marker for the minimum age of crown Teleostei because known material from Schamhaupten (Arratia, 1997: figs 27-28) is housed in a private collection.

Outside southern Germany, Anaethalion is also reported from the lithographic limestones of Cerin, France (Arratia, 1987; Wenz et al., 1994). These beds are classically interpreted as late Kimmeridigian in age, but ammonite biostratigraphy suggests that they might straddle the Kimmeridigian-Tithonian boundary (Enay et al., 1994). The near-simultaneous appearance of the first elopomorphs in German and French localities could be interpreted as evidence that our minimum estimate for the age of the teleost crown might closely approximate the true time of origin for the clade. However, we argue that our minimum date is likely to be a substantially underestimated, because the first elopomorphs are contemporary with the oldest members of more highly nested clades of crown teleosts, including Euteleostei and Ostariophysi (see node 33). We interpret this pattern as a potential artifact of the concentration of lithographic limestones and corresponding fossil-fish Lagerstätten in the Late Jurassic, rather than a definitive signal of a rapid evolutionary radiation of teleosts during this interval.

\section{CROWN CLUPEOCEPHALA (31)}

Node Calibrated. Divergence between Otocephala and Euteleostei.

Fossil Taxon and Specimen. Leptolepides haerteisi Arratia, 1997 from the Solnhofen Formation, Zandt Member, Zandt, Bavaria, Germany (holotype JM SOS 2473, Jura Museum, Eichstätt, Germany).

Phylogenetic Justification. Leptolepides haerteisi is placed in an extinct radiation of Jurassic-Cretaceous teleosts (Orthogonikleithridae) that is resolved as the sister group of Salmonoidei plus Esocoidei in a maximum-parsimony analysis of 135 morphological characters (Arratia, 1997). Because this and subsequent analyses (e.g., Arratia, 1999, 2000; Arratia and Tischlinger, 2010) only include representatives of a single crown euteleost lineage, it is impossible to determine whether Leptolepides and other orthogonikleithrids fall within the euteleost crown or are instead stem members of the clade. Regardless of its precise placement with respect to extant euteleosts, Leptolepides haerteisi provides a minimum age for the divergence between Otocephala and Euteleostei.

Minimum Age. $150.94 \mathrm{Ma}$

Soft Maximum Age. $235 \mathrm{Ma}$

Age Justification. The Zandt Member of the Solnhofen Formation is constrained to the Lithacoceras eigeltingense Horizon of the Lithacoceras riedense Subzone of the Hybonoticeras hybonotum Ammonite Zone (Schweigert, 2007), indicating an earliest Tithonian age. The interpolated age estimate for the top of the Hybonoticeras hybonotum Zone is $150.94 \mathrm{Ma}$ (Ogg et al., 2012a), which represents a minimum time of origin for crown Cluepocephala.

A probable maximum bound on the origin of crown Clupeocephala can only be defined arbitrarily. Immediate outgroups to this clade either appear marginally later (Otocephala; see node 32 ) or ear- 
lier (Elopomorpha; see node 30 ) in the fossil record. This more-or-less simultaneous appearance of highly divergent crown teleost lineages suggests a major gap in the early history of the clade. Crown teleosts are completely absent from older marine Lagerstätten of Triassic-Middle Jurassic age, including the Zorzino Limestone (Norian; Tintori; 1998), the Posidonia Shale (Toarcian; Hauff and Hauff, 1981; Röhl et al., 2001), the Blue Lias (Sinemurian-Hettangian; Page, 2010; Forey et al., 2010), and the Oxford Clay (Callovian-Oxfordian; Hudson and Martill, 1991; Martill, 1991). However, these assemblages all yield a diversity of species that belong to the teleost stem lineage. The oldest fossils that can be recognized as stem teleosts predate these spectacular faunas, and include specimens assigned to Prohalecites from the Calcare di Perledo-Varenna and Meride Kalk in northern Italy (Tintori, 1990; Arratia and Tintori, 1999; Arratia, 2013). These horizons are interpreted as latest Ladininan in age on the basis of palynomorphs (Arratia and Tintori, 1999). Prohalecites or any other stem teleosts are completely absent from the roughly coeval Lagerstätte of Besano-Monte San Giorgio (Tintori, 1998), which otherwise yields a rich fauna of marine fishes. We therefore take the base of the Ladinian, dated approximately as 242 $\mathrm{Ma}$, as an estimated maximum bound for the origin of crown Clupeocephala.

Discussion. In addition to Leptolepides haerteisi, the Zandt Member of the Solnhofen yields remains of another member of total-group Euteleostei: Orthogonikleithrus leichi (Arratia, 1997). The other species of Orthogonikleithrus, $O$. hoelli, is from the site of Ettling (Arratia, 1997), which yields no ammonite fossils and thus cannot be dated precisely (Schweigert, 2007).

Leptolepides is reported from deposits of definitive Kimmeridgian age: Cerin, France (Wenz et al., 1994), Nusplingen, Germany, (Heineke, 1906; Dietl and Schweigert, 2004) and Wattendorf, Germany (Fürsich et al., 2007). We have not used these examples to define our minimum age for Clupeocephala because relevant specimens have not been subjected to detailed anatomical examination or phylogenetic analysis. Leptolepides specimens from Cerin have historically been identified as $L$. sprattiformis (e.g., Wenz, 1994), the placement of which as a crown clupeocephalan has been established (Arratia, 1997). However, Arratia (1997:61) indicated that the fossils from Cerin show differences from Solnhofen material of $L$. sprattiformis, without commenting further on their taxonomic assignment. Specimens from Wattendorf provision- ally assigned to Leptolepides sp. (Fürsich et al., 2007) represent the oldest of these Kimmeridgian records of Leptolepides. The lithographic limestones at Wattendorf can be constrained to the Aulacostephanus pseudomutabilis Subzone of the Aulacostephanus eudoxus Ammonite Zone, which is of early late Kimmeridgian age (Fürsich et al., 2007; Schweigert, 2007). The age of the top of the Aulacostephanus eudoxus Ammonite Zone has been estimated through interpolation as $153.55 \mathrm{Ma}$ (Harland et al., 2012). If placement of these fossils in Leptolepides is corroborated by subsequent anatomical analysis, they would define a new fossil-based minimum for the origin of both crown Clupeocephala and crown Teleostei.

\section{CROWN OTOCEPHALA (= OTOMORPHA) (32)}

Node Calibrated. Divergence between Clupeomorpha and Ostariophysi.

Fossil Taxon and Specimen. Tischlingerichthys viohli Arratia, 1997 from the Mörnsheim Formation of Mühlheim, Bavaria, Germany (holotype JM Moe 8, Jura Museum, Eichstätt, Germany).

Phylogenetic Justification. Tischlingerichthys is placed as the sister taxon of the ostariophysans Gordichthys and Chanos to the exclusion of clupeomorphs and other teleosts in a maximum parsimony analysis of morphological characters (Arratia, 1997; Arratia, 2001).

Minimum Age. $150.94 \mathrm{Ma}$

Soft Maximum Age. $228.4 \mathrm{Ma}$

Age Justification. The Mörnsheim Formation lies within the Subplanites moernsheimensis Subzone of the Hybonoticeras hybonotum Ammonite Zone (Schweigert, 2007). The top of the Hybonoticeras hybonotum Ammonite Zone has been estimated through interpolation as $150.94 \mathrm{Ma}$ (Ogg et al., 2012a), yielding a minimum age for crown Otocephala.

A plausible minimum for the origin of crown Otocephala, like that for crown Clupeocephala discussed above, can only be defined in approximate terms. Crown teleosts are completely absent from older marine Lagerstätten of Triassic-Jurassic age, including the Zorzino Limestone (Norian; Tintori; 1998), the Posidonia Shale (Toarcian; Hauff and Hauff, 1981; Röhl et al., 2001), the Blue Lias (Sinemurian-Hettangian; Page, 2010; Forey et al., 2010), and the Oxford Clay (Callovian-Oxfordian; Hudson and Martill, 1991; Martill, 1991). The oldest locality that yields members of the teleost total group in any diversity is the Carnian of Reingrabener Shale of Polzberg bei Lunz, Austria (Griffiths, 1977). This marine unit contains only stem 
teleosts, which are represented by the putative ichthyokentemid Elpistoichthys and the pholidophorid Pholidophoretes (Griffiths, 1977; Arratia, 2013). The base of the Carnian is dated as approximately $235 \mathrm{Ma}$ (Ogg, 2012), from which we derive our soft maximum for the origin of crown Otocephala.

Discussion. Tischlingerichthys is widely used as a fossil-based minimum for the age of crown Otocephala in studies of actinopterygian divergence times (Hurley et al., 2007; Santini et al., 2009), and has appeared in previous lists of key calibrations in animal phylogeny (Benton and Donoghue, 2007; Benton et al., 2009). Our age estimates are updated here relative to these earlier contributions, and we have corrected details concerning geological provenance.

\section{CROWN OSTARIOPHYSI (33)}

Node Calibrated. Divergence between Gonorynchiformes and Otophysi.

Fossil Taxon and Specimen. Rubiesichthys gregalis Wenz, 1984 from El Montsec lithographic limestone, Lérida, Spain (paratype MNHN MSE $857 a$, b, Muséum national d'Histoire naturelle, Paris).

Phylogenetic Justification. Rubiesichthys gregalis has been described in detail by Poyato-Ariza (1996b), and maximum-parsimony analyses of morphological data place this species as a stem chanid (Grande and Poyato-Ariza, 1995, 1999; Poyato-Ariza 1996a,c).

Minimum Age. 126.3 Ma

Soft Maximum Age. 158.3 Ma

Age Justification. The lithographic limestones of El Montsec are widely cited in recent paleontological literature as late Berriasian-early Valanginian in age (e.g., de Gibert et al., 2010; Brocklehurst et al., 2012), and this date has been applied by some molecular clock analyses using fossil-based calibrations from the site (e.g., Peng et al., 2006; Lavoué et al., 2010; Near et al., 2012). However, clear evidence in support of this estimate is lacking, and a younger age for at least some portions of this unit seems likely. The arguments presented here represent a synthesis of those presented by Gomez et al. (2002) in their review of the geological setting of El Montsec. The marine unit underlying this horizon yields benthic foraminifera (Trocholina alpina) and dasycladales indicating a Berriasian age (Gomez et al., 2002). The freshwater lithographic limestones that bear specimens of Rubiesichthys are estimated to be of Berriasianearly Barremian age on the basis of ostracodes and charophyte algae (Brenner et al., 1974;
Martín-Closas and López-Morón, 1995). These deposits are overlain by marine limestones dated to the late Barremian-early Aptian on the basis of orbitolinid foraminifera (Peybernès, 1976; Schroeder et al., 1982), and which constrain the minimum age of Rubiesichthys. The Barremian is dated approximately as 130.8 to $126.3 \mathrm{Ma}$ (Ogg et al., 2012b), from which we derive our minimum age estimate of $126.3 \mathrm{Ma}$ for the origin of crown Ostariophysi.

The clade uniting Rubiesichthys and the slightly younger Gordichthys represents the earliest diverging branch on the chanid stem. More crownward members of the chanid stem lineage derive from younger deposits, meaning that current chanid phylogenies are largely consistent with the stratigraphic distribution of fossil forms. Immediate outgroups to Chanidae make their first appearance in the fossil record after that clade (Gonorynchidae: Cenomanian; Kneriidae: Eocene: no fossil record; Fara et al., 2010; Davis et al., 2013). The rich fish faunas from Late Jurassic (Kimmeridgian-Tithonian) lithographic limestones in Germany (Wattendorf, Nusplingen, Schamhaupten, Solnhofen, Mörnsheim) and France (Cerin, Canjeurs) yield only a single member of crown Otocephala: Tischlingerichthys (see details for Node 32). The base of the Kimmeridgian is dated to 157.3 Ma $\pm 1.0 \mathrm{Myr}$. From this we derive a maximum age estimate of 158.3 Ma for the origin of crown Ostariophysi.

Discussion. The earliest definitive representatives of crown-group Ostariophysi are all stem chanids from Early Cretaceous freshwater deposits of western Europe (Poyato-Ariza, 1996a). Although they provide a minimum age estimate for crown Ostariophysi, they can be applied more precisely as fossilbased minima for crown Gonorynchiformes (cf. Near et al., 2012, 2013; Broughton et al., 2013). Apart from the lithographic limestones of El Montsec, Rubiesichthys is also known from the late Barremian La Héurguina Formation, another Spanish horizon widely known as Las Hoyas and which yields the stem chanid Gordichthys (Fara et al., 2010). These Spanish chanids are joined by Aethalionopsis, which is best known from the type species $A$. robustus from the Sainte-Barbe Clays Formation of Bernissart, Belgium (Taverne, 1981a). The deposits at Bernissart are regarded as latest Barremian-early Aptian in age on the basis of pollen biostratigraphy and carbon-isotope chemostratigraphy (Yans et al., 2012).

Potentially older remains of crown gonorynchiforms have been reported, but these remain poorly known and are not reliable calibrations at 
present. The first of these is represented by an articulated fish from the ?Berriasian-Hauterivian (Wealden) of England, described by Woodward (1907) as "Leptolepis". Gaudant (1968) referred this specimen to Aethalionopsis with little clear justification. This individual is missing most of the skull, and its phylogenetic placement has not been tested by cladistic analysis. The second example is an indeterminate gonorynchiform from the Berriasian-Hauterivian Lower Wakamiya Formation of Fukuoka Prefecture, Japan (Yabumoto, 1994), which is represented by a single incomplete specimen that is also missing the skull. Aspects of the caudal fin skeleton, position of the median fins, and overall proportions agree with conditions seen in gonorynchiforms, but none represent synapomorphies of that group (Grande and Poyato-Ariza, 1999).

\section{CROWN ACANTHOMORPHA (34)}

Node Calibrated. Divergence between Lampridiformes and Percomorpha (= Percomorphacea) (Figure 6).

Fossil Taxon and Specimen. Stichocentrus liratus Patterson, 1967, from the Sannine Limestone, Hajula, Lebanon (holotype, NHMUK P.47835, The Natural History Museum, London, UK).

Phylogenetic Justification. Cladistic analyses of early acanthomorphs have variously placed Stichocentrus as a stem holocentroid (Gayet, 1982) or a crown trachichthyoid (Otero et al., 1995). Although we remain agnostic with respect to its placement among Beryciformes, there is no doubt that Stichocentrus is a crown-group acanthomorph based on the presence of pelvic-fin spines in this genus. Pelvic-fin spines are classically regarded as a synapomorphy of Acanthopterygii inclusive of Zeiformes (e.g., Johnson and Patterson, 1993). However, molecular analyses strongly support placement of Zeiformes with Gadiformes outside Acanthopterygii (Wiley et al., 2000; Miya et al., 2003; Smith and Wheeler, 2006; Near et al., 2012, 2013). This arrangement implies that pelvic-fin spines either evolved independently in Zeiformes and Acanthopterygii, or have been lost independently in some groups. However, this uncertainty does not affect our confidence in phylogenetic placement of Stichocentrus, because the origin of pelvic-fin spines is constrained to within crown Acanthomorpha under either scenario.

Minimum Age. 98.0 Ma

Soft Maximum Age. 158.3 Ma

Age Justification. The Hajula Lagerstätte is located near the top of subdivision IVd according the local stratigraphic scheme applied to Cenomanian deposits in Lebanon (Hückel, 1970: figure 3). Ammonites attributed to Mantelliceras mantelli are known from the overlying Cenomanian subdivision Va (Zummofen, 1926; Dalla Vecchia et al., 2002). M. mantelli defines the earliest complete ammonite zone of the Cenomanian. The top of the Mantelliceras mantelli Ammonite Zone can be dated as approximately 98.0 Ma (Ogg et al., 2012b), which we apply as our minimum age estimate for crown Acanthomorpha.

Putative stem acanthomorphs like ctenothrissids and aulolepids (Rosen, 1973) first appear in the fossil record at approximately the same time as crown acanthomorphs. The earliest representatives of Myctophiformes, the living sister group of Acanthomorpha, also appear in the Cenomanian (Patterson, 1993b). High taxonomic richness of marine fishes in the Cenomanian has been interpreted as evidence of rapid diversification during the interval, but it is difficult to exclude the possibility that this pattern is an artifactual one arising from Lagerstätten effects (but see Cavin and Forey, 2007). The earliest acanthomorphs are relatively small-bodied, and there are comparatively few fully marine Early Cretaceous localities that preserve moderately diverse assemblages of euteleosts of this size. It is therefore plausible that crown acanthomorphs were present in the Early Cretaceous, but were not preserved. Indirect evidence supporting an older age for crown acanthomorphs comes from the composition of Cenomanian acanthomorph faunas, which include representatives of multiple extant lineages (e.g., Polymixiiformes, Beryciformes). We apply a conservative soft maximum bound on the age of the acanthomorph crown based on the numerous marine Lagerstätten of Late Jurassic (Kimmeridgian-Tithonian) age in Germany (Wattendorf, Nusplingen, Schamhaupten, Solnhofen, Mörnsheim) and France (Cerin, Canjeurs), none of which yield fossils attributable to Acanthomorpha or containing clades (Eurypterygii, Neoteleostei; Wiley and Johnson, 2010). The base of the Kimmeridgian is dated to $157.3 \mathrm{Ma} \pm$ 1.0 Myr. From this we derive a maximum age estimate of 158.3 Ma for the origin of crown Acanthomorpha.

Discussion. In addition to Hajula, two other Lebanese Lagerstätten of Cenomanian age yield fossils that can be assigned to crown Acanthomorpha: Hakel, which has been known to yield fossils since the time of the crusades (Davis, 1887; Gayet et al., 2003), and Namoura, which is a recent discovery (Dalla Vecchia, 2002; Forey et al., 2003). Strati- 
graphically, Hakel lies $20 \mathrm{~m}$ above Hajoula and is placed within Cenomanian subdivision Va (Hückel, 1970; Della Vecchia, 2002). The stratigraphic relationship of Namoura to Hakel and Hajula is less certain, but Dalla Vecchia (2002) present biostratigraphic evidence that it is no younger than middle Cenomanian in age. Several probable members of crown Acanthomorpha are known from Hajula (Forey et al., 2003), but we have selected Stichocentrus as our fossil-based minimum for this clade because it has been the subject of extensive description by both Patterson (1967) and Gayet (1980).

Well-preserved crown acanthomorph fossils are also known from numerous sites of Cenomanian age outside Lebanon (best summarized by Patterson, 1993a and Forey et al., 2003). Some of these examples are of roughly equivalent age to Stichocentrus, such as Xenyllion from the early Cenomanian of Utah, USA, and Alberta, Canada (Wilson and Murray, 1996; Stewart, 1996; Newbrey et al., 2013). However, other Cenomanian acanthomorphs are clearly younger than those from Hadjula (e.g., those from the English Chalk), or derive from horizons that are not well constrained stratigraphically (e.g., Hildago Quarry, Mexico, and Jebel Tselfat, Morocco; González-Rodriguez and Fielitz, 2008; Khalloufi et al., 2010).

\section{ORYZIAS, CICHLIDAE - GASTEROSTEUS, TAKIFUGU, TETRAODON (35)}

Node Calibrated. Divergence between Ovalentaria and Tetraodontiformes (Wainwright et al., 2012), corresponding to an unnamed subclade of Percomorpha.

Fossil Taxon and Specimen. Cretatriacanthus guidottii from the 'Calcari Melissano' (of historical usage) at Canale near Nardò, Italy (holotype MCSNV 1377, Museo Civico di Storia Naturale, Verona, Italy).

Phylogenetic Justification. Molecular hypotheses of teleost relationships indicate that the clade defined by the divergence between Ovalentaria and Tetraodontiformes comprises much of Percomorpha (Near et al., 2013; Betancur-R. et al., 2013). Many generalized percomorphs and 'perciforms' are known from Late Cretaceous deposits (e.g., Patterson, 1993a; López-Arbarello et al., 2003; Arratia et al., 2004; Taverne, 2010). However, none of these has been placed with any precision within percomorph phylogeny, and as such are not appropriate calibrations.

The oldest fossils that can be placed with any confidence within Ovalentaria are all late Pale-
ocene-Eocene in age (Patterson, 1993b; Bellwood and Sorbini, 1996; see node 37). However, there are several reports of Cretaceous tetraodontiforms (Patterson, 1993b; Tyler and Sorbini, 1996; Santini and Tyler, 2003; Gallo et al., 2009; Friedman, 2012b; Tyler and Križnar, 2013). We select Cretatriacanthus, from Nardò, Italy as a conservative minimum constraint for the divergence between Tetraodontiformes and Ovalentaria. Cretatriacanthus represents the youngest putative tetraodontiform of Cretaceous age represented by bodyfossil remains. The absence of an elaborate dermal carapace in Cretatriacanthus means that key tetraodontiform features like the absence of pleural ribs and geometry of the pelvic girdle are readily apparent in this genus, whereas they are generally obscured by large bony plates in other Cretaceous examples.

Minimum Age. $69.71 \mathrm{Ma}$

Soft Maximum Age. 130.8 Ma

Age Justification. The fish-bearing limestones at Nardò are generally referred to the 'Calcari di Melissano', a name historically applied to the Late Cretaceous platform carbonates of Salento (Martinis, 1967). However, usage has since been restricted to one part of the Late Cretaceous carbonate succession in the Apulian platform (e.g., Bosellini and Parente, 1994; Schlüter et al., 2008). Medizza and Sorbini (1980) provide a list of calcareous nannofossil species recovered from the fishbearing layers, the most biostratigraphically relevant of which is Uniplanarus trifidus (reported as Quadrum trifidum). The first appearance of this species marks the beginning of Calcareous Nannoplankton Zone $\mathrm{CC} 23$, and it makes its last appearance in the middle of CC24. The top of CC24 is roughly equivalent to the top of the Baculites clinolobatus Ammonite Zone of the Western Interior Seaway, which contains a bentonite horizon dated as $70.08 \mathrm{Ma} \pm 0.37 \mathrm{Myr}$ (Ogg et al., 2012b). It is from this value that we derive our minimum age estimate of $69.71 \mathrm{Ma}$.

Percomorphs, and acanthomorphs more generally, are unknown from a series of fish faunas of mid-late Early Cretaceous age that represent a range of depositional settings from fully marine to lacustrine: the Gault Clay of England (Albian; Gale and Owen, 2010; Forey and Longbottom, 2010; Nolf, 2010), Helgoland in Germany (Aptian; Taverne, 1981b), the Crato Formation of Brazil (Martill, 1993; early interpretations of Araripichthys as a lampridiform have been decisively rejected by Patterson, 1993a and Maisey and Moody, 2001), and the Coquiero Seco Formation of Brazil (Gallo and 
Cohelo, 2008). The oldest of these deposits, the Coquiero Seco Formation of Brazil, yields the oldest putative representative of Eurypterygii (the clade containing Aulopiformes, Myctophiformes, and Acanthomorpha), and provides the basis for our estimated maximum age divergence between Tetraodontiformes and Ovalentaria. The Barremian is dated to approximately 130.8-126.3 Ma (Ogg et al., 2012b); we derive our soft maximum from the oldest limit.

Discussion. Many Cretaceous fossils have been interpreted as tetraodontiforms. Fragmentary examples from the Maastrichtian represent dermal scutes of batoids (e.g., materials summarized by Patterson, 1993b and Friedman, 2012b) or are of questionable stratigraphic provenance (Gallo et al., 2009); such remains are clearly not appropriate as calibrations. Articulated remains identified as tetraodontiforms require more careful consideration. Tyler and Sorbini (1996) interpreted three remarkable genera of Cretaceous fishes as tetraodontiforms based on detailed description of such material: Plectocretacicus, from the early Cenomanian of Hakel, Lebanon; Protriacanthus, from the late Cenomanian-early Turonian of Comen, Slovenia; and Cretatriacanthus, from the late Campanian-early Maastrichtian of Nardò, Italy. To these, Tyler and Križnar (2013) have recently added a fourth genus: Slovenitriacanthus, from the late Santonian-early Campanian Lipica Formation of Slovenia. These are morphologically heterogeneous, but are all no more than $50 \mathrm{~mm}$ in total length and share modified scales or plates at the base of the pelvic-fin spine and an absence of teeth (Tyler and Sorbini, 1996). Tyler and Sorbini (1996) presented a manual cladogram uniting Plectocretacicus, Protriacanthus, and Cretatriacanthus as a clade named Plectocretacicoidea on the tetraodontiform stem. Santini and Tyler (2003) corroborated this result using a numerical cladistic analysis, which has since been replicated by re-study of their morphological characters in concert with molecular data (Arcila et al., 2015).

Since the initial description and placement of plectocretacicoids, genetic data have substantially revised past morphological interpretations of the living sister group of Tetradontiformes (e.g., Rosen, 1984). Molecular analyses consistently place lophiiforms as the closest extant relatives of tetraodontiforms (Near et al., 2012, 2013; Betancur-R. et al., 2013). Many of the features used to argue for the tetraodontiform affinity of plectocretacicoids (e.g., restricted opercular opening, absence of a beryciform foramen, absence of ribs, absence of an anal-fin spine, reduced vertebral count, reduced caudal-fin ray count) also characterize many or all lophiiforms (Regan, 1912; Pietsch, 1981, 1984; Chanet et al., 2013), suggesting that these traits are candidate synapomorphies of a more extensive clade including lophiiforms and tetraodontiforms. Unfortunately, published analyses incorporating plectocretacicoids do not sample lophiiforms (see comments in Santini et al., 2013, p. 178-179), meaning that available solutions cannot test placement of these fossils within the tetraodontiform total group. Perhaps more critically, tetraodontiforms and lophiiforms share several derived features not apparent in plectocretacicoids, the most notable of which include: absence of infraorbital bones (present in plectocretacicoids); sutural relationship between the posttemporal and cranium (plectocretacicoids have a non-structural connection comparable to that of generalised acanthomorphs); six or fewer branchiostegal rays (a feature also shared with immediate outgroups to [Tetraodontiformes + Lophiiformes] including Caproidae, Priacanthidae, Cepolidae, and Siganidae; Plectocretacicus is the only plectocretacicoid where branchiostegals are visible, and has seven); lateral-line system unenclosed in bony canals (pores for bony canals are present in plectocretacicoids); and absence of procurrent caudal rays (present in plectocretacicoids; loss of procurrent rays is interpreted as crown tetraodontiform synapomorphy by Santini and Tyler, 2003, with inferred reversals within the group) (McAllister, 1968; Pietsch, 1981; Fujita, 1990; Nakae and Sasaki, 2010; Carnevale and Pietsch, 2012). These observations indicate either considerable parallelism between tetraodontiforms and lophiiforms, numerous reversals in plectocretacioids, or that plectocretacicoids are not tetraodontiforms. Selection between these contrasting alternatives requires a formal analysis, which we are not in a position to provide here.

Of the plectocretacicoids, Cretatriacanthus represents the most conservative candidate for establishing a minimum age for Tetraodontiformes, or at least the extended tetraodontiform-lophiiform clade, because it lacks traits that suggest alternative phylogenetic placements. Protriacanthus shares derived features of the skull (e.g., an extended rostrum, subterminal mouth, absence of an ascending process of the premaxilla, absence of teeth), dorsal and anal fins (greatly reduced finray count, with approximately five rays in each), and caudal-fin skeleton (e.g., extensive fusion between hypurals, parhypural, and associated centra) with pegasids (Pietsch, 1978), and many of the 
tetraodontiform features preserved in the genus are also characteristic of this other group (e.g., absence of an anal-fin spine, reduced caudal-fin ray count, reduced vertebral count). Molecular phylogenies place pegasids as close relatives of syngnathiforms, which branch outside the most restrictive clade containing Ovalentaria and Tetraodontiformes. Plectocretacicus, the oldest of the candidate tetraodontiforms, broadly resembles three new genera of small, armoured acanthomorphs of mid-Cretaceous age that González-Rodríguez et al. (2013) identified as beryciforms or, more doubtfully, as non-tetraodontiform percomorphs. These Mexican taxa share a series of clear similarities with Plectocretacicus, including: small size; a bony carapace formed of sutured (Plectocretacicus) or overlapping (Handuichthys, Pseudomonocentris, Dalgoichthys) enlarged plates often bearing central bosses and radiating tuberculation; absence of teeth; absence of dorsal- and anal-fin spines (bases of supposed anal-fin spines in the Mexican taxa are always preserved on the lateral face of specimens, suggesting they are in fact pelvic spines); posteriorly located pelvic fins (following the reinterpretation provided for the Mexican taxa); embrace of pelvic-fin base by dermal shield; and a very narrow caudal peduncle. Nontetraodontiform interpretations of morphologically similar taxa of comparable age suggest some ambiguity in the placement of Plectocretacicus.

Our proposed calibration for this node is revised relative to previous reviews of calibrations for major divergences in animal phylogeny (Benton and Donoghue, 2007; Benton et al., 2009), which advocated the use of Plectocretacicus as a fossilbased minimum. Tetraodontiformes represent one of the most highly nested clades within acanthomorph phylogeny, and are resolved in an apical position within the percomorph tree (Smith and Wheeler, 2006; Near et al., 2012, 2013; BetancurR. et al., 2013). In addition to the reservations we have expressed about the placement of Plectocretacicus with tetraodontiforms on anatomical grounds, it is remarkable that an early representative of such a nested clade would appear in the record without contemporary examples of several additional, identifiable percomorph lineages. Other acanthomorphs known from the early Cenomanian include a diversity of beryciforms, polymixiids, paracanthopterygians, and representatives of various extinct groups (e.g., aipichthyids, pharmacichthyids) recently algined with lampridiforms (Davesne et al., 2014). Assignment of Plectocretacicus to Percomorpha is therefore unique among acanthomorphs of early Cenomanian age (Patterson, 1993a, b; Forey et al., 2003). The contrasting placements of superficially similar fossils offered by González-Rodríguez et al. (2013) suggest that this genus might alternatively be interpreted as an armored beryciform. If the Cenomanian-Turonian Protriacanthus is a percomorph, its affinities might lie with pegasids rather than tetraodontiforms. Apart from enjoying the anatomical support discussed above, this alternative placement is more in line with stratigraphy; pegasids belong to one of the earliest diverging percomorph radiations (Smith and Wheeler, 2006; Near et al., 2013; Betancur-R. et al., 2013). The Campanian-Maastrichtian Cretatriacanthus is coeval with representatives of a series of percomorph lineages, including primitive syngnathiforms (Sorbini, 1981; Patterson, 1993a, b) and incertae sedis 'percoids' (Taverne, 2010). This lends further circumstantial support to our assertion that Cretatriacanthus is the most appropriate minimum marker for the origin of the percomorph clade including Oryzias and Tetraodontiformes. However, our choice of a generous soft maximum age allows for the possibility that subsequent analyses with suitable taxon sampling might demonstrate that Plectocretacicus is indeed a member of the tetraodontiform total group, and thus the appropriate calibration for this node (cf. Benton and Donoghue, 2007; Benton et al., 2009).

\section{ORYZIAS - CICHLIDAE (36)}

Node Calibrated. Divergence between Atherinomorpha and Cichlidae. This delimits one of the two major unnamed crown clades within Ovalentaria, but not crown Ovalentaria itself (Wainwright et al., 2012).

Fossil Taxon and Specimen. Ramphexocetus volans from the 'Calcari nummulitici' of Bolca, Italy (holotype MGUP 8866, Museo di Geologia e Paleontologia, University of Padua, Padua, Italy).

Phylogenetic Justification. Ramphexocetus has not been included in a formal cladistic analysis. However, it presents a series of characters that are interpreted as synapomorphies of successively more restrictive clades within Atherinomorpha. Ramphexocetus can be placed within Beloniformes on the basis of its caudal fin (Rosen and Parenti, 1981), which has an expanded ventral lobe that contains more principal fin-rays than the dorsal lobe (Bannikov et al., 1985). The position of this genus can be further restricted to Exocetoidei, based on the presence of a greatly enlongated dentary (Rosen and Parenti, 1981). This feature is 
apparent at some point of the life history of most beloniforms, and is retained in adults as a 'halfbeak' condition comparable to that of Ramphexocetus in species traditionally assigned to Hemiramphidae, which appears to be paraphyletic (Lovejoy et al., 2004). Among exocetoids, enlarged pectoral and pelvic fins of the kind found in Ramphexocetus are characteristic of Exocetidae (flying fishes).

Minimum Age. 49.11 Ma

Soft Maximum Age. 130.8 Ma

Age Justification. The age of the fish-bearing horizons of the 'Calcari nummulitici' at Bolca can be tightly constrained on the basis of biostratigraphy. Medizza (1975) assigned these deposits to the Discoaster sublodensis Zone (NP 14) on the basis of calcareous nannoplankton, while the larger foraminifera reported by Papazzoni and Trevisani (2006) place the unit within SBZ 11. NP 14 and SBZ 11 overlap narrowly in the late Ypresian, and the age of the fish beds at Bolca can be approximately correlated with the base of NP 14, which is dated as $49.11 \mathrm{Ma}$ (Anthonissen and Ogg, 2012). We accept this date as a fossil-based minimum for the last common ancestor of Atherinomorpha and Cichlidae.

Given that the anatomy of Ramphexocetus suggests that this genus occupies a relatively nested position within crown Atherinomorpha, is it probable that the minimum age for the Atherinomorpha - Cichlidae divergence given here is a substantial underestimate. We therefore suggest the use of a generous soft maximum bound. Percomorphs, and acanthomorphs more generally, are unknown from a series of fish faunas of mid-late Early Cretaceous age that represent a range of depositional settings from fully marine to lacustrine: the Gault Clay of England (Albian; Gale and Owen, 2010; Forey and Longbottom, 2010; Nolf, 2010), Helgoland in Germany (Aptian; Taverne, 1981b), the Crato Formation of Brazil (Martill, 1993; early interpretations of Araripichthys as a lampridiform have been decisively rejected by Patterson, 1993a and Maisey and Moody, 2001), and the Coquiero Seco Formation of Brazil (Gallo and Cohelo, 2008). The oldest of these deposits, the Coquiero Seco Formation of Brazil, yields the oldest putative representative of Eurypterygii, (the clade containing Aulopiformes, Myctophiformes, and Acanthomorpha), and provides the basis for our estimated maximum age divergence between Tetraodontiformes and Ovalentaria. The Barremian is dated to approximately 130.8-126.3 Ma (Ogg et al.,
$2012 b)$; we derive our soft maximum from the oldest limit.

Discussion. The fish beds at Bolca yield a diversity of atherinomophs in addition to Ramphexocetus, but we have selected this genus as our calibration because its placement within the clade is the most clearly and robustly supported by available character evidence. Ramphexocetus is joined by the hemiramphid 'Hemiramphus' edwardsi, putative atherinids assigned to Atherinia but in need of revision, and a series of genera of uncertain affinities and placed in extinct families: Rhamphognathus (Rhamphognathidae), Mesogaster and Lettellagnathus (Mesogasteridae) (Blot, 1980; Bannikov, 2008).

Several atherinomorphs of Late Cretaceous to Paleocene age are mentioned in the literature, but none has been described in sufficient detail to meaningfully assess phylogenetic placement. Isolated scales from the Thanetian Maiz Gordo Formation of Argentina have been identified as belonging to indeterminate poeciliids, but have not been described or illustrated (Cione, 1986), and the reliability of identifications drawn from such remains must be questioned. Gayet (1991) figured material from the Maastrichtian-Danian el Molino Formation of Bolivia that she compared with Cyprinodontiformes. This interpretation is doubtful, however, as the caudal-fin skeleton of these fishes does not appear to match the condition found in living members of the group. Gayet (1991) also reports isolated pharyngeal teeth from the Cenomanian Miraflores Formation of Boliva that broadly resemble those of cyprinodontiforms, but we have no confidence in this phenetic identification.

\section{CROWN CICHLIDAE (37)}

Node Calibrated. Divergence between Etroplinae and Pseudocrenilabrinae.

Fossil Taxon and Specimen. Mahengechromis plethos from Mahenge, Singida Plateu, Tanzania (holotype NMT WM 339/96a, b, National Museum of Tanzania, Dar es Salaam, Tanzania).

Phylogenetic Justification. The most compelling evidence for cichlid monophyly derives from aspects of soft-tissue anatomy and other details unlikely to be preserved in fossils (Stiassny, 1981), but placement of Mahengechromis within Cichlidae is supported by the structure of the lower pharyngeal jaw, details of squamation, and meristic counts of the vertebral column and median fins (Murray, 2000, 2001a, b). The derived presence of a single supraneural and ctenoid scales indicate that Mahengechromis belongs to crown-group 
Cichlidae generally and Pseudocrenilabrinae specifically (Murray, 2000: figure 11; Murray, 2001b: figure 4).

Minimum Age. $45.46 \mathrm{Ma}$

Soft Maximum Age. $100.5 \mathrm{Ma}$

Age Justification. The fossil deposits at Mahenge represent lacustrine sediments that accumulated within a crater formed by intrusion of kimberlite. U$\mathrm{Pb}$ dating of a zircon crystal provides a well-constrained age estimate of $45.83 \mathrm{Ma} \pm 0.17 \mathrm{Myr}$ for the kimberlite at Mahenge (Harrison et al., 2001), but the lacustrine sediments yielding Mahengechromis must postdate this intrusive event. Harrison et al. (2001) provide a convincing argument, based on other crater lakes, that kimberlite emplacement likely predates lacustrine deposition and complete basin infill by only 0.2 to $0.1 \mathrm{Ma}$. We therefore define a minimum age of 45.46 Ma for Mahengechromis and crown-group Cichlidae.

A soft maximum age for crown Cichlidae can be derived from the earliest fossil occurrences of more inclusive acanthomorph clades containing the family. The oldest well-substantiated remains of Ovalentaria only predate the earliest fossil chichlids by a few million years (see node 36 ). We prefer to adopt a more generous soft maximum based on the rich fish faunas of Cenomanian age that yield a diversity of acanthomorphs belonging to deeply diverging groups like polymixiids, lampridiforms, paracanthopterygians, and beryciforms, but only questionable percomorphs (faunas reviewed in Forey et al., 2003; see calibration for node 35 for a discussion of uncertainties surrounding early Late Cretaceous tetraodontiforms). The base of the Cenomanian is dated as $100.5 \mathrm{Ma}$ (Ogg et al., 2012b), which we propose as a soft maximum age for crown Cichlidae.

Discussion. A series of articulated cichlids have been described from the 'Faja Verde' level of the lower Lumbrera Formation of northwestern Argentina (Malabarba et al., 2006, 2010; Perez et al., 2010). Published age estimates for these fossils range from latest Paleocene-earliest Eocene (Sempere et al., 1997) to middle Eocene (Malabarba et al., 2006, 2010; Perez et al., 2010). These proposed ages are particularly remarkable due to the fact that one of the cichlids described from the 'Faja Verde' has been interpreted as nesting within an extant genus (Malabarba et al., 2010).

Historically, the Lumbrera Formation has been assigned to the Casamayoran South American
Land Mammal Age, although this deposit shares no taxa in common with reference horizons in Patagonia (del Papa et al., 2010). Attribution to this land mammal age provides only the coarsest chronostratigraphic resolution; the Casamayoran is correlated with the Ypresian through early Priabonian stages of the international timescale, and therefore spans most of the Eocene (ca. 19 Myr duration). The top of the Casamayoran can be dated only approximately through correlation, yielding an estimate of $37.5 \mathrm{Ma}$ (Vandenberghe et al., 2012). The most robust minimum age constraint for the lower Lumbrera Formation cichlids comes from U/Pb zircon date of $39.9 \mathrm{Ma}$ for the upper Lumbrera Formation (del Papa et al., 2010). López-Fernández et al. (2013) have recently used cichlids from the 'Faja Verde' to calibrate a molecular clock for neotropical cichlids. They assigned a hard minimum age of $49.0 \mathrm{Ma}$ to these taxa, which is nearly 10 Ma older than the more robust minimum constraint endorsed here. The source of this older estimate provides no numerical estimates for the age of the Lumbrera Formation and does not mention this deposit specifically (White et al., 2009). If an age of 49.0 Ma for the Lumbrera cichlids can be substantiated, these fossils would provide the appropriate minimum age constraint for crown Cichlidae.

It is commonplace for molecular clock analyses to specify minimum ages for cichlid divergences based on biogeographical scenarios invoking vicariant events associated with the midMesozoic breakup of Gondwana (Genner et al., 2007; Azuma et al., 2008; López-Fernández et al., 2013), but we do not advocate this calibration strategy at present. These hypothesized divergences substantially predate the earliest fossil evidence for not only cichlids, but also a series of more inclusive teleost clades (e.g., Ovalentaria, Percomorpha, Acanthomorpha, Ctenosquamata; Lundberg, 1993). Additionally, molecular timescales based on well-justified calibrations derived from marine fish fossils with narrowly constrained ages indicate a Late Cretaceous-early Paleogene origin for Cichlidae (Santini et al., 2009; Near et al., 2012, 2013; Betancur-R. et al., 2013; McMahan et al., 2013; Friedman et al., 2013), which is more consistent with the observed paleontological record of the group (Murray, 2001b) and statistical estimates of times of origin based on the distribution of fossil horizons and outgroup ages (Friedman et al., 2013). 


\section{GASTEROSTEUS - TETRAODON, TAKIFUGU} (38)

Node Calibrated. Divergence between Gasterosteidae and Tetraodontiformes. This corresponds to an unnamed clade within Percomorpha.

Fossil Taxon and Specimen. Cretatriacanthus guidottii from the 'Calcari Melissano' (of historical usage) at Canale near Nardò, Italy (holotype MCSNV 1377, Museo Civico di Storia Naturale, Verona, Italy).

Phylogenetic Justification. There are several reports of Cretaceous tetraodontiforms (Patterson, 1993b; Tyler and Sorbini, 1996; Santini and Tyler, 2003; Gallo et al., 2009; Friedman, 2012; Tyler and Križnar, 2013). We select Cretatriacanthus, from Nardò, Italy as a conservative minimum constraint for the divergence between Tetraodontiformes and Ovalentaria. Cretatriacanthus represents the youngest putative tetraodontiform of Cretaceous age represented by body-fossil remains. The absence of an elaborate dermal carapace in Cretatriacanthus means that key tetraodontiform features like the absence of pleural ribs and geometry of the pelvic girdle are readily apparent in this genus, whereas they are generally obscured by an elaborate bony carapace in other Cretaceous examples.

Minimum Age. $69.71 \mathrm{Ma}$

Soft Maximum Age. $130.8 \mathrm{Ma}$

Age Justification. The fish-bearing limestones at Nardò are generally referred to the 'Calcari di Melissano', a name historically applied to the Late Cretaceous platform carbonates of Salento (Martinis, 1967). However, usage has since been restricted to one part of the Late Cretaceous carbonate succession in the Apulian platform (e.g., Bosellini and Parente, 1994; Schlüter et al., 2008). Medizza and Sorbini (1980) provide a list of calcareous nannofossil species recovered from the fishbearing layers, the most biostratigraphically relevant of which is Uniplanarus trifidus (reported as Quadrum trifidum). The first appearance of this species marks the beginning of Calcareous Nannoplankton Zone $\mathrm{CC} 23$, and it makes its last appearance in the middle of CC24. The top of CC24 is roughly equivalent to the top of the Baculites clinolobatus Ammonite Zone of the Western Interior Seaway, which contains a bentonite horizon dated as $70.08 \mathrm{Ma} \pm 0.37 \mathrm{Myr}$. It is from this value that we derive our minimum age estimate of 69.71 Ma.

Percomorphs, and acanthomorphs more generally, are unknown from a series of fish faunas of mid-late Early Cretaceous age that represent a range of depositional settings from fully marine to lacustrine: the Gault Clay of England (Albian; Gale and Owen, 2010; Forey and Longbottom, 2010; Nolf, 2010), Helgoland in Germany (Aptian; Taverne, 1981b), the Crato Formation of Brazil (Martill, 1993; early interpretations of Araripichthys as a lampridiform have been decisively rejected by Patterson, 1993a and Maisey and Moody, 2001), and the Coquiero Seco Formation of Brazil (Gallo and Cohelo, 2008). The oldest of these deposits, the Coquiero Seco Formation of Brazil, yields the oldest putative representative of Eurypterygii (the clade containing Aulopiformes, Myctophiformes, and Acanthomorpha), and provides the basis for our estimated maximum age divergence between Tetraodontiformes and Gasterostidae. The Barremian is dated to approximately 130.8-126.3 Ma (Ogg et al., 2012b); we derive our soft maximum from the oldest limit.

Discussion. Gasterosteiform fishes are classically considered to include gasterosteids (sticklebacks) plus syngnathoids (pipefishes and allies), pegasids (sea moths), aulorhynchids (tubesnouts), hypotychids (sand eel), and, in some classications, indostomids (armored sticklebacks; Pietsch, 1978; Kievany and Nelson, 2006). The monophyly of this assemblage to the exclusion of other acanthomorph clades is rejected decisively by molecular evidence, and its constitutent members have been redistributed within Percomorpha. Syngnathoids and pegasids do appear to be closely related, but they are not resolved as immediate sister taxa (Smith and Wheeler, 2006; Betancur-R. et al., 2013; Near et al., 2013). The clade containing syngnathoids and pegasids is placed among the earliest-diverging percomorph radiations, and other members of the classical Gasterosteiformes are far removed from these taxa. Gasterosteids, hypotychids, and aulorhynchids form a clade in an apical position within Percomorpha and are associated with some taxa classically assigned to Scorpaeniformes, while Indostomus is resolved as a close relative of mastacembalids (swamp eels) (e.g., Smith and Wheeler, 2006; Kawahara et al., 2008; Li et al., 2009; Near et al., 2012, 2013; Wainwright et al., 2012; Betancur-R. et al., 2013). As a consequence, fossil specimens listed as gasterosteiforms in previous reviews of calibrations do not provide suitable fossil-based minimum ages for the Oryzias, Cichlidae - Gasterosteus, Takifugu, Tetraodon divergence. Gasterorhamphosus has been cited in this context as providing a minimum age for the gasterosteiform lineage (Benton and Donoghue, 2007, p. 41; Ben- 
ton et al., 2009, p. 65). However, it is clear that this fossil, which derives from the same beds at Nardò, Italy as Cretatriacanthus (Sorbini, 1981), is a syngnathoid and thus not closely related to Gasterosteus. Our reasons for selecting Cretatriacanthus rather than other Late Cretaceous fossils as a constraint for the origin of Tetraodontiformes are outlined in the discussion for Node 35.

\section{CROWN GASTEROSTEIDAE (39)}

Node Calibrated. Divergence between Pungitius and Gasterosteus.

Fossil Taxon and Specimen. Gasterosteus cf. aculeatus from the Alta Mira Shale, Monterey Formation of Palos Verdes, California, USA (specimen LACM 150177, Los Angeles County Museum of Natural History, Los Angeles, California, USA).

Phylogenetic Justification. The Monterey Formation gasterosteid has not been included in a formal cladistic analysis, but its placement within Gasterosteus is supported by the presence of two elongate, free dorsal-fin spines and a complete series of lateral plates along the flank. Bell et al. (2009) have argued for a more precise association with $G$. aculeatus based on provenance, body size, the number of lateral plates, and the absence of proximal cusps on the anal-fin spine.

Minimum Age. $13.1 \mathrm{Ma}$

Soft Maximum Age. 41.3 Ma

Age Justification. Diatoms associated with the specimen of Gasterosteus cf. aculeatus are indicative of Subzone a of the Denticulopsis hustedtiiDenticulopsis lauta Zone, which is equivalent to the lower Mohnian regional stage (Bell et al., 2009: table 1). Estimates provided by Barron (2003) for first and last appearances of diatom species tightly constrain the age of the Gasterosteus from the Monterey Formation to between 13.1 and $13.3 \mathrm{Ma}$, corresponding to the Serravallian stage of the Miocene. We derived our minimum age of 13.1 Ma for crown Gasterosteus from this reported range.

Because the Gasterosteus from the Monterey Formation represents the earliest reliable fossil occurrence of Gasterosteidae (other examples summarized in Nazarkin et al., 2013), a soft maximum age for crown Gasterosteus must be sought outside the family. Molecular anlyses associate Gasterosteidae and its immediate allies (Hypoptychidae, Aulorhynchidae) with several families generally assigned to Scorpaeniformes in historical classifications (Agonidae, Anoplopomatidae, Anarhichadidae, Bathymasteridae, Cottidae, Cryptacanthodidae, Cyclopteridae, Hexagrammidae, Liparidae, Pholidae, Rhamphocottidae, Stichaei- dae, Trichodontidae, Zaproridae, Zoarcidae; Smith and Wheeler, 2006; Betancur-R. et al., 2013; Near et al., 2013). These groups generally inhabit the North Pacific (Nelson, 2006) and are characterized by sparse fossil records restricted largely to the Neogene (Patterson, 1993b). This likely reflects the fact that the relatively few Cenozoic sites along the margins of the North Pacific that yield abundant articulated fish remains are principally Miocene in age or younger (e.g., Yabumoto and Uyeno, 1994; Bannikov, 2010; Fierstine et al., 2012; Nazarkin et al., 2013a). The oldest skeletal evidence for any of these lineages is material of Cottidae attributed to Cottus from the Oligocene (Rupelian) Argile de Boom, Belgium, although the reliability of this identification is questionable (Patterson, 1993b). In the absence of suitable deposits or extensive fossil histories of immediate relatives, a maximum age for crown Gasterosteidae can only be established arbitrarily. We propose a constraint of $41.3 \mathrm{Ma}$ based on the maximum possible age of the Bartonian Gorny Luch locality in the north Caucasus. This assemblage yields nearly 40 families of marine teleosts (Bannikov, 2010), including the earliest Champsodontidae (Bannikov, 2004), which are placed as members of a broader clade including gasterosteids and other cottoids (sensu Betancur-R. et al., 2013) in molecular phylogenies (Near et al., 2013). However, the fauna from Gorny Luch lacks either gasterosteids or their closest cottoid relatives (Bannikov, 2010). The base of the Bartonian is dated to $41.3 \mathrm{Ma}$, which we designate as a maximum age estimate for the origin of crown Gasterosteidae.

Discussion. We have followed the arguments of Bell et al. (2009) in aligning the Gasterosteus fossil from the Monterey Formation with $G$. aculeatus. However, it is possible that some of the diagnostic characteristics of the species that they cite are primitive, and that this fossil more properly calibrates a less nested node within Gasterosteidae. However, it is clear that derived features of the dorsal fin minimally place the Miocene specimen within total-group Gasterosteus, if not the crown.

\section{TETRAODON -TAKIFUGU (40)}

Node Calibrated. Divergence between Tetraodon and Takifugu.

Fossil Taxon and Specimen. Archaeotetraodon winterbottomi from the Pshekhsky Horizon of the lower Maikop Formation, north Caucasus, Russia (holotype PIN 3363/111 and 111a, Palaeontological Institute of the Russian Academy of Sciences, Moscow, Russia). 
Phylogenetic Justification. Archaeotetradon winterbottomi is described in detail by Tyler and Bannikov (1994) and Carnevale and Tyler (2010). Formal cladistic analyses (Santini and Tyler, 2003: figure 4) and verbal arguments (Carnevale and Tyler, 2010: p. 297-298) based on morphology suggest the exact position of Archaeotetraodon winterbottomi to other Tetradontidae is unclear. However, combined analysis of morphological and molecular data nests Archaeotetradon winterbottomi high within the tetraodontid crown as the sister lineage of a clade comprising Tetraodon, Canthigaster, Monotrete, Auriglobus, Chonerhinos, Chelonodon, and Arthrodon (Arcila et al., 2015).

Minimum Age. $32.02 \mathrm{Ma}$

Soft Maximum Age. 56.0 Ma

Age Justification. The age of the Psekhsky Horizon is constrained by foram, nannoplankton, and dinocyst biostratigraphy (Leonov et al., 1998; Benton and Donoghue, 2006; Benton et al., 2009). The top of this horizon coincides with the first appearance of Sphenolithus predistentus and the base of Paleogene Nannoplankton Zone NP23. The base of NP23 is dated as approximately $32.02 \mathrm{Ma}$ (Anthonissen and Ogg, 2012), which we specify as a minimum age for the last common ancestor of Tetraodon and Takifugu.

We propose a soft maximum for Tetraodon Takifugu divergence based on the Ypresian London Clay of southeast England and 'Calcari nummulitici' of Bolca, Italy (Ellison et al., 1994; Papazzoni and Trevisani, 2006). These deposits yield a diversity of gymnodont tetraodontiforms, including triodontids, diodontids, and stem tetraodontids (Tyler and Patterson, 1991; Tyler and Santini, 2002; Santini and Tyler, 2003; Arcila et al., 2015), implying that crown tetraodontids would have been sampled were they present. The base of the Ypresian is dated to $56.0 \mathrm{Ma}$, defining an estimated soft maximum for the divergence between Takifugu and Tetraodon.

Discussion. The selection of an appropriate calibration for the Tetraodon - Takifugu split hinges on resolution of the relationships among living pufferfishes. Although early molecular analyses (Alfaro et al., 2007), including those based on mitochondrial genomes (Yamanoue et al., 2011), yield alternative tree shapes, most molecular studies indicate that the last common ancestor of Takifugu and Tetraodon is identical to the tetraodontid crown node (Holcroft, 2005; Betancur-R. et al., 2013; Santini et al., 2013; Arcila et al., 2015). Apart from Archaeotetradon winterbottomi and its congeners, the only definitive body-fossil remains of crown tetraodontids are those of Sphoeroides hyperostosus from unit 3 of the Yorktown Formation, Lee Creek Mine, North Carolina, USA (Tyler et al., 1992; Carnevale and Tyler, 2010). Pufferfish jaw fragments from the Miocene and Pliocene of France and Italy have been assigned to Tetraodon, but Tyler and Santini (2002) regard these materials as not sufficiently informative to specify such a precise placement within Tetraodontidae. Snyder et al. (1983) assigned the Yorktown Formation to the uppermost portion of Planktonic Foraminiferal Zone N18 to the middle of Planktonic Foraminiferal Zone N20. The base of the overlying N21 which has been dated as $3.35 \mathrm{Ma}$ (Hilgen et al., 2012; Anthonissen and Ogg, 2014), making Sphoeroides hyperostosus substantially younger than $A$. winterbottomi or other species of Archaeotetraodon (Carnevale and Tyler, 2010). There is no doubt that Sphoeroides hyperostosus is a member of the crown tetraodontid genus Sphoeroides based on presence of trituration teeth in the upper jaw and well-developed remnants of the anterior edge of the dorsal roof of the myodome, combined with the absence of a dorsal flange of the parasphenoid in the orbit, diagnostic features of Sphoeroides not found in close relatives within Tetraodontidae (Tyler et al., 1992, p. 473). More specifically, S. hyperostosus appears to be a close relative of the extant $S$. pachygaster on the basis of three characters of the skull not present in any other species of Sphoeroides: lateral ethmoid with broad upper surface with sloping anterior edge reduced or absent; posterodorsal region of the orbit roofed by expansions of the frontal and spehnotic; ridges on the frontals extending from the orbital region to a posterior extension of the bone overlying the epiotic (Tyler et al., 1992, p. 478). S. hyperostosus has been used by some studies to calibrate the Tetraodon - Takifugu divergence (Alfaro et al., 2007) due to ambiguous relationships between modern tetradontid lineages in past analyses (Santini and Tyler, 2003). However, unless subsequent analyses show that Archaeotetraodon is a stem tetraontid, calibrations based on $S$. hyperostosus substantially underestimate the minimum age for crown Tetraodontidae.

\section{CROWN TETRAPODA (AMPHIBIANS, REPTILES, BIRDS, MAMMALS) (41)}

Node Calibrated. Divergence between Amniota and Amphibia, represented by Lissamphibia today, the clade that includes frogs and toads, salamanders, and caecilians. Crown Tetrapoda is equivalent to the divergence between Batrachomorpha (extant lissamphibians and extinct relatives) and 
Reptiliomorpha (extant amniotes and their extinct relatives).

Fossil Taxon and Specimen. Lethiscus stocki Wellstead, 1982 from the Wardie Shales of the Wardie shore, near Edinburgh, Scotland, with holotype MCZ 2185 (Museum of Comparative Zoology, Harvard).

Phylogenetic Justification. Phylogenetic analyses (e.g., Panchen and Smithson, 1988; Trueb and Cloutier, 1991; Lombard and Sumida, 1992; Ahlberg and Milner, 1994; Vallin and Laurin, 2004) nest Lethiscus within Aïstopoda, one of a putative clade termed Lepospondyli, that was formerly placed in the Batrachomorpha, but appears more likely within Reptiliomorpha (e.g., Ruta et al., 2003). Either way, Lethiscus is the oldest crown tetrapod.

Minimum Age. $337 \mathrm{Ma}$

Soft Maximum Age. $351 \mathrm{Ma}$

Age Justification. The Wardie Shales are part of the Lower Oil Shale Group, dated as older than the East Kirkton locality which has also yielded several crown-group tetrapods (Rolfe et al., 1993). The Wardie Shales are assigned to the Holkerian regional stage on the basis of fossil fishes and palynomorphs (Paton et al., 1999), equivalent to the Livian in Belgium, dated as 343.5-337 Ma (Gradstein et al., 2012, p. 605), so providing the hard minimum constraint of $337 \mathrm{Ma}$.

The soft maximum constraint is harder to determine because most of the close outgroups to the batrachomorph-reptiliomorph clade are known only from younger deposits: the oldest baphetids and crassigyrinids are from the Brigantian (Benton, 1993), the oldest colosteids from the Asbian (Benton, 1993). The whatcheeriids Whatcheeria and Pederpes, from North America and Europe, respectively, are older, however, and dated to the Ivorian regional Western European stage, and so 351-346.5 Ma. These horizons are underlain by further units of Famennian age, dated as $372.2 \mathrm{Ma}$ $\pm 2.0 \mathrm{Myr}-358.9 \mathrm{Ma} \pm 0.4 \mathrm{Myr}$ (Gradstein et al., 2012 , p. 588), with basal tetrapods known from several continents, but no batrachomorphs or reptiliomorphs. We choose the whatcheeriids as marking the soft maximum constraint, even though they are phylogenetically more distant from crown Tetrapoda than baphetids and colosteids-but the latter two are younger than Lethiscus. Thus, we propose a date of $351 \mathrm{Ma}$ as a soft maximum constraint.

Discussion. Lethiscus may be the oldest crown tetrapod currently, but there are a variety of other taxa, both reptiliomorphs and batrachomorphs, from the East Kirkton locality in Scotland, that are only slightly younger. These include the basal lepospondyl Westlothiana lizziae, and on the batrachomorph side, the basal temnospondyl Balanerpeton woodi, a basal temnospondyl, and Eucritta melanolimnetes, described as a possible baphetid (Clack, 1998), and so outside crown Tetrapoda, but perhaps a batrachomorph (Ruta et al., 2003). The East Kirkton fossils come from the Little Cliff Shale, a unit within the East Kirkton Limestone, a subdivision of the upper Oilshale Group of the Midland Valley of Scotland. The fossil beds are ascribed to the Brigantian (D2; lower portion) of the Viséan stage, based on biostratigraphic comparisons of the fossil plants, pollen, and bivalves with the rich records of Lower Carboniferous sites throughout Europe (Rolfe et al., 1993). The Brigantian regional stage is the fourth British regional division of the Viséan, so terminating at $330.9 \mathrm{Ma}$ (Gradstein et al., 2012), and perhaps up to $2 \mathrm{Ma}$ in duration (Gradstein et al., 2012).

Van Tuinen and Hadly (2004) reviewed the amphibian-amniote divergence date in detail, but assigned the Wardie Shales to the Asbian, the stage above the Holkerian, and so came to an age of $332.3 \mathrm{Ma}$. Further, they used radiometric dates from Menning et al. (2000), which have been revised in GTS2012 (Gradstein et al., 2012).

\section{CROWN LISSAMPHIBIA (FROGS, SALAMANDERS, CAECILIANS) (42)}

Node Calibrated. Divergence between Batrachia (frogs and salamanders) and Gymnophiona/Apoda (caecilians).

Fossil Taxon and Specimen. Triadobatrachus massinoti (Piveteau, 1936) from the base of the middle part of the Sakamena Group in northern Madagascar (holotype, Muséum National d'Histoire Naturelle, MHNH MAE 126).

Phylogenetic Justification. Triadobatrachus has always been recognised as a frog, a basal member of Anura within the stem Batrachia, and the oldest member of the crown Lissamphibia, based on its possession of key apomorphies including a toothless dentary, a rod-like and anteriorly directed ilium and fused frontals and parietals (Ruta and Coates, 2007).

Minimum Age. 250.0 Ma

Soft Maximum Age. 272.8 Ma

Age Justification. The Sakamena Group in Madagascar spans from Late Permian to Middle Triassic, and the Middle Sakamena Group/Formation is generally dated as lower Lower Triassic, the Upper Sakamena Group/ Formation, Lower to lower Mid- 
dle Triassic. The entire Sakamena Group is some $4 \mathrm{~km}$ thick, and it is subdivided based on dominant lithologies: the middle portion is a sequence of shales and minor sandstones deposited in a lagoonal or shallow lacustrine and braided river environment, whereas the units below and above are dominated by sandstones and conglomerates indicating higher energies of deposition. Dating of the Sakamena Group is notoriously difficult, as there are no radiometric dates, there has been no magnetostratigraphic study, and the associated fossils are not classic biostratigraphically useful index fossils. Nonetheless, the Middle Sakamena Group is dated as Induan on the basis of the associated fauna of benthosuchid temnospondyls (like those of the Lystrosaurus Assemblage Zone of South Africa and the Vokhmian units of Russia, as well as plants also suggesting Induan age. The top of the Induan stage is dated as 'slightly older than' 251.2 Ma \pm 0.2 Myr (Mundil et al., 2010) and given as $250.01 \mathrm{Ma}$ by Gradstein et al. (2012, p. 718), so we select this age as the minimum constraint, namely $250.0 \mathrm{Ma}$.

It is hard to know how far down to set the soft maximum age for Lissamphibia, as there are no reported stem lissamphibians from older Triassic or Permian rocks. An arbitrary date is set at the base of the Middle Permian, allowing considerable time to span numerous tetrapod-bearing rocks of various facies from South Africa, Russia, and China in which no identifiable lissamphibians, whether stem or crown, have been reported. The base of the Middle Permian is dated as $272.3 \mathrm{Ma} \pm 0.5 \mathrm{Myr}$, so 272.8 Ma.

Discussion. The absence of older putative lissamphibian fossils could perhaps suggest a rapid origin of the crown Lissamphibia in the aftermath of the Permo-Triassic mass extinction. However, some fossil evidence has controversially set the origins of the clade in much older rocks (e.g., Carroll, 2001; Anderson, 2008), and many molecular studies also suggest a Late Paleozoic age, whether Carboniferous or Permian (e.g., San Mauro et al., 2005; Marjanovic and Laurin, 2007; San Mauro, 2010; Pyron, 2011).

\section{CROWN BATRACHIA (FROGS AND SALAMANDERS) (43)}

Node Calibrated. Divergence between Anura (frogs and toads) and Caudata (salamanders and newts).

Fossil Taxon and Specimen. Triadobatrachus massinoti (Piveteau, 1936) from the base of the middle part of the Sakamena Group in northern
Madagascar (holotype, Muséum National d'Histoire Naturelle, MHNH MAE 126).

Phylogenetic Justification. Triadobatrachus has always been recognised as basal member of Anura, within the stem Batrachia, and so the oldest member of the crown Batrachia, based on its possession of the key apomorphies of a posteriorly open maxillary arcade, absence of an ossified postparietal, tabular, jugal, quadratojugal, and other characters (Ruta and Coates, 2007).

Minimum Age. 250.0 Ma

Soft Maximum Age. 272.8 Ma

Age Justification. The Sakamena Group, determining the minimum age constraint, is dated as noted above, under Lissamphibia. As for Lissamphibia, it is hard to know how far down to set the soft maximum age for Batrachia, as there are no reported stem batrachians from older Triassic or Permian rocks. As for Lissamphibia, an arbitrary date is set at the base of the Middle Permian.

Discussion. The absence of older putative lissamphibian fossils could perhaps suggest a rapid origin of the crown Batrachia, as part of crown Lissamphibia, in the aftermath of the Permo-Triassic mass extinction. However, some fossil evidence has controversially set the origins of the clade in much older rocks (e.g., Carroll, 2001; Anderson, 2008), and many molecular studies also suggest a Late Paleozoic age, whether Carboniferous or Permian (e.g., San Mauro et al., 2005; Marjanovic and Laurin, 2007; San Mauro, 2010; Pyron, 2011), so we extend the soft maximum constraint at least to the base of the Middle Permian.

\section{CROWN ANURA (FROGS, TOADS) (44)}

Node Calibrated. Divergence between Leiopelmatidae/Ascaphidae and derived frogs and toads (Neobatrachia, plus stem forms), based recent phylogenies (Roelants et al., 2007; Pyron and Wiens, 2012).

Fossil Taxon and Specimen. Eodiscoglossus oxoniensis Evans et al. (1990) from the Forest Marble Formation, upper Bathonian of Oxfordshire, England (holotype, Natural History Museum, London, NHMUK R11700, a right ilium).

Phylogenetic Justification. Eodiscoglossus is identified as a member of crown Discoglossidae on the basis of two apomorphies in combination, the possession of opisthocoelous vertebrae together with an ilium bearing a dorsal crest (Evans et al., 1990; Ruta and Coates, 2007).

Minimum Age. 165.3 Ma

Soft Maximum Age. 201.5 Ma 
Age Justification. The Forest Marble Formation has long been assigned to the Late Bathonian, dated as 166.5-166.1 Ma $\pm 1.2 \mathrm{Myr}$ (Gradstein et al., 2012, pp. 765, 777), so giving an age of 165.3 $\mathrm{Ma}$ as the minimum constraint.

The soft maximum constraint can be set as equivalent to the base of the Jurassic, allowing for finds of various stem anurans and other small tetrapods from several continents, but as yet no crown taxa, and so $201.3 \mathrm{Ma} \pm 0.2 \mathrm{Myr}$, so 201.5 Ma.

Discussion. There are several stem frogs in the Triassic and Jurassic, with Triadobatrachus the oldest (Triassic, Induan) through Jurassic forms such as Prosalirus, Vieraella, and Notobatrachus, but these do not belong to any modern anuran subclades, and so are not helpful in determining a minimum age for the crown-clade Anura (Roelants and Bossuyt, 2005).

Among major anuran subclades, Discoglossoidea provides the oldest fossil, Eodiscoglossus. This predates the oldest members of other anuran subclades, namely Rhadinosteus parvus from the Kimmeridgian (Rhinophrynoidea), an indeterminate pelobatid from the Late Cretaceous (Pelobatoidea), Shomronella jordanica, Cordicephalus gracilis, and Thoraciliacus rostriceps from the Hauterivian of Israel (Pipidae), and Baurubatrachus pricei from the Late Cretaceous of Brazil (Neobatrachia). Roelants and Bossuyt (2005, p. 120) selected an age of 164 Ma for Eodiscoglossus.

\section{CROWN CAUDATA (SALAMANDERS, NEWTS)}

Node Calibrated. Divergence between the Cryptobranchoidea (cryptobranchids and hynobiids) and the Salamandroidea (all other salamanders).

Fossil Taxon and Specimen. Iridotriton hechti Evans et al., 2005, from the Brushy Basin Member of the Morrison Formation of the Dinosaur National Monument, Rainbow Park microsite, Utah.

Phylogenetic Justification. Iridotriton is identified as a member of Salamandroidea, and hence crown Caudata, by the possession of several apomorphies, including the presence of spinal nerve foramina in the tail.

Minimum Age. $146.8 \mathrm{Ma}$

Soft Maximum Age. 175.1 Ma

Age Justification. The Brushy Basin Member of the Morrison Formation is dated as Kimmeridgian or early Tithonian. The upper boundary of the Early Tithonian is $147.7 \mathrm{Ma} \pm 0.9 \mathrm{Myr}$ (Gradstein et al., 2012, pp. 764,777 ), so $146.8 \mathrm{Ma}$.
The soft maximum constraint is based on the possibility that the Kirtlington 'Salamander B' might be a crown caudate, lowering the age estimate to Late Bathonian, and indeed, the range is extended to the base of the Middle Jurassic, dated as 174.1 $\mathrm{Ma} \pm 1.0 \mathrm{Myr}$, so $175.1 \mathrm{Ma}$.

Discussion. There are various salamander taxa reported from the Middle and Late Jurassic of Eurasia, but these largely belong to the stem caudate family Karauridae: the Late Jurassic Karaurus from Kazakhstan, Kokartus from Kirghizia, Marmorerpeton from the Middle Jurassic of England and Portugal, and unnamed forms from the Middle Jurassic of England (Evans et al., 2005). These authors note that an older salamandroid may be represented by postcranial elements referred to 'Salamander B' from the forest Marble Formation (late Bathonian) of the Kirtlington locality, Oxfordshire, UK.

\section{CROWN GYMNOPHIONA (CAECILIANS) (46)}

Node Calibrated. Divergence between Rhinetrematidae and Caeciliidae.

Fossil Taxon and Specimen. Apodops pricei Estes and Wake, 1972, based on a single trunk vertebra from the Late Paleocene of São José de Itaboraí, Rio de Janeiro, Brazil (Divisão de Geologia e Mineralogia, Depto. Nacional de Producão Mineral, Rio de Janeiro, Brazil, DGM 551).

Phylogenetic Justification. Apodops pricei was identified as a caecilian related to the Holocene genus Dermophis and the extant Geotryptes. It is assigned to crown Gymnophiona based on the apomorphies of having compact vertebrae, and enlarged, projecting parapophyses (Estes and Wake, 1972).

Minimum Age. $56 \mathrm{Ma}$

Soft Maximum Age. $145.8 \mathrm{Ma}$

Age Justification. The fissure fillings of São José de Itaboraí, near Rio de Janeiro, are dated as early Late Paleocene (Mayr et al., 2011), and the maximum age bound is then 56.0 Ma $\pm 0.0 \mathrm{Myr}=56.0$ Ma (Gradstein et al., 2012, pp. 883, 904).

Discussion. The two oldest caecilians, the Early Jurassic Eocaecilia micropodia and the Early Cretaceous Rubricacaecilia monbaroni, belong to the stem (Marjanovic and Laurin, 2007), and so are not helpful in dating. Two unnamed possible crown caecilians are an unnamed form from the Wadi Milk Formation of Sudan (Cenomanian) and a terminal Cretaceous fossil from the Pajcha Pata in Bolivia. These provide hints that older caecilians, whose fossils appear to be so immensely rare, might be found down to the base of the Cretaceous 
at least, dated as $145.0 \mathrm{Ma} \pm 0.8 \mathrm{Myr}$ (Gradstein et al., 2012, p. 838), so $145.8 \mathrm{Ma}$.

\section{CROWN AMNIOTA (REPTILES, BIRDS, MAMMALS) (47)}

Node Calibrated. Divergence between Eureptilia (including Diapsida) and Synapsida.

Fossil Taxon and Specimen. Hylonomus lyelli Dawson, 1860 (holotype, British Museum (Natural History), London, NHMUK R4168), an almost complete skeleton, from division 4 , section $X V$, coal group 15, of the Joggins Formation of Nova Scotia. Phylogenetic Justification. Hylonomus was formerly assigned to the paraphyletic groups "Protorothyrididae' or 'Captorhinidae' (Carroll, 1964), and it falls within Eureptilia, on the stem to Diapsida (Laurin and Reisz, 1995; deBraga and Rieppel, 1997), based on large numbers of morphological synapomorphies.

Minimum Age. $318 \mathrm{Ma}$

Soft Maximum Age. $332.9 \mathrm{Ma}$

Age Justification. The age of the Joggins Formation has been much debated, and figures in the range from 320 to $305 \mathrm{Ma}$ have been quoted. Reisz and Müller (2004) indicate an age of 316$313 \mathrm{Ma}$, while Van Tuinen and Hadly (2004) settle for 310.7 Ma $\pm 8.5 \mathrm{Myr}$. Detailed field logging and biostratigraphy based on palynomorphs (FalconLang et al., 2006; Grey and Fink, 2010; Utting et al., 2010) confirm that the Joggins Formation falls entirely within the Langsettian European time unit, equivalent to the Westphalian $\mathrm{A}$, and roughly matching the Russian Cheremshanian, in the later part of the Bashkirian Stage. Earlier dates for these units were equivocal (Menning et al., 2000), but the Langsettian is given as 319-318 Ma by Gradstein et al. (2012, p. 605), rather older than the 314.5313.4 Ma \pm 1.1 Myr given in GTS2004 (Davydov et al., 2004). This makes the classic 'bird-mammal split' somewhat older than has currently been assumed, at a minimum of $318 \mathrm{Ma}$.

The soft maximum constraint on the birdmammal split is based on the next richly fossiliferous units lying below these horizons. The first is the East Kirkton locality, source of a diverse fauna of batrachomorphs and reptiliomorphs (see node 41 ), but that has hitherto not yielded anything that could be called either a diapsid or a synapsid. Further fossiliferous sites of similar facies lie below the East Kirkton level, and they have not yielded reptile remains. We take the age of the fossiliferous Little Cliff Shale of the East Kirkton locality, assigned to the Brigantian, the fourth British regional division of the Viséan, so terminating at $330.9 \mathrm{Ma}$ (Gradstein et al., 2012), and perhaps up to 2 myr in duration (Gradstein et al., 2004), as the basis for the soft maximum age constraint of $332.9 \mathrm{Ma}$.

Discussion. The ultimate divergence date between birds and mammals has been quoted many times as $310 \mathrm{Ma}$, generally tracing back to Benton (1990). Van Tuinen and Hadly (2004) trace the history of the use of this date in molecular analyses, and they quote a range of estimates from 338 to $247 \mathrm{Ma}$, with a preference for a value of 310 $\mathrm{Ma}$, on the basis of reassessment of the Late Carboniferous timescale. This estimate has been criticized for being used without error bars (Graur and Martin, 2004; Van Tuinen and Hadly, 2004), for being based on uncertain fossils and hence too old (Lee, 1999), for being misdated (Reisz and Müller, 2004; Van Tuinen and Hadly, 2004), and for being poorly bracketed by outgroups above and below (Reisz and Müller, 2004). Reisz and Müller (2004) indeed argue that this calibration point should no longer be used largely because its soft maximum bound is so poorly constrained.

The oldest identified synapsid is Protoclepsydrops haplous Carroll, 1964, also from the Joggins Formation of Joggins, Nova Scotia. This taxon has been classed as an ophiacodontid, not a member of the basalmost synapsid families-Eothyrididae, Caseidae, or Varanopseidae-whose basal members, if ever found, might be of the same age or older. Protoclepsydrops haplous is known from one incomplete partial skeleton and skull (Reisz, 1972), but the remains are fragmentary; even the identification of these remains as a synapsid has been questioned (Reisz, 1986; Reisz and Modesto, 1996). This uncertainty explains why we select Hylonomus lyelli, of the same geological age, but more certain phylogenetic attribution, as the marker fossil.

Phylogenetically, the basalmost member of the Reptilia (= Eureptilia + Parareptilia) is Coelostegus from the Upper Carboniferous (Moscovian, Myachkovskian; $306.5 \mathrm{Ma} \pm 1 \mathrm{Myr}$ ) of the Czech Republic (Müller and Reisz, 2006). This taxon is, however, younger than Hylonomus and the other Joggins animals. Lee (1999) doubted that Hylonomus was a eureptile, and so redated the reptilian branch upwards to $288 \mathrm{Ma}$. This view was refuted by Reisz and Müller (2004), who noted that dating the ultimate bird-mammal split is synonymous with dating the origin of Amniota. So, it may be uncertain whether Protoclepsydrops is a synapsid, and Hylonomus is not a diapsid, but all these taxa are diagnostically members of Amniota, so the 
origin of Amniota happened before the age of the Joggins Formation of Nova Scotia.

Older evidence of amniotes has been reported by Falcon-Lang et al. (2007), footprints with a number of amniote derived characters (pentadactyl manus and pes, slender digits whose relative lengths approximate a phalangeal formula of 23453 (manus) and 23454 (pes), narrow digit splay $\left(40-63^{\circ}\right)$, putative transverse scale impressions on digit pads, and straight tail drag) that come from the Grand Anse Formation of Nova Scotia. This unit lies $1 \mathrm{~km}$ below the Joggins Formation and is dated at $\sim 1$ myr older than the Joggins. However, although these footprints most probably represent amniotes, such fossils are less reliable than skeletal body fossils and can be taken as a indicator of future possible increases in the age of the minimum constraint on the bird-mammal split.

\section{CROWN REPTILIA (PARAREPTILES, TURTLES, AND DIAPSIDS) (48)}

Node Calibrated. Testudines and Diapsida.

Fossil Taxon and Specimen. Protorosaurus speneri Meyer, 1832 (Royal College of Surgeons, RCSHC/Fossil Reptiles 308), holotype of the oldest archosauromorph, from the Kupferschiefer of Germany and the Marl Slate of NE England (Evans and King, 1993).

Phylogenetic Justification. Protorosaurus is a member of Archosauromorpha and of crown Diapsida, based on numerous morphological synapomorphies (Benton, 1985; Gauthier et al., 1988).

Minimum Age. 255.9 Ma

\section{Soft Maximum Age. 295.9 Ma}

Age Justification. The Kupferschiefer of Germany and the Marl Slate of NE England are correlated with each other on independent geological evidence and defined as the basal unit of the Zechstein 1 (EZ1; Werra Folge) depositional cycle. The two units were generally assigned to the Kazanian (e.g., Benton, 1993, p. 695), but subsequent stratigraphic revisions have shown that the Zechstein falls above the Illawarra Reversal, which is at the Wordian-Capitanian boundary. Whereas Ogg (2004) moved the Zechstein I up to equate to the Capitanian, Slowakiewicz et al. (2009) move it higher to equate with the early Wuchiapingian, ranging from 260-257 Ma. Roscher and Schneider (2006) estimate a minimum age for the Kupferschiefer as $255.9 \mathrm{Ma}$, so we accept that here, as a younger estimate, based on new dating evidence, than the date of $259.7 \mathrm{Ma}$ given by Benton and Donoghue (2007). This is close to the alternative suggestion of 254.7 Ma proposed by Ezcurra et al.
(2014), based on a date for the Kupferschiefer (and of Protorosaurus) of 257.3 Ma $\pm 2.6 \mathrm{Myr}$.

In order to establish the soft maximum constraint on this divergence, outgroups to Neodiapsida are considered. Ichthyosauria are known first in the Early Triassic, younger than the minimum age constraint. Younginiformes, Weigeltisauridae (Coelurosauravus), and Claudiosaurus are of similar age to Protorosaurus, or younger. Next oldest was Apsisaurus from the Archer City Formation of Texas, dated as Asselian, but this turns out to be a varanopid synapsid (Reisz et al., 2010). This is a long way below the minimum age constraint, but there is a well-known "gap" in suitable fossiliferous formations through the mid-Permian, and we retain this possibly exaggerated soft maximum constraint.

Discussion. The clade Reptilia, as currently understood to include all amniotes except synapsids, is not subtended by extant animals. Crown Reptilia might be synonymous with crown Diapsida, if turtles are diapsids, as is commonly assumed (Kumazawa and Nishida, 1999; Rieppel and Reisz, 1999; Cao et al., 2000; Zardoya and Meyer, 2001; Meyer and Zardoya, 2003; Iwabe et al., 2005; Hill, 2005; Lyson et al., 2012). However, the clade is given separately here, in case Testudines should later emerge in its traditional position, outside Diapsida. The age of the base is not affected, as the oldest turtle, Odontochelys semitestacea, is Late Triassic in age (Carnian, 237.0$223.0 \mathrm{Ma}$ ), and so considerably postdates the basal crown diapsids.

\section{CROWN DIAPSIDA (= NEODIAPSIDA; 'SAURIA'; CROCODILIANS, BIRDS, LIZARDS, AND SNAKES) (49)}

Node Calibrated. Divergence between Archosauromorpha and Lepidosauromorpha.

Fossil Taxon and Specimen. Protorosaurus speneri Meyer, 1832 (Royal College of Surgeons, RCSHC/Fossil Reptiles 308), holotype of the oldest archosauromorph, from the Kupferschiefer of Germany and the Marl Slate of NE England (Evans and King, 1993).

Phylogenetic Justification. Protorosaurus is a member of Archosauromorpha and of crown Diapsida, based on numerous morphological synapomorphies (Benton, 1985; Gauthier et al., 1988).

Minimum Age. 255.9 Ma

Soft Maximum Age. 295.9 Ma

Age Justification. The Kupferschiefer of Germany and the Marl Slate of NE England are correlated with each other on independent geological evi- 
dence, and defined as the basal unit of the Zechstein 1 (EZ1; Werra Folge) depositional cycle. The two units were generally assigned to the Kazanian (e.g., Benton, 1993, p. 695), but subsequent stratigraphic revisions have shown that the Zechstein falls above the Illawarra Reversal, which is at the Wordian-Capitanian boundary. Whereas Ogg (2004) moved the Zechstein I up to equate to the Capitanian, Slowakiewicz et al. (2009) move it higher to equate with the early Wuchiapingian, ranging from 260-257 Ma. Roscher and Schneider (2006) estimate a minimum age for the Kupferschiefer as $255.9 \mathrm{Ma}$, so we accept that here, as a younger estimate, based on new dating evidence, than the date of $259.7 \mathrm{Ma}$ given by Benton and Donoghue (2007). This is close to the alternative suggestion of 254.7 Ma proposed by Ezcurra et al. (2014), based on a date for the Kupferschiefer (and of Protorosaurus) of 257.3 Ma $\pm 2.6 \mathrm{Myr}$.

In order to establish the soft maximum constraint on this divergence, outgroups to Neodiapsida are considered. Ichthyosauria are known first in the Early Triassic, younger than the minimum age constraint. Younginiformes, Weigeltisauridae (Coelurosauravus), and Claudiosaurus are of similar age to Protorosaurus, or younger. Next oldest was Apsisaurus from the Archer City Formation of Texas, dated as Asselian, but this turns out to be a varanopid synapsid (Reisz et al., 2010). This is a long way below the minimum age constraint, but there is a well-known "gap" in suitable fossiliferous formations through the mid-Permian, and we retain this possibly exaggerated soft maximum constraint.

Discussion. The clades Archosauria (modern crocodilians and birds and their extinct relatives) and Lepidosauria (modern tuatara, lizards and snakes and their extinct relatives) are members, respectively, of the larger clades Archosauromorpha and Lepidosauromorpha. The ultimate split between crocodilians and lizards then is marked by the split between those two, and they, together with a number of basal outgroups, form the major clade Diapsida. Through a series of cladistic analyses (Benton, 1985; Evans, 1988; Gauthier et al., 1988; Laurin and Reisz, 1995; deBraga and Rieppel, 1997; Dilkes, 1998; Müller, 2004; Evans and Jones, 2010), the topology of the basal region of the cladogram around the split of Archosauromorpha and Lepidosauromorpha is widely confirmed (although some higher parts of the cladogram are still much debated, especially the placement of Sauropterygia and Ichthyosauria).
The most ancient lepidosauromorph is debated-Benton (1993, p. 688) indicated that Saurosternon bainii, sole representative of the Saurosternidae, may be the oldest, but he was uncertain. Other authors (Gauthier et al., 1988; Reynoso, 1998; Clark and Hernandez, 1994) were more convinced that this is a true lepidosauromorph. However, numerical cladistic analyses (Caldwell, 1999; Müller, 2004) have shown unequivocally that Saurosternon and other supposed Permo-Triassic "lizards" are not lepidosauromorphs or even neodiapsids, and this view is supported by Evans and Jones (2010) and Ezcurra et al. (2014). Evans and Jones (2010) suggest that the earliest lepidosauromorphs could include Paliguana from the Early Triassic of South Africa, which has a skull 'consistent with lepidosauromorph attribution), but more certainly the kuehneosaur Pamelina polonica Evans, 2009 and stemlepidosaur Sophineta cracoviensis Evans, 2009, both from the Czatkowice deposit in Poland. This fauna is dated as Late Olenekian on the basis of comparisons of tetrapods with those from elsewhere and the presence of the lungfish Gnathorhiza, an Olenekian marker in the Russian successions (Borsuk-Bialynicka et al., 2003). The top of the Olenekian is dated as 247.1 Ma (Mundil et al., 2010; Gradstein et al., 2012, p. 706).

\section{CROWN ARCHOSAURIA (= AVESUCHIA; ARCHOSAURS) (50)}

Node Calibrated. The divergence between Crurotarsi (the 'crocodile line') and Avemetatarsalia (the 'bird line') of archosaurs.

Fossil Taxon and Specimen. Ctenosauriscus koeneni (Geowissenschaftliches Zentrum der Universität Göttingen, Göttingen, Germany, GZG.V.4191), holotype, consisting of a partial skeleton.

Phylogenetic Justification. Ctenosauriscus koeneni is a crown archosaur and a crurotarsan, based on extensive morphological phylogenetic analyses, summarised by Butler et al. (2011).

Minimum Age. 247.1 Ma

Soft Maximum Age. 260.2 Ma

Age Justification. The minimum constraint on the divergence date for birds and crocodiles falls in the late Olenekian, at the upper range of estimated ages for the holotype of Ctenosauriscus koeneni (GZG.V.4191), which comes from the Solling Formation. This unit is part of the upper Middle Buntsandstein, and is placed below the Olenekian/ Anisian boundary on lithostratigraphic evidence. The Olenekian/ Anisian boundary is dated at 247.1 
Ma, based on radioisotopic evidence (Mundil et al., 2010; Gradstein et al., 2012, p. 706), and Kozur and Bachmann $(2005,2008)$ used counts of the number of short-eccentricity Milankovitch cycles within the Solling Formation to infer a date of 247.5 Ma for the base of the Solling Formation. Butler et al. (2011) used this information to estimate an age of approximately 247.5-247.2 Ma (latest Olenekian) for the holotype of Ctenosauriscus koeneni (Geowissenschaftliches Zentrum der Universität Göttingen, Göttingen, Germany, GZG.V.4191). Similar in age is a further ctenosauriscid, Bystrowisuchus flerovi Sennikov, 2012, from the Lipovskaya Svita of the Donskaya Luka locality in southern European Russia (Sennikov, 2012), dated as Yarenskian Gorizont, and hence also late Olenekian (Benton et al., 2004). These dates are older than the 239 Ma estimated by Benton et al. (2009) as the minimum age constraint on this node, and an increase of $4 \mathrm{Myr}$ over the date given by Benton and Donoghue (2007), which was based on less constrained dating of the Anisian Arizonasaurus.

The soft maximum constraint may be assessed from the age distribution of immediate outgroups to Avesuchia, the Proterochampsidae, Euparkeriidae, Erythrosuchidae, and Proterosuchidae (Gauthier, 1986; Sereno, 1991; Benton, 1999; Brusatte et al., 2010; Nesbitt, 2011). Numerous fossil sites from around the world in the early Olenekian and the Induan, the stage below, have produced representatives of these outgroups, but not of avesuchians. For safety, the maximum bound is extended to the oldest archosaur sensu lato, Archosaurus from the Vyazniki beds of European Russia, dated as latest Wuchiapingian (Newell et al., 2010). The age range of the Wuchiapingian is $259.8 \pm 0.4 \mathrm{Myr}-254.2 \mathrm{Ma} \pm 0.3$ Myr (Gradstein et al., 2012, p. 675), and so the soft maximum age constraint is determined as 260.2 Ma.

Discussion. The most recent common ancestor of modern crocodilians and birds was an archosaur that lay at the deep junction of the two major clades within Archosauria: Avemetatarsalia/ Ornithodira and Crurotarsi (Gauthier, 1986; Sereno, 1991; Benton, 1999; Brusatte et al., 2010; Nesbitt, 2011). These two clades together form the Avesuchia (= "crown-group Archosauria").

The oldest crurotarsans noted by Benton et al. (2009) were a number of early to middle Anisian (247.1-243 Ma) forms, including the poposaurid Bromsgroveia from the Bromsgrove Sandstone Formation of England, and the "rauisuchians"
Wangisuchus and Fenhosuchus from the Er-MaYing Series of China, Vjushkovisaurus from the Donguz Svita of Russia, the ctenosauriscid Arizonasaurus from the Moenkopi Formation, and Stagonosuchus and "Mandasuchus" from the Manda Formation of Tanzania (Benton, 1993). These are now trumped by the ctenosauriscid poposauroid Ctenosauriscus koeneni (Huene, 1902) from the Solling Formation of the Buntsandstein in Germany (Butler et al., 2011).

Parham et al. (2012, pp. 352-355) present a detailed case for this same calibration, using the taxon Xilousuchus sapinbgensis (holotype, Institute of Vertebrate Paleontology and Paleoanthropology (IVPP) $\vee$ 6026) from the Heshanggou Formation, Hazhen Commune, Fugu County, northeast Shaanxi Province of China, dated as Olenekian, as the calibration fossil. Both Ctenosauriscus and Xilousuchus are unequivocally members of Archosauria and of Crurotarsi (Nesbitt, 2011), and the choice of taxon can depend on confidence in dating of their respective geological formations.

The phylogenetically basal avemetatarsalian is Scleromochlus from the Carnian of Scotland, but the oldest member of this lineage is now Asilisaurus kongwe Nesbitt et al., 2010, from the Lifua Member of the Manda Formation of Tanzania, dated by vertebrate faunal comparisons as late Anisian (Nesbitt et al., 2010), and hence 243-241.5 Ma \pm 1.0 Myr (Gradstein et al., 2012, pp. 712, 718). This marks a considerable deepening of the date of origin of Avemetatarsalia, and indeed of the included clade Dinosauromorpha, over previous records such as Marasuchus, Lagerpeton, and Pseudolagosuchus from the Chañares Formation of Argentina, dated as Ladinian, so 241.5-237 Ma \pm 1.0 Myr.

\section{CROWN LEPIDOSAURIA (SQUAMATES AND SPHENODONTIANS) (51)}

Node Calibrated. The clade that includes all modern lizards and snakes, as well the famous 'living fossil', the tuatara Sphenodon punctatus Günther, 1867. It hence comprises the clades Squamata and Rhynchocephalia (= Sphenodontia).

Fossil Taxon and Specimen. cf. Diphydontosaurus sp., a partial dentary, SMNS 91060 (Stuttgart Museum of Natural History) from Vellberg, Germany.

Phylogenetic Justification. The jaw specimen SMNS 91060 shows numerous characters of Lepidosauria (coronoid expansion, lingual subdental shelf, mix of acrodont, and pleurodont teeth) and of 
Rhynchocephalia (absence or slow pace of tooth replacement, apparent coalescence of anteriormost teeth), and Jones et al. (2013) provide compelling evidence that this is the oldest crown lepidosaur.

Minimum Age. $238 \mathrm{Ma}$

Soft Maximum Age. 252.7 Ma

Age Justification. The Vellberg jaws are from the Untere Graue Mergel, in the middle of the Erfurt Formation (formerly, Lower Keuper) of BadenWürttemberg in SW Germany. The Erfurt Formation is mid-Ladinian in age and is dated by means of cyclostratigraphy to 238-240 Ma (Menning et al., 2005; Jones et al., 2013, p. 4).

The soft maximum age is extended to the base of the Triassic, so as to accommodate the highly uncertain taxa Palacrodon and Scharschengia, formerly identified as sphenodontids, but now generally regarded as 'enigmatic', but also to allow for the chance that new explorations in Early and Middle Triassic formations in Africa, Russia, and North America, where new small tetrapod fossils are being extracted, might eventually yield some crown or stem lepidosaurs. The base of the Triassic is dated as $252.2 \mathrm{Ma} \pm 0.5 \mathrm{Myr}$ (Gradstein et al., 2012, p. 712), so we choose $252.7 \mathrm{Ma}$. Discussion. Lepidosauria used to include many stem taxa that were loosely compared to lizards, the so-called 'proto-lizards' and others, but that are now identified variously as basal lepidosauromorphs, archosauromorphs, basal neodiapsids, or even non-diapsids. Evans (2003) notes that lepidosaurs all share at least 55 apomorphies, including a derived skin structure that permits shedding, paired male hemipenes, notching of the tongue tip, separate centers of ossification in the epiphyses of limb bones, specialized fracture planes for loss of the tail (autotomy), a unique knee joint in which the fibula meets a lateral recess on the femur, and a specialized foot and ankle (hooked fifth metatarsal, fused astragalocalcaneum and mesotarsal joint, enlarged fourth distal tarsal). A node-based definition of Lepidosauria would be the most recent common ancestor of Lacerta agilis Linnaeus, 1758 and Sphenodon punctatus Gunther, 1867 and all their descendants.

The Vellberg jaws (Jones et al., 2013) push the hard minimum for Lepidosauria $17 \mathrm{Ma}$ deeper than had previously been the case. Benton and Donoghue (2007) selected the rhynchocephalian Brachyrhinodon taylori from the Lossiemouth Sandstone Formation in northeast Scotland as the oldest lepidosaur dated as $221 \mathrm{Ma}$, corresponding to the youngest estimate for the Carnian-Norian boundary.

The most basal known squamate is Bharatagama rebbanensis Evans et al., 2002 from the Upper Member of the Kota Formation of India, dated as Lower Jurassic (Toarcian to ?Aalenian).

The most basal known rhynchocephalian is considerably older. The clade is necessarily stembased, as there is only one living genus, and it may be defined as all taxa closer to Sphenodon punctatus Günther, 1867 than to Lacerta agilis Linnaeus, 1758 and includes all taxa with these apomorphies: acrodont dentition, enlarged lateral palatine tooth row, a posterior extension of the dentary that lies below the posterior mandibular elements, and loss or fusion of the supratemporal (Evans, 2003, p. 518)._Sphenodontids have been known from the Late Triassic for some time, and these include taxa such as Brachyrhinodon, Clevosaurus, Diphydontosaurus, Planocephalosaurus, and Polysphenodon. Of these, the oldest is Brachyrhinodon.

There are two putative Early Triassic sphenodontids. The first is Palacrodon browni Broom, 1906 from the Cynognathus Assemblage Zone of the Karoo Basin in South Africa (= Fremouwsaurus geludens Gow, 1999 from the Fremouw Formation of Antarctica), so Induan-upper Olenekian in age. The second is Scharschengia enigmatics Huene, 1940, named for two vertebrae from the Gostevskaya/ Shilikinskaya Svita, assigned to the Rybinskian Gorizont (Olenekian) of Russia. These taxa are currently regarded as 'enigmatic' and are not certainly assigned to Rhynchocephalia, or to any other diapsid taxon (e.g., Fraser, 1988; Sidor et al., 2008), and so should not be used in establishing any calibration.

\section{CROWN SQUAMATA (LIZARDS AND SNAKES)} (52)

Node Calibrated. The clade that encompasses all modern lizards and snakes, their common ancestor, and all included taxa. There is dispute about the key diverging subclades within Squamata (see below).

Fossil Taxon and Specimen. Bharatagama rebbanensis Evans et al., 2002, based on the holotype (University of Jammu, Geology Department collections, VPL/JU/KR 66), a jaw bone.

Phylogenetic Justification. Bharatagama, represented by some 100 fragmentary specimens, shows numerous apomorphies of the acrodont Iguania: combination of a long fused angular; a short row of pleurodont anterior teeth in a shallow symphysial region; an elongate anteromedial sym- 
physial surface restricted to the dorsal margin of the Meckelian fossa in adults; an acrodont dentition in which the teeth are broad but unflanged, and lack interstices; a pleuroacrodont additional series which follows a fully acrodont hatchling series; a strong pattern of precise dorsoventral (orthal) shear on the labial, but not lingual, surfaces of the dentary teeth; and an abutting premaxillarymaxillary contact in which a medial maxillary shelf extends behind an, apparently, narrow premaxilla (Evans et al., 2002).

Minimum Age. 168.9 Ma

Soft Maximum Age. 209.5 Ma

Age Justification. Bharatagama and an unnamed pleurodont lizard taxon both come from the Upper Member of the Kota Formation, which is dated as Toarcian to ?Aalenian (Bandyopadhyay and Sengupta, 2006), with an age in the range $182.7 \mathrm{Ma} \pm$ $0.7 \mathrm{Myr}-170.3 \mathrm{Ma} \pm 1.4 \mathrm{Myr}$ (Gradstein et al., 2012, p. 768).

The soft maximum date is set somewhat deeper in time because fossil deposits with extensive materials of small-scale diapsids are rare until we reach the Rhaetian (terminal Triassic), and those units include marine Rhaetic and terrestrially derived faunas in Europe and North America. The base of the Rhaetian is dated at 208-209 Ma by Muttoni et al. (2004, 2010), based on intercontinental comparisons of magnetostratigraphic records and radiometric dating, and 209.5 Ma by Gradstein et al. (2012, p. 716), and we select the oldest of these estimates.

Discussion. Squamata has been defined (Evans, 2003, p. 517) as the clade that 'accommodates the last common ancestor of the living Iguania and Scleroglossa and all of its descendants, and is diagnosed by a robust suite of derived character states', including the specialized quadrate articulation with a dorsal joint ('streptostyly'), loss of attachment between the quadrate and epipterygoid, subdivision of the primitive metotic fissure of the braincase, loss of the gastralia, emargination of the anterior margin of the scapulocoracoid, a hooked fifth metatarsal, and numerous soft tissue characters.

The choice of the subclades (Iguania and Scleroglossa) as definitional markers is potentially problematic because of differences in topology between morphological and molecular trees. Morphological cladograms (e.g., Estes et al., 1988; Lee, 1998; Evans, 2003) show a deep split of Squamata into two subclades, Iguania (= Chamaeoleonidae + Agamidae + Iguanidae) and Scleroglossa, and so these can be selected as opposite poles of the clade. However, molecular phylogenies disagree, and they distinguish either Dibamidae (Hedges and Vidal, 2009), or Dibamidae + Gekkota (Wiens et al., 2012) as basal to all other lizard and snake clades. If the molecular trees are correct, then different pointers are required, or the definition can be apomorphy-based.

A second issue is that Squamata was formerly loosely divided into two sub groups, snakes (Serpentes) and lizards (Sauria), but only Serpentes is a clade (and even that is disputed by Wiens et al., 2012) that evolved from lizard ancestors, and so 'Sauria' is paraphyletic. Therefore, in determining the date of origin of Squamata, the age of the oldest fossil snake (currently an unnamed form from the Early Cretaceous [Rage and Richter, 1995]; Barremian, 130.8 Ma $\pm 0.5 \mathrm{Myr}-126.3 \mathrm{Ma} \pm 0.4$ Myr; Gradstein et al., 2012, p. 838) is irrelevant.

In determining the oldest fossil squamate, we do not then follow the usual practice of pursuing a pair of lineages back to the node in question, but simply seek to identify the oldest fossil taxon with squamate synapomorphies. Evans (2003) reviews the fossil record in detail, and summarizes why numerous Triassic taxa formerly called 'lizards' of one sort or another are not: these all fall in other non-squamate and even non-lepidosaur clades, such as archosauromorphs, basal lepidosauromorphs, or even basal diapsids, and were often called 'lizards' only because they were small and diapsid.

Subsequent to Evans' (2003) review, a supposed Triassic lizard, Tikiguania, was reported from the Late Triassic Tiki Formation of India by Datta and Ray (2006), but this has been rejected by Hutchinson et al. (2012) as almost certainly based on the mandible of a modern agamid that was mixed into surface sediments. This means that the oldest crown squamates are Jurassic, and several assemblages from the Early-Middle Jurassic of India, Britain, and Central Asia currently vie for the oldest spot, and of these those from the Kota Formation are potentially the oldest.

\section{CROWN NEORNITHES (= AVES SENSU STRICTO; MODERN BIRDS) (53)}

Node Calibrated. Divergence of Palaeognathae and Neognathae. This node has been traditionally termed Neornithes, whereas Gauthier and de Queiroz (2001, p. 29) proposed to move the term 'Aves' up from the node indicating the most recent common ancestor of Archaeopteryx and birds to refer to crown-clade birds only. Their definition of this node is 'the crown clade stemming from the most 
recent common ancestor of Ratitae (Struthio camelus Linnaeus, 1758), Tinamidae (Tinamus major (Gmelin, 1789)), and Neognathae (Vultur gryphus Linnaeus, 1758).

Fossil Taxon and Specimen. Vegavis iaai (holotype, Museo de la Plata, MLP 93-I-3-1), a partial skeleton from lithostratigraphic unit K3 of Vega Island, Antarctica.

Phylogenetic Justification. Vegavis iaai is identified as a galloanserine, a neognath, and a neornithine on the basis of phylogenetic analysis (Clarke et al., 2005). It shows twenty synapomorphies that place it successively within Ornithurae (e.g., at least 10 sacral vertebrae, domed humeral head, patellar groove present), Neornithes (e.g., at least 15 sacral vertebrae, anteriorly deflected humeral deltopectoral crest), Neognathae, Anseriformes (diminutive pectineal process on pelvis, hypotarsus with well developed cristae and sulci), and Anatoidea (e.g., lack of sternal pneumatic foramen, apneumatic coracoid).

Minimum Age. 66.0 Ma

Soft Maximum Age. 86.8 Ma

Age Justification. Lithostratigraphic unit K3 of Vega Island, Antarctica, dated as mid- to late Maastrichtian, 68-66 Ma (Clarke et al., 2005). This quoted age range is based on biostratigraphic and field evidence for age (Pirrie et al., 1997), and a radiometric date of $71.0 \mathrm{Ma}$ from an underlying rock unit.

The soft maximum constraint is based on older bird-bearing deposits that match some at least of the facies represented in the late Maastrichtian, which are broadly from the shallow marine to coastal belt, namely the Niobrara Chalk Formation of Kansas and neighboring states, dated as Santonian (86.3-83.6 Ma $\pm 0.5 \mathrm{Myr}$ ), and so 86.8 Ma.

\section{CROWN NEOGNATHAE (MODERN FLIGHTED BIRDS) (54)}

Node Calibrated. Divergence between Neoaves and Galloanserae. Neognathae is a crown clade arising from the last common ancestor of Charadrius pluvialis (Pluvialis apricaria) Linnaeus, 1758 (plover) and all extant birds sharing a more recent common ancestor with that species than with Struthio camelus Linnaeus, 1758 (ostrich) and Tinamus major (Gmelin, 1789) (tinamou) (Gauthier and de Queiroz, 2001).

Fossil Taxon and Specimen. Vegavis iaai (holotype, Museo de la Plata, MLP 93-I-3-1), a partial skeleton from lithostratigraphic unit K3 of Vega Island, Antarctica.
Phylogenetic Justification. Vegavis iaai is identified as a galloanserine on the basis of morphological apomorphies (Clarke et al., 2005).

Minimum Age. 66.0 Ma

Soft Maximum Age. 86.8 Ma

Age Justification. Lithostratigraphic unit K3 of Vega Island, Antarctica, dated as mid- to late Maastrichtian, 68-66 Ma (Clarke et al., 2005). This quoted age range is based on biostratigraphic and field evidence for age (Pirrie et al., 1997), and a radiometric date of $71.0 \mathrm{Ma}$ from an underlying rock unit.

The soft maximum constraint is based on older bird-bearing deposits that match some at least of the facies represented in the late Maastrichtian, which are broadly from the shallow marine to coastal belt, namely the Niobrara Chalk Formation of Kansas and neighboring states, dated as Santonian (86.3-83.6 Ma $\pm 0.5 \mathrm{Myr}$ ), and so 86.8 Ma.

Discussion. The oldest galliform fossils that can be identified with confidence are much younger than Vegavis, being early Eocene (Eastman, 1900; Mayr and Weidig, 2004). The oldest neoavians are at present much younger (see Node 55).

\section{CROWN NEOAVES (MODERN FLIGHTED, EXCEPT THE DUCK-CHICKEN CLADE) (55)}

Node Calibrated. Neoaves is a crown clade that, according to Gauthier and de Queiroz (2001, p. 32 ), 'refers to the crown clade stemming from the last common ancestor of Passer domesticus Linnaeus, 1758 and all extant neognaths sharing a more recent common ancestor with that species than with Galloanserae (Gallus gallus Linnaeus, 1758 and Anser anser Linnaeus, 1758).

Fossil Taxon and Specimen. Waimanu manneringi Jones, Ando, and Fordyce, 2006, a partial skeleton (holotype, CM zfa35, Canterbury Museum, Christchurch, New Zealand).

Phylogenetic Justification. Waimanu is unequivocally a penguin, the oldest member of Spehnisciformes, and probably the oldest unequivocal neoavian at present, based on numerous phylogenetic analyses (e.g., Slack et al., 2006; Ksepka et al., 2006, 2012). Two species were named (Slack et al., 2006), both from the middle to upper Waipara Greensand, and the first of the two is selected as calibration fossil.

Minimum Age. $60.2 \mathrm{Ma}$

Soft Maximum Age. $86.8 \mathrm{Ma}$

Age Justification. The Waipara Greensand is dated as Paleocene: Slack et al. (2006, supplementary information) noted that the type locality of 
W. manneringi contained two age-diagnostic calcareous nannofossil taxa, Chiasmolithus solitus (= bidens) and Hornibrookina teuriensis, which suggest a lower Teurian age for $W$. manneringi of about 60.5-61.6 mya. In a revision of the dinoflagellate zonation of the Waipara Greensand, Crouch et al. (2014) mark the last occurrence of Chiasmatolithus solitus as in Chron C26r and upper NP4. In Gradstein et al. (2012), NP4 ends at $60.2 \mathrm{Ma}$, younger than the possible age range for the lower Teurian, so this is taken as a conservative hard minimum bound for Neoaves.

The soft maximum constraint is based on older bird-bearing deposits that match some at least of the facies represented in the late Maastrichtian, which are broadly from the shallow marine to coastal belt, namely the Niobrara Chalk Formation of Kansas and neighboring states, dated as Santonian (86.3-83.6 Ma $\pm 0.5 \mathrm{Myr}$ ), and so 86.8 Ma.

Discussion. This age estimate is almost certainly much younger than the actual age of Neoaves, but it is based on the oldest secure fossil and is intended as a hard minimum. Previously, we identified a hard minimum date of $66 \mathrm{Ma}$ for Neognathae and Neoaves (Benton and Donoghue 2007; Benton et al., 2009), based on the latest Cretaceous birds Polarornis and Neogeornis. However, earlier assertions of unequivocal taxonomic assignment of these specimens to modern bird orders (e.g., Chatterjee 2002) have been queried. For example, Polarornis gregorii from the Maastrichtian Lopez de Bertodano Formation of Seymour Island, Antarctica was described as a loon (gaviiform) by Chatterjee (2002). However, Dyke and Van Tuinen (2004) and Van Tuinen and Hedges (2004) indicated doubt about the taxonomic assignment of the specimen and about its geological provenance, while Mayr (2009) noted that much of the description of the skull is imaginary. An alternative fossil might have been Neogaeornis wetzeli, based on a right tarsometatarsus from the Quiriquina Formation of Chile (Olson, 1992; Hope, 2002), and described as a loon-like bird. Neogaeornis might be synonymous with Polarornis (Mayr, 2004, 2009), but it could equally come from a non-neoavian diving bird such as a hesperornithiform. Probably Neogeornis will never be more precisely classified on cladistic criteria, but re-study of Polarornis might determine that this is indeed an unequivocal neoavian.

Numerous putative neoavians had also been reported from the lower Hornerstown Formation of New Jersey, basal Paleocene in age (Gallagher et al., 2012; Landman et al., 2012). Tytthostonyx glauconiticus, known from a humerus, was identified as a procellariiform (Olson and Parris, 1987; Mayr, 2014), but this is uncertain (Mayr, 2009, pp. 76-77). Novacaesareala hungerfordi Parris and Hope, 2002 is based on a partial humerus and associated wing fragments that were identified as possibly 'pelecaniform', and a possible lithornithid was also identified (Parris and Hope, 2002). Equally uncertain are the 'graculavids', likely a mixed assemblage of supposed 'transitional shorebirds' (Olson and Parris, 1987) that includes Graculavus velox Marsh, 1872 and Anatalavis rex (Shufeld, 1915), possible stem neognaths or early galloanserines (Mayr, 2014).

\section{CROWN PALAEOGNATHAE (RATITES; FLIGHTLESS BIRDS) (56)}

Node Calibrated. Palaeognathae include the flightless ratites, such as the emu, cassowary, and ostrich, as well as the ground-dwelling flying tinamous. According to Gauthier and de Queiroz (2001, p. 29), 'Palaeognathae refers to the crown clade stemming from the most recent common ancestor of Tinamidae, Tinamus major (Gmelin, 1789) and Ratitae (Struthio camelus Linnaeus, 1758).'

Fossil Taxon and Specimen. Lithornis celetius Houde, 1988 (holotype, United States National Museum of Natural History, USNM 290554).

Phylogenetic Justification. Lithornis celetius is a member of clade Lithornithidae, which is in turn a member of the Palaeognathae, on the basis of numerous morphological apomorphies (Houde and Olson, 1981; Houde, 1988; Mayr, 2005; Leonard et al., 2005).

Minimum Age. $56.8 \mathrm{Ma}$

Soft Maximum Age. $86.8 \mathrm{Ma}$

Age Justification. Lithornis celetius comes from the Fort Union Formation (early Tiffanian) of Montana and Wyoming, USA (Houde, 1988). The Tiffanian is equivalent to the middle to late Paleocene, and dated as 60.2-56.8 Ma (Secord, 2008).

The soft maximum constraint is the same as for Neognathae (node 54), equivalent to the age of the Niobrara Chalk Formation, dated as Santonian (86.3-83.6 Ma $\pm 0.5 \mathrm{Myr}$ ), and so $86.8 \mathrm{Ma}$. Various flightless birds have been noted from the Maastrichtian, but none is convincingly palaeognath.

Discussion. The commonly held view (Dyke and Van Tuinen, 2004; Leonard et al., 2005; Lindow and Dyke, 2006; Mayr, 2005, 2009) is that Lithornithidae are the oldest palaeognaths. Lithornithids are an extinct clade of chicken-sized birds from the 
Paleocene and Eocene of North America and Europe. They appear to be more derived than the tinamous, hence members of the crown group and so useful for dating the base of crown Palaeognathae. This phylogenetic position has been disputed, however, with Livezey and Zusi (2007) placing Lithornithidae outside the avian crown clade, and with a real possibility they are stem Ratitae. Here, we follow the general view, with qualifications.

A putative latest Cretaceous lithornithid was reported by Parris and Hope (2002) from the New Jersey greensands. The age of these deposits has been much debated (Dyke and Van Tuinen, 2004), whether they fall either below or above the K-T boundary $(66.0 \mathrm{Ma} \pm 0.1 \mathrm{Myr})$ although current evidence (Gallagher et al., 2012; Landman et al., 2012 ) is that they began in earliest Paleocene. However, the specimen requires confirmation as unequivocally a lithornithid, or at least a crown palaeognath, and it must be regarded as too uncertain to fix a minimum date for Palaeognathae.

The oldest ratite is Diogenornis fragilis Alvarenga, 1983, from the Itaboraí beds (Itaboraian SALMA, 52-54 Ma) of Brazil. The oldest members of various modern ratite families mainly range from mid-Miocene to Pleistocene or even Holocene (Unwin, 1993). The oldest tinamou is Eudromia sp. From the Epecuén Formation, Salinas Grandes de Hidalgo, La Pampa Province, Argentina (mid-Miocene) (Unwin, 1993). Several extinct clades might be assignable to Palaeognathae, such as Remiornithidae from the Thanetian (late Paleocene) of France, Eleutherornis from the middle Eocene of Switzerland, and Palaeotididae and Eleutherornithidae from the middle Eocene of Germany (Unwin, 1993; Mary, 2005; Lindow and Dyke, 2006). However, these taxa have not all been resolved phylogenetically with respect to extant taxa, and they could variously be crown palaeognaths, stem-palaeognaths, or some other neornithine.

There are several large flightless birds from the Late Cretaceous, such as Gargantuavis philoinos from the base of the Marnes de la Maurines Formation, in association with dinosaurs of late Campanian to early Maastrichtian aspect (Buffetaut and Le Loeuff, 1998). However, none of these is a palaeognath or even a neornithine: Buffetaut and Le Loueff (1998) argued that Gargantuavis was not a palaeognath, and suggested it might be related to the non-neornithine Patagopteryx.

\section{CROWN MAMMALIA (57)}

Node Calibrated. Divergence of monotremes, marsupials, and placentals (Figure 10).

Fossil Taxon and Specimen. Bathonian australosphenidans such as Ambondro mahabo (UA10602 University of Antananarivo, Madagascar; Flynn et al., 1999).

Phylogenetic Justification. Ambondro mahabo from Madagascar (Flynn et al., 1999) is placed within the monotreme clade Australosphenida, according to the most widely accepted cladistic analysis of crown Mammalia (Luo et al., 2002; Meng et al., 2011).

Minimum Age. 164.9 Ma

Soft Maximum Age. 201.5 Ma

Age Justification. At present it cannot be said which of the Bathonian eutriconodonts and dryolestoids (Boneham and Wyatt, 1993) and australosphenidans (Flynn et al., 1999) is oldest, but we select Ambondro as most likely. It comes from the upper part of the Isalo "Group" (middle Jurassic, Bathonian) of Madagascar (Flynn et al., 1999), dated as generally Bathonian, so we select the top of the Bathonian as the hard minimum calibration date, 166.1 Ma $\pm 1.2 \mathrm{Myr}=164.9 \mathrm{Ma}$ (Gradstein, 2012).

The closest relatives of crown mammals are Hadrocodium and Docodonta (Luo et al., 2002; Meng et al., 2011). Hadrocodium was originally reported to be early Jurassic of Yunnan Province, China (Sinemurian; Luo et al., 2001), and the oldest docodonts are from the Bathonian of Europe, with a possible earlier form from the Kota Formation of India. Further outgroups, Morganucodontidae, Sinoconodon, and Adelobasileus, are known from the late Triassic and early Jurassic. Deposits of Late Triassic and Early Jurassic age have yielded fossil mammaliaforms, but nothing assignable to the Australosphenida or Theriimorpha. We therefore suggest the Triassic-Jurassic boundary at $201.3 \mathrm{Ma} \pm 0.2 \mathrm{Myr}=201.5 \mathrm{Ma}$ as a soft maximum constraint.

Discussion. Following Luo et al. (2002, 2011), Australosphenida comprises the stem lineage encompassing Monotremata. Its oldest representatives include Ambondro from Madagascar, as well as Amphilestes and Amphitherium from the UK (Boneham and Wyatt, 1993), and Asfaltomylos from the late Middle Jurassic (Callovian) Cañadon Asfalto Formation of Cerro Condor, Argentina (Rauhut et al., 2002).

The base of the crown clade of modern mammals, marking the split between monotremes and therians, depends on how the increasingly diverse, 
extinct Mesozoic mammal groups are included in the clade. As noted earlier, the oldest eutherian, Juramaia, takes the age of Theria back to the Late Jurassic. According to a widely accepted cladogram of Mesozoic mammals (Luo et al., 2002; Meng et al., 2011; but see Woodburne et al., 2003 and Rougier et al., 2012), therians are part of a larger clade that also includes Eutriconodonta, Multituberculata, Spalacotheroidea, and Dryolestoidea. Most of these originated in the late Jurassic, but some lineages appear to have originated in the middle Jurassic. The oldest occurrences of the monotreme stem clade (Australosphenida) include somewhat older Jurassic forms dating to the Bathonian, including Ambondro from Madagascar (Flynn et al., 1999) and Amphilestes and Amphitherium from the UK (Boneham and Wyatt, 1993).

Amphilestes from the Stonesfield Slate is likely a eutriconodont and is referred to the Procerites progracilis Zone of the lower part of the middle Bathonian stage on the basis of ammonites (Boneham and Wyatt, 1993). Tooth-based mammal taxa from the early Jurassic of India (Kotatherium, Nakundon) and North America (Amphidon) that might be spalacotheroids (Kielan Jaworowska et al., 2004) are not convincingly members of the clade (Averianov, 2002) and are ignored here. The oldest dryolestoid appears to be Amphitherium, also from the Stonesfield Slate. The oldest monotremes are Steropodon and Kollikodon from the Griman Creek Formation, Lightning Ridge, South Australia, and dated as middle to late Albian, 109$100 \mathrm{Ma}$. Teinolophos is from the Wonthaggi Formation, Flat Rocks, Victoria, and is dated as early Aptian, 125-121 Ma.

Recently, Zheng et al. (2013) and Bi et al. (2014) have argued that haramiyids are closely related to multituberculates, and that both are in turn related to monotremes and thus part of crown Mammalia. As haramiyids are known from the Triassic (Jenkins et al. 1997), this hypothesis has major implications for the age of the monotremetherian divergence. Previous analyses of haramiyid fossils (e.g., Jenkins et al. 1997) indicated that they were not closely related to multituberculates or crown mammals, but the most recent phylogenetic studies now question this hypothesis (Yuan et al. 2013; Zheng et al. 2013; Bi et al. 2014). If these recent phylogenetic studies are accurate, the first divergence of crown Mammalia would be constrained by the occurrence of Haramiyavia (Haramiyidae, Jenkins et al. 1997) in the Orsted Dal Member of the Fleming Fjord Formation, slightly over $200 \mathrm{Ma}$ ago in ?Norian-Rhaetic stages of the late Triassic. We retain a conservative position here.

\section{CROWN MARSUPIALIA (58)}

Node Calibrated. The opossum-kangaroo split is equivalent to the divergence of the two main crown marsupial clades: Ameridelphia and Australidelphia.

Fossil Taxon and Specimen. Djarthia murgonensis (Queensland Museum, QM F52748; Beck 2012), from the early Eocene of Murgon, Australia.

Phylogenetic Justification. Djarthia possesses a continuous lower ankle joint, a synapomorphy shared with the marsupial clade Australidelphia (Beck, 2012). The status of Djarthia as a crown marsupial is stronger than that for Khasia (Beck et al., 2008; Beck, 2012), and thus it serves as a more definitive record of the latest point by which crown marsupials evolved.

Minimum Age. 47.6 Ma

Soft Maximum Age. 131.3 Ma

Age Justification. The early Eocene locality of Murgon, source of Djarthia, correlate with the Ypresian marine stage (Beck, 2012), the top of which is $47.8 \mathrm{Ma} \pm 0.2 \mathrm{Myr}=47.6 \mathrm{Ma}$ (Gradstein et al., 2012), which we use as the paleontological minimum constraint for Marsupialia.

Numerous metatherian remains are known from the Cretaceous of both North America (Kokopellia; Cifelli, 1993, 1998) and Mongolia (Asiatherium; Szalay and Trofimov, 1996), with the Early Cretaceous Sinodelphys szalayi being the oldest undisputed metatherian (Luo et al., 2003). Hence, we place the soft maximum constraint for Marsupialia at the Liaoning beds that produced Sinodelphys, correlating to the Barremian (Zhou et al., 2003) with a lower bound of $130.8 \mathrm{Ma} \pm 0.5 \mathrm{Myr}=$ 131.3 Ma.

Discussion. There are other metatherians from the Cretaceous, such as Kokopellia and Sinodelphys, but these fall phylogenetically outside the marsupial crown radiation (e.g., Luo et al., 2002). Indeed, non-marsupial metatherians persist well into the Tertiary and, despite close dental similarities with crown didelphids (e.g., Herpetotherium), they fall outside Marsupialia when examined in a cladistic context (Goin et al., 2006; Sánchez et al., 2007; Horovitz et al., 2009; but see Beck, 2012). Hence, the oldest potential marsupials are from the Tiupampa fauna of Bolivia (Muizon and Cifelli, 2001), close to $63 \mathrm{Ma}$. Specifically, the Tiupampan genus Khasia has been reconstructed as having a possible relationship to microbiotheres (Goin et al., 
2006), a radiation for which the only extant genus is Dromiciops. Importantly, microbiotheres have been phylogenetically linked with Australidelphia based on both morphological and molecular data (e.g., Szalay, 1982; Horovitz et al., 2009; Meredith et al., 2011; Beck, 2012). Other elements of the Tiupampa fauna, including the skeletally well known Pucadelphys and Mayulestes, are not demonstrably part of crown Marsupialia (Horovitz et al., 2009; Beck, 2012). The early Paleocene taxon Cocatherium from Chubut province, Argentina is also likely outside crown Marsupialia (Goin et al., 2006).

\section{CROWN THERIA (59)}

Node Calibrated. Divergence of marsupial and placental mammals.

Fossil Taxon and Specimen. Juramaia sinensis (Beijing Museum of Natural History PM1143) from the Daxigou site of the Tiaojishan Formation, Liaoning Province, Northeastern China, with an age corresponding to the Oxfordian stage of the Late Jurassic (Luo et al., 2011).

Phylogenetic Justification. The human-opossum branching point is synonymous with the split of marsupials and placentals, encompassing the clade Theria and containing (respectively) the metatherian and eutherian stem members of each group. Juramaia is known from a skull and front half of the skeleton that show it is therian (Luo et al., 2011). The molars are tribosphenic, so the fossil is assigned to Boreosphenida, and it shows diagnostic characters of Eutheria in the distinctive paraconule, incipient metaconule (M2 only), long preprotocrista past the paracone, and long postprotocrista past the metacone. The forelimb shows evidence for climbing in the grasping hand, a feature shared in common with other early therians.

Minimum Age. 156.3 Ma

Soft Maximum Age. 169.6 Ma

Age Justification. The Daxigou site of the Tiaojishan Formation, Liaoning Province, Northeastern China, source of Juramaia, has been constrained by radiometric dates to derive from deposits of just over $160 \mathrm{Ma}$ in age, equivalent to the Oxfordian stage of the Late Jurassic (Luo et al., 2011). This stage has a minimum bound of $157.3 \mathrm{Ma} \pm 1.0 \mathrm{Myr}$, or $156.3 \mathrm{Ma}$ (Gradstein et al., 2012), the minimum age constraint for the eutherian-metatherian split.

An alternative view (Woodburne et al., 2003) places southern tribosphenic taxa (see above) on the stem to Theria, pushing the minimum age for crown Theria deeper into the Jurassic, in order to include such taxa as Ambondro (Flynn et al.,
1999). Given the possibility that southern, tribosphenic mammals such as Ambondro are therian (even eutherian), we would set the soft maximum age constraint for Theria within the Jurassic (Bathonian) at 168.3 Ma $\pm 1.3 \mathrm{Myr}$, so $169.6 \mathrm{Ma}$.

Discussion. The earliest alleged "marsupial" dental fossils come from the mid Cretaceous of North America, including Kokopellia juddi reported (Cifelli, 1993) from the Mussentuchit Member, in the upper part of the Cedar Mountain Formation, Utah, which is dated as middle to late Albian on the basis of bivalves and palynomorphs. A date of 98.37 Ma $\pm 0.07 \mathrm{Myr}$ was obtained from radiometric dating of zircons in a bentonitic clay layer. However, Kokopellia has not been demonstrably placed within crown Marsupialia by any phylogenetic analysis, and indeed lies outside the marsupial crown (but still on its stem) in the few cases in which it has been tested (e.g., Luo et al., 2002). Even older is the boreosphenidan Sinodelphys szalayi from the Yixian Formation, Liaoning Province, China, which is placed phylogenetically closer to marsupials than to placentals by Luo et al. (2003). This then has taken the stem of the marsupial clade back to the Barremian with an age of at least 124 Ma.

The oldest eutherians (on the stem to Placentalia) were also, until recently, restricted to the mid and Late Cretaceous, but subsequent finds have pushed the age back step-by-step deeper into the Late Jurassic. First were Prokennalestes trofimovi and $P$. minor, from the Höövör beds of Mongolia (Kielan-Jaworowska and Dashzeveg, 1989), dated as either Aptian or Albian. Then came Montanalestes keeblerorum (Cifelli 1999) from the Cloverly Formation (late Aptian-early Albian, about $100 \mathrm{Ma}$ ). Then, Murtoilestes abramovi was named (Averianov and Skutschas, 2001) from the Murtoi Svita, Buryatia, Transbaikalia, Russia, and dated as late Barremian to middle Aptian (about 128-120 Ma). These three taxa were based on isolated jaws and teeth. A more complete fossil, Eomaia scansoria from the Yixian Formation of Liaoning Province, China comprised a flattened but complete skeleton with some evidence of soft tissues. Ji et al. (2002) argued it was a eutherian, whereas O'Leary et al. (2013) placed it as the sister taxon of Theria.

Dating of the Jehol Group of China has been contentious, with early suggestions of a late Jurassic age for some or all of the fossiliferous beds. Biostratigraphic evidence now confirms an Early Cretaceous (Barremian) age, with several radiometric dates, using different techniques, on three tuff layers that occur among the fossil beds of 
124.6 Ma $\pm 0.01 \mathrm{Myr}, 125.06 \mathrm{Ma} \pm 0.18 \mathrm{Myr}$, and $125.2 \mathrm{Ma} \pm 0.9 \mathrm{Myr}$ (Zhou et al., 2003).

\section{CROWN PLACENTALIA (60)}

Node Calibrated. The human-tenrec split is equivalent to the origin of the clade comprising Boreoeutheria (Laurasiatheria and Euarchontoglires) and Atlantogenata (Xenarthra and Afrotheria).

Fossil Taxon and Specimen. The carnivoran Ravenictis krausei (UALVP 31175) from the Ravenscrag Formation, Saskatchewan (Fox and Youzwyshyn, 1994; Fox et al., 2010).

Phylogenetic Justification. Ravenictis is identified as a carnivoran based on synapomorphies of M1 shared with viverravids including the asymmetry of the crown, the proportions of the cusps, virtually identical wear patterns, and the development of the protocone cingula (Fox and Youzwyshyn, 1994; Fox et al., 2010).

Minimum Age. $61.6 \mathrm{Ma}$

Soft Maximum Age. 164.6 Ma

Age Justification. The Ravenscrag Formation is early Puercan in age, corresponding to the earliest part of the Danian (Gradstein et al., 2012, p. 400). To be conservative, we treat this as broadly early Paleocene (Danian) in age, with the top corresponding to an age of $61.7 \mathrm{Ma} \pm 0.1 \mathrm{Myr}$, hence 61.6 Ma.

The soft maximum date is based on the divergence of Eutheria from other mammals in the late Jurassic, represented by Juramaia (Luo et al., 2011). This taxon is represented in the Daxigou site of the Tiaojishan Formation, Liaoning Province, Northeastern China, and has been constrained by radiometric dates to derive from deposits of just over $160 \mathrm{Ma}$ in age (Luo et al., 2011). The equivalent marine stage is the Oxfordian (Gradstein et al., 2012), with a lower boundary of $163.5 \mathrm{Ma} \pm 1.1 \mathrm{Myr}$, and thus $164.6 \mathrm{Ma}$ is a soft maximum.

Discussion. The oldest boreoeutherians (see node 66) are early Paleocene carnivorans, glires, and archontans, with the carnivorans at least 61.6 $\mathrm{Ma}$ in age. The oldest reported atlantogenatans derive from somewhat younger Paleocene deposits: Eritherium (Proboscidea) from the late Paleocene of the Ouled Abdoun basin in Morocco (Gheerbrant, 2009).

\section{CROWN ATLANTOGENATA (61)}

Node Calibrated. Divergence of xenarthrans from afrotherians.
Fossil Taxon and Specimen. The extinct proboscidean Eritherium azzouzorum (MNHN PM69, Paris) from the Sidi Chennane quarries, phosphate bed Ila, lower bone-bed, Ouled Abdoun Basin of Morocco, regarded as upper Paleocene (early Thanetian; Gheerbrant, 2009).

Phylogenetic Justification. Eritherium is classed as a proboscidean based on numerous dental and cranial synapomorphies (Gheerbrant, 2009): $I_{1}$ enlarged, larger than $I_{2}, I_{1-2}$ with high (styliform), labio-lingually compressed, asymmetric, and procumbent crown; $\mathrm{I}_{3}$ strongly reduced; $\mathrm{C} 1$ very small; (d) $\mathrm{P}_{1}$ small and simple; molar hypoconulid labial; coronoid retromolar fossa enlarged. As a proboscidean, Eritherium is then a member of wider clades Paenungulata, Afrotheria, and Atlantogenata.

Minimum Age. $56 \mathrm{Ma}$

Soft Maximum Age. 164.6 Ma

Age Justification. The minimum age estimate is based on the occurrence of Eritherium in the Sidi Chennane quarries, phosphate bed Ila, lower bone-bed, Ouled Abdoun Basin of Morocco, regarded as upper Paleocene (early Thanetian; Gheerbrant, 2009), whose upper bound is dated as 56.0 Ma $\pm 0.0 \mathrm{Myr}$ (Gradstein et al., 2012).

The soft maximum date is based on the divergence of Eutheria from other mammals in the late Jurassic, represented by Juramaia (Luo et al., 2011). This taxon is represented in the Daxigou site of the Tiaojishan Formation, Liaoning Province, Northeastern China, and has been constrained by radiometric dates to derive from deposits of just over $160 \mathrm{Ma}$ in age (Luo et al., 2011). The equivalent marine stage is the Oxfordian (Gradstein et al., 2012), with a lower boundary of $163.5 \mathrm{Ma} \pm 1.1 \mathrm{Myr}$, and thus $164.6 \mathrm{Ma}$ is a soft maximum.

Discussion. The oldest xenarthrans (armadillos, anteaters, sloths) are represented by the cingulate species Riostegatherium from Itaborai, Brazil (Scillato-Yané 1976). Until recently, this locality was regarded as upper Paleocene in age, but may be slightly younger. Woodburne et al. (2014) suggest that the Itaboraian SALMA may in fact be early Eocene. This leaves the upper Paleocene record of the proboscidean Eritherium from Morocco (Gheerbrant, 2009) as the oldest record of Atlantogenata. The oldest records of pilosans (i.e., sloths and anteaters) are substantially younger based on fragmentary material from the Eocene of Antarctica (Rose et al., 2005). Importantly, Eurotamandua from the middle-Eocene of Messel (Germany) was once regarded as a geologically ancient anteater (Storch, 1981); however, recent studies do not sup- 
port this interpretation, and suggest instead that it is related to pangolins and/or extinct palaeanodonts (Rose 1999; Rose et al., 2005).

\section{CROWN XENARTHRA (62)}

Node Calibrated. Divergence of cingulates (armadillos) from Pilosa (i.e., sloths and anteaters).

Fossil Taxon and Specimen. Riostegotherium yanei from Itaboraí, Brasil (Scillato-Yané 1976). The holotype of this species is an osteoderm in the collections of the Museu de Ciências Naturais, Fundação Zoobotânica do Rio Grande do Sul, Porto Alegre: MCN-PV 1774 (Bergqvist et al., 2004: figure 1).

Phylogenetic Justification. Riostegotherium belongs to crown Xenarthra based on the diagnostically cingulate osteoderms (e.g., the type mentioned above). Other skeletal elements (e.g., astragali) with a close resemblance to cingulates are also known from Itaboraí (Bergqvist et al., 2004).

Minimum Age. $47.6 \mathrm{Ma}$

Soft Maximum Age. 164.6 Ma

Age Justification. Until recently, Itaboraí was regarded as upper Paleocene in age, but Woodburne et al. (2014) suggest that it is early Eocene, which would lead to a paleontological minimum estimate for crown Xenarthra corresponding to the the top of the Ypresian marine stage, 47.8 Ma \pm 0.2 Myr $=47.6 \mathrm{Ma}$ (Gradstein et al., 2012).

The soft maximum date is based on the divergence of Eutheria from other mammals in the late Jurassic, represented by Juramaia (Luo et al., 2011). This taxon is represented in the Daxigou site of the Tiaojishan Formation, Liaoning Province, Northeastern China, and has been constrained by radiometric dates to derive from deposits of just over $160 \mathrm{Ma}$ in age (Luo et al., 2011). The equivalent marine stage is the Oxfordian (Gradstein et al., 2012), with a lower boundary of $163.5 \mathrm{Ma} \pm 1.1 \mathrm{Myr}$, and thus $164.6 \mathrm{Ma}$ is a soft maximum.

\section{CROWN AFROTHERIA (63)}

Node Calibrated. Last common ancestor of living afrotheres.

Fossil Taxon and Specimen. The extinct proboscidean Eritherium azzouzorum (MNHN PM69, Paris) from the Sidi Chennane quarries, phosphate bed Ila, lower bone-bed, Ouled Abdoun Basin of Morocco, regarded as upper Paleocene (early Thanetian; Gheerbrant, 2009).
Phylogenetic Justification. Eritherium is classed as a proboscidean based on numerous dental and cranial synapomorphies (Gheerbrant, 2009): $I_{1}$ enlarged, larger than $I_{2}, I_{1-2}$ with high (styliform), labio-lingually compressed, asymmetric, and procumbent crown; $\mathrm{I}_{3}$ strongly reduced; $\mathrm{C} 1$ very small; (d) $\mathrm{P}_{1}$ small and simple; molar hypoconulid labial; coronoid retromolar fossa enlarged. As a proboscidean, Eritherium is then a member of wider clades Paenungulata, Afrotheria, and Atlantogeneta.

Minimum Age. $56 \mathrm{Ma}$

Soft Maximum Age. 164.6 Ma

Age Justification. The minimum age estimate is based on the occurrence of Eritherium in the Sidi Chennane quarries, phosphate bed Ila, lower bone-bed, Ouled Abdoun Basin of Morocco, regarded as upper Paleocene (early Thanetian; Gheerbrant, 2009), whose upper bound is dated as $56.0 \mathrm{Ma} \pm 0.0 \mathrm{Myr}$ (Gradstein et al., 2012).

The soft maximum date is based on the divergence of Eutheria from other mammals in the late Jurassic, represented by Juramaia (Luo et al., 2011). This taxon is represented in the Daxigou site of the Tiaojishan Formation, Liaoning Province, Northeastern China, and has been constrained by radiometric dates to derive from deposits of just over $160 \mathrm{Ma}$ in age (Luo et al., 2011). The equivalent marine stage is the Oxfordian (Gradstein et al., 2012), with a lower boundary of $163.5 \mathrm{Ma} \pm 1.1 \mathrm{Myr}$, and thus $164.6 \mathrm{Ma}$ is a soft maximum.

Discussion. According to current phylogenies, tenrecs (Tenrecidae), golden moles (Chrysochloridae), elephant shrews (Macroscelidea), and aardvarks (Tubulidentata) form the Afroinsectiphilia, and the elephants (Proboscidea), hyraxes (Hyracoidea), and sea cows (Sirenia) form the Paenungulata. As a clade, Paenungulata dates to Simpson (1945) and has a long precedent in mammalian systematics. The association of other groups with paenungulates has sporadically appeared in the literature (e.g., Sonntag and LeGros Clark, 1925; DeJong et al., 1981), and is now strongly supported by genomic (Murphy et al., 2001; Meredith et al., 2011) and some comparative anatomical evidence (Sánchez et al., 2007; Asher and Lehmann, 2008). Hence, the last common ancestor of tenrec and elephant corresponds to the base of crownclade Afrotheria.

The oldest unambiguous fossil aardvarks, tenrecs, and golden moles are Miocene (Lehmann, 2009; Asher and Seiffert, 2010; Asher and Avery, 2010). Macroscelidids are older, extending well into the Eocene (Zack et al., 2005; Tabuce et al., 2007). 
Seiffert and Simons (2001) and Seiffert (2007) suggested that Jawharia, Eochrysochloris, and Widanelfarasia from the Eocene/Oligocene boundary in Egypt might be related to the tenrec-golden mole common ancestor. All of these records are equaled or predated by the oldest paenungulates, in particular proboscideans. The oldest hyraxes are known from the early Eocene of North Africa (e.g., Seggeurius from El Kohol, Algeria). The oldest sirenians are slightly younger; Prorastomus and Pezosiren are known from the early middle Eocene of Jamaica (Domning, 2001). As of this writing, the oldest afrotherian fossil is that of a proboscidean: Eritherium azzouzorum from the late Paleocene of Morocco (Gheerbrant, 2009). At present, no extant clade within Afrotheria, nor any confirmed extinct afrothere clade (with the apheliscine/"condylarth" possibility deserving further scrutiny; Robinson and Seiffert, 2004; Zack et al., 2005; Tabuce et al., 2006, 2008) predates the late Paleocene.

\section{CROWN PROBOSCIDEA (64)}

Node Calibrated. Divergence of Elephas from Loxodonta.

Fossil Taxon and Specimen. Loxodonta sp. molars from the Lukeino Formation of the Tugen Hills in Kenya (Hill 2002), including KNM-LU 916 (Sanders et al., 2010), and Toros-Menalla of Chad (Brunet et al., 2000).

Phylogenetic Justification. Following Sanders et al. (2010), isolated teeth from the African sites mentioned above exhibit loxodont apomorphies, including propeller or lozenge shaped wear patterns.

Minimum Age. $5.33 \mathrm{Ma}$

Soft Maximum Age. $23.03 \mathrm{Ma}$

Age Justification. The oldest crown proboscideans are represented by cheek teeth from the upper Miocene, including the Lukeino Formation (Kenya) and Toros Menalla (Chad). While Toros Menalla is likely older, both correlate to the Messinian marine stage with a minimum bound of 5.33 Ma (Sanders et al., 2010; Gradstein et al., 2012).

Paleogene strata have yielded abundant proboscidean remains, spanning the upper Paleocene (Gheerbrant, 2009) through the early Miocene (Sanders et al., 2010). Sediments prior to the Miocene lack any fossils remotely similar to members of Elephantinae. Hence, we define the paleontological soft maximum constraint as the Oligocene-Miocene boundary, equivalent to the base of the Aquitanian marine stage at $23.03 \mathrm{Ma}$.

\section{CROWN SIRENIA (65)}

Node Calibrated. Divergence of Dugong from Trichechus.

Fossil Taxon and Specimen. Eotheroides aegypticum cranial endocast BMNH 46722 from the Mokattam Formation of the Mokattam Hills, Egypt (Sickenberg 1934; Domning et al., 2010).

Phylogenetic Justification. Eotherioides is identified by Domning et al. (2010) and Gheerbrant et al. (2005) as more closely related to Dugong than to Trichechus, and the associated specimens of skulls and postcranial remains show apomorphies of Dugongidae, including an upper dental formula of 3.1.5.3, and the deciduous P5 is not replaced (Domning et al., 2010). It is therefore nested within crown Sirenia.

Minimum Age. 47.6 Ma

Soft Maximum Age. $66 \mathrm{Ma}$

Age Justification. Sirenian remains, referrable to "halitheriine" dugonids from the Mokattam Hills in Egypt, have been interpreted as Lutetian, or middle Eocene (Domning et al., 2010; Sickenberg, 1934) with a minimum bound of $47.8-0.2 \mathrm{Ma}$. Paleogene strata have yielded abundant sirenian remains, including stem taxa, for much of the Eocene (Domning et al., 2010). Tethythere (i.e., SireniaProboscidea) remains are known from the Paleocene and early Eocene (Gheerbrant, 2009), but lack crown Sirenia. Hence, we define the paleontological soft maximum constraint as the base of the Paleocene, equivalent to the base of the Danian marine stage at $66.04 \mathrm{Ma} \pm 0.4 \mathrm{Myr}=66 \mathrm{Ma}$.

Discussion. Eosiren is another taxon from the Lutetian of Egypt that is identified by Domning et al. (2010) and Gheerbrant et al. (2005) as more closely related to Dugong than to Trichechus and as such is also a member of crown Sirenia. Both Eotheroides and Eosiren are now known by cranial and postcranial elements, and traditionally placed in the (probably) paraphyletic subfamily Halitheriinae.

\section{CROWN BOREOEUTHERIA (66)}

Node Calibrated. common ancestor of Euarchontoglires and Laurasiatheria.

Fossil Taxon and Specimen. The carnivoran Ravenictis krausei (UALVP 31175) from the Ravenscrag Formation, Saskatchewan (Fox and Youzwyshyn, 1994; Fox et al., 2010).

Phylogenetic Justification. Ravenictis is identified as a carnivoran based on synapomorphies of M1 shared with viverravids including the asymmetry of the crown, the proportions of the cusps, virtu- 
ally identical wear patterns, and the development of the protocone cingula (Fox and Youzwyshyn, 1994; Fox et al., 2010).

Minimum Age. $61.6 \mathrm{Ma}$

Soft Maximum Age. 164.6 Ma

Age Justification. The Ravenscrag Formation is early Puercan in age, corresponding to the earliest part of the Danian (Gradstein et al., 2012, p. 400). To be conservative, we treat this as broadly early Paleocene (Danian) in age, with the top corresponding to an age of $61.7 \mathrm{Ma} \pm 0.1 \mathrm{Myr}$, hence 61.6 Ma.

The soft maximum date is based on the divergence of Eutheria from other mammals in the late Jurassic, represented by Juramaia (Luo et al., 2011). This taxon is represented in the Daxigou site of the Tiaojishan Formation, Liaoning Province, Northeastern China, and has been constrained by radiometric dates to derive from deposits of just over $160 \mathrm{Ma}$ in age (Luo et al., 2011). The equivalent marine stage is the Oxfordian (Gradstein et al., 2012), with a lower boundary of $163.5 \mathrm{Ma} \pm 1.1$ Myr, and thus $164.6 \mathrm{Ma}$ is a soft maximum.

Discussion. Claims for late Cretaceous laurasiatherians, included within Boreoeutheria, include zhelestids (Archibald et al., 2001; Averianov and Archibald, 2005), from the Bissekty Formation of Dzharakuduk, Kyzylkum Desert, Uzbekistan, and the even older Khodzhakul Formation at Sheikhdzhili, which would provide a very ancient minimum age constraint on the clade (early Cenomanian, $95.3 \mathrm{Ma}$ ) if the assignment is correct (Averianov and Archibald, 2005). Crown placental affinities for zhelestids and other Cretaceous eutherians have been disproven by more comprehensive cladistic analyses of basal Eutheria (Asher et al., 2005; Wible et al., 2009; Goswami et al., 2011; O'Leary et al., 2013).

The oldest boreoeutherians include Ravenictis, and other early Paleocene carnivorans, glires, and archontans (Fox et al., 2010).

\section{CROWN LAURASIATHERIA (67)}

Node Calibrated. common ancestor of lipotyphlans, chiropterans, artiodactyls (including Cetacea), perissodactyls, carnivorans, and pholidotes.

Fossil Taxon and Specimen. The carnivoran Ravenictis krausei (UALVP 31175) from the Ravenscrag Formation, Saskatchewan (Fox and Youzwyshyn, 1994; Fox et al., 2010).

Phylogenetic Justification. Ravenictis is identified as a carnivoran based on synapomorphies of M1 shared with viverravids including the asymmetry of the crown, the proportions of the cusps, virtu- ally identical wear patterns, and the development of the protocone cingula (Fox and Youzwyshyn, 1994; Fox et al., 2010).

Minimum Age. $61.6 \mathrm{Ma}$

Soft Maximum Age. 164.6 Ma

Age Justification. The Ravenscrag Formation is early Puercan in age, corresponding to the earliest part of the Danian (Gradstein et al., 2012, p. 400). To be conservative, we treat this as broadly early Paleocene (Danian) in age, with the top corresponding to an age of $61.7 \mathrm{Ma} \pm 0.1 \mathrm{Myr}$, hence 61.6 Ma.

The soft maximum date is based on the divergence of Eutheria from other mammals in the late Jurassic, represented by Juramaia (Luo et al., 2011). This taxon is represented in the Daxigou site of the Tiaojishan Formation, Liaoning Province, Northeastern China, and has been constrained by radiometric dates to derive from deposits of just over $160 \mathrm{Ma}$ in age (Luo et al., 2011). The equivalent marine stage is the Oxfordian (Gradstein et al., 2012), with a lower boundary of $163.5 \mathrm{Ma} \pm 1.1 \mathrm{Myr}$, and thus $164.6 \mathrm{Ma}$ is a soft maximum.

Discussion. Viverravid carnivorans are well represented in the Paleocene, with multiple genera known from the Torrejonian (Gingerich and Winkler, 1985) and some representatives also in the Puercan (Fox et al., 2010). Wesley-Hunt and Flynn (2005) placed viverravids such as Protictis on the stem to Carnivora. Due to their recovery in the Puercan, Carnivora is arguably the oldest definitive crown placental order.

The oldest, definitive records of Laurasiatheria are Paleocene carnivorans including Protictis from the Torrejonian of western North America (e.g., Rock Bench Quarry, Clark's Fork Basin, Wyoming and San Juan Basin, New Mexico; Gingerich and Winkler, 1985) and Ravenictis from Puercan deposits in the Ravenscrag Formation, Saskatchewan [Fox and Youzwyshyn, 1994]).

\section{CROWN LIPOTYPHLA (68)}

Node Calibrated. common ancestor of modern soricids, talpids, erinaceids, and Solenodon.

Fossil Taxon and Specimen. Adunator ladae (USNM 9640; Bown and Schankler 1982: 42) from the Fort Union Formation of the Gidley Quarry, Sweetgrass County, Montana USA.

Phylogenetic Justification. Adunator is a member of Erinaceomorpha, according to phylogenetic analyses by Novacek (1985) and Smith et al. (2002) and is a nested within crown Lipotyphla.

Minimum Age. 61.6 Ma 
Soft Maximum Age. 164.6 Ma

Age Justification. With records from the Torrejonian, the minimum estimate of Adunator can be tied to the top of the Danian at $61.6 \mathrm{Ma} \pm 0.0 \mathrm{Myr}$ (Gradstein et al., 2012, p. 400; Woodburne, 2004).

The soft maximum date is based on the divergence of Eutheria from other mammals in the late Jurassic, represented by Juramaia (Luo et al., 2011). This taxon is represented in the Daxigou site of the Tiaojishan Formation, Liaoning Province, Northeastern China, and has been constrained by radiometric dates to derive from deposits of just over $160 \mathrm{Ma}$ in age (Luo et al., 2011). The equivalent marine stage is the Oxfordian (Gradstein et al., 2012), with a lower boundary of $163.5 \mathrm{Ma} \pm 1.1 \mathrm{Myr}$, and thus $164.6 \mathrm{Ma}$ is a soft maximum.

Discussion. Note that this species has been discussed with varying genus-level affinities, including Mckennatherium, Diacodon, and Leptacodon. We follow Bown and Schankler (1982) in giving priority to Adunator. Following Storch (2008), the European species Adunator lehmani (Wa 368, Geologisch-Paläontologisches Institut, Halle; Russell, 1964) from the Paleocene site of Walbeck, Germany is likely somewhat younger than the Torrejonian age given to Adunator from the US Fort Union Formation.

"Insectivora" has often been regarded as the primitive grade from which other placental mammals evolved (Wyss, 1987). Thus, alleged Late Cretaceous soricomorphs include Otlestes, Paranyctoides, and Batodon (McKenna and Bell, 1997), but a cladistic analysis placing them close to soricid lipotyphlans is still lacking. Micropternodontids such as Carnilestes and Prosarcodon from the early Paleocene of Asia may also be soricid relatives (McKenna and Bell, 1997). A stronger case can be made that Paleocene erinaceomorphs, such as Adunator, comprise the oldest occurrence of an erinaceoid relative (Novacek, 1985). Undisputed records of soricids, talpids, and Solenodon are much younger (Asher, 2005).

\section{CROWN CARNIVORA (69)}

Node Calibrated. Common ancestor of Caniformia (dogs, bears, raccoons, seals) and Feliformia (cats, mongooses, hyaenas), excluding stem carnivoramorphans sensu Wesley Hunt and Flynn (2005).

Fossil Taxon and Specimen. Hesperocyon gregarius (SMNH P1899.6; Bryant, 1992) from the Cypress Hills Formation, Duchesnian NALMA, Lac Pelletier local fauna, Saskatchewan.
Phylogenetic Justification. Phylogenetic analysis shows that Hesperocyon is closely related to Canidae, based on its possession of a fully ossified auditory bulla composed mainly of the caudal entotympanic, with contributions from the ecotympanic and rostral entotympanic, and the caudla entotympanic forms a partial septum within the middle-ear cavity (Wesley-Hunt and Flynn, 2005).

Minimum Age. 37.3 Ma

Soft Maximum Age. $66 \mathrm{Ma}$

Age Justification. The oldest caniforms are amphicyonids such as Daphoenus and canids such as Hesperocyon, known from the earliest Duchesnean NALMA, which corresponds to magnetochron $18 \mathrm{~N}$ and is dated as $39.74 \mathrm{Ma} \pm 0.07$ Myr, based on radiometric dating of the LaPoint Tuff (Robinson et al., 2004). This correlates to the Bartonian stage with a minimum limit of $37.8 \pm 0.5$ Ma (Gradstein et al., 2012), thus providing a minimum constraint of $37.3 \mathrm{Ma}$.

The soft maximum constraint is based on the occurrence of the oldest stem-carnivorans (miacids, viverravids) in the early Paleocene (Fox et al., 2010), so 66.04 Ma $\pm 0.4 \mathrm{Myr}=66 \mathrm{Ma}$.

Discussion. Daphoenus is also known from the Duchesnian (Bryant, 1992); both genera are reconstructed by Wesley Hunt and Flynn (2005) as basal caniformes. The oldest stem carnivorans are viverravids (not to be confused with extant, feliform viverrids) and paraphyletic "miacids", known from the early Paleocene onwards. Both groups have been reconstructed outside crown Carnivora (Wesley-Hunt and Flynn, 2005) and cannot provide a minimum date for the dog-cat split. Tapocyon may be an even older caniform; it comes from the Middle Eocene, Uintan, dated as 46-43 Ma, although Wesley-Hunt and Flynn (2005) place this taxon outside crown Carnivora. The oldest feliforms may be the nimravids, also known first from the White River carnivore fauna of the Chadronian NALMA, with uncertain records extending to the base of that unit (Hunt, 2004).

\section{CROWN ARTIODACTYLA, INCLUDING CETACEA (70)}

Node Calibrated. Common ancestor of ruminants and "Suiformes", including the now well-established hippo-whale clade (Gatesy et al., 2002; Geisler and Theodor, 2009).

Fossil Taxon and Specimen. Himalayacetus subathuensis, Roorkee University Vertebrate Paleontology Laboratory (RUSB) specimen 2003, from early Eocene deposits of the Subathu Formation 
type section in Kuthar Nala, India (Bajpai and Gingerich, 1998).

Phylogenetic Justification. Himalayacetus is known only from a partial dentary and two molars, but it was claimed that these show characterisics of Pakicetidae (Bajpaj and Gingerich, 1998). The phylogenetic placement within Cetacea is controversial, and a conservative phylogenetic analysis (O'Leary and Uhen, 1999) confirmed that Himalayacetus might be more closely related to ambulocetids than to pakicetids. Either way, Himalayacetus is a member of total-group Cetacea, and nested well within crown Artiodactyla, as currently understood.

Minimum Age. 52.4 Ma

Soft Maximum Age. $66 \mathrm{Ma}$

Age Justification. The cow-pig division is dated minimally by the record of Himalayacetus from the base of the Subathu Formation in Pakistan (Bajpai and Gingerich, 1998) where it co-occurs with Nummulites atacicus whose range correlates with nannoplankton zones $11-12$, providing a minimum age of 52.4 Ma (Martín-Martín et al., 2001). The availability of this marine correlation for this fossil enables us to forego use of the corresponding marine stage (Ypresian).

The absence of any crown cetartiodactyls during the Paleocene may point to a soft maximum constraint of $66.04 \mathrm{Ma} \pm 0.4 \mathrm{Myr}=66 \mathrm{Ma}$.

Discussion. Cetaceans comprise closer relatives to ruminant artiodactyls than do either suids or camels (Gatesy et al., 2002; Spaulding et al., 2009; Geisler and Theodor, 2009). While stem artiodactyls (e.g., Diacodexis) date to the Wasatchian NALMA (Rose, 2006), Himalaycetus is only slightly younger, and as such exceeds other crown artiodactyl lineages in age.

\section{WHIPPOMORPHA - RUMINANTIA (71)}

Node Calibrated. Divergence of the common ancestor of ruminants and cetaceans, excluding suids and tylopods.

Fossil Taxon and Specimen. Himalayacetus subathuensis, Roorkee University Vertebrate Paleontology Laboratory (RUSB) specimen 2003, from early Eocene deposits of the Subathu Formation type section in Kuthar Nala, India (Bajpai and Gingerich, 1998).

Phylogenetic Justification. Himalayacetus is known only from a partial dentary and two molars, but it was claimed that these show characterisics of Pakicetidae (Bajpaj and Gingerich, 1998). The phylogenetic placement within Cetacea is controversial, and a conservative phylogenetic analysis
(O'Leary and Uhen, 1999) confirmed that Himalayacetus might be more closely related to ambulocetids than to pakicetids. Either way, Himalayacetus is a member of total-group Cetacea, and nested well within crown Whippomorpha.

Minimum Age. 52.4 Ma

Soft Maximum Age. $66 \mathrm{Ma}$

Age Justification. The cow-pig division is dated minimally by the record of Himalayacetus from the base of the Subathu Formation in Pakistan (Bajpai and Gingerich, 1998) where it co-occurs with Nummulites atacicus whose range correlates with nannoplankton zones 11-12, providing a minimum age of 52.4 Ma (Martín-Martín et al., 2001). The availability of this marine correlation for this fossil enables us to forego use of the corresponding marine stage (Ypresian).

The absence of any crown cetartiodactyls during the Paleocene may point to a soft maximum constraint of $66.04 \mathrm{Ma} \pm 0.4 \mathrm{Myr}=66 \mathrm{Ma}$.

Discussion. Within extant Cetartiodactyla, suiforms and camelids fall outside the whippomorph + ruminant clade (Gatesy et al., 2002). The term "whippomorph" for cetaceans + hippopotamids is based on Waddell et al. (1999); this name unfortunately appeared prior to more palatable alternatives, such as "Cetancodonta" of Arnason et al. (2000), and therefore has priority (see discussion in Asher and Helgen 2010). Older terrestrial artiodactyls (Diacodexis) cannot be unambiguously reconstructed within the crown clade (Geisler and Uhen, 2003).

\section{CROWN CETACEA (72)}

Node Calibrated. Divergence of baleen and toothed whales.

Fossil Taxon and Specimen. Llanocetus denticrenatus (USNM 183022; Mitchell, 1989) from the Eocene La Meseta Formation of Seymour Island, Antarctica (Mitchell, 1989).

Phylogenetic Justification. Phylogenetic analysis of living and fossil mysticetes (Steeman, 2007) shows that Llanocetus is the closest relative of the toothless mysticetes (Chaeomysticeti Mitchell, 1989), based on two apomorphies: the premaxilla is straight in lateral view (not abruptly depressed anterior to nasals), and the occipital condyles are not situated on a swelling, but are rather levelled with the skull.

Minimum Age. $33.9 \mathrm{Ma}$

Soft Maximum Age. $56 \mathrm{Ma}$

Age Justification. The upper La Meseta Formation of Seymour Island, Antarctica is dated as latest Priabonian (late Eocene) on the basis of a wide 
variety of fossils, including palynomorphs (Mitchell, 1989). Elsewhere, the La Meseta Formation appears to be restricted in age to the eaely Eocene (Ypresian), but upper units run to the end of theEocene on Seymour Island (Reguero et al., 2013). Hence, the Priabonian record of Llanocetus serves as the minimum constraint for the crown cetacean divergence (33.9 Ma $\pm 0.0 \mathrm{Myr}=33.9 \mathrm{Ma})$.

The presence of a diverse, early Eocene artiodactyl record, including archaeocetes but no crown cetaceans during the Ypresian, suggests the base of the Eocene may serve as a soft maximum for the odontocete-mysticete divergence, dated at $55.8 \mathrm{Ma} \pm 0.2 \mathrm{Myr}=56.0 \mathrm{Ma}$ (Gradstein et al., 2012).

Discussion. The fossil record famously illuminates the transition from terrestrial artiodactyls to fully aquatic cetaceans in substantial detail (Thewissen et al., 2009). What is somewhat less appreciated by the lay public is the fact that the major divergence within cetaceans, i.e., that between baleen (mysticete) and toothed (odontocete) whales from an archaeocete common ancestor, is also well documented paleontologically. For example, Demere et al. (2008) discussed the stepwise-accumulation of mysticete characters evident using a phylogenetic and developmental understanding of the Tertiary cetacean record, particularly that from coastal regions of Australia and New Zealand. Thus, the Oligocene basal mysticete Janjucetus exhibts a wide, mysticete-like rostrum; more crownward taxa such as Mammalodon and aetiocetids show in addition lateral bowing of the mandibles and a laterally thin maxilla; aetiocetids (and crown mysticetes) show in addition an abundance of nutrient sulci and foramina on the palate indicative of the presence of baleen during life; and finally fossils such as Eomysticetus share with living mysticetes the absence of mineralized teeth as adults. Not all phylogenetic treatments are completely in agreement with this scenario; for example, Marx (2011: figure 3) places the phylogenetically basal-most mysticetes (Janjucetus, mammalodontids, and aetiocetids) together in a clade, and Fitzgerald (2010, 2011) differs from Demere et al. (2008) in his interpretation of the evidence for lateral thinning of the maxilla and the extent of fusion of the mandibular symphysis in Janjucetus, and is less certain about the presence of baleen in aetiocetids.

Importantly, the geologically oldest mysticete Llanocetus from the latest Eocene of Seymour Island, Antarctica - also shows palatal sulci and foramina consistent with the interpretation that it simultaneously possessed mineralized teeth and baleen, along with considerable diastemata between its maxillary teeth (Fordyce 2003 and pers. comm.). Hence, there appears to be substantial mosaic evolution among basal mysticetes, with recent analyses (Demere et al., 2008; Beatty and Dooley, 2010; Fitzgerald, 2010; Marx, 2011) consistent with the inference that loss of mineralized teeth took place independently of, and subsequent to, lateral thinning of the maxilla and lateral bowing of the mandibles.

By the late Eocene, archaeocetes had a nearglobal distribution, corresponding with the first appearance of crown-group cetaceans. The oldest odontocete is likely Simocetus from early Oligocene (Rupelian) deposits in the Alsea Formation of Oregon (Fitzgerald, 2010: figure 48).

\section{BOVINAE-ANTILOPINAE (73)}

Node Calibrated. The branching between the cow (Bos) and sheep (Ovis) is an intrafamilial split within the Family Bovidae. Bos is a member of the Tribe Bovini, and Ovis is a member of the Tribe Caprini that belong respectively, to the subfamilies Bovinae and Antilopinae (see Marcot 2007).

Fossil Taxon and Specimen. Pseudoeotragus seegrabensis (Joanneum 3678, Natural History Museum Graz; van der Made, 1989) from the Austrian Miocene.

Phylogenetic Justification. Pseudoeotragus has been determined phylogenetically as closer to antelopines than bovines (Bibi 2009: figure 1), but with some uncertainty. However, it is certainly accepted as a member of crown Bovidae and is similar in age to many other records of crown bovids, such as those from the Miocene site of Ft. Ternan, Kenya (Bibi, 2013).

Minimum Age. $16 \mathrm{Ma}$

Soft Maximum Age. 28.1 Ma

Age Justification. Pseudoeotragus seegrabensis is from the MN4 planktic foraminifera zone, with a quoted age of 18-17 Ma (Bibi, 2013). MN4 is part of the Burdigalian stage, so we adopt a conservative stance, and select the top of the Burdigalian as our hard minimum constraint, namely $15.97 \mathrm{Ma} \pm$ $0.0 \mathrm{Myr}=15.97 \mathrm{Ma}$ (Gradstein et al., 2012).

We set the soft maximum constraint at the base of the Chattian stage of the late Oligocene (28.1 Ma), encompassing many equivocal stem bovids, but lacking those from the crown.

Discussion. A number of putative late Oligocene bovids are not demonstrably descended from the common ancestor of extant bovines and antelopines (Bibi, 2013). One such candidate was Palaeohypsodontus zinensis from the Oligocene of 
the Bugti Hills, Pakistan, and the early Oligocene of Mongolia and China. This appears to be a ruminant, but it lacks unequivocal anatomical features of Bovidae, and is currently excluded from that family (Metais et al., 2003; Barry et al., 2005). More secure records of bovids may be identified by the presence of horn cores. The oldest such fossils come from the early Miocene of Western Europe and Pakistan; Eotragus noyei (for example) is known from the base of the terrestrial sequence on the Potwar Plateau and dated at approximately 18.3 Ma (Solounias et al., 1995). E. noyei may in fact be a paraphyletic, wastebasket taxon (Azanza and Morales, 1994; Bibi et al., 2009). While Bibi (2013: table 1) suggests use of $E$. noyei as a calibration for crown Bovidae, and gives a minimum divergence date of $18 \mathrm{Ma}$ for this node, he further notes that "it is not clear whether this and other Eotragus species belong on the stem lineage or in the crown clade of Bovidae."

\section{CROWN EUARCHONTOGLIRES (74)}

Node Calibrated. Euarchontoglires (Figure 11) is composed of two clades, the Archonta and the Glires. Primates belong to the former, Rodentia to the latter, the common ancestor of which corresponds to the origin of Euarchontoglires.

Fossil Taxon and Specimen. The minimum constraint on the origin of Euarchontoglires is set in the early Paleocene based on Torrejonian occurences of extinct primate sister taxa such as plesiadapids from north-eastern Montana, e.g., Paromomys farrandi (UCMP 189520; Clemens and Wilson, 2009). Phylogenetic Justification. Paromomys is determined phylogenetically as a member of Paromomyidae, which is sister to Plesiadapiformes + Euprimates, and so a part of total-group Primates, nested well within Euarchontoglires (Block et al., 2007).

Minimum Age. $61.6 \mathrm{Ma}$

Soft Maximum Age. 164.6 Ma

Age Justification. The upper bound of the Torrejonian North American Land Mammal Age (NALMA) correlates to the top of the Danian, 61.6 Ma \pm 0.0 Myr = 61.6 Ma (Woodburne, 2004).

The soft maximum date is based on the divergence of Eutheria from other mammals in the late Jurassic, represented by Juramaia (Luo et al., 2011). This taxon is represented in the Daxigou site of the Tiaojishan Formation, Liaoning Province, Northeastern China, and has been constrained by radiometric dates to derive from deposits of just over $160 \mathrm{Ma}$ in age (Luo et al., 2011). The equivalent marine stage is the Oxford- ian (Gradstein et al., 2012), with a lower boundary of $163.5 \mathrm{Ma} \pm 1.1 \mathrm{Myr}$, and thus $164.6 \mathrm{Ma}$ is a soft maximum.

Discussion. The oldest confirmed primates are from the Paleocene-Eocene boundary, 55.5 Ma (Bloch et al., 2007). The oldest "plesiadapiform"grade mammals include early Paleocene paromomyids and carpolestids. Undisputed fossil rodents are known from the Thanetian, including members of the Family Ischyromidae from North America and Europe (Stucky and McKenna, 1993). Some or all eurymyloids from Asia may fall on the stem to Rodentia and/or Lagomorpha (Meng et al., 2003; Asher et al., 2005). Mimotona lii and Heomys sp. from the Wanghudun Formation., Qianshan Basin, China, have been interpreted to derive from the Paleocene Shanghuan Asian Land Mammal Age (Dashzeveg and Russell, 1988; Li and Ting, 1993). However, Missiaen (2011) suggests that in fact these Wanghudun Formation glires may in fact be closer to the Nongshanian ALMA, making them presumably younger than early Paleocene plesiadapiforms, such as Paromomys (Clemens and Wilson, 2009) and Palaechthon (Lucas and Froelich, 1989) from the Torrejonian NALMA.

\section{CROWN GLIRES (75)}

Node Calibrated. The last common ancestor of Rodentia and Lagomorpha.

Fossil Taxon and Specimen. Mimotona lii (IVPP V-4377, Dashzeveg and Russell 1988), from the Wanghudun Formation of Anhui, China.

Phylogenetic Justification. Meng et al. (2003) placed Mimotona, and the coeval Heomys, on the stems leading to Lagomorpha and Rodentia, respectively. Using a combined morphology-DNA dataset, and noting the impact of DNA data on fossil taxa even when they are sampled for living species alone, Asher et al. (2005) also placed these taxa within Glires, but placed Heomys along with other eurymylids on the stem to Lagomorpha. Either way, these fossils provide a minimum date for the radiation of Glires.

Minimum Age. $56 \mathrm{Ma}$

Soft Maximum Age. 164.6 Ma

Age Justification. The Wanghudun Formation, Qianshan Basin, China is of debated age. First, it was interpreted as belonging to the Paleocene Shanghuan Asian Land Mammal Age (Dashzeveg and Russell, 1988; Li and Ting, 1993). However, Missiaen (2011) suggests that the Wanghudun Formation may be closer to the Nongshanian ALMA. We use this younger estimate for age of the Wanghudun Formation for two reasons: it is the more 
current interpretation, and it is younger, and so more conservative. The marine correlate of the Nongshanian ALMA is the Thanetian, with a minimum bound of $56 \mathrm{Ma} \pm 0.0 \mathrm{Myr}=56 \mathrm{Ma}$ (Gradstein et al., 2012).

The soft maximum date is based on the divergence of Eutheria from other mammals in the late Jurassic, represented by Juramaia (Luo et al., 2011). This taxon is represented in the Daxigou site of the Tiaojishan Formation, Liaoning Province, Northeastern China, and has been constrained by radiometric dates to derive from deposits of just over $160 \mathrm{Ma}$ in age (Luo et al., 2011). The equivalent marine stage is the Oxfordian (Gradstein et al., 2012), with a lower boundary of $163.5 \mathrm{Ma} \pm 1.1 \mathrm{Myr}$, and thus $164.6 \mathrm{Ma}$ is a soft maximum.

Discussion. Mimotona and Heomys may be similar in age to late Paleocene stem rodents (e.g., Tribosphenomys), but they are still older than crown lagomorphs. Stucky and McKenna (1993) indicate several Eocene taxa from the Lutetian: Lushilagus from China, Procaprolagus from Canada, and Mytonolagus from the United States. Rose et al. (2008) described hindlimb elements attributable to leporids from the middle Eocene of south Asia (see below).

\section{CROWN LAGOMORPHA (76)}

Node Calibrated. The common ancestor of leporids (rabbits and hares) and ochotonids (pikas).

Fossil Taxon and Specimen. Our minimum estimate for crown Lagomorpha is based on the unnamed Indian leporid fossils (isolated calcaneus, GU/RSR/VAS 711, Garhwal University, Srinagar, India) described by Rose et al. (2008) from the Vastan mine, Cambay Shale, in West-Central India.

Phylogenetic Justification. Rose et al. (2008) identified these fossils as lagomorph on the basis of the occurrence of a calcaneal canal that passes diagonally through the bone, entering on the lateral side just inferior or proximal to the fibular facet and emerging just distal to the sustentacular facet and proximal to the cuboid facet. Further, in their cladistic analysis, Rose et al. (2008) assigned the Vastan ankle bones unequivocally to Leporidae, the hares, nested well within crown Lagomorpha.

Minimum Age. 47.6 Ma

Soft Maximum Age. $66 \mathrm{Ma}$

Age Justification. The Cambay Shale of WestCentral India is dated as middle Ypresian based on the occurrence of foraminifera diagnostic of the Shallow Benthic Zone 10 and planktonic zone 6b
(Rose et al., 2008). The top of the Ypresian is dated at 47.8 Ma $\pm 0.2 \mathrm{Myr}=47.6 \mathrm{Ma}$ (Gradstein et al., 2012).

For the soft maximum divergence of crown lagomorphs we choose the K-Pg boundary at $66.04 \mathrm{Ma} \pm 0.4 \mathrm{Myr}=66 \mathrm{Ma}$, based on the occurrence of basal Glires such as Mimotona and Heomys (Dashzeveg and Russell, 1988; Li and Ting, 1993).

Discussion. There are many fossil Glires on the stem to Lagomorpha that long predate the first unambiguous occurrence of a leporid or ochotonid (Meng et al., 2003; Asher et al., 2005). None of these Paleocene Glires are members of Leporidae or Ochotonidae (Meng et al., 2003; Asher et al., 2005).

There are just under a dozen species of pikas (Ochotonidae, Ochotona), the oldest relative of which (to the exclusion of leporids) has been reported to be the late Eocene Asian form Desmatolagus (McKenna and Bell, 1997). A yet older taxon, Decipomys from the early Eocene of central Asia, shows a pattern of enamel microstructure that could be a "structural predecessor" to that of modern ochotonids (Martin, 2004). The status of Decipomys as an ochotonid, or of Eocene palaeolagids as close relatives of rabbits and hares, would indicate a divergence within crown Lagomorpha by the early or middle Eocene, respectively. A recent analysis of isolated hindlimb elements from China and India (Rose et al., 2008) also indicates that leporids and ochotonids were distinct by the early Eocene. Although fragmentary, these elements are clearly diagnostic for the Leporidae. These identifications are consistent with the interpretation of the early Eocene Strenulagus and Gobiolagus from central Asia as leporids (Meng et al., 2005), although Lopatin and Averianov (2006) have more cautiously assigned them to "Lagomorpha, Family Strengulidae" without specifying a crown affiliation.

\section{CROWN RODENTIA (77)}

Node Calibrated. The common ancestor of the three major, extant rodent clades: Muroidea (mouse-related.), Sciuromorpha (squirrel-related.), and Ctenohystrica (guinea-pig related.), following Churakov et al. (2010).

Fossil Taxon and Specimen. Paramys atavus (type specimen YPM-PU 14200; Yale Peabody Museum Princeton Collection; Jepsen, 1937) from the Fort Union Formation of the Eagle Mine, Carbon County, Montana. 
Phylogenetic Justification. Phylogenetic analyses place Paramys in Sciuromorpha, the squirrelrelated clade, based on characters of the ear region (Korth, 1984; McKenna and Bell, 1997; Marivaux et al., 2004). Paramys is then nested well within crown Rodentia.

Minimum Age. $56 \mathrm{Ma}$

Soft Maximum Age. $66 \mathrm{Ma}$

Age Justification. An index taxon for the Clarkforkian (Rose, 1981; Anemone and Dirks, 2009), Paramys is known from late Paleocene localities in North America and as such correlates with the Thanetian stage, the minimum bound of which is $56 \mathrm{Ma} \pm 0.0 \mathrm{Myr}=56 \mathrm{Ma}$ (Gradstein et al., 2012).

Taxa such as Heomys and Mimotona are Glires, but do not belong within crown Rodentia or Lagomorpha (Meng et al., 2003; Asher et al., 2005). Therefore, a reasonable soft maximum constraint on the base of crown Rodentia could be set by these stem rodents at the base of the Paleocene, at $66.04 \mathrm{Ma} \pm 0.4 \mathrm{Myr}=66 \mathrm{Ma}$.

Discussion. The relationships of major rodent groups to each other enjoy a moderate level of consensus, although several questions remain. Recent studies generally recognize three groups: mouse-related (muroids plus castoromorphs), squirrel-related (sciuroids plus glirids), and guinea pig-related (Ctenohystrica). Atkins et al. (2003) and Blanga-Kanfi et al. (2009) support a topology in which squirrel-like rodents are basal to a mouselike-ctenohystricid clade. Churakov et al. (2010) supported this arrangement but noted the likely influence of incomplete lineage sorting and very short branches near the root.

\section{RODENTIA MINUS SCIUROMORPHS (78)}

Node Calibrated. The divergence of Muroidea + Ctenohystrica (see above and Churakov et al., 2010) to the exclusion of sciuromorphs.

Fossil Taxon and Specimen. Chapattimyidae such as Birbalomys sondaari (Geological Survey of Pakistan, Howard University Collection, H-GSP 92161 of Thewissen et al., 2001) from the Kuldana Formation of the Ganda Kas area, Pakistan.

Phylogenetic Justification. Phylogenetic analysis by Marivaux et al. (2004) placed Eocene chapattimyids within the Ctenohystrica, close to hystricognaths and to the exclusion of diatomyids. They are therefore nested within the unnamed crown clade comprising Muroidea and Ctenohystrica.

Minimum Age. 47.6 Ma

Soft Maximum Age. 59.2 Ma

Age Justification. The Kuldana Formation of Pakistan has been dated as early-middle Eocene, and ages may differ in different regions of northern India, and mammals occur in different horizons. Birbalomys is noted as occurring at $51 \mathrm{Ma}$ by Marivaux et al. (2004, p. 132), thus well within the Ypresian. Hence, we assign a minimum constraint for rodents excluding the squirrel-like clade at the top of the Ypresian marine stage, hence 47.8 Ma \pm $0.2 \mathrm{Myr}=47.6 \mathrm{Ma}$ (Gradstein et al., 2012).

The soft maximum constraint might be taken as equivalent to the age of the ischyromyids and other entirely extinct rodent groups from the late Paleocene (base of the Thanetian) of North America and Europe, 59.2 Ma $\pm 0.0 \mathrm{Myr}=59.2 \mathrm{Ma}$.

Discussion. Fossils associated with the mouserelated stem group are younger, including Eocene dipodids such as Ulkenulastomys, Blentosomys, and Aksyiromys from the Obayla Svita of the Zaysan Basin, Kazakhstan (Shevyreva, 1984). Lucas (1998) assigned a younger, Irdinmanhan age to this site based on biostratigraphic comparisons, changing its previous stratigraphic interpretation from early Eocene to the base of the middle Eocene.

\section{INTRA-MURINAE (79)}

Node Calibrated. Divergence of Mus from Rattus. Fossil Taxon and Specimen. Karnimata darwini (YGSP 7720, Yale University-Geological Survey of Pakistan, from the Dhok Pathan Formation, Pakistan, middle Miocene; Jacobs, 1978).

Phylogenetic Justification. Karnimata is identified by phylogenetic analysis as a member of the Rattus-Mus clade within crown Murinae, closer to Rattus than Mus (Jacobs and Flynn, 2005).

Minimum Age. 10.4 Ma

Soft Maximum Age. 14.0 Ma

Age Justification. The Dhok Pathan Formation is dated by means of detailed field stratigraphic study, including magnetostratigraphy and radiometric dating (Johnson et al., 1985; Barry et al., 2002). These indicate an absolute age in the vicinity of 10.4 Ma, within the Tortonian stage. The upper limit of the Tortonian is $7.246 \mathrm{Ma}$ (Gradstein et al., 2012).

The soft maximum constraint on this date is taken as the oldest record of Antemurus at 14.0 $\mathrm{Ma}$, correlating with the Langhian stage with a lower bound of $16 \mathrm{Ma}$.

Discussion. The mouse (Mus musculus) and rat (Rattus norvegicus) are both murine rodents, a hugely diverse group with over 500 species that appears to have radiated rapidly in Europe, Africa, Asia, and Australia. The phylogeny of all genera within Murinae has not been determined; however, 
current morphological and molecular phylogenies (Michaux et al., 2001; Jansa and Weksler, 2004; Steppan et al., 2004; Chevret et al., 2005) indicate that Mus and Rattus diverged early in the evolution of Murinae, although not at the base of that clade.

Stem murine fossils are older, e.g., Antemus chinjiensis, from the middle Miocene Chinji Formation of Pakistan, dated at about 14.0-12.7 Ma on the basis of magnetostratigraphy and radiometric dating. The oldest fossil example of Mus dates from 7.3 Ma, a specimen of Mus sp. from locality Y457 in the Siwaliks. Contra Mein et al. (1993), Jacobs and Flynn (2005) regard Karnimata as generically distinct from Progonomys woelferi.

\section{CROWN ARCHONTA (80)}

Node Calibrated. Divergence of primates, dermopterans, and scandentians.

Fossil Taxon and Specimen. The minimum constraint on the origin of Archonta is set in the early Paleocene based on Torrejonian occurences of extinct primate sister taxa such as plesiadapids from north-eastern Montana, e.g., Paromomys farrandi from the Farrand Channel, Garfield County, Montana (UCMP 189520; Clemens and Wilson, 2009).

Phylogenetic Justification. Paromomys is determined phylogenetically as a member of Paromomyidae, which is sister to Plesiadapiformes + Euprimates, and so a part of total-group Primates, nested well within Archonta (Bloch et al., 2007).

Minimum Age. $61.6 \mathrm{Ma}$

Soft Maximum Age. 164.6 Ma

Age Justification. The upper bound of the Torrejonian North American Land Mammal Age (NALMA) correlates to the top of the Danian, 61.6 Ma \pm 0.0 Myr = 61.6 Ma (Woodburne, 2004).

The soft maximum date is based on the divergence of Eutheria from other mammals in the late Jurassic, represented by Juramaia (Luo et al., 2011). This taxon is represented in the Daxigou site of the Tiaojishan Formation, Liaoning Province, Northeastern China, and has been constrained by radiometric dates to derive from deposits of just over $160 \mathrm{Ma}$ in age (Luo et al., 2011). The equivalent marine stage is the Oxfordian (Gradstein et al., 2012), with a lower boundary of $163.5 \mathrm{Ma} \pm 1.1 \mathrm{Myr}$, and thus $164.6 \mathrm{Ma}$ is a soft maximum.

Discussion. Tree shrews are members of Scandentia, an order that has long been seen as a close relative of Primates. Some recent phylogenies place scandentians closer to dermopterans in Sundatheria (Olson et al., 2005; Bloch et al., 2007;
Murphy et al., 2007) or as the sister taxon to Dermoptera-Primates (Janecka et al., 2007). Meredith et al. (2011) depicted them as the sister taxon to Glires, a novel hypothesis that deserves further scrutiny but one which we will not consider further here. With this caveat, the minimum constraint on dating the split between tree shrews and any of the primates is set then by determination of the oldest member of orders Scandentia, Dermoptera or Primates or their respective stem relatives.

Scandentia (tree shrews) and Dermoptera (flying lemurs) are taxonomically depauperate orders of mammals with equally sparse fossil records. The oldest scandentian is Eodendrogale from the middle Miocene of China and the oldest dermopteran is a single specimen from the late Eocene of Thailand, Dermotherium (Silcox et al., 2005). Primates are much more diverse and ancient and demonstrate the existence of the order by the early Paleocene, as discussed above.

\section{CROWN PRIMATES (81)}

Node Calibrated. Crown-group Primates, or Euprimates, encompass living forms plus the extinct adapoids and omomyoids; the latter are more closely related to extant lemuriforms than to anthropoids (Silcox et al., 2005; Bloch et al., 2007; Seiffert et al., 2009).

Fossil Taxon and Specimen. Altiatlasius koulchii from the late Paleocene of Adrar Mgorn 1, Morocco is regarded as the oldest euprimate (THR 141, represented in the MNHN Paris; Sigé et al., 1990).

Phylogenetic Justification. Cladistic analyses by Seiffert et al. (2005) and Tabuce et al. (2009) indicate that Altiatlasius is a member of crown Primates, and may even be a stem anthropoid.

Minimum Age. $56 \mathrm{Ma}$

Soft Maximum Age. $66 \mathrm{Ma}$

Age Justification. Altiatlasius comes from the Adrar Mgorn 1 locality in the Ouarzazate Basin of Morocco, dated generally as late Paleocene (Thanetian stage). Magnetostratigraphic study (Gheerbrant et al., 1998) narrows the age range of the locality to "late or latest Thanetian," and so the age of the top of the Thanetian Stage (56 Ma \pm 0.0 Myr $=56 \mathrm{Ma}$, Gradstein et al., 2012) provides the minimum constraint.

The soft maximum constraint may be marked by older possible primate fossils. McKenna and Bell (1997) implied in their classification that carpolestids, with a record in the Danian (early Paleocene) are euprimates, but this has not been substantiated elsewhere. They also attribute the basal Paleocene Decoredon from China to Pri- 
mates (following Szalay and Li, 1986), although this is disputed; Kondrashov and Lucas (2004) suggested affinities to the poorly understood group Anagalidae instead. In general, early Paleocene strata have yielded fossils of several groups (plesiadapids, paromomyids, carpolestids) reconstructed closer to crown primates than to Scandentia or Dermoptera (Bloch et al., 2007), but no definitive crown primates. Hence, the paleontological soft maximum constraint can be defined as the base of the Paleocene, at 66.04 Ma $\pm 0.4 \mathrm{Myr}=$ $66 \mathrm{Ma}$.

Discussion. The oldest fossil sometimes attributed to primates is Purgatorius from the early Paleocene, reputed from time to time to have been latest Cretaceous in age. However, these remains are marginally diagnostic teeth. The remains of Altiatlasius are also dental, but this taxon has more consistently been reconstructed within the primate radiation (Seiffert et al., 2005; Tabuce et al., 2009).

\section{CROWN STREPSIRHINI (82)}

Node Calibrated. The crown clade comprising lemurs, lorises, galagos, and other extant primates that possess a toothcomb (Fleagle, 1999).

Fossil Taxon and Specimen. Karanisia clarki (CGM40265, Cairo Geological Museum) from the late Eocene Birket Quarun Formation of the Fayûm, Egypt (Seiffert et al., 2003).

Phylogenetic Justification. Phylogenetic analysis (Seffert et al., 2003) shows Karanisia is a member of crown Stresirrhini. It is loris-like, and has a dentition similar to the extant lorisid Arctocebus. Subsequent cladistic study (Seiffert, 2007) still could not place Karanisia unequivocally, and it was identified as either a stem lorisiform or a crown strepsirrhine of uncertain affinities; in either case it is nested within crown Strepsirrhini.

Minimum Age. $33.9 \mathrm{Ma}$

Soft Maximum Age. $56 \mathrm{Ma}$

Age Justification. Following Seiffert (2006), the Birket Quarun Formation of the Fayûm corresponds to the Priabonian with an upper bound of 33.9 Ma.

Fossil primates are relatively common mammalian fossils at many localities in North America and Eurasia throughout the Eocene; yet crown strepsirhines remain conspicuously absent prior to the late Eocene. Hence, we suggest the first appearance of euprimates, represented by Altiatlasius from the late Paleocene of Morocco (Sigé et al., 1990) as the soft maximum for Strepsirhini, namely $56 \mathrm{Ma} \pm 0.0 \mathrm{Myr}=56 \mathrm{Ma}$.
Discussion. Malagasy primates comprise an extant radiation that shares a single common ancestor to the exclusion of other primates such as galagos, lorises, and monkeys (Poux et al., 2005). There is an extraordinary diversity of subfossil strepsirhine primates from Madagascar, but neither these nor other lemuriforms has a fossil record demonstrably older than the Holocene (Seiffert, 2007). In contrast, the lorisiform sister-radiation of Malagasy lemurids (including galagos and bushbabies) shows a less ambiguous fossil record through the late Eocene, including the oldest-known records of toothcombed primates from the Birket Quarun Formation of the Fayûm, Egypt (e.g., Karanisia, Seiffert et al., 2003).

\section{CROWN ANTHROPOIDEA (83)}

Node Calibrated. Last common ancestor of platyrrine and catarrhine primates.

Fossil Taxon and Specimen. The oldest anthropoid is Catopithecus browni from the Fayûm Quarry L-41 (DPC 8701, Duke University USA; Simons and Rasmussen, 1996).

Phylogenetic Justification. Catopithecus is identified as a member of crown Anthropoidea on the basis of phylogenetic analysis (Seiffert, 2006). It shows complete postorbital closure and is a member of crown Catarrhini, so nested well within crown Anthropoidea.

Minimum Age. 33.9 Ma

Soft Maximum Age. $66 \mathrm{Ma}$

Age Justification. Catopithecus from the Fayûm Quarry L-41 is dated at the end of the Priabonian (Seiffert 2006) with an upper bound of $33.9 \mathrm{Ma}$.

Older taxa such as the African Altiatlassius and Biretia, and the Asian eosimiids and amphipithecids, may in fact be anthropoids, but appear to fall outside crown Anthropoidea (Seiffert et al., 2005). Given the fact that the oldest known euprimate (Altiatlasius) has been regarded tentatively as an anthropoid sister-taxon (Seiffert et al., 2005), the soft maximum for anthropoids must predate this occurrence in the late Paleocene. Early Paleocene strata has yielded fossils of several groups (plesiadapids, paromomyids, carpolestids) reconstructed closer to crown primates than to Scandentia or Dermoptera (Bloch et al., 2007), but has not yielded any definitive crown primates. Hence, the paleontological soft maximum can be defined as the base of the Paleocene, at 66.04 Ma $\pm 0.4 \mathrm{Myr}=$ $66 \mathrm{Ma}$.

Discussion. The oldest South American primate, Branisella from the late Oligocene of Bolivia, is widely regarded to be a platyrrine relative but can- 
not be more precisely linked to any single platyrrhine crown group (Fleagle, 1999). The middle Miocene locality of La Venta, Columbia, has produced the oldest remains of essentially modern platyrrhines, including the possible marmosets Micodon, Patasola, and Lagonimico (Kay and Meldrum, 1997). All are younger than Catopithecus.

\section{CROWN CATARRHINI (84)}

Node Calibrated. The common ancestor of Old World monkeys (Cercopithecoidea) and apes (Hominoidea), which together form crown Catarrhini.

Fossil Taxon and Specimen. Rukwapithecus fleaglei (RRBP 12444A, Ohio University USA) from the Nsungwe Formation, Rukwa Rift Basin, Tanzania, is the oldest stem hominoid and crown catarrhine yet known.

Phylogenetic Justification. Rukwapithecus fleaglei is based on a right mandible with p4-m3. Phylogenetic analysis by Stevens et al. (2013) places this taxon within crown Catarrhini, basal to the gibbon-great ape split but closer to hominoids than to cercopithecoids. Stevens et al. (2013) also attributed an isolated $\mathrm{m} 3$ from the same locality to Cercopithecoidea.

Minimum Age. $24.44 \mathrm{Ma}$

Soft Maximum Age. $34.0 \mathrm{Ma}$

Age Justification. The deposits of the Nsungwe Formation containing Rukwapithecus are constrained by multiple radiometric dates, indicating an absolute age of $24.93 \pm 0.49 \mathrm{Ma}$ (Roberts et al., 2010), hence minimally $24.44 \mathrm{Ma}$.

The soft maximum constraint is based on members of the stem of Catarrhini, namely the families Propliopithecidae (Propliopithecus, Aegyptopithecus) and Oligopithecidae (Oligopithecus, Catopithecus) that are basal to the cercopithecoidhominoid split (Rasmussen, 2002; Stevens et al., 2013). These are represented in the Fayûm beds in Egypt, which possess a diverse anthropoid primate fauna, including stem platyrrhines and catarrhines from $33.9-28.4 \mathrm{Ma} \pm 0.1 \mathrm{Myr}$ (Seiffert et al., 2005; Seiffert, 2006). Hence, at the base of the Oligocene at $33.9 \mathrm{Ma} \pm 0.1 \mathrm{Myr}$, the Fayûm shows a diversity of primates and other mammals, but no members of crown-group hominoids or cercopithecoids.

Discussion. Prior to these discoveries, the oldest cercopithecoids were regarded as Victoriapithecus macinnesi from Kenya, and two species of Prohylobates from Libya and Egypt. Miller (1999) surveyed these two genera and compared ages of their respective deposits. The oldest cercopithecoid fossil is a tooth identified as Victoriapithecus sp. from Napak V, Uganda (about $19 \mathrm{Ma}$ ), followed by Prohylobates tandyi from Moghara, Egypt (18 $17 \mathrm{Ma}$ ) and Prohylobates sp. from Buluk, Kenya (at least 17.2 Ma), P. simonsi from Gebel Zelten, Libya (about 17 - $15 \mathrm{Ma}$ ), and $\mathrm{V}$. macinnesi from Maboko, Kenya (about 16-14.7 Ma). MacLatchy et al. (2003) report an even older cercopithecoid, a fragment of a maxilla from the Moroto II locality in Uganda, which has been radiometrically dated to be older than 20.6 Ma $\pm 0.05 \mathrm{Myr}$ (Gebo et al., 1997). Other fossil hominoids include Morotopithecus, also from the Moroto II locality in Uganda (Gebo et al., 1997). Young and MacLatchy (2004) determined that this taxon is a hominoid, located in the cladogram above the gibbons, and so not the most basal member of the group. Because of incompleteness of the material, Finarelli and Clyde (2004) are less certain of its phylogenetic position, but Morotopithecus appears to be a catarrhine. The first record of the long-ranging hominoid genus Proconsul from Meswa Bridge in Kenya is even older, biostratigraphically constrained to ca. 23.5 Ma (Pickford et al., 1981; Tassy and Pickford, 1983). Older still is the purported hominoid Kamoyapithecus from the Eragaliet Beds of the Lothidok Formation of Kenya, dated at 24.3-27.5 Ma (Boschetto et al., 1992), but the material is insufficient to determine whether it is a hominoid or a catarrhine, possibly lying below the humanmacaque split (Finarelli and Clyde, 2004).

\section{CROWN HOMINOIDEA (85)}

Node Calibrated. Last common ancestor of gibbons and great apes, i.e., crown hominoids.

Fossil Taxon and Specimen. Sivapithecus indicus (e.g., Geological Survey of Pakistan, Islamabad, partial maxilla GSP Y-16075; Kappleman et al., 1991) from the Miocene Chinji Formation of Pakistan.

Phylogenetic Justification. Sivapithecus is identified by phylogenetic analysis as a member of totalgroup Ponginae, a stem gibbon, and so nested within crown Hominoidea (Ward and Kimbel, 1983; Seiffert, 2006).

Minimum Age. 11.6 Ma

Soft Maximum Age. 33.9 Ma

Age Justification. The Chinji Formation of Pakistan corresponds to magnetic polarity chron $5 \mathrm{Ar}$, estimated to be ca. $12 \mathrm{Ma}$ before present (Kappelman et al., 1991). This correlates to the Serravallian stage, the top of which is at $11.6 \mathrm{Ma}$, our 
minimum estimate for the divergence of the orangutan from other great apes.

As a soft maximum we suggest the first diverse occurrence of anthropoids from the earliest Oligocene of the Fayûm, Egypt. These primates comprise a diverse radiation just on the Oligocene side of the Eocene-Oligocene boundary at 33.9 Ma (Seiffert, 2006; Gradstein et al., 2012) and lack derived features of the extant great ape lineages.

Discussion. Numerous taxa of Miocene apes may share a close relation with extant gibbons to the exclusion of other hominoids. European taxa such as Dryopithecus and Oreopithecus, with a record dating to the middle Miocene, have over the years occasionally been linked to hylobatids (Fleagle, 1999). However, recent cladistic analyses do not place any of these taxa with hylobatids to the exclusion of other catarrhines (Rossie and McLatchy, 2006; Stevens et al., 2013). Gibbons cannot be said to have a definitive fossil record prior to Pleistocene occurrences of the extant genus in east Asia, and previously named Miocene species of Pongo are now recognized under other Miocene hominoid genera (Harrison and $\mathrm{Gu}$, 1999). Hence, Sivapithecus remains the oldest crown hominoid (Andrews and Cronin, 1982; Pilbeam, 1986).

\section{CROWN HOMINIDAE (86)}

Node Calibrated. Last common ancestor of great apes, including human, chimp, gorilla, and orangutan.

Fossil Taxon and Specimen. Sivapithecus indicus (e.g., Geological Survey of Pakistan, Islamabad, partial maxilla GSP Y-16075; Kappleman et al., 1991) from the Miocene Chinji Formation of Pakistan.

Phylogenetic Justification. Sivapithecus is identified by phylogenetic analysis as a member of totalgroup Ponginae, a stem gibbon, and so nested within crown Hominidae (Ward and Kimbel, 1983; Seiffert, 2006).

Minimum Age. 11.6 Ma

Soft Maximum Age. $33.9 \mathrm{Ma}$

Age Justification. The Chinji Formation of Pakistan corresponds to magnetic polarity chron $5 \mathrm{Ar}$, estimated to be ca. $12 \mathrm{Ma}$ before present (Kappelman et al., 1991). This correlates to the Serravallian stage, the top of which is at $11.6 \mathrm{Ma}$, our minimum estimate for the divergence of the orangutan from other great apes.

As a soft maximum we suggest the first diverse occurrence of anthropoids from the earliest Oligocene of the Fayûm, Egypt. These primates comprise a diverse radiation just on the Oligocene side of the Eocene-Oligocene boundary at $33.9 \mathrm{Ma}$ (Seiffert, 2006; Gradstein et al., 2012), and lack derived features of the extant great ape lineages.

Discussion. While there are numerous taxa of fossil hominoids from Africa and Eurasia, few can be unambiguously attributed to an extant ape lineage besides Homo and Pongo. Numerous fossils associated with the Pongo lineage are known from Pleistocene sites in east Asia; another fossil orangutan relative, Gigantopithecus, is known from the late Miocene and Pliocene (Fleagle, 1999). Of crown hominoid lineages, Sivapithecus is the oldest (Andrews and Cronin, 1982; Pilbeam, 1986).

\section{CHIMPANZEE-HUMAN (87)}

Node Calibrated. Divergence between humans and our closest living relative, Pan.

Fossil Taxon and Specimen. Skull of Sahelanthropus chadensis (TM 266-01-060-1) from TorosMenalla, northern Chad, formally accessioned into the Département de Conservation des Collections, CNAR, Ndjaména, Chad (Brunet et al., 2002).

Phylogenetic Justification. The skull of Sahelanthropus shows a mixture of primitive and advanced characters: the brain size, at $320-380 \mathrm{~cm}^{3}$, is comparable to that of chimpanzees, but the canine teeth are small, more like those of a human, and the prominent brow ridges are of the kind seen only in Homo. Sahelanthropus has generally been accepted, however, as a basal hominin (CelaConde and Ayala, 2003; Strait, 2013). Hominin apomorphies include incisors with a broad, deep, and round section, roots of premolars buccolingually narrow and in contact, and roots of molars curved (Emonet et al., 2014). Additional hominin apomorphies include the inferiorly facing foramen magnum, implying bipedalism, and the upper canine morphology showing no evidence of a honing complex (Strait, 2013).

Minimum Age. $6.5 \mathrm{Ma}$

Soft Maximum Age. $10 \mathrm{Ma}$

Age Justification. Dating of the Sahelanthropus beds in Chad is indirect. Biostratigraphic evidence from fossil mammals, fish, and reptiles indicates that the unit is older than $5.33 \mathrm{Ma}$, and older than the Lukeino Formation of Kenya (the source of Orrorin), dated at 6.56 - 5.73 Ma from Ar/Ar dates on volcanic layers (Deino et al., 2002). The Chadian fossil may derive from equivalents to the lower fossiliferous units of the Nawata Formation at Lothagam, dated as 7.4-6.5 Ma (Vignaud et al., 2002). This might suggest a date for the sediments containing Sahelanthropus of 7.5-6.5 Ma, based 
on biostratigraphy and external dating. Thus, we determine a $6.5 \mathrm{Ma}$ age for the minimum constraint on the human-chimp split.

A range of ape taxa, Ankarapithecus from Turkey (10 Ma), Gigantopithecus from China (8-0.3 $\mathrm{Ma})$, Lufengopithecus from China (10 Ma), Ouranopithecus from Greece (10-9 Ma), and Sivapithecus from Pakistan (10-7 Ma) give maximum ages of $10 \mathrm{Ma}$, early in the late Miocene, and these deposits have yielded no fossils attributable to either chimps or humans. This is taken as the soft maximum constraint on the human-chimp divergence.

Discussion. Paleontological estimates for the chimp-human split during the 1960s-70s placed the branching point deep in the Miocene, up to $20 \mathrm{Ma}$, but this was revised dramatically upwards to about 5 Ma by early molecular studies (Sarich and Wilson, 1967), some of which gave estimates as recent as 2.7 Ma (Hasegawa et al., 1985). Paleontological evidence for the branching point remains heavily oriented around the human line, and so the question of human-chimp divergence has been roughly equivalent to the divergence of the first hominin.

At roughly $0.5 \mathrm{Ma}$, the oldest chimpanzee fossils are much younger than the oldest hominins (McBrearty and Jablonski, 2005). The report by Suwa et al. (2007) on a late Miocene fossil gorilla hints at a similar age for the gorilla and orang-utan lineages. Some late Miocene ape fossils, such as Gigantopithecus and Sivapithecus, may be stemorangs.

The alleged early Miocene antiquity of hominins claimed in older textbooks (e.g., Simons, 1972) was based on south-Asian fossils now known to be closer to modern orang-utans than to humans (Andrews and Cronin, 1982; Pilbeam, 1986). While the paleontological understanding of the earliest hominin is now therefore generally regarded as much more recent than early Miocene, it has nevertheless reclaimed a position in the Miocene, although towards the end of this epoch rather than its beginning. Discoveries since 2001 indicate a late Miocene divergence: Ororrin tugenenis from Kenya dates to about $6 \mathrm{Ma}$ (Senut et al., 2001) and Sahelanthropus tchadensis from Chad to nearly $7 \mathrm{Ma}$ (Brunet et al., 2002). The case that Sahelhanthropus and Orrorin are hominins is not universally accepted, but is nevertheless a view with demonstrated empirical support (Zollikofer et al., 2005; Richmond and Jungers, 2008). We note that Parham et al. (2012) regard Australopithecus anamensis (Leakey et al., 1998) as a more conservative minimum estimate of hominin divergence at just over $4 \mathrm{Ma}$.

\section{HUMANITY (88)}

Node Calibrated. Divergence between anatomically modern humans ( $H$. sapiens) and neanderthals $(H$. neanderthalensis).

Fossil Taxon and Specimens. Cranial vaults of Homo neanderthalensis from Biache Saint Vaast, France (Vandermeersch, 1978; Guipert et al., 2011; termed specimens BSV1 and BSV2).

Phylogenetic Justification. The Biache Saint cranial vaults are widely accepted as definitively examples of Homo neanderthalensis, and so by definition part of the neanderthalensis-sapiens clade (Klein, 1999). Anatomical apomorphies shared with the early and classic Neanderthals are: the pattern and development of the frontal sinus; the development of the supraorbital torus; a postero-superior depression of the parietal bone corresponding to a prelambdatic depression; the alignment of the zygomatic process with the external auditory meatus; a coronally orientated tympanic plate; non alignment of the digastric groove with the base of the styloid process and the stylomastoid foramen; the pattern and dimensions of the semicircular canals (Guipert et al. 2011).

Minimum Age. 0.2 Ma

Soft Maximum Age. $1 \mathrm{Ma}$

Age Justification. The oldest Neanderthal fossils are just under $0.2 \mathrm{Ma}$ from Biache St. Vaast (France) and Ehringsdorf (Germany; Klein, 1999). As these dates postdate our marine timescale (Gradstein et al., 2012), we use the radiometric and faunal dates provided in the primary literature instead.

For the soft maximum split within $H$. sapiens, we would suggest the widespread occurrences of H. erectus outside Africa over 1 Ma (Klein, 1999). In the case of central Asia, there appears to have been populations of $H$. erectus nearly $1.8 \mathrm{Ma}$ (Lordkipanidze et al., 2007). Despite occurrences of the genus Homo throughout Asia and Africa by around $1 \mathrm{Ma}$, no evidence for Neanderthals or anatomically modern humans from this time is yet known (Klein, 1999).

Discussion. Neanderthals predate the European arrival of anatomically modern humans by thousands of years and are marked by a number of anatomical features distinct from those of anatomically modern humans (Klein, 1999).

Our own subspecies first becomes anatomically apparent at sites in the Levant such as Skhul and Qafzeh caves in Israel, associated at Skuhl 
with ornamented gastropod remains (Nassarius gibbosulus) shown to have been manipulated by humans between 0.1 and $0.135 \mathrm{Ma}$ (Vanhaeren et al., 2006). The neandertal record is older; hence, the paleontologically minimum date for modern humans may be estimated based on the earliest, undisputed Neanderthal sites in Europe at 0.2 Ma.

\section{ACKNOWLEDGEMENTS}

We thank Dan Ksepka and Jim Parham for their immense drive in bringing the 'Calibrating the tree of life' initiative to fruition, through meetings, publications, and the web resources. RJA thanks E. Bärmann for helpful comments on the manuscript concerning mammalian calibrations. MJB thanks J.S. Anderson, R.J. Butler, S.E. Evans, J. Fröbisch, D. Ksepka, R.R. Reisz, and M. Van Tuinen for advice on tetrapod dates. PCJD thanks R.J. Aldridge, S. Bengtson, Dong Xiping, G. Edgecombe, Huang Diying, A. Kouchinsky, J. Laurie, Ma Xiaoya, G. Miller, R.S. Nicoll, J. Patterson, D. Pisani, I. Rahman, I. Sansom, D. Schmidt, A.B. Smith, and E. Sperling for help in establishing phylogenetic, taxonomic, or age constraints on calibrations. We further thank J. Parham, D. Ksepka, D. Polly, D.A.T. Harper, and two anonymous referees for their thorough work on the MS. This work is supported by National Evolutionary Synthesis Center (NESCent) through NSF grant no. EF-0905606.

\section{REFERENCES}

Adkins, R.M., Walton, A.H., and Honeycutt, R.L. 2003. Higher-level systematics of rodents and divergence time estimates based on two congruent nuclear genes. Molecular Phylogenetics and Evolution, 26:409-420.

Aldridge, R.J., Hou, X.G., Siveter, D.J., Siveter, D.J., and Gabbott, S.E. 2007. The systematics and phylogenetic relationships of vetulicolians. Palaeontology, 50:131-168.

Alfaro, M.E., Santini, F., and Brock, C.D. 2007. Do reefs drive diversification in marine teleosts? Evidence from the pufferfishes and their allies (order Tetraodontiformes). Evolution, 61:2104-2126.

Alvarenga, H.M.F. 1983. Uma ave ratitae do Paleoceno Brasileiro: bacia calcária de Itaboraí, Estado do Rio de Janeiro, Brasil. Boletim do Museu Nacional, Nova Série, Geologia 41:1-8.

Anderson, J.S. 2001. The phylogenetic trunk: Maximal inclusion of taxa with missing data in an analysis of the Lepospondyli (Vertebrata, Tetrapoda). Systematic Biology, 50:170-193.

Anderson, J.S. 2008. Focal review: The origin(s) of modern amphibians. Evolutionary Biology, 35:231-247.
Anderson, M.E., Hiller, N., and Gess, R.W. 1994. The first Bothriolepis-associated Devonian fish fauna from Africa. South African Journal of Science, 90:397-403.

Anderson, M.E., Long, J.A., Gess, R.W., and Hiller, N. 1999. An unusual new fossil shark (Pisces: Chondrichthyes) from the Late Devonian of South Africa. Records of the Western Australian Museum, 57:151156.

Andrews, P. and Cronin, J.E. 1982. The relationships of Sivapithecus and Ramapithecus and the evolution of the orang-utan. Nature, 297:541-546.

Anemone, R.L. and Dirks, W. 2009. An anachronistic Clarkforkian mammal fauna from the Paleocene Fort Union Formation (Great Divide Basin, Wyoming, USA). Geologica Acta, 7:113-124.

Antcliffe, J.B., and Brasier, M.D. 2007. Charnia and sea pens are poles apart. Journal of the Geological Society, London, 164:49-51.

Antcliffe, J.B. and Brasier, M.D. 2008. Charnia at 50: developmental models for Ediacaran fronds. Palaeontology, 51:11-26.

Anthonissen, D.E. and Ogg, J.G. 2012. Appendix 3: Cenozoic and Cretaceous biochronology of planktonic foraminifera and calcareous nannofossils, $p$. 1083-1127. In Gradstein, F.M., Ogg, J.G., Schmitz, M., and Ogg, G. (eds.), The Geologic Time Scale 2012. Elsevier, Amsterdam.

Archibald, J.D. 2003. Timing and biogeography of the eutherian radiation:fossils and molecules compared. Molecular Phylogenetics and Evolution, 28:350-359.

Archibald, J.D., Averianov, A.O., and Ekdale, E.G. 2001. Late Cretaceous relatives of rabbits, rodents, and other extant eutherian mammals. Nature, 414:62-65.

Arcila, D., Pyron, R.A., Tyler, J.C., Ortí, G., and Betancur -R., R. 2015. An evaluation of fossil tip-dating versus node-age calibrations in tetraodontiform fishes (Teleostei: Percomorphaceae). Molecular Phylogenetics and Evolution, 82:131-145.

Arnason, U., Gullberg, A., Gretarsdottir, S., Ursing, B., and Janke, A. 2000. The mitochondrial genome of the sperm whale and a new molecular reference for estimating eutherian divergence dates. Journal of Molecular Evolution, 50:569-578.

Arratia, G. 1987. Anaethalion and similar teleosts (Actinopterygii, Pisces) from the Late Jurassic (Tithonian) of southern Germany and their relationships. Palaeontographica, Abteilung A, 200:1-44.

Arratia, G. 1996. The Jurassic and the early history of teleosts, p. 243-259. In Arratia, G. and Viohl, G. (eds.), Mesozoic Fishes - Systematics and Paleoecology. Verlag Dr. Friedrich Pfeil, Munich.

Arratia, G. 1997. Basal teleosts and teleostean phylogeny. Palaeo Ichthyologica, 7:1-168.

Arratia, G. 1999. The monophyly of Teleostei and stemgroup teleosts, p. 265-334. In Arratia, G. and Schultze, H.-P. (eds.), Mesozoic Fishes 2 - Systematics and Fossil Record. Verlag Dr. Friedrich Pfeil, Munich. 
Arratia, G. 2000. Remarkable teleostean fishes from the Late Jurassic of southern Germany and their phylogenetic relationships. Mitteilungen aus dem Museum für Naturkunde in Berlin, Geowissenschaftliche, Reihe 3:137-179.

Arratia, G. 2001. The monophyly of Teleostei and stemgroup teleosts. Consensus and disagreements, $p$. 265-334. In Arratia, G. and Schultze, H.-P. (eds.), Mesozoic Fishes 2-Systematics and Fossil Record. Verlag Dr. Friedrich Pfeil, Munich.

Arratia, G. 2004. Mesozoic halecostomes and the early radiation of teleosts, p. 279-315. In Arratia, G. and Tintori, A. (eds.), Mesozoic Fishes 3 - Systematics, Paleoenvironments and Biodiversity. Verlag Dr. Friedrich Pfeil, Munich.

Arratia, G. 2013. Morphology, taxonomy, and phylogeny of Triassic pholidophorid fishes (Actinopterygii: Teleostei). Society of Vertebrate Paleontology Memoir, 13:1-138

Arratia, G. and Thies, D. 2001. A new teleost (Osteichthyes, Actinopterygii) from the Early Jurassic Posidonia shale of northern Germany. Mitteilungen aus dem Museum für Naturkunde in Berlin, Geowissenschaftliche, Reihe 4:167-187.

Arratia, G. and Tintori, A. 1999. The caudal skeleton of the Triassic actinopterygian †Prohalecites and its phylogenetic position, p. 121-142. In Arratia, G. and Schultze, H.-P. (eds.), Mesozoic Fishes 2 - Systematics and Fossil Record. Verlag Dr. Friedrich Pfeil, Munich.

Arratia, G. and Tischlinger, H. 2010. The first record of Late Jurassic crossognathiform fishes from Europe and their phylogenetic importance for teleostean phylogeny. Fossil Record, 13:317-341.

Arratia, G., López-Arbarello, A., Prasad, G.V.R., Parmar, V., and Kriwet, J. 2004. Late Cretaceous-Paleocene percomorphs (Teleostei) from India-early radiation of Perciformes, p. 635-663. In Arratia, G., Wilson, M.V.H., and Cloutier, R. (eds.), Recent Advances in the Origin and Early Radiation of Vertebrates. Verlag Dr. Friedrich Pfeil, Munich.

Asher, R.J. 1999. A morphological basis for assessing the phylogeny of the "Tenrecoidea" (Mammalia, Lipotyphla). Cladistics, 15:231-252.

Asher, R.J. 2007. A web-database of mammalian morphology and a reanalysis of placental phylogeny. BMC Evolutionary Biology, 7:108.

Asher, R.J. and Avery, D.M. 2010. New golden moles (Afrotheria, Chrysochloridae) from the Pliocene of South Africa. Paleontologica Electronica, 13:3A.

Asher, R.J. and Helgen, K.M. 2010. Nomenclature and placental mammal phylogeny. BMC Evolutionary Biology, 10:102.

Asher, R.J. and Lehmann, T. 2008. Dental eruption in afrotherian mammals. BMC Biology, 6:14.

Asher, R.J. and Seiffert, E.R. 2010. Systematics of endemic African mammals, p. 903-920 In Werdelin, L. and Sanders, W.J. (eds.), Cenozoic Mammals of Africa. University of California Press, Berkeley.
Asher, R.J., Bennett, N., and Lehmann, T. 2009. The new framework for understanding placental mammal evolution. Bioessays, 31:853-64.

Asher, R.J., Meng, J., Wible, J.R., McKenna, M.C., Rougier, G.W., Dashzeveg, D., and Novacek, M.J. 2005. Stem Lagomorpha and the antiquity of Glires. Science, 307:1091-1094.

Averianov, A. 2002. Early Cretaceous" symmetrodont" mammal Gobiotheriodon from Mongolia and the classification of" Symmetrodonta". Acta Palaeontologica Polonica, 47:705-716.

Averianov, A. and Archibald, J.D. 2005. Mammals from the mid-Cretaceous Khodzhakul Formation, Kyzylkum Desert, Uzbekistan. Cretaceous Research, 26:593-608.

Averianov, A. and Skutschas, P.P. 2001. A new genus of eutherian mammal from the Early Cretaceous of Transbaikalia, Russia. Acta Palaeontologica Polonica, 46:431-436.

Azanza, B. and Morales, J. 1994. Tethytragus nov. gen et Gentrytragus nov. gen. Deux nouveaux Bovidés (Artiodactyla, Mammalia) du Miocène moyen. Proceedings, Koninklijke Nederlandse Akademie van Wetenschappen B, 97:249-282.

Azuma, Y., Kumazawa, Y., Miya, M., Mabuchi, K., and Nishida, M. 2008. Mitogenomic evaluation of the historical biogeography of cichlids toward reliable dating of teleostean lineages. BMC Evolutionary Biology, 8:215.

Bajpai, S. and Gingerich, P.D. 1998. A new Eocene archaeocete (Mammalia, Cetacea) from India and the time of origin of whales. Proceedings of the National Academy of Sciences, USA, 95:1546415468.

Bajpai, S., Thewissen, J.G., and Sahni, A. 2009. The origin and early evolution of whales: macroevolution documented on the Indian subcontinent. Journal of Biosciences, 34:673-686.

Bandyopadhyay, S. and Sengupta, D.P. 2006. Vertebrate faunal turnover during the Triassic-Jurassic transition: an Indian scenario. New Mexico Museum of Natural History \& Science Bulletin, 37:77-85.

Bannikov, A.F. 2004. Discovery of a champsodontid (Pisces, Teleostei, Perciformes) in the Eocene of the northern Caucasus. Paleontological Journal, 38:311315.

Bannikov, A.F. 2008. Revision of the atheriniform fish genera Rhamphognathus Agassiz and Mesogaster Agassiz (Teleostei) from the Eocene of Bolca, northern Italy. Studie Ricerche sui Giacimenti Terziari di Bolca, 12:77-96.

Bannikov, A.F. 2010. Fossil Vertebrates of Russia and Adjacent Countries: Fossil Acanthopterygians Fishes. GEOS, Moscow.

Bannikov, A., Parin, N.V., and Pinna, G. 1985. Rhamphexocetus volans, gen. et sp. nov: a new beloniform fish (Beloniformes, Exocetoidei) from the Lower Eocene of Italy. Journal of Ichthyology, 25:150-155. 
Barron, J.A. 2003. Planktonic marine diatom record of the past 18 m.y.: appearances and extinctions in the Pacific and Southern oceans. Diatom Research, 18:203-224.

Barry, J.C., Cote, S., Maclatchy, L., Lindsay, E.H., Kityo, R., and Rajpar, A.R. 2005. Oligocene and Early Miocene Ruminants (Mammalia, Artiodactyla) from Pakistan and Uganda. Palaeontologia Electronica, 8:129.

Barry, J.C., Morgan, M.L.E., Flynn, L.J., Pilbeam, D., Behrensmeyer, A.K., Raza, S.M., Khan, I.A., Badgley, C., Hicks, J., and Kelley, J. 2002. Faunal and environmental change in the late Miocene Siwaliks of northern Pakistan. Paleobiology, 28:1-71.

Beard, K.C. 1993. Phylogenetic systematics of the Primatomorpha, with special reference to Dermoptera, p. 129-150. In Szalay, F.S., Novacek, M.J., and McKenna, M.C. (eds.) Mammal Phylogeny, Vol. 2: Placentals. Springer, New York.

Beatty, B.L. and Dooley, A.C. 2010. More than just old bones: the fossil record informs us about homology, and convergences of anatomy, physiology and behavior in the Cetacea otherwise unknown from modern animals, p. 129-140. In Murray, C.A. (ed.), Whales and Dolphins. Nova Publishers, New York.

Beck, R.M. 2012. An 'ameridelphian' marsupial from the early Eocene of Australia supports a complex model of Southern Hemisphere marsupial biogeography. Naturwissenschaften, 99:715-729.

Beck, R.M., Godthelp, H., Weisbecker, V., Archer, M., and Hand, S.J. 2008. Australia's oldest marsupial fossils and their biogeographical implications. PLoS ONE 3:e1858.

Becker, R.T., Gradstein, F.M., and Hammer, Ø. 2012. The Devonian Period, p. 559-601. In Gradstein, F.M., Ogg, J.G., Schmitz, M., and Ogg, G. (eds.), The Geologic Time Scale 2012. Elsevier, Amsterdam.

Bell, M.A., Stewart, J.D., and Park, P.J. 2009. The world's oldest fossil threespine stickleback fish. Copeia, 2009:256-265.

Bellwood, D.R. and Sorbini, L. 1996. A review of the fossil record of the Pomacentridae (Teleostei: Labroidei) with a description of a new genus and species from the Eocene of Monte Bolca, Italy. Zoological Journal of the Linnean Society, 117:159-174.

Bengtson, S., and Urbanek, A. 1986. Rhabdotubus, a Middle Cambrian rhabdopleurid hemichordate. Lethaia, 19:293-308.

Benton, M.J. 1985. Classification and phylogeny of the diapsid reptiles. Zoological Journal of the Linnean Society, 84:97-164.

Benton, M.J. 1990. Phylogeny of the major tetrapod groups: morphological data and divergence dates. Journal of Molecular Evolution, 30:409-424.

Benton, M.J. 1993. The Fossil Record 2, Chapman and Hall, London, 845 pp (editor).

Benton, M.J. 1999. Scleromochlus taylori and the origin of dinosaurs and pterosaurs. Philosophical Transactions of the Royal Society, Series B, 354:1423-1446.
Benton, M.J. and Donoghue, P.C.J. 2007. Palaeontological evidence to date the tree of life. Molecular Biology and Evolution, 24:26-53.

Benton, M.J., Donoghue, P.C.J., and Asher, R.A. 2009. Calibrating and constraining molecular clocks, p. 3586. In Hedges, S.B. and Kumar, S. (eds.), The Timetree of Life. Oxford University Press, Oxford.

Benton, M.J., Tverdokhlebov, V.P., and Surkov, M.V. 2004. Ecosystem remodelling among vertebrates at the Permian-Triassic boundary in Russia. Nature, 432:97-100.

Bergqvist, L.P., Abrantes, E.A.L., and Avilla, L.D. 2004. The Xenarthra (Mammalia) of Sao Jose de Itaborai Basin (upper Paleocene, Itaboraian), Rio de Janeiro, Brazil. Geodiversitas, 26:323-337.

Betancur-R., R., Broughton, R.E., Wiley, E.O., Carpenter, K., López, J.A., Li, C., Holcroft, N.I., Arcila, D., Sanciangco, M., Cureton, J.C., II, Zhang, F., Buser, T., Campbell, M.A., Ballesteros, J.A., Roa-Varon, A., Willis, S., Borden, W.C., Rowley, T., Reneau, P.C., Hough, D.J., Lu, G., Grande, T., Arratia, G., and Ortí, G. 2013. The tree of life and a new classification of bony fishes. PLoS Currents Tree of Life, doi: 10.1371/currents.tol.53ba26640df0ccaee75bb165c8c26288.

Bi, S., Wang, Y., Guan, J., Sheng, X., and Meng, J. 2014. Three new Jurassic euharamiyidan species reinforce early divergence of mammals. Nature, 514:579-84.

Bibi, F. 2013. A multi-calibrated mitochondrial phylogeny of extant Bovidae (Artiodactyla, Ruminantia) and the importance of the fossil record to systematics. BMC Evolutionary Biology 13: 166.

Bibi, F., Bukhsianidze, M., Gentry, A.W., Geraads, D., Kostopoulos, D.S., and Vrba, E. 2009. The fossil record and evolution of Bovidae: state of the field. Palaeontologia Electronica, 12:1-11.

Bininda-Emonds, O.R. and Purvis, A. 2012. Comment on "Impacts of the Cretaceous Terrestrial Revolution and $\mathrm{KPg}$ extinction on mammal diversification." Science, 337:34.

Bininda-Emonds, O.R., Cardillo, M., Jones, K.E., MacPhee, R.D., Beck, R.M., Grenyer, R., Price, S.A., Vos, R.A., Gittleman, J.L., and Purvis, A. 2007. The delayed rise of present-day mammals. Nature, 446:507-512.

Blanga-Kanfi, S., Miranda, H., Penn, O., Pupko, T., DeBry, R.W., and Huchon, D. 2009. Rodent phylogeny revised: analysis of six nuclear genes from all major rodent clades. BMC Evolutionary Biology, 9:71.

Blieck, A., Turner, S., Burrow, C.J., Schultze, H.P., Rexroad, C.B., Bultynck, P., and Nowlan, G.S. 2010. Fossils, histology, and phylogeny: Why conodonts are not vertebrates. Episodes, 33:234-241.

Bloch, J.I., Silcox, M.T., Boyer, D.M., and Sargis, E.J. 2007. New Paleocene skeletons and the relationship of plesiadapiforms to crown-clade primates. Proceedings of the National Academy of Sciences, USA, 104:1159-1164. 
Blot, J. 1980. La faune ichthyologique des gisements du Monte Bolca (Province de Vérone, Italie). Catalogue systématique présentat l'état actuel des recherches concernant cette faune. Bulletin du Museum national d'Histoire naturelle, Paris, $4^{e}$ serie, section C, 2:339396.

Borsuk-Białynicka M., Maryańska, T., and Shishkin, M.A. 2003. New data on the age of the bone breccia from the locality Czatkowice 1 (Cracow Upland, Poland). Acta Palaeontologica Polonica, 48:153-155.

Boschetto, H.B., Brown, F.H., and Mcdougall, I. 1992. Stratigraphy of the Lothidok Range, Northern Kenya, and K/Ar Ages of Its Miocene Primates. Journal of Human Evolution, 22:47-71.

Bosellini, A. and Parente, M. 1994. The Apulia Platform margin in the Salento Peninusla (southern Italy). Giornale di Geologia, Rivisita di Geologia Seimentaria e Geologia Marinia Ser. 3a, 56:167-177.

Botella, H., Blom, H., Dorka, M., Ahlberg, P.E., and Janvier, P. 2007. Jaws and teeth of the earliest bony fishes. Nature, 448:583-586.

Bown, T.M. and Schankler, D. 1982. A review of the Proteutheria and Insectivora of the Willwood Formation (lower Eocene), Bighorn Basin, Wyoming. United States Geological Survey Bulletin, 1523:1-79.

Brazeau, M.D. 2009. The braincase and jaws of a Devonian "acanthodian" and modern gnathostome origins. Nature, 457:305-308.

Brazeau, M.D. and Friedman, M. 2014. The characters of Palaeozoic jawed vertebrates. Zoological Journal of the Linnean Society, 170:779-821.

Brenner, P., Geldmacher, W., and Schroeder, R. 1974. Ostrakoden und Alter der Plattenkalken von Rúbies (Serria del Monsech, Prov. Lérida, NE-Spanien). Neues Jahrbuch für Geologie und Paläontologie, Abhandlungen, 8:513-524.

Brocklehurst, N., Upchurch, P., Mannion, P.D., and O'Connor, J. 2012. The completeness of Mesozoic birds: implications for early avian evolution. PLOS ONE, 7:e39056.

Bromham, L.D. and Degnan, B.M. 1999. Hemichordates and deuterostome evolution: robust molecular phylogenetic support for a hemichordate + echinoderm clade. Evolution \& Development, 1:166-171.

Broughton, R.E., Betancur-R., R., Li, C., Arratia, G., and Ortí, G. 2013. Multi-locus phylogenetic analysis reveals the pattern and tempo of bony fish evolution. PLoS Currents Tree of Life, doi: 10.1371/currents.tol.2ca8041495ffafd0c92756e75247483e.

Brown, J.W. and Van Tuinen, M. 2011. Evolving perceptions on the antiquity of the modern avian tree, $p$. 306-323. In Dyke, G.J. and Kaiser, G. (eds.), Living Dinosaurs: the Evolutionary History of Modern Birds. Wiley, New York.

Brunet, M. 2000. Chad: Discovery of a vertebrate fauna close to the Mio-Pliocene boundary. Journal of Vertebrate Paleontology 20:205-209.
Brunet, M., Guy, F., Pilbeam, D., Mackaye, H.T., Likius, A., Ahounta, D., Beauvilain, A., Blondel, C., Bocherens, H., Boisserie, J.R., De Bonis, L., Coppens, Y., Dejax, J., Denys, C., Duringer, P., Eisenmann, V.R., Fanone, G., Fronty, P., Geraads, D., Lehmann, T., Lihoreau, F., Louchart, A., Mahamat, A., Merceron, G., Mouchelin, G., Otero, O., Campomanes, P.P., De Leon, M.P., Rage, J.C., Sapanet, M., Schuster, M., Sudre, J., Tassy, P., Valentin, X., Vignaud, P., Viriot, L., Zazze, A., and Zellikefer, C. 2002. A new hominid from the Upper Miocene of Chad, Central Africa. Nature, 418:145-151.

Brusatte, S.L., Benton, M.J., Desojo, J.B., and Langer, M.C. 2010. The higher-level phylogeny of Archosauria (Tetrapoda: Diapsida). Journal of Systematic Palaeontology, 8:3-47

Budd, G.E. and Jensen, S. 2000. A critical reappraisal of the fossil record of bilaterian phyla. Biological Reviews, 74:253-295.

Buffetaut, E. and Le Loeuff, J., 1998. A new giant ground bird from the Upper Cretaceous of southern France. Journal of the Geological Society, London, 155:1-4.

Butler, R.J., Brusatte, S.L., Reich, M., Nesbitt, S.J., Schoch, R.R., and Hornung, J.J. 2011. The sailbacked reptile_Ctenosauriscus_from the latest Early Triassic of Germany and the timing and biogeography of the early archosaur radiation. PLoS ONE, 6 (10):e25693.

Butterfield, N.J. 2006. Hooking some stem-group 'worms': fossil lophotrochozoans in the Burgess Shale. BioEssays, 28:1161-1166.

Butterfield, N.J., Knoll, A.H., and Swett, K. 1994. Paleobiology of the Neoproterozoic Svanbergfjellet Formation, Spitsbergen. Fossils \& Strata, 34:1-84.

Cai, C.Y., Fang, Z.J., Li, X.X., Wang, Y., Geng, L.Y., Gao, L.D., Wang, N.Z., Li, D.Y., and Liu, Z.H. 1994. New advance in the biostratigraphy of Lower and Middle Devonian marine-continental transitional strata in east Yunnan. Science in China (Series B), 24:634639.

Caldwell, M.W. 1999. Squamate phylogeny and the relationships of snakes and mosasauroids. Zoological Journal of the Linnean Society, 125:115-147.

Cameron, C.B., Garey, J.R., and Swalla, B.J. 2000. Evolution of the chordate body plan: new insights from phylogenetic analyses of deuterostome phyla. Proceedings of the National Academy of Sciences, USA, 97:4469-4474.

Campbell, L.I., Rota-Stabelli, O., Edgecombe, G.D., Marchioro, T., Longhorn, S.J., Telford, M.J., Philippe, H., Rebecchi, L., Peterson, K.J., and Pisani, D. 2011. MicroRNAs and phylogenomics resolve the relationships of Tardigrada and suggest that velvet worms are the sister group of Arthropoda. Proceedings of the National Academy of Sciences, USA, 108:1592015924. 
Cannon, J.T., Rychel, A.L., Blasczyk, H., Halanych, K.M., and Swalla, B.J. 2009. Molecular phylogeny of Hemichordata. Molecular Phylogenetics \& Evolution, 52:17-24.

Cantuneanu, O., Khalifa, M.A., and Wanas, H.A. 2006. Sequence stratigraphy of the Lower Cenomanian Bahariya Formation, Bahariya Oasis, Western Desert, Egypt. Sedimentary Geology, 190:121-137.

Cao, Y., Sorenson, M.D., Kumazawa, Y., Mindell, D.P., and Hasegawa, M. 2000. Phylogenetic position of turtles among amniotes: evidence from mitochondrial and nuclear genes. Gene, 259:139-148.

Carnevale, G. and Pietsch, T.W. 2012. †Caruso, a new genus of anglerfishes from the Eocene of Monte Bolca, Italy, with comparative osteology and phylogeny of the teleost family Lophiidae. Journal of Systematic Paleontology, 10:47-72.

Carnevale, G. and Tyler, J.C. 2010. Review of the fossil pufferfish genus Archaeotetradon (Teleostei, Tetraodontidae), with description of three new taxa from the Miocene of Italy. Geobios, 43:283-304.

Caron, J.-B., Conway Morris, S., and Shu, D. 2010. Tentaculate fossils from the Cambrian of Canada (British Columbia) and China (Yunnan) interpreted as primitive deuterostomes. PLoS ONE, 5(3):e9586.

Carroll, R.L. 2001. The origin and early radiation of terrestrial vertebrates. Journal of Palaeontology, 75:1202-1213.

Cater, J.M.L., Briggs, D.E.G., and Clarkson, E.N.K. 1989. Shrimp-bearing sedimentary successions in the Lower Carboniferous (Dinantian) Cementstone and Oil Shale groups of northern Britain. Transactions of the Royal Society of Edinburgh: Earth Sciences, 80:5-15.

Cavin, L. 2010. Diversity of Mesozoic semionotiform fishes and the origin of gars (Lepisosteidae). Naturwissenschaften, 97:1035-1040.

Cavin, L. and Forey, P.L. 2007. Using ghost lineages to identify diversification events in the fossil record. Biology Letters, 3:201-204.

Cela-Conde, C.J. and Ayala, F.J. 2003. Genera of the human lineage. Proceedings of the National Academy of Sciences, USA, 100:7684-689.

Chaimanee, Y., Suteethorn, V., Triamwichanon, S., and Jaeger, J.J. 1996. A new stephanodont Murinae (Mammalia, Rodentia) from the early Pleistocene of Thailand and the age and place of the Rattus adaptive radiation in south east Asia. Comptes Rendus de l'Académie des Sciences, Série II Fascicule A-Sciences de la Terre et des Planètes, 322:155-162.

Chambers, L.M., Pringle, M., Fitton, G., Larsen, L.M., Pedersen, A.K., and Parrish, R. 2003. Recalibration of the Palaeocene-Eocene boundary (PE) using high precision $\mathrm{U}-\mathrm{Pb}$ and $\mathrm{Ar}-\mathrm{Ar}$ isotopic dating. Abstracts, EGS-AGU-EUG Joint Assembly, Nice, 6th-11 th April 2003.
Chanet, B., Guintard, C., Betti, E., Gallut, C., Dettaï, A., and Lecointre, G. 2013. Evidence for a close phylogenetic relationship between the teleost orders Tetraodontiformes and Lophiiformes based on an analysis of soft anatomy. Cybium, 37:179-198.

Chang, M.-M. 1982. The Braincase of Youngolepis, a Lower Devonian Crossopterygian from Yunnan, south-western China. Unpublished PhD thesis, Department of Geology, University of Stockholm, and Section of Palaeozoology, Swedish Museum of Natural History.

Chang, M.-M. and Yu, X. 1984. Structure and phylogenetic significance of Diabolichthys speratus gen. et sp. nov., a new dipnoan-like form from the Lower Devonian of eastern Yunnan, China. Proceedings of the Linnean Society of New South Wales, 107:171184.

Chatterjee, S. 2002. The morphology and systematics of Polarornis, a Cretaceous loon (Aves: Gaviidae) from Antarctica, p. 125-155. In Zhou, Z. and Zhang, F. (eds.), Proceedings of the 5th International Meeting of the Society of Avian Paleontology and Evolution. Science Press, Beijing.

Chen, J.Y., Huang, D.Y., and Li, C.W. 1999. An early Cambrian craniate-like chordate. Nature, 402:518522.

Chen, J.Y., Dzik, J., Edgecombe, G.D., Ramsköld, L., and Zhou, G.-Q. 1995. A possible Early Cambrian chordate. Nature, 377:720-722.

Chen, J.Y., Huang, D.Y., Peng, Q.Q., Chi, H.M., Wang, X.Q., and Feng, M. 2003. The first tunicate from the Early Cambrian of South China. Proceedings of the National Academy of Sciences, USA, 100:83148318.

Chevret, P. and Dobigny, G. 2005. Systematics and evolution of the subfamily Gerbillinae (Mammalia, Rodentia, Muridae). Molecular Phylogenetics and Evolution, 35:674-688.

Churakov, G., Sadasivuni, M.K., Rosenbloom, K.R., Huchon, D., Brosius, J., and Schmitz, J. 2010. Rodent evolution: back to the root. Molecular Biology and Evolution, 27:1315-1326.

Cifelli, R.L. 1993. Early Cretaceous mammal from North America and the evolution of marsupial dental characters. Proceedings of the National Academy of Sciences, USA, 90:9413-9416.

Cifelli, R.L. 1999. Tribosphenic mammal from the North American Early Cretaceous. Nature, 401:363-6.

Cione, A. 1986. Los pesces continentales del Cenozoico de Argentina. Su signifcación paleoambiental y paleobiogeográfica. Congreso Argentino de Paleontología y Bioestratigrafia, No. 4, Actas, 2:101-106.

Clark, J.M. and Hernandez, R. 1994. A new burrowing diapsid from the Jurassic La Boca Formation of Tamaulipas, Mexico. Journal of Vertebrate Paleontology, 14:180-195. 
Clarke, J.A. and Norell, M.A. 2004. New avian remains and a review of the known avifauna from the Late Cretaceous Nemegt Formation of Mongolia. American Museum Novitates, 3447:1-12.

Clarke, J.A., Tambussi, C.P., Noriega, J.I., Erickson, G.M., and Ketcham, R.A. 2005. Definitive fossil evidence for the extant avian radiation in the Cretaceous. Nature, 433:305-308.

Clausen, S. and Smith, A.B. 2008. Stem structure and evolution in the earliest pelmatozoan echinoderms. Palaeontology, 82:737-748.

Clemens, W.A. and Wilson, G.P. 2009. Early Torrejonian mammalian local fauna from northeastern Montana, U.S.A. Museum of Northern Arizona Bulletin, 65:111158.

Cloutier, R. and Ahlberg, P.E. 1996. Morphology, characters, and the interrelationships of basal sarcopterygians, p. 445-479. In Stiassny, M.L.J., Parenti, L.R., and Johnson, G.D. (eds.), Interrelationships of fishes. Academic Press, San Diego.

Coates, M.I. 1998. Actinopterygian neurocrania from the Namurian of Bearsden, Scotland, with comments on early actinopterygian neurocrania. Zoological Journal of the Linnean Society, 122:27-59.

Coates, M.I. 1999. Endocranial preservation of a Carboniferous actinopterygian of Lancashire, UK, and the interrelationships of primitive actinopterygians. Philosophical Transactions of the Royal Society of London, Series B, 354:435-462.

Coates, M.I. and Gess, R.W. 2007. A new reconstruction of Onychoselache traquairi, comments on early chondrichthyan pectoral girdles and hybodontiform phylogeny. Palaeontology, 50:1421-1446.

Condon, D., Zhu, M., Bowring, S.A., Wang, W., Yang, A., and Jin, Y. 2005. U-Pb ages from the Neoproterozoic Doushantuo Formation, China. Science, 308:95-98.

Conway Morris, S. 1979. Middle Cambrian polychaetes from the Burgess Shale of British Columbia. Philosophical Transactions of the Royal Society of London, Series B, 285:227-274.

Conway Morris, S. and Caron, J.-B. 2012. Pikaia gracilens Walcott, a stem-group chordate from the Middle Cambrian of British Columbia. Biological Reviews, 87:480-512.

Conway Morris, S., and Peel, J.S. 2008. The earliest annelids: Lower Cambrian polychaetes from the Sirius Passet Lagerstätte, Peary Land, North Greenland. Acta Palaeontologica Polonica, 53:137-148.

Cooper, A. and Penny, D. 1997. Mass survival of birds across the Cretaceous-Tertiary boundary: molecular evidence. Science, 275:1109-1113.

Cooper, R.A. and Sadler, P.M. 2012. The Ordovician Period, p. 489-523. In Gradstein, F.M., Ogg, J.G., Schmitz, M., and Ogg, G. (eds.), The Geologic Time Scale 2012. Elsevier, Amsterdam.
Cracraft, J., Barker, F.K., Braun, M., et al. (14 coauthors). 2004. Phylogenetic relationships among modern birds (Neornithes): toward an avian tree of life, p. 469-489. In Cracraft, J. and Donoghue, M.J. (eds.), Assembling the Tree of Life. Oxford University Press, New York.

Crimes, T.P. 1987. Trace fossils and correlation of late Precambrian and early Cambrian strata. Geological Magazine, 124:97-119.

Crimes, T.P. and Jiang, Z.W. 1986. Trace fossils from the Precambrian-Cambrian boundary candidate at Meishucun, Jinning, Yunnan, China. Geological Magazine, 123:641-649.

Crouch, E.M., Willumsen, P.S., Kulhanek, D.K., and Gibbs, S.J. 2014. A revised Paleocene (Teurian) dinoflagellate zonation from eastern New Zealand. Review of Palaeobotany and Palynology, 202, 47-79.

Dalla Vecchia, F.M., Venturini, S., and Tentor, M. 2002. The Cenomanian (Late Cretaceous) KonservatLagerstätte of en Nammoûra, (Kesrouâne Province), northern Lebanon. Bolletino della Società Paleontologica Italiana, 41:51-68.

Daly, M., Brugler, M.R., Cartwright, P., Collins, A.G., Dawson, M.N., Fautin, D.G., France, S.C., McFadden, C.S., Opresko, D.M., Rodriguez, E., Romano, S.L., and Stake, J.L. 2007. The phylum Cnidaria: A review of phylogenetic patterns and diversity 300 years after Linnaeus. Zootaxa 1668:127-182.

Darras, L., Derycke, C., Alieck, A., and Vachard, D. 2008. The oldest holocephalan (Chondrichthyes) from the Middle Devonian of the Boulonnais (Pas-deCalais, France). Comptes Rendus Palevol, 7:297304.

Dashzeveg, D. and Russell, D.E. 1988. Palaeocene and Eocene Mixodontia (Mammalia, Glires) of Mongolia and China. Palaeontology, 31:129-164.

Datta, P.M. and Ray, S. 2006. Earliest lizard from the Late Triassic (Carnian) of India. Journal of Vertebrate Paleontology, 26:795-800.

Davesne, D., Friedman, M., Barriel, V., Lecointre, G., Janvier, P., Gallut, C., and Otero, O. 2014. Early fossils illuminate character evolution and interrelationships of Lampridiformes (Teleostei, Acanthomorpha). Zoological Journal of the Linnean Society, 172:475498.

David, B., Lefebvre, B., Mooi, R., and Parsley, R. 2000. Are homalozoans echinoderms? An answer from the extraxial-axial theory. Paleobiology, 26:529-555.

Davies, N.S., Sansom, I.J., Nicoll, R.S., and Ritchie, A. 2011. Ichnofacies of the Stairway Sandstone fish-fossil beds (Middle Ordovician, Northern Territory, Australia). Alcheringa, 35:553-569.

Davis, J.W. 1887. The fossil fishes of the Chalk of Mount Lebanon in Syria. Scientific Transactions of the Royal Dublin Society, 3:457-636. 
Davis, M.P., Arratia, G., and Kaiser, T.M. 2013. The first fossil shellear and its implications for the evolution and divergence of the Kneriidae (Teleostei: Gonorynchiformes), p. 325-362. In Arratia, G., Schultze, H.-P., and Wilson, M.V.H. (eds.), Mesozoic Fishes 5 - Global Diversity and Evolution. Verlag Dr. Friedrich Pfeil, Munich.

Davis, S.P., Finarelli, J.A., and Coates, M.I. 2012. Acanthodes and shark-like conditions in the last common ancestor of modern gnathostomes. Nature, 486:247250.

Davydov, V., Wardlaw, B.R., and Gradstein, F.M. 2004. The Carboniferous Period, p. 603-651. In Gradstein, F.M., Ogg, J.G., and Smith, A.G. (eds.), A Geologic Time Scale 2004. Cambridge University Press, Cambridge.

Davydov, V., Korn, D., Schmitz, M.D., Gradstein, F.M., and Hammer, O. 2012. The Carboniferous Period, p. 437-488. In Gradstein, F.M., Ogg, J.G., Schmitz, M., and Ogg, G. (eds.), The Geologic Timescale 2012. Elsevier, Amsterdam.

de Gibert, J.M., Fregenal-Martínez, M.A., Buatois, L.A., and Mángano, M.G. 2010. Trace fossils and their palaeoecological significance in Lower Cretaceous lacustrine conservation deposits, El Montsec, Spain. Palaeogeography, Palaeoclimatology, Palaeoecology, 156:89-101.

de Jong, W.W., Leunissen, J.A.M., and Wistow, G.J. 1993. Eye lens crystallins and the phylogeny of placental orders: Evidence for a macroscelidid-paenungulate clade?, p. 5-12. In Szalay, F.S., Novacek, M.J., and McKenna, M.C. (eds.), Mammal Phylogeny, Vol. 2: Placentals. Springer, New York.

de Jong, W.W., Zweers, A., and Goodman, M. 1981. Relationship of aardvark to elephants, hyraxes and sea cows from a-crystallin sequences. Nature, 292:538-540.

deBraga, M. and Rieppel, O. 1997. Reptile phylogeny and the interrelationships of turtles. Zoological Journal of the Linnean Society, 120:281-354.

Deino, A.L., Tauxe, L., Monaghan, M., and Hill, A. 2002. 40Ar/(39)Ar geochronology and paleomagnetic stratigraphy of the Lukeino and lower Chemeron Formations at Tabarin and Kapcheberek, Tugen Hills, Kenya. Journal of Human Evolution, 42:117-140.

del Papa, C., Kirschbaum, A., Powell, J., Brod, A., Hongn, F., and Pimentel, M. 2010. Sedimentological, geochemical and paleontological insights applied to continental omission surfaces: a new approach for reconstructing an Eocene foreland basin in NW Argentina. Journal of South American Earth Sciences, 29:327-345.

Delsuc, F., Brinkmann, H., Chourrout, D., and Philippe, H. 2006. Tunicates and not cephalochordates are the closest living relatives of vertebrates. Nature, 439:965-968.

Delsuc, F., Tsagkogeorga, G., Lartillot, N., and Philippe, H. 2008. Additional molecular support for the new chordate phylogeny. Genesis, 46:592-604.
Demere, T.A., McGowen, M.R., Berta, A., and Gatesy, J. 2008. Morphological and molecular evidence for a stepwise evolutionary transition from teeth to baleen in mysticete whales. Systematic Biology, 57:15-37.

Dick, J.R.F. 1978. On the Carboniferous shark Tristychius arcuatus Agassiz from Scotland. Transactions of the Royal Society of Edinburgh, 70:63-109.

Dietl, G. and Schweigert, G. 2004. The Nusplingen lithographic limestone - a "fossil Lagerstaette" of late Kimmeridigian age from the Swabian Alb (Germany). Rivista Italiana di Paleontologia e Stratigrafia, 110:303-309.

Dilkes, D.W. 1998. The Early Triassic rhynchosaur Mesosuchus browni and the interrelationships of basal archosauromorph reptiles. Philosophical Transactions of the Royal Society of London, Series $B, 353: 501-541$.

Domning, D.P., Zalmout, I.S., and Gingerich, P.D. 2010. Sirenia, p. 147-160. In Werdelin, L. and Sanders, W.J. (eds.), Cenozoic Mammals of Africa. University of California Press, Berkeley.

Dong, X.-P., Cunningham, J.A., Bengtson, S., Thomas, C.-W., Liu, J.-B., Stampanoni, M., and Donoghue, P.C.J. 2013. Embryos, polyps and medusae of the early Cambrian scyphozoan Olivooides. Proceedings of the Royal Society, Series B, 280(20130071):1-8.

Donoghue, P.C.J. and Benton, M.J. 2007. Rocks and clocks: calibrating the Tree of Life using fossils and molecules. Trends in Ecology and Evolution, 22:424431.

Donoghue, P.C.J. and Keating, J.N. 2014. Early vertebrate evolution, Palaeontology, 57:879-893.

Donoghue, P.C.J. and Purnell, M.A. 2009. Distinguishing heat from light in debate over controversial fossils. BioEssays, 31:178-189.

Donoghue, P.C.J. and Smith, M.P. 2001. The anatomy of Turinia pagei (Powrie) and the phylogenetic status of the Thelodonti. Transactions of the Royal Society of Edinburgh: Earth Sciences, 92:15-37.

Donoghue, P.C.J., Forey, P.L., and Aldridge, R.J. 2000. Conodont affinity and chordate phylogeny. Biological Reviews, 75:191-251.

Donoghue, P.C.J., Smith, M.P., and Sansom, I.J. 2003. The origin and early evolution of chordates: molecular clocks and the fossil record, p. 190-223. In Donoghue, P.C.J. and Smith, M.P. (eds.), Telling the Evolutionary Time: Molecular Clocks and the Fossil Record. CRC Press, London.

dos Reis, M., Donoghue, P.C.J., and Yang, Z. 2014 Neither phylogenomic nor palaeontological data support a Palaeogene origin of placental mammals. Biology Letters, 10:20131003.

dos Reis, M., Inoue, J., Hasegawa, M., Asher, R.J., Donoghue, P.C., and Yang, Z. 2012. Phylogenomic datasets provide both precision and accuracy in estimating the timescale of placental mammal phylogeny. Proceedings of the Royal Society, Series B, 279:3491-3500. 
Droser, M.L. and Gehling, J.G. 2012. Old and groovy. Science, 336:1646-1647.

Dunkle, D. 1939. A new paleoniscid fish from the Texas Permian. American Journal of Science, 237:262-274.

Dunn, C.W., Hejnol, A., Matus, D.Q., Pang, K., Browne, W.E., Smith, S.A., Seaver, E., Rouse, G.W., Obst, M., Edgecombe, G.D., Sorensen, M.V., Haddock, S.H.D., Schmidt-Rhaesa, A., Okusu, A., Kristensen, R.M., Wheeler, W.C., Martindale, M.Q., and Giribet, G. 2008. Broad phylogenomic sampling improves resolution of the animal tree of life. Nature, 452:745-749.

Dupret, V., Sanchez, S., Goujet, D., Tafforeau, P., and Ahlberg, P.E. 2014. A primitive placoderm sheds light on the origin of the jawed vertebrate face. Nature, 507:500-503.

Dyke, G.J. 2001. The fossil waterfowl (Aves: Anseriformes) from the Eocene of England. American Museum Novitates, 3354:1-15.

Dyke, G.J. and van Tuinen, M. 2004. The evolutionary radiation of modern birds (Neornithes): reconciling molecules, morphology and the fossil record. Zoological Journal of the Linnean Society, 141:153-177.

Dzik, J. 1995. Yunnanozoon and the ancestry of the vertebrates. Acta Palaeontologica Polonica, 40:341360.

Eastman, C.R. 1900. New fossil bird and fish remains from the Middle Eocene of Wyoming. Geological Magazine, Decade 4, 7:54-58.

Eastman, C.R. 1908. Devonian fishes of lowa. Annual Report, lowa Geological Survey, 18:29-291.

Edgecombe, G.D., Giribet, G., Dunn, C.W., Hejnol, A., Kristensen, R.M., Neves, R.C., Rouse, G.W., Worsaae, K., and Sørensen, M.V. 2011. Higher-level metazoan relationships: recent progress and remaining questions. Organisms, Diversity and Evolution, 11:151-172.

Eernisse, D.J. and Peterson, K.J. 2004. The interrelationships of animal phyla, p. 197-208. In Cracraft, J. and Donoghue, M.J. (eds.), Assembling the Tree of Life. Oxford University Press, New York.

Eibye-Jacobsen, D. 2004. A reevaluation of Wiwaxia and the polychaetes of the Burgess Shale. Lethaia, $37: 317-335$.

Ellison, R.A., Knox, W.O'B., Jolley, D.W., and King, C. 1994. A revision of the lithostratigraphical classification of the early Palaeogene stratigraphy of the London Basin and East Anglia. Proceedings of the Geologists' Association, 105:187-197.

Elzanowski, A. and Stidham, T.A. 2011. A galloanserine quadrate from the Late Cretaceous Lance Formation of Wyoming. The Auk, 128:138-145.

Emonet, E.-G., Andossa, L., Mackaye, H.T., and Brunet, M. 2014. Subocclusal ental morphology of Sahelanthropus tchadensis and the evolution of teeth in hominins. American Journal of Physical Anthropology, 153:116-123.
Enay, R., Bernier, P., Barale, G., Borseau, J.-P., Buffetaut, E., Gaillard, C., Gall, J.-C., and Wenz, S. 1994. Les ammonites des calcaires lithographiques de Cerin (Ain, France): stratigraphie et taphonomie. Geobios, Mémoire Spéciale, 16:25-36.

Erdtmann, B.-D., Weber, B., Schultze, H.-P., and Egenhoff, S. 2000. A possible agnathan plate from the lower Arenig (Lower Ordovician) of south Bolivia. Journal of Vertebrate Paleontology, 20:394-399.

Ericson, P.G., Anderson, C.L., Britton, T. et al . 2006. Diversification of Neoaves: integration of molecular sequence data and fossils. Biology Letters, 2:543547.

Estes, R., and Wake, M.H. 1972. The first fossil record of caecilian amphibians. Nature, 239:228-231.

Estes, R., de Queiroz, K., and Gauthier, J. 1988. Phylogenetic relationship within Squamata, p. 119-281. In Estes, R.G. and Pregill, G.K. (eds.), Phylogenetic Relationships of the Lizard Families. Stanford University Press, Stanford, California.

Ettachfini, E.M. and Andreu, B. 2004. Le Cénomanien et le Turonien de la plate-forme Préafricaine du Maroc. Cretaceous Research 25:277-302.

Evans, S.E. 1988. The early history and relationships of the Diapsida, p. 221-260. In M.J. Benton (ed.), The Phylogeny and Classification of the Tetrapods, Vol. 1: Amphibians, Reptiles, Birds. Clarendon Press. Oxford

Evans, S.E. 2003. At the feet of the dinosaurs: the early history and radiation of lizards. Biological Reviews, 78:513-551.

Evans, S.E. and Jones, M.E.H. 2010. The origin, early history and diversification of lepidosauromorph reptiles, p. 27-44. In Bandyopadhyay, S. (ed.), New Aspects of Mesozoic Biodiversity. Springer, Berlin.

Evans, S.E., Milner, A.R., and Mussett, F. 1990. A discoglossid frog (Amphibia: Anura) from the Middle Jurassic of England. Palaeontology, 33:299-311.

Evans, S.E., Prasad, G.V.R., and Manhas, B. 2002. An acrodont iguanian from the Mesozoic Kota Formation of India. Journal of Vertebrate Paleontology, 22:299312.

Evans, S.E., Lally, C., Chure, D.C., Elder, A., and Maisano, J.A. 2005. A late Jurassic salamander (Amphibia: Caudata) from the Morrison Formation of North America. Zoological Journal of the Linnean Society, 143:599-616.

Ezcurra, M.D., Scheyer, T.M., and Butler, R.J. 2014. The origin and early evolution of Sauria: reassessing the Permian saurian fossil record and the timing of the crocodile-lizard divergence. PLOS ONE, 9(2):e89165.

Falcon-Lang, H.J., Benton, M.J., and Stimson, H. 2007. Ecology of earliest reptiles inferred from basal Pennsylvanian trackways. Journal of the Geological Society, 164:1113-1118. 
Falcon-Lang, H.J., Benton, M.J., Braddy, S.J., and Davies, S.J. 2006. The Pennsylvanian tropical biome reconstructed from the Joggins Formation of Canada. Journal of the Geological Society, London, 163:561-576.

Fara, E., Gayet, M., and Taverne, L. 2010. The fossil record of Gonorynchiformes, p. 173-226. In Grande, T., Poyato-Ariza, F.J., and Diogo, R. (eds.), Gonorynchiformes and Ostariophysan Relationships: a Comprehensive Review. Science Publishers, Enfield, New Hampshire, USA.

Fedonkin, M.A. and Waggoner, B.M. 1997. The Late Precambrian fossil Kimberella is a mollusc-like bilaterian organism. Nature, 388:868-871.

Fedonkin, M.A., Gehling, J.G., Grey, K., Narbonne, G.M., and Vickers-Rich, P. 2007. The Rise of Animals: Evolution and Diversification of the Kingdom Animalia. Johns Hopkins, Baltimore.

Feduccia, A. 1999. The Origin and Evolution of Birds. 2nd ed. Yale University Press, New Haven, CT.

Feduccia, A. 2003. Big Bang for Tertiary birds? Trends in Ecology and Evolution, 18:172-176.

Felsenstein, J. 1978. Number of evolutionary trees. Systematic Zoology, 27:27-33.

Field, D.J., Gauthier, J.A., King, B.L., Pisani, D., Lyson, T.R., and Peterson, K.J. 2014. Toward consilience in reptile phylogeny: miRNAs support an archosaur, not lepidosaur, affinity for turtles. Evolution and Development, 16:189-196.

Fierstine, H.L., Huddleston, R.W., and Takeuchi, G.T. 2012. Catalog of the Neogene bony fishes of California. A systematic inventory of all published accounts. Occasional Papers of the California Academy of Sciences, 159:1-206.

Finarelli, J.A. and Clyde, W.C. 2004. Reassessing hominoid phylogeny: evaluating congruence in the morphological and temporal data. Paleobiology, 30:614651.

Finarelli, J.A. and Coates, M.I. 2012. First tooth-set outside the jaws in a vertebrate. Proceedings of the Royal Society, Series B, 279:775-779.

Finarelli, J.A. and Coates, M.I. 2014. Chondrenchelys problematica (Traquair, 1888) redescribed: a Lower Carboniferous, eel-like holocephalan from Scotland. Earth and Environmental Science Transactions of the Royal Society of Edinburgh, 105:35-59.

Fischer, M.S. and Tassy, P. 1993. The interrelation between Proboscidea, Sirenia, Hyracoidea, and Mesaxonia: the morphological evidence, p. 217-234. In Szalay, F.S., Novacek, M.J., and McKenna, M.C. (eds.), Mammal Phylogeny, Vol. 2: Placentals. Springer, New York.

Fitzgerald, E.M.G. 2010. The morphology and systematics of Mammalodon colliveri (Cetacea: Mysticeti), a toothed mysticete from the Oligocene of Australia. Zoological Journal of the Linnean Society, 158:367476.
Fitzgerald, E.M.G. 2011. Archaeocete-like jaws in a baleen whale. Biology Letters, 8:94-96.

Fleagle, J.G. 1999. Primate Adaptation and Evolution, 2nd ed. Academic Press, San Diego.

Flynn, J.J., Finarelli, J.A., Zehr, S., Hsu, J., and Nedbal, M.A. 2005. Molecular phylogeny of the carnivora (mammalia): assessing the impact of increased sampling on resolving enigmatic relationships. Systematic Biology, 54:317-337.

Flynn, J.J., Parrish, J.M., Rakotosamimanana, B., Simpson, W.F., and Wyss, A.R. 1999. A Middle Jurassic mammal from Madagascar. Nature, 401:57-60.

Fong, J.J., Brown, J.M., Fujita, M.K., and Boussau, B. 2012. A phylogenomic approach to vertebrate phylogeny supports a turtle-archosaur affinity and a possible paraphyletic Lissamphibia. PLOS ONE, 7(11):e48990.

Fordyce, R.E. 2003. Early crown-group Cetacea in the southern ocean: the toothed archaic mysticete Llanocetus. Journal of Vertebrate Paleontology, 23:50A.

Forey, P.L. and Longbottom, A. 2010. Bony fishes, p. 261-296. In Young, J.R., Gale, A.S., Knight, R.I., and Smith, A.B. (eds.), Fossils of the Gault Clay. Palaeontological Association, London.

Forey, P.L., Longbottom, A., and Mulley, J. 2010. Fishes - bony fishes, p. 341-371. In Lord, A.R. and Davis, P.G. (eds.), Fossils from the Lower Lias of the Dorset Coast. Palaeontological Association, London.

Forey, P.L., Lu, Y., Patterson, C., and Davies, C.E. 2003. Fossil fishes from the Cenomanian (Upper Cretaceous) of Namoura, Lebanon. Journal of Systematic Palaeontology, 4:227-330.

Fox, R.C. and Youzwyshyn, G.P. 1994. New primitive carnivorans (Mammalia) from the Paleocene of Western Canada, and their bearing on relationships of the order. Journal of Vertebrate Paleontology, $14: 382-404$.

Fox, R.C., Scott, C.S., and Rankin, B.D. 2010. New early carnivoran specimens from the Puercan (earliest Paleocene) of Saskatchewan, Canada. Journal of Paleontology, 84:1035-1039.

Fraser, N.C. 1988. The osteology and relationships of Clevosaurus (Reptilia: Sphenodontida). Philosophical Transactions of the Royal Society of London, Series B, 321:125-178.

Fraser, N.C. and Benton, M.J. 1989. The Triassic reptiles Brachyrhinodon and Polysphenodon and relationships of the sphenodontids. Zoological Journal of the Linnean Society, 96:413-445.

Friedman, M. 2007a. Styloichthys as the oldest coelacanth: implications for early osteichthyan interrelationships. Journal of Systematic Palaeontology, 5:289-343.

Friedman, M. 2007b. The interrelationships of Devonian lungfishes (Sarcopterygii: Dipnoi) as inferred from neurocranial evidence and new data from the genus Soederberghia Lehman, 1959. Zoological Journal of the Linnean Society, 151:115-171. 
Friedman, M. 2012a. Parallel evolutionary trajectories underlie the origin of giant suspension-feeding whales and bony fishes. Proceedings of the Royal Society B, 279:944-951.

Friedman, M. 2012b. Ray-finned fishes (Osteichthyes, Actinopterygii) from the type Maastrichtian, the Netherlands and Belgium. Scripta Geologica Special Issue, 8:113-142.

Friedman, M. and Brazeau, M.D. 2010. A reappraisal of the origin and basal radiation of the Osteichthyes. Journal of Vertebrate Paleontology, 30:35-56.

Friedman, M. and Sallan, L.C. 2012. Five hundred million years of extinction and recovery: a Phanerozoic survey of large-scale diversity patterns in fishes. Palaeontology, 55:707-742.

Friedman, M., Keck, B.P., Dornburg, A., Eytan, R.I., Martin, C.H., Hulsey, C.D., Wainwright, P.C., and Near, T.J. 2013. Molecular and fossil evidence place the origin of cichlid fishes long after Gondwanan rifting. Proceedings of the Royal Society B, 280:20131733.

Frost, D.R., Grant, T., Faivovich, J., Bain, R.H., Haas, A., Haddad, C.F.B., De Sa, R.O., Channing, A., Wilkinson, M., Donnellan, S.C., Raxworthy, C.J., Campbell, J.A., Blotto, B.L., Moler, P., Drewes, R.C., Nussbaum, R.A., Lynch, J.D., Green, D.M., and Wheeler, W.C. 2006. The amphibian tree of life. Bulletin of the American Museum of Natural History, 297:8-370.

Fujita, K. 1990. The Caudal Skeleton of Teleostean Fishes. Tokai University Press, Tokyo, $897 \mathrm{pp}$.

Furlong, R.F. and Holland, P.W.H. 2002. Bayesian phylogenetic analysis supports monophyly of Ambulacraria and of cyclostomes. Zoological Science, 19:593-599.

Gagnier, P.-Y. 1989. The oldest vertebrate: a 470 million years old jawless fish, Sacabambaspis janvieri, from the Ordovician of Bolivia. National Geographic Research, 5:250-253.

Gagnier, P.-Y. and Wilson, M.V.H. 1996. Early Devonian acanthodians from northern Canada. Palaeontology, 39:241-258.

Gale, A.S. and Owen, H.G. 2010. Introduction to the Gault, p. 1-15. In Young, J.R., Gale, A.S., Knight, R.I., and Smith, A.B. (eds.), Fossils of the Gault Clay. Palaeontological Association, London.

Gallagher, W.B., Miller, K.G., Sherrell, R.M., Browning, J.V., Field, M.P., Olsson, R.K., Sugarman, P.J., Tuorto, S., and Wahyudi, H. 2012. On the last mosasaurs: Late Maastrichtian mosasaurs and the Cretaceous-Paleogene boundary in New Jersey. Bulletin de la Société Géologique du France. 183:145-150.

Gallo, V. and Coelho, P.M. 2008. First occurrence of an aulopiform fish in the Barremian of the SergipeAlgoas Basin, northeastern Brazil, p. 351-371. In Arratia, G., Schultze, H.-P., and Wilson, M.V.H. (eds.), Mesozoic Fishes 4-Homology and Phylogeny. Verlag Dr. Friedrich Pfeil, Munich.
Gallo, V., Carvalho, M.S.S. de, and Suto, A.A. 2009. A possible occurrence of Diodontidae (Teleostei, Tetraodontiformes) in the Upper Cretaceous of the Paraíba Basin, northeastern Brazil. Cretaceous Research, 30:599-604.

Gardiner, B.G. 1984. The relationships of palaeoniscid fishes, a review based on new specimens of Mimia and Moythomasia from the Upper Devonian of Western Australia. Bulletin of the British Museum (Natural History): Geology, 37:173-428.

Gardiner, B.G. and Schaeffer, B. 1989. Interrelationships of lower actinopterygian fishes. Zoological Journal of the Linnean Society, 97:135-187.

Gardiner, B.G., Maisey, J.G., and Littlewood, D.T.J. 1996. Interrelationships of basal neopterygians, p. 117-146. In Stiassny, M.L.J., Parenti, L.R., and Johnson, G.D. (eds.), Interrelationships of Fishes. Academic Press, San Diego.

Gardiner, B.G., Schaeffer, B., and Masserie, J.A. 2005. A review of the lower actinopterygian phylogeny. Zoological Journal of the Linnean Society, 144:511-525.

Gatesy, J., Matthee, C., DeSalle, R., and Hayashi, C. 2002. Resolution of a supertree/ supermatrix paradox. Systematic Biology, 51:652-664.

Gaucher, C., Poiré, D.G., Bossi, J., Bettucci, L.S., and Beri, Á. 2013. Comment on "Bilaterian Burrows and Grazing Behavior at $>585$ Million Years Ago." Science, 339:906.

Gaudant, J. 1968. Contribution à une revision des Anaethalion de Cérin (Ain). Bulletin du Bureau de Recherches Géologiques et Minières, 4:95-107.

Gauthier, J.A. 1986. Saurischian monophyly and the origin of birds. Memoirs of the California Academy of Sciences, 8:1-55.

Gauthier, J.A. 1994. The diversification of the amniotes, p. 129-159. In Prothero, D.R. and Schoch, R.M. (eds.), Major Features of Vertebrate Evolution. Paleontological Society, Knoxville, Tennessee.

Gauthier, J.A. and de Queiroz, K. 2001. Feathered dinosaurs, flying dinosaurs, crown dinosaurs, and the name "Aves", p. 7-41. In Gauthier, J.A. and Gall, L.F. (eds.), New Perspectives on the Origin and Early Evolution of Birds: Proceedings of the International Symposium in Honor of John H. Ostrom. Peabody Museum of Natural History, Yale University, New Haven, Connecticut.

Gauthier, J.A., Estes, R., and de Queiroz, K. 1988. A phylogenetic analysis of Lepidosauromorpha, p. 1598. In Estes, R. and Pregill, G. (eds.), The Phylogenetic Relationships of the Lizard Families. Stanford University Press, Palo Alto.

Gauthier, J.A., Kluge, A.G., and Rowe, T. 1988 Amniote phylogeny and the importance of fossils. Cladistics, 4:105-209.

Gayet, M. 1980. Contribution a l'étude anatomique et systématique des poissons cénomaniens du Liban, anciennement placés dans les acanthoptérygiens. Mémoires du Muséum national d'Histoire naturelle, Nouvelle Série, Série C, 44:1-149. 
Gayet, M. 1982. Essai de definition des relations phylogénetiques des Holocentroidea nov. et des Trachichthyoidea nov. (Pisces, Acanthopterygii, Béryciformes). Bulletin du Museum national d'Histoire naturelle, Paris, $4^{e}$ sér., section $C, 1-2: 21-41$.

Gayet, M. 1991. "Holostean" and teleostean fishes of Bolivia, p. 453-494. In Suarez Soruco, R. (ed.), Fosiles y Facies de Bolivia. Volumen I - Vertebrados. Revista Técnica de YPFB 12:359-369.

Gayet, M., Belouze, A., and Abi Saad, P. 2003. LibanMémoire du Temps: les Poissons Fossiles. Éditions DésIris, Méolans-Revel, France.

Gebo, D.L., MacLatchy, L., Kityo, R., Deino, A., Kingston, J., and Pilbeam, D. 1997. A hominoid genus from the early Miocene of Uganda. Science, 276:401-404.

Geisler, J.H. and Theodor, J.M. 2009. Hippopotamus and whale phylogeny. Nature, 458:E1-4; discussion E5.

Geisler, J.H. and Uhen, M.D. 2003. Morphological support for a close relationship between hippos and whales. Journal of Vertebrate Paleontology, 23:991996.

Genner, M.J., Seehausen, O., Lunt, D.H., Joyce, D.A., Shaw, P.W., Carvalho, G.R., and Turner, G.F. 2007. Age of cichlids: new dates for ancient lake fish radiations. Molecular Biology and Evolution, 24:12691282.

Gess, R.W. 2011. High-latitude Gondwanan Famennian Biodiversity Patterns-Evidence from the South African Witpoort Formation (Cape Supergroup, Witteberg Group). Unpublished PhD Thesis, University of the Witwatersrand, Johannesburgh, South Africa.

Gess, R.W. and Coates, M.I. 2014. High-latitude chondrichthyans from the Late Devonian (Famennian) Witpoort formation of South Africa. Paläontologische Zeitschrift.

Gess, R.W. and Hiller, N. 1995. A preliminary catalogue of fossil algal, plant, arthropod, and fish remains from a Late Devonian black shale near Grahamstown, South Africa. Annals of the Cape Provincial Museums (Natural History), 19:225-304.

Gess, R.W., Coates, M.I., and Rubidge, B.S. 2006. A lamprey from the Devonian period of South Africa. Nature, 443:981-984.

Geyer, G. and Landing, E. 1995. The Cambrian of the Moroccan Atlas regions. Beringeria, 2 (special issue):7-46.

Gheerbrant, E. 2009. Paleocene emergence of elephant relatives and the rapid radiation of African ungulates. Proceedings of the National Academy of Sciences, USA, 106:10717-10721.

Gill, E.L. 1923. The Permian fishes of the genus Acentrophorus. Proceedings of the Zoological Society of London, 93:19-40.

Gingerich, P.D. 2005. Cetacea, p. 234-252. In Rose, K.D. and Archibald, J.D. (eds.), The Rise of Placental Mammals: Origins and Relationships of the Major Extant Clades. Johns Hopkins University Press, Baltimore.
Gingerich, P.D. and Winkler, D.A. 1985. Systematics of Paleocene Viverravidae (Mammalia, Carnivora) In the Bighorn Basin and Clark's Fork Basin, Wyoming. University of Michigan Contributions from the Museum of Paleontology, 27:87-128.

Glaessner, M.F. 1971. The genus Conomedusites Glaessner \& Wade and the diversification of the Cnidaria. Paläontologische Zeitschrift, 45:7-17.

Glaessner, M.F. and Wade, M. 1966. The Late Precambrian fossils from Ediacara, South Australia. Palaeontology, 9:599-628.

Goin, F.J., Pascual, R., Tejedor, M.F., and Gelfo, J.N. 2006. The earliest Tertiary therian mammal from South America. Journal of Vertebrate Paleontology, 26:505-510.

Goldring, R. and Jensen, S. 1996. Trace fossils and biofabrics at the Precambrian-Cambrian boundary interval in western Mongolia. Geological Magazine, 133:403-415.

Gomez, B., Martín-Closas, C., Barale, G., Solé de Porta, N., Thévenard, F., and Guignard, G. 2002. Frenelopsis (Coniferales: Cheirolepidiaceae) and related male organ genera from the Lower Cretaceous of Spain. Palaeontology, 45:997-1036.

González-Rodríguez, K. and Fielitz, C. 2008. A new species of acanthomorph fish from the Upper Cretaceous Muhi Quarry, Hidalgo, central Mexico, p. 399411. In Arratia, G., Schultze, H.-P., and Wilson, M.V.H. (eds.), Mesozoic Fishes 4 - Homology and Phylogeny. Verlag Dr. Friedrich Pfeil, Munich.

González-Rodríguez, K., Schultze, H.-P., and Arratia, G. 2013. Miniature armoured acanthomorph teleosts from the Albian/Cenomanian (Cretaceous) of Mexico, p. 457-487. In Arratia, G., Schultze, H.-P., and Wilson, M.V.H. (eds.), Mesozoic Fishes 5 - Global Diversity and Evolution. Verlag Dr. Friedrich Pfeil, Munich.

Goodman, M., Miyamoto, M.M., and Czelisniak, J. 1987. Pattern and process in vertebrate phylogeny revealed by coevolution of molecules and morphologies, p. 141-176. In Patterson, C. (ed.), Molecules and Morphology in Evolution: Conflict or Compromise? Cambridge University Press, Cambridge.

Goswami, A., Prasad, G.V., Upchurch, P., Boyer, D.M., Seiffert, E.R., Verma, O., Gheerbrant, E., and Flynn, J.J.2011. A radiation of arboreal basal eutherian mammals beginning in the Late Cretaceous of India. Proceedings of the National Academy of Sciences, USA, 108:16333-16338.

Gradstein, F.M., Ogg, J.G., Schmitz, M., and Ogg, G. 2012. The Geologic Time Scale 2012. Elsevier, Amsterdam, 1176 pp.

Grande, L. 2010. An empirical synthetic pattern study of gars (Lepisosteiformes) and closely related species, based mostly on skeletal anatomy. The resurrection of the Holostei. Amercan Society of Ichthyologists and Herpetologists Special Publication, 6:1-871. 
Grande, L. and Bemis, W.E. 1991. Osteology and phylogenetic relationships of fossil and Recent paddlefishes (Polyodontidae) with comments on the interrelationships of Acipenseriformes. Society of Vertebrate Paleontology Memoir, 1:1-121.

Grande, L. and Bemis, W.E. 1996. Interrelationships of Acipenseriformes, with comments on "Chondrostei", p. 85-115. In Stiassny, M.L.J., Parenti, L.R., and Johnson, G.D. (eds.), Interrelationships of Fishes. Academic Press, San Diego.

Grande, L. and Bemis, W.E. 1998. A comprehensive phylogenetic study of amiid fishes (Amiidae) based on comparative skeletal anatomy: an empirical search for interconnected patterns of natural history. Society of Vertebrate Paleontology Memoir, 4:1-690.

Grande, L., Fan, J., Yabumoto, Y., and Bemis, W.E. 2002. †Protopsephurus liui, a well-preserved primitive paddlefish (Acipenseriformes: Poylodontidae) from the Lower Cretaceous of China. Journal of Vertebrate Paleontology, 22:209-237.

Grande, L. and Grande, T. 1999. A new species of †Notogoneus (Teleostei: Gonorynchidae) from the Upper Cretaceous Two Medicine Formation of Montana, and the poor Cretaceous record of freshwater fishes from North America. Journal of Vertebrate Paleontology, 19:612-622.

Grande, L. and Hilton, E.J. 2006. An exquisitely preserved skeleton representing a primitive sturgeon from the Upper Cretaceous Judith River Formation of Montana (Acipenseriformes: Acipenseridae: $\mathrm{n}$. gen. and sp.). Journal of Paleontology, Memoir, 65:1-39.

Grande, T. and Poyato-Ariza, F.J. 1995. A cladistic analysis of fossil and living gonorynchiform ostariophysan fishes. Geobios, Mémoire Spéciale, 19:197-199.

Grande, T. and Poyato-Ariza, F.J. 1999. Phylogenetic relationships of fossil and Recent gonorynchiform fishes (Teleostei: Ostariophysi). Zoological Journal of the Linnean Society, 125:197-238.

Grazhdankin, D. and Gerdes, G. 2007. Ediacaran microbial colonies. Lethaia, 40:201-210.

Greenwood, D.R., Archibald, S.B., Mathewes, R.W., and Moss, P.T. 2005. Fossil biotas from the Okanagan Highlands, southern British Columbia and northeastern Washington State: climates and ecosystems across an Eocene landscape. Canadian Journal of Earth Sciences, 42:167-185.

Gregory, W.K. 1910. The orders of mammals. Bulletin of the American Museum of Natural History, 27:1-524.

Grey, M. and Fink, Z.V. 2010. The Joggins Fossil Cliffs UNESCO World Heritage site: a review of recent research. Atlantic Geology, 47:185-200.

Griffith, J. 1977. The Upper Triassic fishes from Polzberg bei Lunz, Austria. Zoological Journal of the Linnean Society, 60:1-93.

Guipert, G., Lumley, M.-S. de, Tuffreau, A., and Mafart, B. 2011. A late Middle Pleistocene hominid: BiacheSaint-Vaast2, North France. Comptes Rendus Palevol, 10:21-33.
Hackett, S.J., Kimball, R.T., Reddy, S., Bowie, R.C.K., Braun, E.L., Braun, M.J., Chojnowski, J.L., Cox, W.A., Han, K.L., Harshman, J., Huddleston, C.J., Marks, B.D., Miglia, K.J., Moore, W.S., Sheldon, F.H., Steadman, D.W., Witt, C.C., and Yuri, T. 2008. A phylogenomic study of birds reveals their evolutionary history. Science, 320:1763-1768.

Halanych, K.M. 2004. The new view of animal phylogeny. Annual Review of Ecology, Evolution, and Systematics, 35:229-56.

Halanych, K.M., Bacheller, J.D., Aguinaldo, A.M.A., Liva, S.M., Hillis, D.M., and Lake, J.A. 1995. Evidence from $18 \mathrm{~S}$ ribosomal DNA that the lophophorates are protostome animals. Science, 267:1641-1643.

Hallstrom, B.M. and Janke, A.2010. Mammalian evolution may not be strictly bifurcating. Molecular Biology and Evolution, 27:2804-2816.

Halverson, G.P., Hoffman, P.F., Schrag, D.P., Maloof, A.C., and Rice, A.H.N. 2005. Toward a Neoproterozoic composite carbon-isotope record. Geological Society of America Bulletin, 117:1181-1207.

Halverson, G.P., Maloof, A.C., Schrag, D.P., Dudás, F.Ö., and Hurtgen, M. 2007. Stratigraphy and geochemistry of a ca 800 Ma negative carbon isotope interval in northeastern Svalbard. Chemical Geology, 237:5-27.

Harrison, T. and Gu, Y. 1999. Taxonomy and phylogenetic relationships of early Miocene catarrhines from Sihong, China. Journal of Human Evolution, 37:225277.

Harrison, T., Msuya, C.P., Murray, A.M., Jacobs, B.F., Báez, A.M., Mundil, R., and Ludwig, K.R. 2001. Paleontological investigations at the Eocene locality of Mahenge in north-central Tanzania, East Africa, p. 39-74. In Gunnell, G.F. (ed.), Eocene Biodiversity: Unusual Occurrences and Rarely Sampled Habitats. Kluwer Academic/Plenum Publishers, New York.

Harvey, T.H.P., Williams, M., Condon, D.J., Wilby, P.R., Siveter, D.J., Rushton, A.W.A., Leng, M.J., and Gabbott, S.E. 2011. A refined chronology for the Cambrian succession of southern Britain. Journal of the Geological Society, 168:705-716.

Hasegawa, M., Kishino, H., and Yano, T. 1985. Dating of the human-ape splitting by a molecular clock of mitochondrial DNA. Journal of Molecular Evolution, 22:160-174.

Hauff, B. and Hauff, R.B. 1981. Das Holzmadenbuch. REPRO-DRUCK GmbH, Fellbach, Germany.

Hautier, L., Weisbecker, V., Sanchez-Villagra, M.R., Goswami, A., and Asher, R.J. 2010. Skeletal development in sloths and the evolution of mammalian vertebral patterning. Proceedings of the National Academy of Sciences, USA, 107:18903-18908.

Hedges, S.B. 2011. On the use of high-level taxonomic names. Zootaxa, 2867:67-68.

Hedges, S.B. and Poling, L.L. 1999. A molecular phylogeny of reptiles. Science, 283:998-1001 
Hedges, S.B. and Vidal, N. 2009. Lizards, snakes, and amphisbaenians (Squamata), p. 383-389. In Hedges, S.B. and Kumar, S. (eds.), The Timetree of Life. Oxford University Press, Oxford.

Hedges, S.B., Parker, P.H., Sibley, C.G., and Kumar, S. 1996. Continental breakup and the ordinal diversification of birds and mammals. Nature, 381:226-229.

Heimberg, A.M., Cowper-Sal lari, R., Sémon, M., Donoghue, P.C.J., and Peterson, K.J. 2010. microRNAs reveal the interrelationships of hagfish, lampreys, and gnathostomes and the nature of the ancestral vertebrate. Proceedings of the National Academy of Sciences, USA, 107:19379-19383.

Heimberg, A.M., Sempere, L.F., Moy, V.N., Donoghue, P.C.J., and Peterson, K.J. 2008. MicroRNAs and the advent of vertebrate morphological complexity. Proceedings of the National Academy of Sciences, USA, 105:2946-2950.

Heineke, E. 1906. Die Ganoiden und Teleostier des lithografischen Schiefers von Nusplingen. Geologische und Paläontolgoische Abhandlungen, N.F., 8:159-214.

Helm, C., Bernhart, S.H., Höner zu Siederdissen, C., Nickel, B., and Bleidorn, C. 2012. Deep sequencing of small RNAs confirms an annelid affinity of Myzostomida. Molecular Phylogenetics and Evolution, 64:198-203.

Hilgen, F.J., Lourens, L.J., Van Dam, J.A., Krijgsman, W., Ogg, J.G., Piller, W.E., and Wilson, D.S. 2012. The Neogene Period, p. 923-1010. In Gradstein, F.M., Ogg, J.G., Schmitz, M., and Ogg, G. (eds.), The Geologic Time Scale 2012. Elsevier, Amsterdam.

Hill, A. 2002. Paleoanthropological research in the Tugen Hills, Kenya. Introduction. Journal of Human Evolution, 42:1-10.

Hill, R.V. 2005. Integration of morphological data sets for phylogenetic analysis of Amniota: the importance of integumentary characters and increased taxonomic sampling. Systematic Biology, 54:530-547.

Hill, A.C., Cotter, K.L., and Grey, K. 2000. Mid-Neoproterozoic biostratigraphy and isotope stratigraphy in Australia. Precambrian Research, 100:281-298.

Hill, A.C. and Walter, M.R. 2000. Mid-Neoproterozoic (similar to 830-750 Ma) isotope stratigraphy of Australia and global correlation. Precambrian Research, 100:181-211.

Hilton, E.J. and Forey, P.L. 2009. Redescription of †Chondrosteus acipenseroides Egerton, 1858 (Acipenseriformes, †Chondrosteidae) from the Lower Lias of Lyme Regis (Dorset, England) with comments on the early evolution of sturgeons and paddlefishes. Journal of Systematic Palaeontology, 7:427-453.

Hilton, E.J. and Grande, L. 2006. Review of the fossil record of sturgeons, family Acipenseridae (Actinopterygii: Acipenseriformes), from North America. Journal of Paleontology, 80:672-683.
Hilton, E.J., Grande, L., and Bemis, W.E. 2011. Skeletal anatomy of the shortnose sturgeon, Acipenser brevirostrum Lesueur, 1818, and the systematic of sturgeons (Acipenseriformes, Acipenseridae). Fieldiana Life and Earth Sciences, 3:1-168.

Hints, O. and Nõlvak, J. 2006. Early Ordovician scolecodonts and chitinozoans from Tallinn, North Estonia. Review of Palaeobotany and Palynology, 139:189209.

Holcroft, N. 2005. A molecular analysis of the interrelationships of tetraodontiform fishes (Acanthomorpha: Tetraodontiformes). Molecular Phylogenetics and Evolution, 34:525-544.

Holland, N.D. and Chen, J.Y. 2001. Origin and early evolution of the vertebrates: new insights from advances in molecular biology, anatomy, and palaeontology. BioEssays, 23:142-151.

Hope, S. 2002. The Mesozoic radiation of Neornithes, p. 339-388. In Chiappe, L.M. and Witmer, L.D. (eds.), Mesozoic Birds: Above the Heads of Dinosaurs. University of California Press, Berkeley.

Horovitz, I., Martin, T., Bloch, J., Ladeveze, S., Kurz, C., and Sanchez-Villagra, M.R. 2009. Cranial anatomy of the earliest marsupials and the origin of opossums. PLoS ONE, 4:e8278.

Hou, X.G., Aldridge, R.J., Siveter, D.J., and Feng, X.H. 2002. New evidence on the anatomy and phylogeny of the earliest vertebrates. Proceedings of the Royal Society of London Series B, 269:1865-1869.

Hou, X.G., Aldridge, R.J., Bergström, J., Siveter, D.J., Siveter, D.J., and Feng, X.H. 2004. The Cambrian Fossils of Chengjiang, China: the Flowering of Animal Life. Blackwell Science Ltd, London.

Houde, P.W. 1988. Palaeognathous birds from the early Tertiary of the Northern Hemisphere. Publications of the Nuttall Ornithological Club, 22:1-148.

Houde, P.W. and Olson, S.L. 1981. Palaeognathous carinate birds from the Early Tertiary of North America. Science, 214:1236-1237.

Hounslow, M. and Muttoni, G. 2010. The geomagnetic polarity timescale for the Triassic: linkage to stage boundary definitions, p. 61-102. In S.G. Lucas (ed.), The Triassic Timescale: Geological Society, London, Special Publications, 334.

Hu, D., Hou, L., Zhang, L., and Xu, X. 2009. A preArchaeopteryx troodontid theropod from China with long feathers on the metatarsus. Nature 461:640643.

Hückel, U. 1970. Die Fischschiefer von Haqel und Hjoula in der Oberkreide des Libanon. Neues Jahrburch für Geologie und Paläontologie, Abhandlungen, 135:113-149.

Hudson, J.D. and Martill, D.M. 1991. Introduction, p. 1134. In Hudson, J.D. and Martill, D.M. (eds.), Fossils of the Oxford Clay. Palaeontological Association, London. 
Hunt, R.M. 2004. Global climate change and the evolution of large mammalian carnivores during the later Cenozoic in North America. Bulletin of the American Museum of Natural History, 285:139-156.

Hurley, I.A., Mueller, R.L., Dunn, K.A., Schmidt, E.J., Friedman, M., Ho, R.K., Prince, V.E., Yang, Z., Thomas, M.G., and Coates, M.I. 2007. A new timescale for ray-finned fish evolution. Proceedings of the Royal Society, Series B, 274: 489-498.

Hutchinson, M.N., Skinner, A., and Lee, M.S.Y. 2012. Tikiguania and the antiquity of squamate reptiles (lizards, snakes). Biology Letters, 8:665-669.

Huxley, T.H. 1867. On the classification of birds; and on the taxonomic value of the modifications of certain of the cranial bones observable in that class. Proceedings of the Zoological Society of London, 1867:415472.

Isachsen, C.E., Bowring, S.A., Landing, E., and Samson, S.D. 1994. New constraint on the division of Cambrian time. Geology, 22:496-498.

Ivantsov, A.Y. 2009. New reconstruction of Kimberella, problematic Vendian metazoan. Paleontological Journal, 43:601-611.

Ivantsov, A.Y. 2010. Paleontological evidence for the supposed Precambrian occurrence of mollusks. Paleontological Journal, 44:1552-1559.

Iwabe, N., Hara, Y., Kumazawa, Y., Shibamoto, K., Saito, Y., and Miyata, T. 2005. Sister group relationship of turtles to the bird - crocodilian clade revealed by nuclear DNA-coded proteins. Molecular Biology and Evolution, 22:810-813.

Jacobs, L.L. 1978. Fossil rodents (Rhizomyidae and Muridae) from Neogene Siwalik deposits, Pakistan. Museum of Northern Arizona Press, Bulletin, 52:1103.

Jacobs, L.L. and Downs, W.R. 1994. The evolution of murine rodents in Asia, p. 149-156. In Tomida, Y., Li, C.K., and Setoguschi, T. (eds.), Rodent and Lagomorph Families of Asia, Origins and Their Diversification. National Science Museum Monograph, Tokyo.

Jacobs, L.L. and Flynn, L.J. 2005. Of mice ... again: the Siwalik rodent record, murine distribution, and molecular clocks, p. 63-80. In Lieberman, D., Smith, R., and Kelley, J. (eds.), Interpreting the Past: Essays on Human, Primate and Mammal Evolution. Brill Academic Publishers, Leiden.

Jacobs, L.L. and Pilbeam, D. 1980. Of mice and men fossil-based divergence dates and molecular clocks. Journal of Human Evolution, 9:551-555.

Jaeger, J.J., Tong, H., and Denys, C. 1986. The age of the Mus-Rattus divergence - paleontological data compared with the molecular clock. Comptes Rendus de l'Académie des Sciences, Série II, 302:917922.

Jakobsen, K.G., Nielsen, A.T., Harper, D.A.T., and Brock. G.A. 2014. Trilobites from the Middle Ordovician Stairway Sandstone, Amadeus Basin, central Australia. Alcheringa, 38:70-96.
Janecka, J.E., Miller, W., Pringle, T.H., Wiens, F., Zitzmann, A., Helgen, K.M., Springer, M.S., and Murphy, W.J. 2007. Molecular and genomic data identify the closest living relative of primates. Science, 318:792794.

Janke, A., Xu, X., and Arnason, U. 1997. The complete mitochondrial genome of the wallaroo (Macropus robustus) and the phylogenetic relationship among Monotremata, Marsupialia, and Eutheria. Proceedings of the National Academy of Sciences, USA, 94:1276-1281.

Jansa, S.A. and Weksler, M. 2004. Phylogeny of muroid rodents: relationships within and among major lineages as determined by IRBP gene sequences. Molecular Phylogenetics and Evolution, 31:256-276.

Janvier, P. 1981. The phylogeny of the Craniata, with particular reference to the significance of fossil "agnathans". Journal of Vertebrate Paleontology, 1:121-159.

Janvier, P. 1996a. The dawn of the vertebrates: characters versus common ascent in the rise of current vertebrate phylogenies. Palaeontology, 39:259-287.

Janvier, P. 1996b. Early Vertebrates. Oxford University Press, Oxford.

Janvier, P. and Blieck, A. 1993. The Silurian-Devonian agnathan biostratigraphy of the Old Red continent, $p$. 67-86. In Long, J.A. (ed.), Palaeozoic Vertebrate Biostratigraphy and Biogeography. Johns Hopkins University Press, Baltimore.

Jenkins, F.A., Gatesy, S.M., Shubin, N.H. and Amaral, W.W. 1997. Haramiyids and Triassic mammalian evolution. Nature, 385:715-718.

Jensen, S., Gehling, J.G., Droser, M.L., and Grant, S.W.F. 2002. A scratch circle origin for the medusoid fossil Kullingia. 35:291-299.

Jepsen, G.L. 1937. A Paleocene rodent, Paramys atavus. Proceedings of the American Philosophical Society, 78:291-301.

Jessen, H.L. 1980. Lower Devonian Porolepiformes from the Canadian Arctic with special reference to Powichthys thorsteinssoni Jessen. Palaeontographica, Abteilung A, 167:180-214.

Ji, Q., Luo, Z.X., Yuan, C.X., Wible, J.R., Zhang, J.P., and Georgi, J.A. 2002. The earliest known eutherian mammal. Nature, 416:816-822.

Johnson, G.D. and Patterson, C. 1993. Percomorph phylogeny: a survey of acanthomorphs and a new proposal. Bulletin of Marine Science, 52:554-626.

Johnson, N.M., Stix, J., Tauxe, L., Cerveny, P.F., and Tahirkheli, R.A.K.1985. Paleomagnetic chronology, fluvial processes, and tectonic implications of the Siwalik deposits near Chinji Village, Pakistan. Journal of Geology, 93:27-40.

Jones, M.E.H., Anderson, C.L., Hipsley, C.A., Müller, J., Evans, S.E., and Schoch, R.R. 2013. Integration of molecules and new fossils supports a Triassic origin for Lepidosauria (lizards, snakes, and tuatara). BMC Evolutionary Biology, 13:208. 
Kaas, J.H. and Preuss, T.M. 1993. Archontan affinities as reflected in the visual system, p. 115-128. In Szalay, F.S., Novacek, M.J., and McKenna, M.C. (eds.), Mammal Phylogeny, Vol. 2: Placentals. Springer, New York.

Kappelman, J., Kelley, J., Pilbeam, D., Sheikh, K.A., Ward, S., Anwar, M., Barry, J.C., Brown, B., Hake, P., Johnson, N.M., Raza, S.M., and Shah, S.M.I. 1991. The earliest occurrence of Sivapithecus from the Middle Miocene Chinji Formation of Pakistan. Journal of Human Evolution, 21:61-73.

Karatajuté-Talimaa, V. and Predtechenskyj, N. 1995. The distribution of the vertebrates in the Late Ordovician and Early Silurian palaeobasins of the Siberian Platform. Bulletin du Museum National d'Histoire Naturelle, Paris, $4^{e}$ sér., Section C, 17:39-55.

Kawahara, R., Miya, M., Mabuchi, K., Lavoué, S., Inoue, J.G., Satoh, T.P., Kawaguchi, A., and Nishida, M. 2008. Interrelationships of the 11 gasterosteiform families (sticklebacks, pipefishes, and their relatives): a new perspective based on whole mitogenome sequences from 75 higher teleosts. Molecular Phylogenetics and Evolution, 46:224-236.

Kay, R.F. and Meldrum, D.J. 1997. A new small Platyrrhine and the Phyletic Position of Callitrichinae. Smithsonian Institution Press, Washington, D.C.

Khalloufi, B., Ouarhache, D., and Lelièvre, H. 2010. New paleontological and geological data about Jbel Tselfat (Late Cretaceous of Morocco). Historical Biology, 22:57-70.

Kielan-Jaworowska, Z. 1978. Evolution of the therian mammals in the Late Cretaceous of Asia. Part III. Postcranial skeleton in Zalambdalestidae. Palaeontologica Polonica, 38:5-41.

Kielan-Jaworowska, Z. and Dashzeveg, D. 1989. Eutherian mammals from the Early Cretaceous of Mongolia. Zoologica Scripta 18:347-355.

Kielan-Jaworowska, Z., Bown, T.M., and Lillegraven, J.A. 1979. Eutheria, p. 221-258. In Lillegraven, J.A., Kielan-Jaworowska, Z., and Clemens, W.A. (eds.), Mesozoic Mammals. University of California Press, Los Angeles.

Kielan-Jaworowska, Z., Cifelli, R.L., and Luo, Z.-X. 2004. Mammals from the Age of Dinosaurs: Origins, Evolution and Structure. Columbia University Press, New York.

Klein, R.G. 1999. The Human Career: Human Biological and Cultural Origins, 2nd ed. University of Chicago Press, Chicago.

Kocot, K.M., Cannon, J.T., Todt, C., Citarella, M.R., Kohn, A.B., Meyer, A., Santos, S.R., Schander, C., Moroz, L.L., Lieb, B., and Halanych, K.M. 2011. Phylogenomics reveals deep molluscan relationship. Nature, 477:452-456.

Kondrashov, P.E. and Lucas, S.G.2004. Revised distribution of condylarths (Mammalia, Eutheria) in Asia. New Mexico Museum of Natural History and Science Bulletin, 26:209-214.
Korth, W.W. 1984. Earliest Tertiary evolution and radiation of rodents in North America. Bulletin of Carnegie Museum of Natural History, 24:1-71.

Kouchinsky, A., Bengtson, S., Runnegar, B., Skovsted, C., Steiner, M., and Vendrasco, M. 2012. Chronology of early Cambrian biomineralization. Geological Magazine, 149:221-251.

Kozur, H.W. and Bachmann, G.H. 2005. Correlation of the Germanic Triassic with the international scale. Albertiana, 32:21-35.

Kozur, H.W. and Bachmann, G.H. 2008. Updated correlation of the Germanic Triassic with the Tethyan scale and assigned numeric ages. In Krystyn, L., Mandl, G.W. (eds.), Upper Triassic zonations and events. Berichte der Geologische Bundesanstalt, 76:53-58.

Ksepka, D., Bertelli, S., and Giannini, N. 2006. The phylogeny of the living and fossil Sphenisciformes (penguins). Cladistics, 22:412-441.

Ksepka, D.T., Fordyce, R.E., Ando, T., and Jones, C.M. 2012. New fossil penguins (Aves, sphenisciformes) from the Oligocene of New Zealand reveal the skeletal plan of stem penguins. Journal of Vertebrate Palaeontology, 32:235-254.

Kumazawa, Y. and Nishida, M. 1999. Complete mitochondrial DNA sequences of the green turtle and blue-tailed mole skink: statistical evidence for archosaurian affinity of turtles. Molecular Biology and Evolution, 16:784-792.

Kuraku, S., Hoshiyama, D., Katoh, K., Suga, K., and Miyata, T. 1999. Monophyly of lampreys and hagfishes supported by nuclear DNA-coded genes. Journal of Molecular Evolution, 49:729-735.

Kurochkin, E.N. and Dyke, G.J. 2010. A large collection of Presbyornis (Aves, Anseriformes, Presbyornithidae) from the late Paleocene and early Eocene of Mongolia. Geological Journal, 45:375-387.

Kurochkin, E.N., Dyke, G.J., and Karhu, A.A. 2002. A new presbyornithid (Aves, Anseriformes) from the Late Cretaceous of Mongolia. American Museum Novitates, 3386:1-11.

Lacalli, T.C. 2002. Vetulicolians - are they deuterostomes? Chordates? Bioessays, 24:208-211.

Landman, N.H., Garb, M.P., Rovelli, R., Ebel, D.S., and Edwards, L.E. 2012. Short-term survival of ammonites in New Jersey after the end-Cretaceous bolide impact. Acta Palaeontologica Polonica, 57:703-715.

Langer, M.C., Ezcurra, M.D., Bittencourt, J.S., and Novas, F.E. 2010. The origin and early evolution of dinosaurs. Biological Reviews, 85:55-110.

Laurin M. 1991. The osteology of a Lower Permian eosuchian from Texas and a review of diapsid phylogeny. Zoological Journal of the Linnean Society, 101:59-95.

Laurin, M. 2002. Tetrapod phylogeny, amphibian origins, and the definition of the name Tetrapoda. Systematic Biology, 51:364-369.

Laurin, M. and Anderson, J.S. 2004. Meaning of the name Tetrapoda in the scientific literature: an exchange. Systematic Biology, 53:68-80. 
Laurin, M. and Reisz, R.R. 1995. A reevaluation of early amniote phylogeny. Zoological Journal of the Linnean Society, 113:165-223.

Lavoué, S., Miya, M., Moritz, T., and Nishida, M. 2011. A molecular timescale for the evolution of the African freshwater fish family Kneriidae (Teleostei: Gonorynchiformes). Ichthyological Research, 59:104-112.

Le Gros Clark, W.E. and Sonntag, C.F. 1926. A monograph of Orycteropus afer. III. The skull, the skeleton of the trunk, and limbs. Proceedings of the Zoological Society of London, 1926:445-485.

Lee, M.S.Y. 1998. Convergent evolution and character correlation in burrowing reptiles: towards a resolution of squamate relationships. Biological Journal of the Linnean Society, 65:369-453.

Lee, M.S.Y. 1999. Molecular clock calibrations and metazoan divergence dates. Journal of Molecular Evolution, 49:385-391.

Lee, M.S.Y. 2001 Molecules, morphology, and the monophyly of diapsid reptiles. Contributions to Zoology, 70:121-138.

Lehman, J.-P. 1952. Notes paléoichthyologiques. Annales de Paléontologie, 38:59-67.

Lehmann, T. 2009. Phylogeny and systematics of the Orycteropodidae (Mammalia, Tubulidentata). Zoological journal of the Linnean Society, 155:649-702.

Lelièvre, H., Feist, R., Goujet, D., and Blieck, A. 1987. Les vertébrés dévoniens de la Montagne Noire (sud de la France) et leur apport à la phylogénie des Pachyostéomorphes (Placodermes, Arthrodires). Palaeovertebrata, 17:1-26.

Leonard, L.M. Dyke, G.J., and Van Tuinen, M. 2005. A new specimen of the fossil palaeognath Lithornis from the Lower Eocene of Denmark. American Museum Novitates, 3491:1-11.

Leonov, Y.G., Akhmetiev, M.A., Gavrilov, Y.O., Karyakin, Y.V., Kurenov, S.A., and Semikhatov, M.A. 1998. Late Eocene-Early Oligocene Geological and Biological Events on the Territory of the Former Soviet Union. Part II. The Geological and Biotical Events. GEOS, Moscow, 250 pp.

Li, B., Dettaï, A., Cruaud, C., Couloux, A., DsoutterMeniger, M., and Lecointre, G. 2009. RNF213, a new marker for acanthomorph phylogeny. Molecular Phylogenetics and Evolution, 50:345-363.

Li, C.K. 1977. Paleocene eurymyloids (AnagalidA.Mammalia) of Qianshan Anhui. Vertebrata PalAsiatica, 15:103-118.

Li, C.K. and Ting, S. 1983. The Paleogene mammals of China. Bulletin Carnegie Museum, 21:1-98.

Lillegraven, J.A. and McKenna, M.C. 1986. Fossil mammals from the "Verde" Formation (Late Cretaceous, Judithian) of the Bighorn and Wind River Formations, Wyoming, with definitions of Late Cretaceous North American Land Mammal "Ages". American Museum Novitates, 2840:1-68.
Lindow, B.E.K. and Dyke, G.J. 2006. Bird evolution in the Eocene: climate change in Europe and a Danish fossil fauna. Biological Reviews, 81:483-499.

Liu, A.G., Mcllroy, D., and Brasier, M.D. 2010. First evidence for locomotion in the Ediacara biota from the $565 \mathrm{Ma}$ Mistaken Point Formation, Newfoundland. Geology, 38:123-126.

Liu, A.G., Mcllroy, D., and Brasier, M.D. 2010. First evidence for locomotion in the Ediacara biota from the 565 Ma Mistaken Point Formation, Newfoundland: REPLY. Geology, 38(10):e224.

Liu, P., Xiao, S., Yin, C., Zhou, C., Gao, L., and Tang, F. 2008. Systematic description and phylogenetic affinity of tubular microfossils from the Ediacaran Doushantuo Formation at Weng'an, South China. Palaeontology, 51:339-366.

Livezey, B.C. and Zusi, R.L. 2007. Higher-order phylogeny of modern birds (Theropoda, Aves: Neornithes) based on comparative anatomy. II. Analysis and discussion. Zoological Journal of the Linnean Society, 149:1-95.

Lloyd, G.T. and Friedman, M. 2013. A survey of palaeontological sampling biases in fishes based on the phanerozoic record of Great Britain. Palaeogeography, Palaeoclimatology, Palaeoecology, 372:5-17.

Löfgren, A. and Zhang, J.-h. 2003. Element assocition and morphology in some Middle Ordovician platformequipped conodonts. Journal of Paleontology, 77:721-737.

Lofgren, D.L., Lillegraven, J.A., Clemens, W.A., Gingerich, P.D., and Williamson, T.E. 2004. Paleocene biochronology: The Puercan through Clarkforkian Land Mamma Ages, p. 43-105. In Woodburne, M.O. (ed.), Late Cretaceous and Cenozoic Mammals of North America. Columbia University Press, New York.

Long, J.A. 1988. New palaeoniscoid fish from the Late Devonian and Early Carboniferous of Victoria. Memoir of the Association of Australasian Palaeontologists, 7:1-64.

Long, J.A. and Trinajstic, K. 2010. The Late Devonian Gogo Formation Lägerstatte [sic] of Western Australia: exceptional early vertebrate preservation and diversity. Annual Review of Earth and Planetary Sciences, 38:255-279.

Longrich, N.R., Tokaryk, T., and Field, D.J. 2011. Mass extinction of birds at the Cretaceous-Paleogene (K$\mathrm{Pg}$ ) boundary. Proceedings of the National Academy of Sciences, U.S.A., 108:15253-15257.

Lopatin, A.V. and Averianov, A.O. 2006. Eocene Lagomorpha (Mammalia) of Asia:2. Strenulagus and Gobiolagus (Strenulagidae). Paleontological Journal, 40:198-206.

López-Arbarello, A. 2012. Phylogenetic interrelationships of ginglymodian fishes (Actinopterygii: Neopterygii). PloS ONE, 7:e39370. 
López-Arbarello, A., Arratia, G., and Tunik, M.A. 2003. Saldenoichthys remotus gen. et sp. nov. (Teleostei, Perciformes) and other acanthomorph remains from the Maastrichtian Saldeño Formation (Mendoza, Argentina). Mitteilungen aus dem Museum für Naturkunde in Berlin, Geowissenschaftliche Reihe, 6:161-172.

López-Fernández, H., Arbour, J.H., Winemiller, K.O., and Honeycutt, R.L. 2013. Testing for ancient adaptive radiations in neotropical cichlid fishes. Evolution, 67:1321-1337.

Lordkipanidze, D., Jashashvili, T., Vekua, A., Ponce de Leon, M.S., Zollikofer, C.P., Rightmire, G.P., Pontzer, H., Ferring, R., Oms, O., Tappen, M., Bukhsianidze, M., Agusti, J., Kahlke, R., Kiladze, G., MartinezNavarro, B., Mouskhelishvili, A., Nioradze, M., and Rook, L. 2007. Postcranial evidence from early Homo from Dmanisi, Georgia. Nature, 449:305-310.

Love, G.D., Grosjean, E., Stalvies, C., Fike, D.A., Grotzinger, J.P., Bradley, A.S., Kelly, A.E., Bhatia, M., Meredith, W., Snape, C.E., Bowring, S.A., Condon, D.J., and Summons, R.E. 2009. Fossil steroids record the appearance of Demospongiae during the Cryogenian period. Nature, 457:718-721.

Lovejoy, N.R., Iranpour, M., and Collette, B.B. 2004. Phylogeny and jaw ontogeny of beloniform fishes. Integrative and Comparative Biology, 44:366-377.

Lü, J., Unwin, D.M., Jin, X., Liu, Y., and Ji, Q. 2009. Evidence for modular evolution in a long- tailed pterosaur with a pterodactyloid skull. Proceedings of the Royal Society of London Series B, 227:383-389.

Lucas, S.G. 1998. Fossil mammals and the Paleocene/ Eocene Series boundary in Europe, p. 451-500, In Aubry, M.P., Lucas, S.G., and Berggren, W.A. (eds.), Late Paleocene-Early Eocene Climatic and Biotic Events in the Marine and Terrestrial Records. Columbia University Press, New York.

Lukševičs, E., Lebedev, O.A., and Zakharenko, G.V. 2010. Palaeozoogeographical connections of the Devonian communities of the Baltica Province. Part I. Eifelian-Givetian. Palaeoworld, 19:94-107.

Lund, R. and Grogan, E.D. 1997. Relationships of the Chimaeriformes and the basal radiation of the Chondrichthyes. Reviews in Fish Biology and Fisheries, 7:65-123.

Lund, R. and Poplin, C. 1999. Fish diversity of the Bear Gulch Limestone, Namurian, Lower Carboniferous of Montana, USA. Geobios, 32:285-295.

Lund, R., Poplin, C., and McCarthy, K. 1995. Preliminary analysis of the interrelationships of some Paleozoic Actinopterygii. Geobios, Mémoire Spéciale, 19:215220.

Lundberg, J.G. 1993. African-South American freshwater fish clades and continental drift: problems with a paradigm, p. 156-199. In Goldblatt, P. (ed.) Biological Relationships between Africa and South America (ed. by P. Goldblatt). Yale University Press, New Haven.
Luo, Z.X. 2007. Transformation and diversification in early mammal evolution. Nature, 450:1011-1019.

Luo, Z.-X., Kielan-Jaworowska, Z., and Cifelli, R.L. 2002. In quest for a phylogeny of Mesozoic mammals. Acta Palaeontologica Polonica, 47:1-78.

Luo, Z.X., Ji, Q., Wible, J.R., and Yuan, C.X. 2003. An Early Cretaceous tribosphenic mammal and metatherian evolution. Science, 302:1934-1940.

Luo, Z.X., Yuan, C.X., Meng, Q.J., and Ji, Q. 2011. A Jurassic eutherian mammal and divergence of marsupials and placentals. Nature, 476:442-445.

Lyson, T.R., Bever, G.S., Bhullar, B.-A.S., Joyce, W.G., and Gauthier, J.A. 2010. Transitional fossils and the origin of turtles. Biology Letters, 6:830-833.

Lyson, T.R., Sperling, E.A., Heimberg, A.M., Gauthier, J.A., King, B.L., and Peterson, K.J. 2012. MicroRNAs support a turtle + lizard clade. Biology Letters, 8:104107.

MacLatchy, L., Downs, W., Kityo, R., Mafabi, M., and M., M. 2003. New catarrhine fossils from the Lower Miocene of Uganda, with implications for the ape-monkey split. Abstracts of the Paleoanthropology Society, 2003 Meeting.

MacNaughton, R.B. and Narbonne, G.M. 1999. Evolution and ecology of Neoproterozoic lower Cambrian trace fossils, NW Canada. Palaios, 14:97-115.

Maisey, J.G. and Anderson, M.E. 2001. A primitive chondrichthyan braincase from the Early Devonian of South Africa. Journal of Vertebrate Paleontology, 21:702-713.

Maisey, J.G. and Moody, J.M. 2001. A review of the problematic extinct teleost fish Araripichthys, with a description of a new spcies from the Lower Cretaceous of Venezuela. American Museum Novitates, 3324:1-27.

Malabarba, M.C., Malabarba, L.R., and del Papa, C. 2006. Proterocara argentina, a new fossil cichlid from the Lumbrera Formation, Eocene of Argentina. Journal of Vertebrate Paleontology, 26:267-275.

Malabarba, M.C., Malabarba, L.R., and del Papa, C. 2010. Gymnogeophagus eocenicus, n. sp. (Perciformes: Cichlidae), an Eocene cichlid from the Lumbrera Formation in Argentina. Journal of Vertebrate Paleontology, 30:341-350.

Mallatt, J. and Chen, J.Y. 2003. Fossil sister group of craniates: predicted and found. Journal of Morphology, 258:1-31.

Maloof, A.C., Porter, S.M., Moore, J.L., Dudás, F.Ö., Bowring, S.A., Higgins, J.A., Fike, D.A., and Eddy, M.P. 2010. The earliest Cambrian record of animals and ocean geochemical change. Geological Society of America Bulletin, 122:1731-1774.

Maloof, A.C., Ramezani, J., Bowring, S.A., Fike, D.A., Porter, S.M., and Mazouad, M. 2010. Constraints on early Cambrian carbon cycling from the duration of the Nemakit-Daldynian - Tommotian boundary $213 \mathrm{C}$ shift, Morocco. Geology, 38:623-626. 
Marcot, J.D. 2007. Molecular phylogeny of terrestrial artiodactyls, p. 4-18. In Prothero, D.R. and Foss, S.E. (eds.), The Evolution of Artiodactyls. Johns Hopkins University Press, Baltimore.

Marivaux, L., Vianey-Liaud, M., and Jaeger, J.J. 2004. High-level phylogeny of early Tertiary rodents: dental evidence. Zoological Journal of the Linnean Society, 142:105-134.

Marjanović, D. and Laurin, M. 2007. Divergence times and the origin of lissamphibians. Systematic Biology, 56:369-388.

Martill, D.M. 1991. Fish, p. 197-225. In Hudson, J.D. and Martill, D.M. (eds.), Fossils of the Oxford Clay. Palaeontological Association, London.

Martill, D.M. 1993. Fossils of the Santana and Crato formations, Brazil. Palaeontological Association, London.

Martín-Closas, C. and López-Morón, N. 1995. The charophyte fauna, p. 29-31. In Martínez-Delclós, X. (ed.), Field Trip Guide Book, Second International Symposium on Lithographic Limestones, Montsec and Montral Alcover. Two Konservat-Lagerstätten, Catalonia, Spain, July the 9-11th 1995. Institut d'Estudis Ilerdencs, Lleida.

Martin, M.W., Grazhdankin, D.V., Bowring, S.A., Evans, D.A.D., Fedonkin, M.A., and Kirschvink, J.L. 2000. Age of Neoproterozoic bilaterian body and trace fossils, White Sea, Russia: implications for metazoan evolution. Science, 288:841-845.

Martin, T. 2004. Evolution of incisor enamel microstructure in Lagomorpha. Journal of Vertebrate Paleontology, 24:411-426.

Martinis, B. 1967. Note geologiche sui dintorni dei Casarano e Castro (Lecce). Rivista Italiana di Paleontologia e Stratigrafia, 95:95-136.

Marx, F. 2011. The more the merrier? A large cladistic analysis of mysticetes, and comments on the transition from teeth to baleen. Journal of Mammalian Evolution, 18:77-100.

Mayr, G. 2004. A partial skeleton of a new fossil loon (Aves, Gaviiformes) from the early Oligocene of Germany with preserved stomach contents. Journal of Ornithology, 145:281-286.

Mayr, G. 2005. The Paleogene fossil record of birds in Europe. Biological Reviews, 80:515542.

Mayr, G. 2009. Mesozoic Neornithes, p. 19-23. In Mayr, G. (ed.), Paleogene Fossil Birds. Springer, Frankfurt.

Mayr, G. 2014. The origins of crown group birds: molecules and fossils. Palaeontology 57:231-242.

Mayr, G. and Weidig, I. 2004. The Early Eocene bird Gallinuloides wyomingensis-a stem group representative of Galliformes. Acta Palaeontologica Polonica, 49:211-217.

Mayr, G., Alvarenga, H., and Clarke, J.A. 2011. An Elaphrocnemus-like landbird and other avian remains from the late Paleocene of Brazi. Acta Palaeontologica Polonica, 56:679-684.
McAllister, D.E. The evolution of branchiostegals and associated opercular, gular, and hyoid bones, and the classification of fishes, living and fossil. National Museum of Canada Bulletin, 221:1-239.

McBrearty, S. and Jablonski, N.G. 2005. First fossil chimpanzee. Nature, 437:105-108.

McDowell, S.B. 1958. The Greater Antillean insectivores. Bulletin of the American Museum of Natural History, 117:1-214.

McKenna, M.C., Bell, S.K., and Simpson, G.G. 1997. Classification of Mammals above the Species Level. Columbia University Press, New York.

McMahan, C.D., Chakrabarty, P., Sparks, J.S., Smith, W.L., and Davis, M.P. 2013. Temporal patterns of diversification across global cichlid biodiversity (Acanthomorpha: Cichlidae). PLoS ONE, 8:e71162

Medizza, F. 1975. II nannoplancton calcareo della Pesciara di Bolca (Monti Lessini). Studi e Ricerche sui Giacimenti Terziari di Bolca, 2:433-444.

Medizza, F. and Sorbini, L. 1980. II giaciamento del Salento (Lecce), p. 131-134. In I Vertebrati Fossil Italiani - Catalogo della Mostra. Museo Civco di Storia Naturale, Verona.

Meehan, T.J. and Wilson, R.W. 2002. New viverravids from the Torrejonian (Middle Paleocene) of Kutz Canyon, New Mexico and the oldest skull of the Order Carnivora. Journal of Paleontology, 76:1091-1101.

Melchin, M.J., Sadler, P.M., and Cramer, B.D. 2012. The Silurian Period, p. 525-558. In Gradstein, F.M., Ogg, J.G., Schmitz, M., and Ogg, G. (eds.), The Geologic Time Scale 2012. Elsevier, Amsterdam.

Meng, J. and Wyss, A. 2005. Glires, p. 145-158. In Rose, K.D. and Archibald, J.D. (eds.), The Rise of Placental Mammals: Origins and Relationships of the Major Extant Clades. Johns Hopkins University Press, Baltimore.

Meng, J., Hu, Y.M., and Li, C.K. 2003. The osteology of Rhombomylus (Mammalia, Glires): Implications for phylogeny and evolution of Glires. Bulletin of The American Museum of Natural History, 275:1-247.

Menning, M., Gast, R., Hagdorn, H., Kading, K.C., Simon, T., Szurlies, M., and Nitsch, E. 2005. Time scale for the Permian and Triassic groups in the Stratigraphical Scale of Germany 2002, cyclostratigraphic calibration of the Dyassic and Germanic Triassic groups and the age of the strata Roadium to Rhaetium. Newsletters in Stratigraphy, 41:173-210

Menning, M., Weyer, D., Drozdzewski, G., Amerom, H.W.J., and Wendt, I.A. 2000. Carboniferous time scale 2000: discussion and use of geological parameters as time indicators from Central and Western Europe. Geologische Jahrbuch, A, 156:3-44.

Meredith, R.W., Janecka, J.E., Gatesy, J., Ryder, O.A., Fisher, C.A., Teeling, E.C., Goodbla, A., Eizirik, E., Simao, T.L., Stadler, T., Rabosky, D.L., Honeycutt, R.L., Flynn, J.J., Ingram, C.M., Steiner, C., Williams, T.L., Robinson, T.J., Burk-Herrick, A., Westerman, 
M., Ayoub, N.A., Springer, M.S., and Murphy, W.J. 2011. Impacts of the Cretaceous Terrestrial Revolution and $\mathrm{KPg}$ extinction on mammal diversification. Science, 334:521-524.

Métais, G., Antoine, P.-O., Marivaux, L., Welcomme, J.L., and Ducrocq, S. 2003. New artiodactyl ruminant mammal from the late Oligocene of Pakistan. Acta Palaeontologica Polonica, 48:375-382.

Meyer, A. and Zardoya, R. 2003. Recent advances in the (molecular) phylogeny of vertebrates. Annual Review of Ecology and Systematics, 34:311-338.

Michaux, J., Reyes, A., and Catzeflis, F. 2001. Evolutionary history of the most speciose mammals: molecular phylogeny of muroid rodents. Molecular Biology and Evolution, 18:2017-2031.

Miles, R.S. 1973. Articulated acanthodian fishes from the Old Red Sandstone of England, with a review of the structure and evolution of the acanthodian shouldergirdle. Bulletin of the British Museum (Natural History): Geology, 24:111-213.

Miller, E.R. 1999. Faunal correlation of Wadi Moghara, Egypt: implications for the age of Prohylobates tandyi. Journal of Human Evolution, 36:519-533.

Miller, R.F., Cloutier, R., and Turner, S. 2003. The oldest articulated chondrichthyan from the Early Devonian period. Nature, 425:501-504.

Mitchell, E.D. 1989. A new cetacean from the Late Eocene La Meseta Formation, Seymour Island, Antarctic Peninsula. Canadian Journal of Fisheries and Aquatic Sciences, 46:2219-2235.

Miya, M., Takeshima, H., Endo, H., Ishiguro, N.B., Inoue, J.G., Mukai, T., Satoh, T.P., Yamaguchi, M., Kawaguchi, A., Mabuchi, K., Shirai, S.M., and Nishida, M. 2003. Major patterns of higher teleostean phylogenies: a new perspective based on 100 complete mitochondrial DNA sequences. Molecular Phylogenetics and Evolution, 26:121-138.

Modesto, S.P. and Anderson, J.S. 2004. The phylogenetic definition of Reptilia. Systematic Biology, 53:815-821.

Mooi, R. 2001. Not all written in stone: interdisciplinary syntheses in echinoderm paleontology. Canadian Journal of Zoology, 79:1209-1231.

Muizon, C.de and Cifelli, R.L. 2001. A new basal "didelphoid" (Marsupialia, Mammalia) from the Early Paleocene of Tiupampa (Bolivia). Journal of Vertebrate Paleontology, 21:87-97.

Müller, J. 2004. The relationships among diapsid reptiles and the influence of taxon selection, p. 379-408. In Arratia, M.V.H. and Cloutier, R. (eds.) Recent Advances in the Origin and Early Radiation of Vertebrates. Dr. Friedrich Pfeil, München.

Müller, J. and Reisz, R.R. 2006. The phylogeny of early eureptiles: comparing parsimony and Bayesian approaches in the investigation of a basal fossil clade. Systematic Biology, 55:503-511.
Muller, J., Scheyer, T.M., Head, J.J., Barrett, P.M., Werneburg, I., Ericson, P.G., Pol, D., and Sanchez-Villagra, M.R. 2010. Homeotic effects, somitogenesis and the evolution of vertebral numbers in recent and fossil amniotes. Proceedings of the National Academy of Sciences, USA, 107:2118-2123.

Mundil, R., Pálfy, J., Renne, P.R., and Brack, P. 2010. The Triassic timescale: new constraints and a review of geochronological data, p. 41-60. In S.G. Lucas (ed.), The Triassic Timescale: Geological Society, London, Special Publications, 334.

Murphy, W.J., Eizirik, E., O'Brien, S.J., Madsen, O., Scally, M., Douady, C.J., Teeling, E., Ryder, O.A., Stanhope, M.J., de Jong, W.W., and Springer, M.S. 2001. Resolution of the early placental mammal radiation using Bayesian phylogenetics. Science, 294:2348-2351.

Murphy, W.J., Pringle, T.H., Crider, T.A., Springer, M.S., and Miller, W. 2007. Using genomic data to unravel the root of the placental mammal phylogeny. Genome Research, 17:413-421.

Murray, A.M. 2000. Eocene cichlid fishes from Tanzania, East Africa. Journal of Vertebrate Paleontology, 20:651-664.

Murray, A.M. 2001a. The oldest fossil cichlids (Teleostei: Perciformes): indication of a 45 million-year-old species flock. Proceedings of the Royal Society, Series $B, 268: 679-684$.

Murray, A.M. 2001b. The fossil record and biogeography of the Cichlidae (Actinopterygii: Labroidei). Biological Journal of the Linnean Society, 74:517-532.

Muttoni, G., Kent, D.V., Jadoul, F., Olsen, P.E., Rigo, M., Galli, M.T., and Nicora, A. 2010. Rhaetian magnetobiostratigraphy from the Southern Alps (Italy): constraints on Triassic chronology. Palaeogeography, Palaeoclimatology, Palaeoecology, 285:1-16.

Muttoni, G., Kent, D.V., Olsen, P.E., Di Stefano, P., Lowrie, W., Bernasconi, S.M., and Hernández, F.M. 2004. Tethyan magnetostratigraphy from Pizzo Mondello (Sicily) and correlation to the Late Triassic Newark astrochronological polarity time scale. Geological Society of America Bulletin, 116:1043-58.

Nakae, M. and Sasaki, K. 2010. Lateral line system and its innervations in Tetraodontiformes with outgroup comparisons: descriptions and phylogenetic implications. Journal of Morphology, 271:559-579.

Narbonne, G.M., Xiao, S., and Shields, G.A. 2012. The Ediacaran Period, p. 413-435. In Gradstein, F.M., Ogg, J.G., Schmitz, M., and Ogg, G. (eds.), The Geologic Time Scale 2012. Elsevier, Amsterdam.

Narbonne, G.M., Maow, P.M., Landing, E., and Anderson, M.M. 1987. A candidate stratotype for the Precambrian-Cambrian boundary, Fortune Head, Burin Peninsula, southeastern Newfoundland. Canadian Journal of Earth Sciences, 24:1277-1293. 
Narita, Y. and Kuratani, S. 2005. Evolution of the vertebral formulae in mammals: a perspective on developmental constraints. Journal of Experimental Zoology, B, Molecular and Developmental Evolution, 304:91106.

Nazarkin, M.V., Carnevale, G., and Bannikov, A.F. 2013a. A new greenling (Teleostei, Cottoidei) from the Miocene of Sakhalin Island, Russia. Journal of Vertebrate Paleontology, 33:794-803.

Nazarkin, M.V., Yabumoto, K., and Urabe, A. 2013b. A new Miocene three-spined stickleback (Pisces: Gasterosteidae) from Central Japan. Paleontological Research, 16:318-328.

Near, T.J., Dornburg, A., Eytan, R.I., Keck, B.P., Smith, W.L., Kuhn, K.L., Moore, J.A., Price, S.A., Burbrink, F.T., Friedman, M., and Wainwright, P.C. 2013. Phylogeny and tempo of diversification in the superradiation of spiny-rayed fishes. Proceedings of the National Academy of Sciences, USA, 110:1273812743.

Near, T.J., Eytan, R.I., Dornburg, A., Kuhn, K.L., Moore, J.A., Davis, M.P., Wainwright, P.C., Friedman, M., and Smith, W.L. 2012. Resolution of ray-finned fish phylogeny and timing of diversification. Proceedings of the National Academy of Sciences, USA, 109:13698-13703.

Nelson, J.S. 2006. Fishes of the World, fourth edition. John Wiley \& Sons, Hoboken, New Jersey.

Nesbitt, S.J. 2011. The early evolution of Archosauria: relationships and the origin of major clades. Bulletin of the American Museum of Natural History, 352:1292.

Nesbitt, S.J., Sidor, C.A., Irmis, R.B., Angielczyk, K.D., Smith, R.M.H., and Tsuji, L.A. 2010. Ecologically distinct dinosaurian sister group shows early diversification of Ornithodira. Nature, 464:95-98.

Newbrey, M.G., Murray, A.M., Wilson, M.V.H., Brinkman, D.B., and Neuman, A.G. 2013. A new species of the paracanthopterygian Xenyllion (Sphenocephaliformes) from the Mowry Formation (Cenomanian) of Utah, USA, p. 363-384. In Arratia, G., Schultze, H.-P. and Wilson, M.V.H. (eds.), Mesozoic Fishes 5 Global Diversity and Evolution. Verlag Dr. Friedrich Pfeil, Munich.

Newell, A.J., Sennikov, A.G., Benton, M.J., Molostovskaya, I.I., Golubev, V.K., Minikh, A.V., and Minikh, M.G. 2010. Disruption of playa-lacustrine depositional systems at the Permo-Triassic boundary: evidence from Vyazniki and Gorokhovets on the Russian Platform. Journal of the Geological Society, London, 167:695-716

Nielsen, C. 1997. Origin and evolution of animal life cycles. Biological Reviews, 73:125-155.

Nishihara, H., Maruyama, S., and Okada, N. 2009. Retroposon analysis and recent geological data suggest near-simultaneous divergence of the three superorders of mammals. Proceedings of the National Academy of Sciences, USA, 106:5235-5240.
Nolf, D. 2010. Otoliths, p. 270-274. In Young, J.R., Gale, A.S., Knight, R.I., and Smith, A.B. (eds.), Fossils of the Gault Clay. Palaeontological Association, London.

Nosenko, T., Schreiber, F., Adamska, M., Adamski, M., Eitel, M., Hammel, J., Maldonado, M., Müller, W.E.G., Nickel, M., Schierwater, B., Vacelet, J., Wiens, M., and Wörheide, G. 2013. Deep metazoan phylogeny: When different genes tell different stories. Molecular Phylogenetics \& Evolution.

Novacek, M.J. 1985. On the classification of early Tertiary Erinaceomorpha (Insectivora, Mammalia). American Museum Novitates, 2813:1-22.

Ogg, J.G. 2012. Triassic, p. 681-730. In Gradstein, F.M., Ogg, J.G., Schmitz, M., and Ogg, G. (eds.), The Geologic Time Scale 2012. Elsevier, Amsterdam.

Ogg, J.G., Hinov, L.A., and Huang, C. 2012a. Jurassic, p. 731-791. In Gradstein, F.M., Ogg, J.G., Schmitz, M., and Ogg, G. (eds.), The Geologic Time Scale 2012. Elsevier, Amsterdam.

Ogg, J.G., Hinov, L.A., and Huang, C. 2012b. Cretaceous, p. 793-853. In Gradstein, F.M., Ogg, J.G., Schmitz, M., and Ogg, G. (eds.), The Geologic Time Scale 2012. Elsevier, Amsterdam.

O'Leary, M.A., Bloch, J.I., Flynn, J.J., Gaudin, T.J., Giallombardo, A., Giannini, N.P., Goldberg, S.L., Kraatz, B.P., Luo, Z.X., Meng, J., Ni, X., Novacek, M.J., Perini, F.A., Randall, Z.S., Rougier, G.W., Sargis, E.J., Silcox, M.T., Simmons, N.B., Spaulding, M., Velazco, P.M., Weksler, M., Wible, J.R., and Cirranello, A.L. 2013. The placental mammal ancestor and the postK-Pg radiation of placentals. Science, 339:662-667.

O'Leary, M.A. and Uhen, M.D. 1999. The time of origin of whales and the role of behavioral changes in the terrestrial-aquatic transition. Paleobiology, 25:534-556.

Olson, L.E., Sargis, E.J., and Martin, R.D. 2005. Intraordinal phylogenetics of treeshrews (Mammalia:Scandentia) based on evidence from the mitochondrial 12S rRNA gene. Molecular Phylogenetics and Evolution, 35:656-673.

Olson, S.L. 1992. Neogaeornis wetzeli Lambrecht, a Cretaceous loon from Chile (Aves: Gaviidae). Journal of Vertebrate Paleontology, 12:122-124.

Otero, O., Dutour, Y., and Gayet, M. 1995. Hgulichthys, nouveau genre de Lissoberycinae (Trachichthyiformes, Trachichthyoidea) du Cénomanien inférieur marin de Hgula (Liban). Implications phylogénétiques. Geobios, Mémoire Spéciale, 28:711717.

Otto, M. 1999. New finds of vertebrates in the Middle Devonian Brandenberg Group (Sauerland, Northwest Germany). Part 2. Ptyctodontida, Acanthodii, Actinopterygii and Sarcopterygii. Paläontologische Zeitschrift, 73:113-131.

Ou, Q., Conway Morris, S., Han, J., Zhang, Z., Liu, J., Chen, A., Zhang, X., and Shu, D. 2012. Evidence for gill slits and a pharynx in Cambrian vetulicolians: implications for the early evolution of deuterostomes. BMC Biology, 10(1):81. 
Owen, R. 1853. Descriptive Catalogue of the Osteological Series Contained in the Museum of the Royal College of Surgeons of England. Royal College of Surgeons, London.

Pacheco, M.A., Battistuzzi, F.U., Lentino, M., Aguilar, R., Kumar, S., and Escalante, A.A. 2011. Evolution of modern birds revealed by mitogenomics: timing the radiation and origin of major orders. Molecular Biology and Evolution, 28:1927-1942.

Page, K.N. 2010. Stratigraphical framework, p. 33-53. In Lord, A.R. and Davis, P.G. (eds.), Fossils from the Lower Lias of the Dorset Coast. §Palaeontological Association, London.

Panchen, A.C. and Smithson, T.J. 1988. The relationships of the earliest tetrapods, p. 1-32. In M.J. Benton (ed.), The Phylogeny and Classification of the Tetrapods, Vol. 1: Amphibians, Reptiles, Birds. Clarendon Press. Oxford.

Papazzoni, C.A. and Trevisani, E. 2006. Facies analysis, palaeoenvironmental reconstruction, and biostratigraphy of the "Pesciara di Bolca" (Verona, northern Italy): An early Eocene Fossil-Lagerstätte. Palaeogeography, Palaeoclimatology, Palaeoecology, 242:2135.

Parham, J.F., Donoghue, P.C.J., Bell, C.J., Calway, T.D., Head, J.J., Holroyd, P.A., Inoue, J.G., Irmis, R.B., Joyce, W.G., Ksepka, D.T., Patané, J.S.L., Smith, N.D., Tarver, J.E., Van Tuinen, M., Yang, Z., Angielczyk, K.D., Greenwood, J., Hipsley, C.A., Jacobs, L., Makovicky, P.J., Müller, J., Smith, K.T.,Theodor, J.M., Warnock, R.C.M., Benton, M.J. 2012. Best practices for justifying fossil calibrations. Systematic Biology, 61:346-359.

Parris, D.C. and Hope, S. 2002. New interpretations of birds from the Navesink and Hornerstown formations, New Jersey, USA (Aves: Neornithes), p. 113124. In Zhou, Z. and Zhang, F. (eds.), Proceedings of the $5^{\text {th }}$ International Meeting of the Society of Avian Paleontology and Evolution. Science Press, Beijing, 2002.

Parsons, T.S. and Williams, E.E. 1963. The relationship of the modern Amphibia: a re-examination. Quarterly Review of Biology, 38:26-53.

Patterson, C. 1967. New Cretaceous berycoid fishes from the Lebanon. Bulletin of the British Museum (Natural History): Geology, 14:69-109.

Patterson, C. 1973. Interrelationships of holosteans, p. 233-305. In Greenwood, P.H., Miles, R.S., and Patterson, C. (eds.), Interrelationships of fishes. Academic Press, London.

Patterson, C. 1982. Morphology and interrelationships of primitive actinopterygian fishes. American Zoologist, 22:241-259.

Patterson, C. 1993a. An overview of the early fossil record of acanthomorphs. Bulletin of Marine Science, 52:29-59.

Patterson, C. 1993b. Osteichthyes: Teleostei, p. 621656. In Benton, M.J. (ed.), The Fossil Record 2. Chapman \& Hall, London.
Pecoits, E., Konhauser, K.O., Aubet, N.R., Heaman, L.M., Veroslavsky, G., Stern, R.A., and Gingras, M.K. 2013. Response to comment on "Bilaterian burrows and grazing behavior at $>585$ million years ago." Science, 339:906.

Pecoits, E., Konhauser, K.O., Aubet, N.R., Heaman, L.M., Veroslavsky, G., Stern, R.A., and Gingras, M.K. 2012. Bilaterian Burrows and Grazing Behavior at >585 Million Years Ago. Science, 336:1693-1696.

Pecoits, E., Konhauser, K.O., Aubet, N.R., Heaman, L.M., Veroslavsky, G., Stern, R., and Gingras, M.K. 2013. Response to comment on "Bilaterian burrows and grazing

Peng, S. 2003. Chronostratigraphic subdivision of the Cambrian of China. Geologica Acta, 1:135-144.

Peng, S. 2009. The newly-developed Cambrian biostratigraphic succession and chronostratigraphic scheme for South China. Chinese Science Bulletin, 54:41614170.

Peng, S., and Babcock, L. 2008. Cambrian Period, p. 3746. In Ogg, J.G., Ogg, G., and Gradstein, F.M. (eds.), The concise geologic time scale. Cambridge University Press, New York.

Peng, S., Babcock, L.E., and Cooper, R.A. 2012. The Cambrian Period, p. 437-488. In Gradstein, F.M., Ogg, J.G., Schmitz, M., and Ogg, G. (eds.), The Geologic Timescale 2012. Elsevier, Amsterdam.

Peng, Z., He, S., Wang, J., Wang, W., and Diogo, R. 2006. Mitochondrial molecular clocks and the origin of the major otocephalan clades (Pisces: Teleostei): a new insight. Gene, 370:113-124.

Perez, P.A., Malabarba, M.C., and del Papa, C. 2010. A new genus and species of Heroini (Perciformes: Cichlidae) from the early Eocene of southern South America. Neotropical Ichthyology, 8:631-642.

Peterson, K.J., Su, Y.-H., Arnone, M.I., Swalla, B., and King, B. 2013 microRNAs support the monophyly of enteropneust hemichordates. Journal of Experimental Zoology: Molecular and Developmental Evolution, 320:368-374.

Peybernès, B. 1976. Le Jurassique et le Crétacé inférieur des Pyrénées franco-espagnoles entre la Garonne et la Méditerranée. Thèse Doctorat de Sciences Naturelles, Université Paul-Sabatier. Imprimerie CRDP, Toulouse.

Philippe, H. and 19 other authors 2009. Phylogenomics revives traditional views on deep animal relationships. Current Biology, 19:706-12.

Philippe, H., Brinkmann, H., Copley, R.R., Moroz, L.L., Nakano, H., Poustka, A.J., Wallberg, A., Peterson, K.J., and Telford, M.J. 2011. Acoelomorph flatworms are deuterostomes related to Xenoturbella. Nature, 470:255-258

Pickford, M. and Andrews, P. 1981. The Tinderet Miocene Sequence in Kenya. Journal of Human Evolution, 10:11-33.

Pietsch, T.W. 1978. Evolutionary relationships of sea moths (Teleostei: Pegasidae) with a classification of gasterosteiform families. Copeia, 1978:517-529. 
Pietsch, T.W. 1981. The osteology and relationships of the anglerfish genus Tetrabrachium with comments on lophiiform classification. Fishery Bulletin, 79:387419.

Pietsch, T.W. 1984. Lophiiformes: development and relationships, p. 320-325. In Moser, H.G., Richards, W.J., Cohen, D.M., Fahay, M.P., Kendall, A.W. Jr., Richardson, S. L. (eds.), Ontogeny and systematics of fishes. Special Publication 1, American Society of Ichthyologists and Herpetologists. Allen Press, Lawrence, KS.

Pilbeam, D. 1986. Distinguished lecture - Hominoid evolution and hominoid origins. American Anthropologist, 88:295-312.

Pirrie, D., Crame, J.A., Lomas, S.A., and Riding, J. B. 1997. Late Cretaceous lithostratigraphy and palynology of the Admiralty Sound region, James Ross Basin, Antarctica. Cretaceous Research, 18:109137.

Polly, P.D., Wesley-Hunt, G.D., Heinrich, R.E., Davis, G., and Houde, P. 2006. Earliest known carnivoran auditory bulla and support for a recent origin of crown group Carnivora (Eutheria, Mammalia). Palaeontology, 49:1019-1027.

Poty, E., Aretz, M., and Hance, L. 2014. Belgian substages as a basis for an international chronostratigraphic division of the Tournaisian and Viséan. Geological Magazine, 151:229-243.

Poux, C., Madsen, O., Glos, J., de Jong, W.W., and Vences, M. 2008. Molecular phylogeny and divergence times of Malagasy tenrecs: influence of data partitioning and taxon sampling on dating analyses. BMC Evolutionary Biology, 8:102.

Poux, C., Madsen, O., Marquard, E., Vieites, D.R., de Jong, W.W., and Vences, M. 2005. Asynchronous colonization of Madagascar by the four endemic clades of primates, tenrecs, carnivores, and rodents as inferred from nuclear genes. Systematic Biology, 54:719-730.

Poyato-Ariza, F.J. 1996a. The phylogenetic relationships of Rubiesichthys gregalis and Gordichthys coquensis (Ostariophysi, Chanidae) from the Early Cretaceous of Spain, p. 329-348. In Arratia, G. and Viohl, G. (eds.), Mesozoic fishes - systematics and paleoecology. Verlag Dr. Friedrich Pfeil, Munich.

Poyato-Ariza, F.J. 1996b. A revision of Rubiesichthys gregalis Wenz 1984, p. 361-368. In Arratia, G. and Viohl, G. (eds.), Mesozoic fishes - systematics and paleoecology. Verlag Dr. Friedrich Pfeil, Munich.

Poyato-Ariza, F.J. 1996c. A revision of the ostariophysan fish family Chanidae, with special reference to the Mesozoic forms. Palaeolchthyologica, 6:1-52.

Poyato-Ariza, F.J. 1999. The elopiform fish †Anaethalion angustus restored, with comments on individual variation, p. 361-368. In Arratia, G. and Schultze, H.-P. (eds.), Mesozoic fishes - systematics and fossil record. Verlag Dr. Friedrich Pfeil, Munich.
Prasad, A.B., Allard, M.W., Program, N.C.S., and Green, E.D. 2008. Confirming the phylogeny of mammals by use of large comparative sequence data sets. Molecular Biology and Evolution, 25:1795-1808.

Preuss, T.M. 2000. Preface: from basic uniformity to diversity in cortical organization. Brain Behavior and Evolution, 55:283-286.

Prothero, D.R. 1993. Ungulate phylogeny:morphological vs. molecular evidence p. 173-181. In Szalay, F.S., Novacek, M.J., and McKenna, M.C. (eds.), Mammal phylogeny, Vol. 2: Placentals. Springer, New York.

Prothero, D.R. and Emery, R.J. 2004. The Chadronian, Orellan, and Whitneyan North American land mammal ages, p. 156-168. In Woodburne, M.O. (ed.), Late Cretaceous and Cenozoic mammals of North America: Biostratigraphy and geochronology. Columbia University Press, New York.

Purnell, M.A. and Cossey, P.J. 2004. Northumberland trough, p. 107-166. In Cossey, P.J., Adams, A.E., Purnell, M.A., Whiteley, M.J., Whyte, M.A., and Wright, V.P. (eds.), British Lower Carboniferous Stratigraphy. Joint Nature Conservation Committee, Peterborough.

Pycraft, W.P. 1901. On the morphology and phylogeny of the Palaeognathae (Ratitae and Crypturi) and Neognathae (Carinatae).Transactions of the Zoological Society of London, 15:149-290.

Pyron, R.A. 2011. Divergence time estimation using fossils as terminal taxa and the origins of Lissamphibia. Systematic Biology, 60:466-481.

Pyron, R.A. and Wiens, J.J. 2011. A large-scale phylogeny of Amphibia including over 2800 species, and a revised classification of extant frogs, salamanders, and caecilians. Molecular Phylogenetics \& Evolution, 61:543-583.

Qu, Q.M., Zhu, M., and Zhao, W.J. 2010. Silurian atmospheric $\mathrm{O}_{2}$ changes and the early radiation of gnathostomes. Palaeoworld 19:146-159.

Radley, J.D. 2006. A Wealden guide 1: the Weald subbasin. Geology Today, 22:109-118.

Rage, J.-C. and Richter, A. 1995. A snake from the lower Cretaceous (Barremian) of Spain: the oldest known snake. Neues Jahrbuch für Geologie und Paläontologie, Monatshefte, 1995:561-565.

Rasmussen, D.T. 2002. Early catarrhines of the African Eocene and Oligocene, p. 203-220. In Hartwig, W.C. (ed.), The Primate Fossil Record. Cambridge University Press, Cambridge.

Rauhut, O.W., Martin, T., Ortiz-Jaureguizar, E., and Puerta, P. 2002. A Jurassic mammal from South America. Nature, 416:165-8.

Rayner, D.H. 1941. The structure and evolution of the holostean fishes. Biological Reviews, 16:218-237.

Regan, C.T. 1912. The classification of the teleostean fishes of the order Pediculati. Annals and Magazine of Natural History, 9(8):277-289. 
Reguero, M., Goin, F., Hospitaleche, C.A., Marenssi, S., and Dutra, T. 2013. Late Cretaceous/ Pelogene stratigraphy in the James Ross Basin, p. 19-25. In Reguero, M., Goin, F., Hospitaleche, C.A., Dutra, T., and Marenssi, S. (eds.), Late Cretaceous/Paleogene West Antarctica terrestrial biota and its intercontinental affinities. Springer, Dordrecht.

Reisz, R.R. 1972. Pelycosaurian reptiles from the Middle Pennsylvanian of North America. Bulletin of the Museum of Comparative Zoology, Harvard, 144:2762.

Reisz, R.R. 1986. Pelycosauria. In Westphal F (ed.). Handbuch der Paläoherpetologie. Gustav Fischer, Stuttgart. 17A:1-102. Gustav Fischer, Stuttgart.

Reisz, R.R., Laurin, M., and Marjanoviv, D. 2010. Apsisaurus witteri from the Lower Permian of Texas: yet another small varanopid synapsid, not a diapsid. Journal of Vertebrate Paleontology, 30:1628-1631.

Reisz, R.R. and Modesto, S.P. 1996. Archerpeton anthracos from the Joggins Formation of Nova Scotia: a microsaur, not a reptile. Canadian Journal of Earth Sciences, 33:703-709.

Reisz, R.R. and Müller, J. 2004. Molecular timescales and the fossil record: a paleontological perspective. Trends in Genetics, 20:237-241.

Reynoso, V.H. 1998. Huehuecuetzpalli mixtecus gen. et sp. nov: a basal squamate (Reptilia) from the Early Cretaceous of Tepexi de Rodríguez, Central México. Philosophical Transactions of the Royal Society, Series B, 353:477-500.

Richmond, B.G. and Jungers, W.L. 2008. Orrorin tugenensis femoral morphology and the evolution of hominin bipedalism. Science, 319:1662-5.

Rieppel, O. and Reisz, R.R. 1999. The origin and early evolution of turtles. Annual Review of Ecology \& Systematics, 30:1-22.

Ritchie, A. and Gilbert-Tomlinson, J. 1977. First Ordovician vertebrates from the Southern Hemisphere. Alcheringa, 1:351-368.

Roberts, E.M., O'Connor, P.M., Stevens, N.J., Gottfried, M.D., Jinnah, Z.A., Ngasala, S., Choh, A.M., and Armstrong, R.A. 2010. Sedimentology and depositional environments of the Red Sandstone Group, Rukwa Rift Basin, southwestern Tanzania: New insight into Cretaceous and Paleogene terrestrial ecosystems and tectonics in sub-equatorial Africa. Journal of African Earth Sciences, 57:179-212.

Robinson, P., Gunnell, G.F., Walsh, S.L., Clyde, W.C., Storer, J.E., Stucky, R.K., Froehlich, D.J., FerrusquiaVillafranca, I., and McKenna, M.C. 2004. Wasatchian through Duchesnean biochronology, p. 106-155. In Woodburne, M.O. (ed.), Late Cretaceous and Cenozoic mammals of North America: Biostratigraphy and geochronology. Columbia University Press, New York.

Robinson, T.J. and Seiffert, E.R. 2004. Afrotherian origins and interrelationships:new views and future prospects. Current Topics in Developmental Biology, 63:37-60.
Roca, A.L., Bar-Gal, G.K., Eizirik, E., Helgen, K.M., Maria, R., Springer, M.S., O'Brien, S.J., and Murphy, W.J. 2004. Mesozoic origin for West Indian insectivores. Nature, 429:649-651.

Roelants, K. and Bossuyt, F. 2005. Archaeobatrachian paraphyly and Pangaean diversification of crowngroup frogs. Systematic Biology, 54:111-126.

Roelants, K., Gower, D.J., Wilkinson, M., Loader, S.P., Biju, S.D., Guillaume, K., Moriau,L., and Bossuyt, F., 2007. Global patterns of diversification in the history of modern amphibians. Proceedings of the National Academy of Sciences, USA, 104:887-892.

Rogov, V., Marusin, V., Bykova, N., Goy, Y., Nagovitsin, K., Kochnev, B., Karlova, G., and Grazhdankin, D. 20120. The oldest evidence of bioturbation on Earth. Geology, 40:395-398.

Röhl, H.J., Schmid-Röhl, A., Oschmann, W., Frimmel, A., and Schwark, L. 2001. The Posidonia Shale (Lower Toarcian) of SW-Germany: an oxygen-depleted ecosystem controlled by sea level and palaeoclimate. Palaeogeography, Palaeoclimatology, Palaeoecology, 165:27-52.

Roscher, M. and Schneider, J.W. 2006. Permo-Carboniferous climate: Early Pennsylvanian to Late Permian climate development of central Europe in a regional and global context. In Lucas, S.G., Cassinis, G., Schneider, J.W. (eds.), Non-marine Permian biostratigraphy and biochronology. Special Publications of the Geological Society, London, 265: 95-136.

Rose, K.D. 1981. The Clarkforkian land-mammal age and mammalian faunal composition across the Paleocene-Eocene boundary. Museum of Paleontology, University of Michigan, Ann Arbor, Mich.

Rose, K.D. 1999. Eurotamandua and Palaeanodonta: convergent or related? Paläontologische Zeitschrift, 73:395-401.

Rose, K.D., Emry, R.J., Gaudin, T.J., and Storch, G. 2005. Xenarthra and Pholidota, p. 106-126. In Rose, K.D. and Archibald, J.D. (eds.) The rise of placental mammals: Origins and relationships of the major extant clades. Johns Hopkins University Press, Baltimore.

Rose, K.D., DeLeon, V.B., Missiaen, P., Rana, R.S., Sahni, A., Singh, L., and Smith, T. 2008. Early Eocene lagomorph (Mammalia) from Western India and the early diversification of Lagomorpha. Proceedings of the Royal Society, Series B, 275:12031208.

Rose, K.D., Walker, A., and Jacobs, L.L. 1981. Function of the mandibular tooth comb in living and extinct mammals. Nature, 289:583-585.

Rosen, D.E. 1973. Interrelationships of higher euteleostean fishes, p. 397-513. In Greenwood, P.H., Miles, R.S., and Patterson, C. (eds.), Interrelationships of fishes. Academic Press, London.

Rosen, D.E. 1984. Zeiforms as primitive plectognath fishes. American Museum Novitates, 2782:1-45. 
Rosen, D.E. and Parenti, L.R. 1981. Relationships of Oryzias and the groups of atherinomorph fishes. American Museum Novitates, 2719:1-

Rossie, J.B. and MacLatchy, L. 2006. A new pliopithecoid genus from the early Miocene of Uganda. Journal of Human Evolution, 50:568-586.

Rota-Stabelli, O., Campbell, L., Brinkmann, H., Edgecombe, G.D., Longhorn, S.J., Peterson, K.J., Pisani, D., Philippe, H., and Telford, M.J. 2010. A congruent solution to arthropod phylogeny: phylogenomics, microRNAs and morphology support monophyletic Mandibulata. Proceedings of the Royal Society B: Biological Sciences, 278:298-306.

Röttinger, E. and Lowe, C.J. 2012. Evolutionary crossroads in developmental biology: hemichordates. Development, 139:2463-2475.

Rougier, G.W., Wible, J.R., Beck, R.M., and Apesteguia, S. 2012. The Miocene mammal Necrolestes demonstrates the survival of a Mesozoic nontherian lineage into the late Cenozoic of South America. Proceedings of the National Academy of Sciences, USA, 109:20053-20058.

Runnegar, B. 1981. Muscle scars, shell form and torsion in Cambrian and Ordovician univalved molluscs. Lethaia 14:311-322.

Ruta M. and Coates M.I. 2007. Dates, nodes and character conflict: addressing the lissamphibian origin problem. Journal of Systematic Palaeontology, 5:69122.

Ruta, M., Coates, M.I., and Quicke, D.L.J. 2003. Early tetrapod relationships revisited. Biological Reviews, 78:251-345.

Salazar, C., Stinnesbeck, W., and Quinzio-Sinn, L.A. 1986. Ammonites from the Maastrichtian (Upper Cretaceous) Quiriquina Formation in central Chile. Neues Jahrbuch für Geologie und Paläontologie, Abhandlungen, 257:181-236.

Sallan, L.C. 2014. Major issues in the origins of rayfinned fish (Actinopterygii) biodiversity. Biological Reviews.

Salton, J.A. and Sargis, E.J. 2009. Evolutionary morphology of the Tenrecoidea (Mammalia) hindlimb skeleton. Journal of Morphology, 270:3673-87.

San Mauro, D. 2010. A multilocus timescale for the origin of extant amphibians. Molecular Phylogenetics and Evolution, 56, 554-561.

San Mauro, D., Vences, M., Alcobendas, M., Zardoya, R., and Meyer, A. 2005. Initial diversification of living amphibians predated the breakup of Pangaea. The American Naturalist, 165:590-599.

Sánchez-Villagra, M.R. 2010. Developmental palaeontology in synapsids: the fossil record of ontogeny in mammals and their closest relatives. Proceedings of the Royal Society, Series B, 277:1139-1147.
Sánchez-Villagra, M.R., Ladeveze, S., Horovitz, I., Argot, C., Hooker, J.J., Macrini, T.E., Martin, T., Moore-Fay, S., de Muizon, C., Schmelzle, T., and Asher, R.J. 2007. Exceptionally preserved North American Paleogene metatherians: adaptations and discovery of a major gap in the opossum fossil record. Biology Letters, 3:318-322.

Sánchez-Villagra, M.R., Narita, Y., and Kuratani, S. 2007. Thoracolumbar vertebral number: The first skeletal synapomorphy for afrotherian mammals. Systematics and Biodiversity, 5:1-7.

Sanders, W.J., Gheerbrant, E., Harris, J.M., Saegusa, H., and Delmer, C. 2010. Proboscidea, p. 161-251. In Werdelin, L. and Sanders, W.J. (eds.), Cenozoic Mammals of Africa. University of California Press, Berkeley.

Sansom, I.J. 1996. Pseudooneotodus: a histological study of an Ordovician to Devonian vertebrate lineage. Zoological Journal of the Linnean Society, 118:47-57.

Sansom, I.J., Haines, P.W., Adreev, P., and Nicoll, R.S. 2013. A new pteraspidomorph from the Nibil Formation (Katian, Late Ordovician) of the Canning Basin, Western Australia. Journal of Vertebrate Paleontology, 33:764-769.

Sansom, I.J., Smith, M.M., and Smith, M.P. 2001. The Ordovician radiation of vertebrates, p. 363-384. In Ahlberg, P.E. (ed.), Major events in vertebrate evolution. Taylor \& Francis, London.

Sansom, I.J., Smith, M.P., and Smith, M.M. 1996. Scales of thelodont and shark-like fishes from the Ordovician. Nature, 379:628-630.

Sansom, I.J., Wang, N.-Z., and Smith, M. 2005. The histology and affinities of sinacanthid fishes: primitive gnathostomes from the Silurian of China. Zoological Journal of the Linnean Society, 144:379-386.

Sansom, R.S., Freedman, K., Gabbott, S.E., Aldridge, R.J., and Purnell, M.A. 2010. Taphonomy and affinity of an enigmatic Silurian vertebrate, Jamoytius kerwoodi White. Palaeontology, 53:1393-1409.

Sansom, I.J., Davies, N.S., Coates, M.I., Nicoll, R.S., and Ritchie, A. 2012. Chondrichthyan-like scales from the Middle Ordovician of Australia. Palaeontology, 55:243-247.

Santini, F., Harmon, L.J., Carnevale, G., and Alfaro, M.E. 2009. Did genome duplication drive the origin of teleosts? A comparative study of diversification in rayfinned fishes. BMC Evolutionary Biology, 9:194.

Santini, F. and Tyler, J.C. 2003. A phylogeny of the families of fossil and extant tetraodontiform fishes (Acanthomorpha, Tetraodontiformes), Upper Cretaceous to Recent. Zoological Journal of the Linnean Society, 139:565-617.

Santini, F., Sorenson, L., and Alfaro, M.E. 2013. A new phylogeny of tetraodontiform fishes (Tetraodontiformes, Acanthomorpha) based on 22 loci. Molecular Phylogenetics and Evolution, 69:177-187. 
Sanz, J.L., Wenz, S., Yebenes, A., Estes, R., MartinezDelclos, X., Jimenes-Fuentes, E., Diéguez, C., Buscaloni, A.D., Barbadillo, L.J., and Via, L. 1988. An Early Cretaceous faunal and floral continental assemblage: Las Hoyas fossil site (Cuenca, Spain). Geobios, 21:611-635.

Sarich, V.M. and Wilson, A.C. 1967. Immunological time scale for hominid evolution. Science, 158:1200-3.

Sato, A., Rickards, B., and Holland, P.W.H. 2008. The origins of graptolites and other pterobranchs: a journey from 'Polyzoa'. Lethaia, 41:303-316.

Schlüter, M., Steuber, T., and Puente, M. 2008. Chronostratigraphy of Campanian-Maastrichtian platform carbonates and rudist associations of Salento (Apulia, Italy). Cretaceous Research, 29:100-114.

Schopf, J.W. 1968. Microflora of the Bitter Springs Formation, Late Precambrian, central Australia. Journal of Paleontology, 42:651-688.

Schroeder, R., Altenbach, A., Brinnel, P., Cherchi, A., and Wallrabe, H.-J. 1982. El Barremienense marine de la Serria del Montsec (Provincia de LéridaaHuesca). Cuadernos de Geología Ibérica, 8:915-933.

Schweigert, G. 2007. Ammonite biostratigraphy as a tool for dating Upper Jurassic lithographic limestones from South Germany - first results and open questions. Neues Jarhbuch für Geologie und Paläontologie, Abhandlungen, 245:117-125.

Scillato-Yané, G.J. 1976. Sobre un Dasypodidae (Mammalia, Xenarthra) de edad Riochiquense (Paleoceno superior) de Itaboraí, Brasil. Anais da Academia Brasileira de Ciências, 48:527-530.

Secord, R. 2008. The Tiffanian Land-Mammal Age (middle and late Paleocene) in the Northern Bighorn Basin, Wyoming. University of Michigan Papers in Paleontology, 35:1-192.

Seiffert, E.R. 2006. Revised age estimates for the later Paleogene mammal faunas of Egypt and Oman. Proceedings of the National Academy of Sciences, USA, 103:5000-5005.

Seiffert, E.R. and Simons, E.L. 2000. Widanelfarasia, a diminutive placental from the late Eocene of Egypt. Proceedings of the National Academy of Sciences, USA, 97:2646-2651.

Seiffert, E.R., Simons, E.L., and Attia, Y. 2003. Fossil evidence for an ancient divergence of lorises and galagos. Nature, 422:421-424.

Santini, F. and Tyler, J.C. 2003. A phylogeny of the families of fossil and extant tetraodontiform fishes (Acanthomorpha, Tetraodontiformes), Upper Cretaceous to Recent. Zoological Journal of the Linnean Society, 139:565-617.

Seiffert, E.R., Simons, E.L., Clyde, W.C., Rossie, J.B., Attia, Y., Bown, T.M., Chatrath, P., and Mathison, M.E. 2005. Basal anthropoids from Egypt and the antiquity of Africa's higher primate radiation. Science, 310:300-4.
Seiffert, E.R., Simons, E.L., Ryan, T.M., Bown, T.M., and Attia, Y. 2007. New remains of Eocene and Oligocene Afrosoricida (Afrotheria) from Egypt, with implications for the origin(s) of afrosoricid zalambdodonty. Journal of Vertebrate Paleontology, 27:963-972.

Sempere, T., Butler, R.F., Richards, D.R., Marshall, L.G., Sharp, W., and Swisher, C.C., III. 1997. Stratigraphy and chronology of Upper Cretaceous-lower Paleogene strata in Bolivia and northwest Argentina. Geological Society of America Bulletin, 109:709-727.

Sennikov, A.G. 2012. The first ctenosauriscid (Reptilia: Archosauromorpha) from the Lower Triassic of Eastern Europe. Paleontological Journal, 46:499-511.

Senut, B., Pickford, M., Gommery, D., Mein, P., Cheboi, K., and Coppens, Y. 2001. First hominid from the Miocene (Lukeino Formation, Kenya). Comptes Rendus de l'Académie des Sciences, Série II, Fascicule A-Sciences de la Terre et des Planètes, 332:137144.

Sereno, P.C. 1991. Basal archosaurs: phylogenetic relationships and phylogenetic implications. Society of Vertebrate Paleontology, Memoir, 2:153.

Sereno, P.C. 1999. Definitions in phylogenetic taxonomy: Critique and rationale. Systematic Biology, 48:329351.

Sereno, P.C. 2005. The logical basis of phylogenetic taxonomy. Systematic Biology, 54:595-619.

Shevyreva, N.S. 1984. New Early Eocene rodents from the Zaysan Basin, p. 77-114. In Gabunia, L.K. (ed.), Flora i Fauna Zaysanskoi Vpadiny. Akademiya Nauk Gruzinskoy SSR, Tblisi. (In Russian.)

Shoshani, J. and McKenna, M.C. 1998. Higher taxonomic relationships among extant mammals based on morphology, with selected comparisons of results from molecular data. Molecular Phylogenetics and Evolution, 9:572-584.

Shu, D.-G. 2003. A paleontological perspective of vertebrate origin. Chinese Science Bulletin, 48:725-735.

Shu, D.-G., Chen, L., Han, J., and Zhang, X.-L. 2001. An early Cambrian tunicate from China. Nature, 411:472-473.

Shu, D.-G., Conway Morris, S., Han, J., Zhang, Z.-F., and Liu, J.-N. 2004. Ancestral echinoderms from the Chengjiang deposits of China. Nature, 430:422-428.

Shu, D.-G., Conway Morris, S., Han, J., Zhang, Z.-F., Yasui, K., Janvier, P., Chen, L., Zhang, X.-L., Liu, J.N., and Liu, H.-Q. 2003. Head and backbone of the Early Cambrian vertebrate Haikouichthys. Nature, 421:526-529.

Shu, D.-G., Luo, H.-L., Conway Morris, S., Zhang, X.-L., Hu, S.-X., Chen, L., Han, J., Zhu, M., Li, Y., and Chen, L.-Z. 1999. Lower Cambrian vertebrates from south China. Nature, 402:42-46.

Shu, D.-G., Zhang, X., and Chen, L. 1996. Reinterpretation of Yunnanozoon as the earliest known hemichordate. Nature, 380:428-430.

Sibley, C.G., and Ahlquist. J.E. 1990. Phylogeny and classification of birds: a study in molecular evolution. Yale University Press, New Haven, CT. 
Sickenberg, O. 1934. Beitrage zur Kenntnis Tertiärer Sirenen. Mémoires de Musée Royal d'Histoire Naturelle de Belgique 63: 1-352.

Sidor, C.A., Damiani, R., and Hammer, W.R. 2008. A new Triassic temnospondyl from Antarctica and a review of Fremouw Formation biostratigraphy. Journal of Vertebrate Paleontology, 28:656-663.

Siegl, A., Kamke, J., Hochmuth, T., Piel, J., Richter, M., Liang, C., Dandekar, T., and Hentschel, U. 2011. Single-cell genomics reveals the lifestyle of Poribacteria, a candidate phylum symbiotically associated with marine sponges. ISME J, 5:61-70.

Sigé, B. 1990. New bats from the Middle Oligocene Quercy Phosphorites, France. Comptes Rendus de l'Académie des Sciences, Série II, Fascicule A-Sciences de la Terre et des Planètes, 310:1131-1137.

Sigé, B., Jaeger, J.J., Sudre, J., and Vianey Liaud, M. 1990. Altiatlasius koulchii n. gen. et sp., primate omomyidé du Paléocène supérieur du Maroc, et les origines des euprimates Palaeontographica, Abteilung $A, 214: 31-56$.

Silcox, M.T., Bloch, J.I., Sargis, E.J., and Boyer, D.M. 2005. Euarchonta, p. 127-144. In Rose, K.D. and Archibald, J.D. (eds.) The rise of placental mammals: Origins and relationships of the major extant clades. Johns Hopkins University Press, Baltimore.

Simons, E.L. 1972. Primate Evolution; an Introduction to Man's Place in Nature. Macmillan, New York.

Simons, E.L. and Rasmussen, D.T.1996. Skull of Catopithecus browni, an early Tertiary catarrhine. American Journal of Physical Anthropology, 100:261-292.

Simpson, G.G. 1942. Tempo and Mode in Evolution. Columbia University Press, New York.

Simpson, G.G. 1945. The principles of classification and a classification of mammals. Bulletin of The American Museum of Natural History, 85:1-350.

Slowakiewicz, M., Kiersnowski, H., and Wanger, R. 2009. Correlation of the Upper Permian marine and terrestrial sedimentary sequences in Polish, German, and USA Western Interior Basins with reference to global time markers. Palaeoworld, 18:193-211.

Smith, A.B. 1984. Classification of the Echinodermata. Palaeontology, 27:431-459.

Smith, A.B. 1985. Cambrian eleutherozoan echinoderms and the early diversification of edrioasteroids. Palaeontology, 28:715-756.

Smith, W.L. and Wheeler, W.C. 2006. Venom evolution widespread in fishes: a phylogenetic road map for the bioprospecting of piscine venoms. Journal of Heredity, 97:206-217.

Smith, A.B., Zamora, S., and Álvaro, J.J. 2013. The oldest echinoderm faunas from Gondwana show that echinoderm body plan diversification was rapid. Nature Communications, 4(1385).

Smith, M.P., Sansom, I.J., and Cochrane, K.D. 2001. The Cambrian origin of vertebrates, p. 67-84. In Ahlberg, P.E. (ed.), Major events in early vertebrate evolution: palaeontology, phylogeny, genetics and development. Taylor \& Francis, London.
Smith, M.P., Sansom, I.J., and Repetski, J.E. 1996. Histology of the first fish. Nature, 380:702-704.

Smith, P.E., Evensen, N.M., York, D., Chang, M.-M., Jin, F., Li, J.-L., Cumbaa, S., and Russell, D. 1995. Dates and rates in ancient lakes: ${ }^{40} \mathrm{Ar}-{ }^{39} \mathrm{Ar}$ evidence for an Early Cretaceous age for the Jehol Group, northeast China. Canadian Journal of Earth Sciences, 32:1426-1431.

Smith, S.A., Wilson, N.G., Goetz, F.E., Feehery, C., Andrade, S.C.S., Rouse, G.W., Giribet, G., and Dunn, C.W. 2011. Resolving the evolutionary relationships of molluscs with phylogenomic tools. Nature, 480:364-367.

Smith, T., Bloch, J.I., Strait, S.G., and Gingerich, P.D. 2002. New species of Macrocranion (Mammalia, Lipotyphla) from the earliest Eocene of North America ad its biogeographic relationships. Contributions from the Museum of Paleontology, The University of Michigan, 30:373-384.

Snyder, S.W., Mauger, L.L., and Akers, W.H. 1983. Planktonic foraminifera and biostratigraphy of the Yorktown Formation, Lee Creek Mine. Smithsonian Contributions to Paleobiology, 53:455-480.

Solounias, N., Barry, J.C., Bernor, R.L., Lindsay, E.H., and Raza, S.M. 1995. The oldest bovid from the Siwaliks, Pakistan. Journal of Vertebrate Paleontology, 15:806-814.

Sorbini, L. 1981. The Cretaceous fishes of Nardò. $1^{\circ}$. Order Gasterosteiformes (Pisces). Bollettino del Museo Civico di Storia Naturale di Verona, 8:1-27.

Spaulding, M., O'Leary, M.A., and Gatesy, J.2009. Relationships of Cetacea (Artiodactyla) among mammals:increased taxon sampling alters interpretations of key fossils and character evolution. PLOS ONE, 4:e7062.

Sperling, E.A., Peterson, K.J., and Pisani, D. 2009. Phylogenetic-signal dissection of nuclear housekeeping genes supports the paraphyly of sponges and the monophyly of Eumetazoa. Molecular Biology and Evolution, 26:2261-2274.

Sperling, E.A., and Vinther, J. 2010. A placozoan affinity for Dickinsonia and the evolution of late Proterozoic metazoan feeding modes. Evolution \& Development, 12:201-209.

Sperling, E.A., Vinther, J., Moy, V.N., Wheeler, B.M., Sémon, M., Briggs, D.E.G., and Peterson, K.J. 2009. MicroRNAs resolve an apparent conflict between annelid systematics and their fossil record. Proceedings of the Royal Society B: Biological Sciences, 276:4315-4322.

Springer, M.S. and de Jong, W.W. 2001. Phylogenetics. Which mammalian supertree to bark up? Science, 291:1709-1711.

Springer, M.S., Cleven, G.C., Madsen, O., deJong, W.W., Waddell, V.G., Amrine, H.M., and Stanhope, M.J. 1997. Endemic African mammals shake the phylogenetic tree. Nature, 388:61-64. 
Springer, M.S. and Murphy, W.J. 2007. Mammalian evolution and biomedicine: new views from phylogeny. Biological Reviews, 82:375-392.

Springer, M.S., Westerman, M., and Kirsch, J.A.W. 1994. Relationships Among Orders and Families of Marsupials Based on 12S Ribosomal DNA Sequences and the Timing of the Marsupial Radiation. Journal of Mammalian Evolution, 2:85-115.

Springer, M.S., Murphy, W.J., Eizirik, E., Madsen, O., and Scally, M. 2007. A molecular classification for the living orders of placental mammals and the phylogenetic classification of primates, p. 1-28. In Ravosa, M.J. and Dagosto, M. (eds.) Primate Origins: Adaptation and Evolution. Springer, New York.

Springer, M.S., Murphy, W.J., Eizirik, E., and O'Brien, S.J. 2003. Placental mammal diversification and the Cretaceous-Tertiary boundary. Proceedings of the National Academy of Sciences, USA, 100:1056-1061.

Springer, M.S., Murphy, W.J., Eizirik, E., and O'Brien, S.J. 2005. Molecular evidence for major placental clades. , p. 37-49. In Rose, K.D. and Archibald, J.D. (eds.) The rise of placental mammals: Origins and relationships of the major extant clades. Johns Hopkins University Press, Baltimore.

Springer, M.S., Stanhope, M.J., Madsen, O., and de Jong, W.W. 2004. Molecules consolidate the placental mammal tree. Trends in Ecology and Evolution, 19:430-438.

Stahl, B.J. 1999. Chondrichthyes III: Holocephali, p. 1164. In Schultze, H.-P. (ed.), Handbook of Paleoichthyology, Volume 4. Verlag Dr. Friedrich Pfeil, Munich.

Stanhope, M.J., Waddell, V.G., Madsen, O., de Jong, W., Hedges, S.B., Cleven, G.C., Kao, D., and Springer, M.S. 1998. Molecular evidence for multiple origins of Insectivora and for a new order of endemic African insectivore mammals. Proceedings of the National Academy of Sciences, USA, 95:9967-9972.

Steeman, M.E. 2007. Cladistic analysis and a revised classification of fossil and recent mysticetes. Zoological Journal of the Linnean Society, 150:875-894.

Steiner, M., Li, G., Qian, Y., Zhu, M., and Erdtmann, B.-D. 2007. Neoproterozoic to Early Cambrian small shelly fossil assemblages and a revised biostratigraphic correlation of the Yangtze Platform (China). Palaeogeography, Palaeoclimatology, Palaeoecology, 254:67-99.

Steppan, S., Adkins, R., and Anderson, J. 2004. Phylogeny and divergence-date estimates of rapid radiations in muroid rodents based on multiple nuclear genes. Systematic Biology, 53:533-553.

Stevens, N.J., Seiffert, E.R., O'Connor, P.M., Roberts, E.M., Schmitz, M.D., Krause, C., Gorscak, E., Ngasala, S., Hieronymus, T.L., and Temu, J. 2013. Palaeontological evidence for an Oligocene divergence between Old World monkeys and apes. Nature, 497, 611-614
Stewart, J.D. 1996. Cretaceous acanthomorphs of North America, p. 383-394. In Arratia, G. and Viohl, G. (eds.), Mesozoic fishes - systematics and paleoecology. Verlag Dr. Friedrich Pfeil, Munich.

Stiassny, M.L.J. 1981. The phyletic status of the family Cichlidae (Pisces: Perciformes): a comparative anatomical investigation. Netherlands Journal of Zoology, 31:275-314.

Storch, G. 1981. Eurotamandua joresi, ein Mamecophagide aus dem Eozan der "Grube Messel" bei Darmstadt (Mammalia, Xenarthra). Senckenbergiana Lethaea, 61:247-289.

Storch, G. 2008. Skeletal remains of a diminutive primate from the Paleocene of Germany. Naturwissenschaften, 95:927-930.

Strait, D.S. 2013. Human systematics, p. 37-54. In Begun, D.R. (ed.), A companion to paleoanthropology. John Wiley \& Sons, Oxford.

Struck, T.H., Paul, C., Hill, N., Hartmann, S., Hosel, C., Kube, M., Lieb, B., Meyer, A., Tiedemann, R., Purschke, G., and Bleidorn, C. 2011. Phylogenomic analyses unravel annelid evolution. Nature, 471:95-98.

Stucky, R.K. and McKenna, M.C. 1993. Mammalia, p. 739-771 .In Benton, M.J, (ed.), The Fossil Record 2. Chapman and Hall, London.

Suwa, G., Kono, R.T., Katoh, S., Asfaw, B., and Beyene, Y. 2007. A new species of great ape from the late Miocene epoch in Ethiopia. Nature, 448:921-924.

Swalla, B.J. and Smith, A.B. 2008. Deciphering deuterostome phylogeny: molecular, morphological and palaeontological perspectives. Philosophical Transactions of the Royal Society B: Biological Sciences, 363:1557-1568.

Swisher, C.C., III, Wang, Y., Wang, X., Xing, X., and Wang, Y. 1999. Cretaceous age for the feathered dinosaurs of Liaoning, China. Nature, 400:58-61.

Swisher, C.C., III, Wang, X., Zhou, Z., Wang, Y., Jin, F., Zhang, J., Xu, X., Zhang, F., and Wang, Y. 2002. Further support for a Cretaceous age for the feathereddinosaur beds of Liaoning, China: New ${ }^{40} \mathrm{Ar} /{ }^{39} \mathrm{Ar}$ dating of the Yixian and Tuchengzi formations. Chinese Science Bulletin, 47:136-139.

Symonds, M.R.E. 2005. Phylogeny and life histories of the 'Insectivora': controversies and consequences. Biological Reviews, 80:93-128.

Szalay, F.S. 1982. A new appraisal of marsupial phylogeny and classification, p. 621-640. In Archer, M. (ed.) Carnivorous marsupials. Royal Zoological Society of New South Wales, Sydney.

Szalay, F.S. and Li, C.K. 1986. Middle Paleocene euprimate from southern China and the distribution of primates in the Paleogene. Journal of Human Evolution, 15:387-397.

Szalay, F.S. and Trofimov, B.A. 1996. The Mongolian Late Cretaceous Asiatherium, and the early phylogeny and paleobiogeography of Metatheria. Journal of Vertebrate Paleontology, 16:474-509. 
Tabuce, R., Asher, R.J., and Lehmann, T. 2008. Afrotherian mammals: a review of current data. Mammalia, $72: 2-14$

Tabuce, R., Marivaux, L., Adaci, M., Bensalah, M., Hartenberger, J.L., Mahboubi, M., Mebrouk, F., Tafforeau, P., and Jaeger, J.J. 2007. Early Tertiary mammals from North Africa reinforce the molecular Afrotheria clade. Proceedings of the Royal Society, Series B, 274:1159-66.

Tassy, P. and Pickford, M. 1983. A new zygolophodont mastodon (Proboscidea, Mammalia) in the Early Miocene of East Africa - systematics and palaeoenvironment. Geobios, 16:53-77.

Taverne, L. 1981a. Ostéologie et position systématique d'Aethalionopsis robustus (Pisces, Teleostei) du Crétacé inférieur de Bernissart (Belgique) et considerations sur les affinitiés des Gonorynchiformes. Bulletin de l'Académie Royale de Belgique, Classes des Sciences, Série 5, 67:958-982.

Taverne, L. 1981b. Les actinoptérygiens de l'Aptien inférieur (Töck) d'Helgoland. Mitteilung für GeologiePaläontologie, Institut Universität Hamburg, 51:4382.

Taverne, L. 2010. Les poissons crétacés de Nardò. $32^{\circ}$. Trois nouveaux Perciformes: Zorzinperca weverberghi gen. et sp. nov., Johnsonperca annavaccarii gen. et sp. nov. et Bannikovperca apula gen. et sp. nov. Bollettino del Museo Civico di Storia Naturale di Verona: Geologia Paleontologia Preistoria, 34:51-80.

Thewissen, J.G.M., Williams, E.M., and Hussain, S.T. 2001. Eocene mammal faunas from northern IndoPakistan. Journal of Vertebrate Paleontology, 21:347-366.

Thomson, R.C., Plachetzki, D.C., Mahler, D.L., and Moore, B.R., 2014, A critical appraisal of the use of microRNA data in phylogenetics. Proceedings of thre National Academy of Sciences, USA, 111:E3659E3668.

Tintori, A. 1990. The actinopterygian fish Prohalecites from the Triassic of northern Italy. Palaeontology, 33:155-174

Tintori, A. 1998. Fish biodiversity in the marine Norian (Late Triassic) of northern Italy: the first neopterygian radiation. Italian Journal of Zoology, supplement, 65:193-198.

Traquair, R.H. 1911. Les Poissons Wealdiens de Bernissart. Mémoires du Musée Royal d'Histoire Naturelle de Belgique, 6:1-65.

Trewin, N.H., and Davidson, R.G. 1995. An Early Devonian lake and its associated biota in the Midland Valley of Scotland. Transactions of the Royal Society of Edinburgh: Earth Sciences, 86:233-246.

Tsuji, L. and Müller, J. 2009. Assembling the history of the Parareptilia: phylogeny, diversification, and a new definition of the clade. Fossil Record, 12:71-81.

Turner, S., Burrow, C.J., Schultze, H.P., Blieck, A., Reif, W.E., Rexroad, C.B., Bultynck, P., and Nowlan, G.S. 2010. False teeth: conodont-vertebrate phylogenetic relationships revisited. Geodiversitas, 32:545-594.
Tyler, J.C. and Bannikov, A.F. 1994. A new genus of fossil pufferfish (Tetraodontidae: Tetraodontiformes) based on a new species from the Oligocene of Russia and a referred species from the Miocene of Ukraine. Proceedings of the Biological Society of Washington, 107:97-108.

Tyler, J.C. and Križnar, M. 2013. A new genus and species, Slovenitriacanthus saksidai, from southwestern Slovenia, of the Upper Cretaceous basal tetraodontiform fish family Cretatriacanthidae (Plecocretacicoidea). Bollettino del Museo Civico di Storia Naturale di Verona: Geologia Preistoria, 37:45-56.

Tyler, J.C. and Patterson, C. 1991. The skull of the Eocene Triodon antiquus (Triodontidae; Tetraodontiformes): similar to that of the Recent threetooth pufferfish T. macropterus. Proceedings of the Biological Society of Washington, 104:878-891.

Tyler, J.C., Purdy, R.W., and Oliver, K.H. 1992. A new species of Sphoeroides pufferfish (Teleostei: Tetraodontidae) with extensive hyperostosis from the Pliocene of North Carolina. Proceedings of the Biological Society of Washington, 105:462-482.

Tyler, J.C. and Sorbini, L. 1996. New superfamily and three new families of tetraodontiform fishes from the Upper Cretaceous: the earliest and most morphologically primitive plectognaths. Smithsonian Contributions to Paleobiology, 82:1-59.

Unwin, D.M. 1993. Aves, p. 717-737. In Benton, M.J. (ed.), The Fossil Record 2. Chapman \& Hall, London.

Utting, J., Giles, P.S., and Dolby, G. 2010. Palynostratigraphy of Mississippian and Pennsylvanian rocks, Joggins area, Nova Scotia and New Brunswick, Canada, Palynology, 34:43-89.

Vandenberghe, N., Hilgen, F.J., Speijer, R.P., Ogg, J.G., Gradstein, F.M., Hammer, O., Hollis, C.J., and Hooker, J.J. 2012. The Paleogene Period, p. 855921. In Gradstein, F.M., Ogg, J.G., Schmitz, M., and Ogg, G. (eds.), The Geologic Time Scale 2012. Elsevier, Amsterdam.

Vandermade, J. 1989. The bovid Pseudoetragus seegrabensis nov. gen., nov. sp. from the Aragonian (Miocene) of Seegraben near Leoben (Austria). Proceedings of the Koninklijke Nederlandse Akademie Van Wetenschappen Series B-Palaeontology Geology Physics Chemistry Anthropology 92:215239.

Van Tuinen, M. and Hadly, E.A. 2004. Calibration and error in placental molecular clocks: a conservative approach using the cetartiodactyl fossil record. Journal of Heredity, 95:200-208.

Van Tuinen, M. and Hedges, S.B. 2004. The effect of external and internal fossil calibrations on the avian evolutionary timescale. Journal of Paleontology, 78:45-50.

Van Valen, L. 1964. A possible origin for rabbits. Evolution, 18:484-491. 
Vandermeersch, B. 1978. Étude préliminaire du crâne humain du gisement paléolithique de Biache-SaintVaast (Pas-de-Calais). Bulletin de I'Association française pour l'Étude du Quaternaire, 15:65-67.

Vanhaeren, M., d'Errico, F., Stringer, C., James, S.L., Todd, J.A., and Mienis, H.K. 2006. Middle Paleolithic shell beads in Israel and Algeria. Science, 312:17851788.

Vignaud, P., Duringer, P., Mackaye, H.T., Likius, A., Blondel, C., Boisserie, J.R., De Bonis, L., Eisenmann, V., Etienne, M.E., Geraads, D., Guy, F., Lehmann, T., Lihoreau, F., Lopez-Martinez, N., MourerChauvire, C., Otero, O., Rage, J.C., Schuster, M., Viriot, L., Zazzo, A., and Brunet, M. 2002. Geology and palaeontology of the Upper Miocene TorosMenalla hominid locality, Chad. Nature, 418:152-155.

Viohl, G. and Zapp, M. 2007. Schamhaupten, an outstanding Fossil-Lagerstätte in a silicified Plattenkalk around the Kimmeridgian-Tithonian boundary (Southern Franconian Alb, Bavaria). Neues Jarhbuch für Geologie und Paläontologie, Abhandlungen, 245:127-142.

Vinther, J., Eibye-Jacobsen, D., and Harper, D.A.T. 2011. An Early Cambrian stem polychaete with pygidial cirri. Biology Letters 7:929-932.

Vinther, J., Smith, M.P., and Harper, D.A.T. 2011. Vetulicolians from the Lower Cambrian Sirius Passet Lagerstätte, North Greenland, and the polarity of morphological characters in basal deuterostomes. Palaeontology, 54:711-719.

Vinther, J., Sperling, E.A., Briggs, D.E., and Peterson, K.J. 2012. A molecular palaeobiological hypothesis for the origin of aplacophoran molluscs and their derivation from chiton-like ancestors. Proceedings of the Royal Society B: Biological Sciences, 279:12591268.

von Huene. F. 1902. Übersicht über die Reptilien der Trias. Geologische und Paläontologische Abhandlungen (Neue Serie), 6:1-84.

Waddell, P.J., Kishino, H., and Ota, R. 2001. A phylogenetic foundation for comparative mammalian genomics. Genome Informatics Series, 12:141-154.

Waddell, P.J., Okada, N., and Hasegawa, M. 1999. Towards resolving the interordinal relationships of placental mammals. Systematic Biology, 48:1-5.

Waddell, P.J. and Shelley, S.2003. Evaluating placental inter-ordinal phylogenies with novel sequences including RAG1, gamma-fibrinogen, ND6, and mttRNA, plus MCMC-driven nucleotide, amino acid, and codon models. Molecular Phylogenetetics and Evolution, 28:197-224.

Wade, M. 1968. Preservation of soft-bodied animals in Precambrian sandstones at Ediacara, South Australia. Lethaia, 1:238-267.

Wade, M. 1972. Hydrozoa and Scyphozoa and other medusoids from the Precambrian Ediacara fauna, South Australia. Palaeontology, 15:197-225.
Wainwright, P.C., Smith, W.L., Price, S.A., Tang, K.L., Sparks, J.S., Ferry, L.A., Kuhn, K.L., Eytan, R.I., and Near, T.J. 2012. The evolution of pharyngognathy: a phylogenetic and functional appraisal of the pharyngeal jaw key innovation in labroid fishes and beyond. Systematic Biology, 61:1001-1027.

Walliser, O.H. and Wang, C.Y. 1989. Upper Silurian stratigraphy and conodonts from the Qujing District, East Yunnan, China. Courier Forschungsinstitut Senckenberg, 110:111-121.

Wang, C.Y. 2001. Age of the Guandi Formation in Qujing District, E. Yunnan. Journal of Stratigraphy, 25:125127.

Wang, J.Q. 1991. The Antiarchi from Early Silurian of Hunan. Vertebrata PalAsiatica, 29:240-244.

Ward, S.C. and Kimbel, W.H. 1983. Subnasal alveolar morphology and the systematic position of Sivapithecus. American Journal of Physical Anthropology, 61:157-171.

Weber, B. and Zhu, M.Y. 2003. Arthropod trace fossils from the Zhujiaqing Formation (Meishucunian, Yunnan) and their palaeobiological implications. Progress in Natural Science, 13:795-800.

Wenz, S., Bernier, P., Barale, G., Bourseau, J.-P., Buffetaut, E., Gaillard, C., and Gall, J.-C. 1994. L'ichthyofaune des calcaires lithographiques du Kimméridgien supérieur de Cerin (Ain, France). Geobios, Mémoire Spéciale, 16:61-70.

Wenz, S. and Poyato-Ariza, F.J. 1994. Les actinoptérygiens juveniles du Crétacé inférieur du Montsec et de Las Hoyas (Espagne). Geobios, M.S., 16:203-212.

Werneburg, I. and Sánchez-Villagra, M.R. 2009. Timing of organogenesis support basal position of turtles in the amniote tree of life. BMC Evolutionary Biology, 2009:e82.

Wescott, W.A. and Diggens, J.N. 1998. Depositional history and stratigraphical evolution of the Sakamena Group (Middle Karoo Supergroup) in the southern Morondava Basin, Madagascar. Journal of African Earth Sciences, 27:461-479.

Wesley-Hunt, G. and Flynn, J.J. 2005. Phylogeny of the Carnivora:basal relationships among the carnivoramorphans, and assessment of the position of 'Miacoidea' relative to Carnivora. Journal of Systematic Palaeontology, 3:1-28.

Wheeler, B.M., Heimberg, A.M., Moy, V.N., Sperling, E.A., Holstein, T.W., Heber, S., and Peterson, K.J. 2009. The deep evolution of metazoan microRNAs. Evolution \& Development, 11:50-68.

White, T. S., del Papa, C., and Rodriguez, R. 2009. Paleosol-based paleoclimate reconstructions of late Paleocene through middle Eocene Argentina. Geological Society of America Abstracts with Programs, 41: 567.

Wible, J.R., Rougier, G.W., Novacek, M.J., and Asher, R.J. 2007. Cretaceous eutherians and Laurasian origin for placental mammals near the K/T boundary. Nature, 447:1003-1006. 
Wible, J.R., Rougier, G.W., Novacek, M.J., and Asher, R.J. 2009. The eutherian mammal Maelestes gobiensis from the Late Cretaceous of Mongolia and the phylogeny of Cretaceous Eutheria. Bulletin of The American Museum of Natural History, 327:1-123.

Wiens, J.J., Hutter, C.R., Mulcahy, D.G., Noonan, B.P., Townsend, T.M., Sites, J.W., and Reeder, T.W. 2012. Resolving the, phylogeny of lizards, and snakes (squamata), with extensive sampling, of genes and species. Biology Letters, 8:1043-1046.

Wildman, D.E., Uddin, M., Opazo, J.C., Liu, G., Lefort, V., Guindon, S., Gascuel, O., Grossman, L.I., Romero, R., and Goodman, M. 2007. Genomics, biogeography, and the diversification of placental mammals. Proceedings of the National Academy of Sciences, USA, 104:14395-143400.

Wiley, E.O. and Johnson, G.D. 2010. A teleost classification based on monophyletic groups, p. 123-182. In Nelson, J.S., Schultze, H.-P., and Wilson, M.V.H. (eds.), Origin and phylogenetic interrelationships of teleosts. Verlag Dr. Friedrich Pfeil, Munich.

Wiley, E.O., Johnson, G.D., and Dimmick, W.W. 2000. The interrelationships of acanthomorph fishes: a total evidence approach using molecular and morphological data. Biochemical Systematics and Ecology, 28:319-350.

Wilson, M.V.H. and Murray, A.M. 1996. Early Cenomanian acanthomorph teleost in the Cretaceous Fish Scale Zone, Albian/Cenomanian boundary, Alberta, Canada, p. 369-382. In Arratia, G. and Viohl, G. (eds.), Mesozoic fishes - systematics and paleoecology. Verlag Dr. Friedrich Pfeil, Munich.

Wood, A.E. 1962. The early Tertiary rodents of the family Paramyidae. American Philosophical Society, Philadelphia,.

Wood, R.A. 2011. Paleoecology of the earliest skeletal metazoan communities: Implications for early biomineralization. Earth-Science Reviews, 106:184-190.

Woodburn, M.O. 2004. Late Cretaceous and Cenozoic mammals of North America: biostratigraphy and geochronology. Columbia University Press, New York, $391 \mathrm{pp}$.

Woodburne, M.O., Rich, T.H., and Springer, M.S. 2003. The evolution of tribospheny and the antiquity of mammalian clades. Molecular Phylogenetics and Evolution, 28:360-385.

Woodburne, M.O., Goin, F.J., Bond, M., Carlini, A.A., Gelfo, J.N., López, G.M., Iglesias, A., and Zimicz, A.N. 2014. Paleogene land mammal faunas of South America; a response to global climatic changes and indigenous floral diversity. Journal of Mammalian Evolution, 21:1-73.

Woodward, A.S. 1907. On a new leptolepid fish from the Weald Clay of Southwater, Sussex. Annals and Magazine of Natural History, Series 7, 20:93-95.

Woodward, A.S. 1915-1917. The fossil fishes of the English Wealden and Purbeck formations. The Palaeontographical Society, London.
Woolley, S., Johnson, J., Smith, M.J., Crandall, K., Zardoya, R., and Meyer, A. 2001. The evolutionary position of turtles revisited. Naturwissenschaften, 88:193200.

Xiao, S., Yuan, X., and Knoll, A.H. 2000. Eumetazoan fossils in terminal Proterozoic phosphorites? Proceedings of the National Academy of Sciences, USA, 97:13684-13689.

Xu, G.-H., Gao, K.-Q., and Finarelli, J.A. 2014. A revision of the Middle Triassic scanilepiform fish Fukangichthys longidorsalis from Xinjiang, China, with comments on the phylogeny of the Actinopteri. Journal of Vertebrate Paleontology, 34: 747-759

Yabumoto, Y. 1994. Early Cretaceous freshwater fish fauna in Kyushu, Japan. Bulletin of the Kitakyushu Museum of Natural History, 13:107-254.

Yabumoto, Y. and Uyeno, T. 1994. Late Mesozoic and Cenozoic fish faunas of Japan. The Island Arc, 3:255-269.

Yamanoue, Y., Miya, M., Doi, H., Mabuchi, K., Sakai, H., and Nishida, M. 2011. Multiple invasions into freshwater by pufferfishes (Teleostei: Tetraodontidae): a mitogenomic perspective. PLoS ONE, 6:e17410.

Yans, J., Dejax, J., and Schnyder. 2012. On the age of the Bernissart Iguanodons, p. 79-86. In Godefroit, P. (ed.), Bernissart dinosaurs and Early Cretaceous terrestrial ecosystems. Indiana University Press, Bloomington.

Young, G.C. 1993. Middle Palaeozoic macrovertebrate biostratigraphy of eastern Gondwana, p. 208-251. In Long, J.A. (ed.), Palaeozoic vertebrate biostratigraphy and biogeography. Belhaven Press, London.

Young, G.C. 1997. Ordovician microvertebrate remains from the Amadeus Basin, central Australia. Journal of Vertebrate Paleontology, 17:1-25.

Young, G.C., Karatajute-Talimaa, V.N., and Smith, M.M. 1996. A possible Late Cambrian vertebrate from Australia. Nature, 383:810-812.

Young, N.M. and MacLatchy, L. 2004. The phylogenetic position of Morotopithecus. Journal of Human Evolution, 46:163-184.

Yuan, C.-X., Ji, Q., Meng, Q.-J., Tabrum, A. R. \& Luo, Z.X. 2013. Earliest evolution of multituberculate mammals revealed by a new Jurassic fossil. Science, 341:779-783.

Yuan, X., Chen, Z., Xiao, S., Zhou, C., and Hua, H. 2011. An early Ediacaran assemblage of macroscopic and morphologically differentiated eukaryotes. Nature, 470:390-393.

Yuan, X., Xiao, S., Yin, L., Knoll, A.H., Chuanming, Z., and Xinan, M. 2002. Doushantuo fossils: life on the eve of animal radiation. University of Science and Technology of China Press.

Zack, S.P., Penkrot, T.A., Bloch, J.I., and Rose, K.D. 2005. Affinities of 'hyopsodontids' to elephant shrews and a Holarctic origin of Afrotheria. Nature, 434:497501. 
Zamora, S., Lefebvre, B., Álvaro, J.J., Clausen, S., Elicki, O., Fatka, O., Jell, P., Kouchinsky, A., Lin, J.P., Nardin, E., Parsley, R., Rozhnov, S., Sprinkle, J., Sumrall, C.D., Vizcaino, D., and Smith, A.B. 2013. Cambrian echinoderm diversity and palaeobiogeography. In Harper, D.A.T., and Servais, T. (eds.), Early Palaeozoic palaeography and biogeography. Geological Society of London, Special Publication, London, 38:157-171.

Zhang, G.-R., Wang, S.-T., Wang, J.-Q., Wang, N.-Z., and Zhu, M. 2010. A basal antiarch (placoderm fish) from the Silurian of Qujing, Yunnan, China. Paleoworld, 19: 129-135.

Zhang, X.G., Siveter, D.J., Waloszek, D., and Maas, A. 2007. An epipodite-bearing crown-group crustacean from the Lower Cambrian. Nature, 449:595-598.

Zhang, X.G., Maas, A., Haug, J.T., Siveter, D.J., and Waloszek, D. 2010. A eucrustacean metanauplius from the Lower Cambrian. Current Biology, 20:10751079.

Zhao, W.J. and Zhu, M. 2010. Siluro-Devonian vertebrate biostratigraphy and biogeography of China. Palaeoworld, 19:4-26.

Zheng, S. 1993. Quaternary Rodents of SichuanGuizhou. Science Press, Beijing.

Zheng, X., Bi, S., Wang, X., and Meng, J. 2013. A new arboreal haramiyid shows the diversity of crown mammals in the Jurassic period. Nature, 500, 199202.

Zhu, M. and Fan, J. 1995. Youngolepis from the Xishancun Formation (early Lochkovian) of Qujing, China. Geobios, Mémoire Spéciale, 19:293-299.
Zhu, M. and Yu, X. 2002. A primitive fish close to the common ancestor of tetrapods and lungfish. Nature, 418:767-770.

Zhou, Z., Barrett, P.M., and Hilton, J. 2003. An exceptionally preserved Lower Cretaceous ecosystem. Nature, 421:807-814.

Zhu, M., Yu, X., and Janvier, P. 1999. A primitive fossil fish sheds light on the origin of bony fishes. Nature, 397:607-610.

Zhu, M., Liu, Y.-H., Jia, L.-T., and Gai, Z.-K. 2012. A new genus of eugaleaspidiforms (Agnatha: Galeaspida) from the Ludlow, Silurian of Qujing, Yunnan, southwestern China. Vertebrata PalAsiatica, 50:1-7.

Zhu, M., Yu, H., Ahlberg, P.E., Choo, B., Lu, J., Qiao, T., Qu, Q., Zhao, W., Jia, L., Blom, H., and Zhu, Y. 2013. A Silurian placoderm with osteichthyan-like marginal jaw bones. Nature, 502:188-193.

Zhu, M., Yu, X., Wang, W., Zhao, W., and Jia, L. 2006. A primitive fish provides key characters bearing on deep osteichthyan phylogeny. Nature, 441:77-80.

Zhu, M., Zhao, W., Jia, L., Lu, J., Qiao, T., and Qu, Q. 2009. The oldest articulated osteichthyan reveals mosaic gnathostome characters. Nature, 458:469474.

Zollikofer, C.P., Ponce de Leon, M.S., Lieberman, D.E., Guy, F., Pilbeam, D., Likius, A., Mackaye, H.T., Vignaud, P., and Brunet, M. 2005. Virtual cranial reconstruction of Sahelanthropus tchadensis. Nature, 434:755-759.

Zumoffen, G. 1926. Géologie du Liban. Barrèrre, Paris. 